\title{
EXPERIMENTAL INVESTIGATION OF USING DEEP MIXING METHOD TO \\ STABILISE PROBLEMATIC CLAYS IN ONTARIO
}

\author{
BY \\ Shuihan Li \\ B.A.Sc, University of Toronto, 2013
}

\begin{abstract}
A thesis,
presented to Ryerson University

in partial fulfillment of the

requirements for the degree of

Master of Applied Science

in the program of

Civil Engineering
\end{abstract}

Toronto, Ontario, Canada, 2017

(C) Shuihan Li 2017 


\section{AUTHOR'S DECLARATION}

I hereby declare that I am the sole author of this thesis. This is a true copy of the thesis, including any required final revisions, as accepted by my examiners.

I authorize Ryerson University to lend this thesis to other institutions or individuals for the purpose of scholarly research.

I further authorize Ryerson University to reproduce this thesis by photocopying or by other means, in total or in part, at the request of other institutions or individuals for the purpose of scholarly research.

I understand that my thesis may be made electronically available to the public. 


\begin{abstract}
Experimental Investigation of Using Deep Mixing Method to Stabilise Problematic Soils in Ontario, Master of Applied Science, 2017, Shuihan Li, Department of Civil Engineering, Ryerson University
\end{abstract}

Champlain Sea clay is a sensitive marine clay which can lose more than $90 \%$ of its strength when disturbed. Organic silty clay, commonly found in Ontario, has a high compressibility and a low shear strength. In this experimental study, different binders were applied to Champlain Sea clay and organic silty clay to improve its strength properties. The results indicate that cement and slag/cement can significantly improve the strength of these problematic clays. A cement dosage ranging from $150 \mathrm{~kg} / \mathrm{m}^{3}$ to $250 \mathrm{~kg} / \mathrm{m}^{3}$ can consistently improve the undrained shear strength of Champlain Sea clay and organic silty clay with the maximum strength improvement ratio of 10 and 18 respectively. A slag/cement dosage of $290 \mathrm{~kg} / \mathrm{m}^{3}$ with a mass ratio of $3: 1$ can improve the undrained shear strength of Champlain Sea clay for more than 50 times. Lime was found to be effective in treating organic silty clay as well. 


\section{ACKNOWLEDGEMENTS}

First, I would like to express my sincere gratitude to Dr. Jinyuan Liu for providing me with this wonderful opportunity. Not only did Dr. Liu provide academic guidance throughout this research, he also shared indispensable advice about tackling difficulties in work and life. Dr. Liu has continued to inspire me with new ideas, novel approaches, and a strong work ethic throughout the research. I gratefully acknowledge Dr. Liu's assistance and guidance to complete the thesis.

Next, I would like to specially thank Mr. Naresh Gurpersaud of Geo-Foundations Contractors Inc. and Mr. Al Varshoi of Golder Associates for providing the opportunity of collaboration between academia and industry. The success of the project is rooted in the need to solve a real world problem. I would also like to thank NSERC, OCE, Golder Associates for the financial support of this research.

Furthermore, I would like to thank Mr. Andries Kirstein for his invaluable contribution in completing the Champlain Sea clay analysis. Andries' attention to detail and ingenious solution has lifted the project over difficult spots. I would also to thank Mr. Ali Ahmad, Mr. Chandra Pouydal, Mr. Cong Shi, and Mr. Markus Jesswein for their help and contribution on the project as well. Finally, I would like to thank my wife and family for their unwavering support throughout my time at Ryerson University. 


\section{TABLE OF CONTENTS}

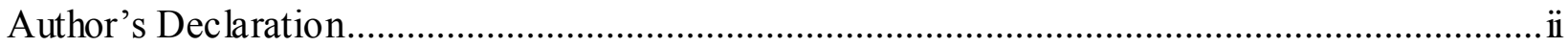

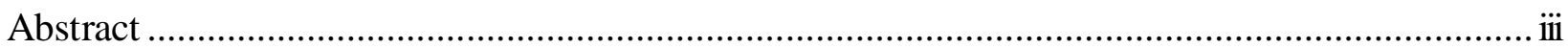

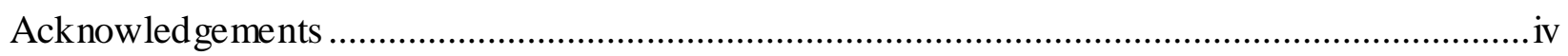

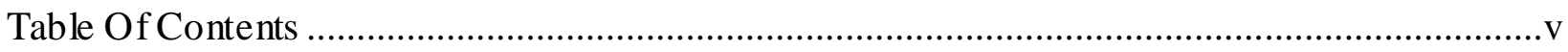

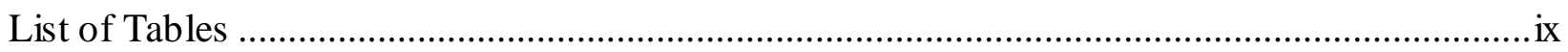

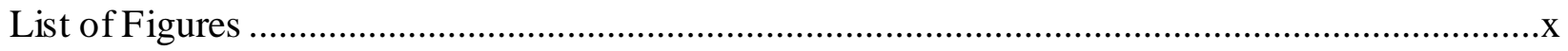

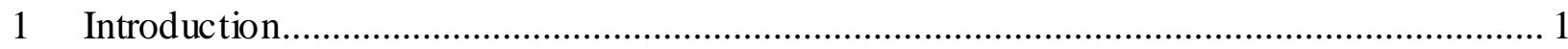

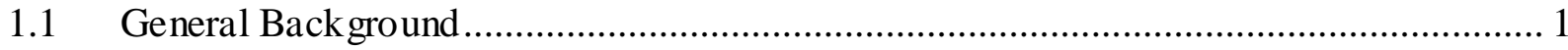

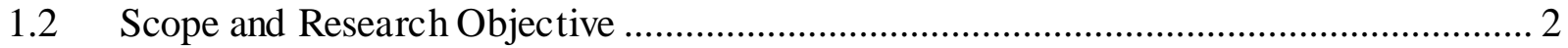

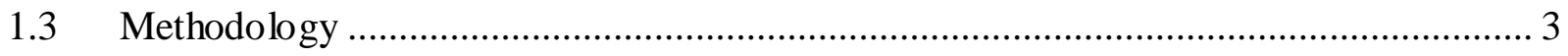

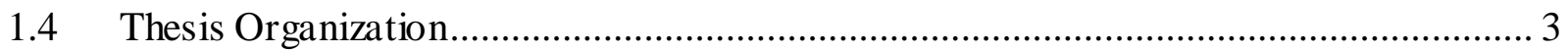

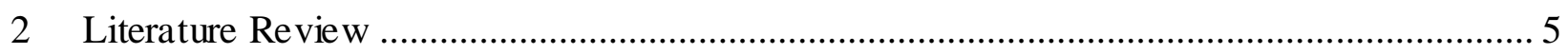

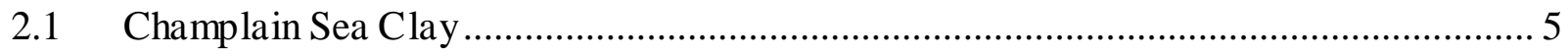

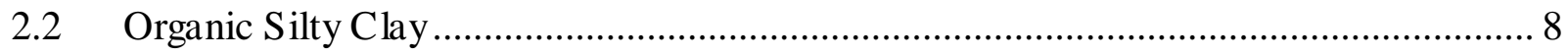

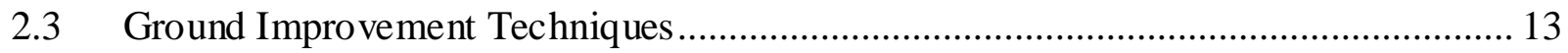

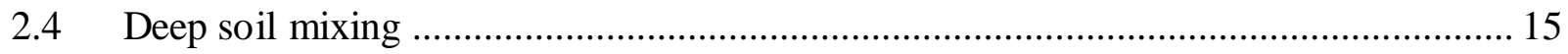

2.4.1 Mechanism of binder strength improvement .............................................. 16

2.4.2 Deep mixing method classifications ........................................................ 19

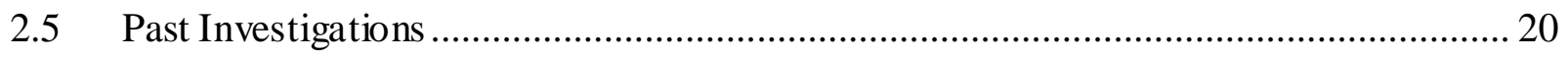

2.5.1 Binder Dosage ......................................................................................... 21

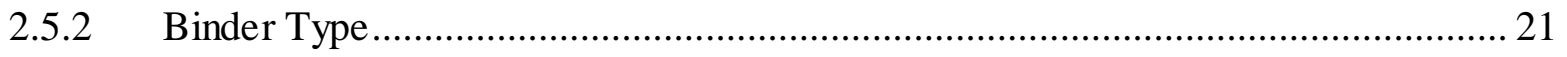

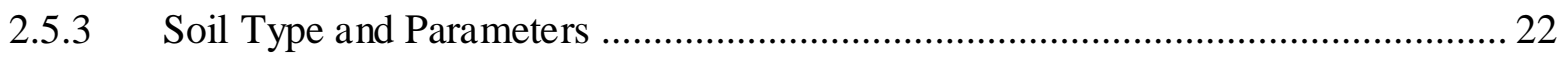

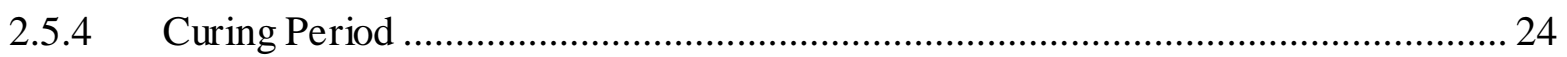




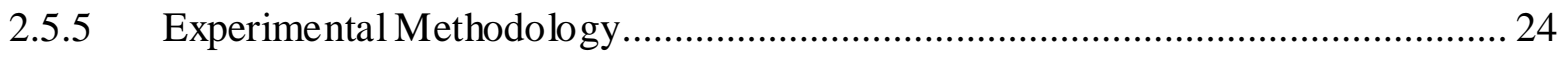

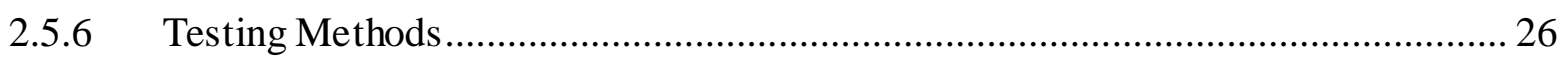

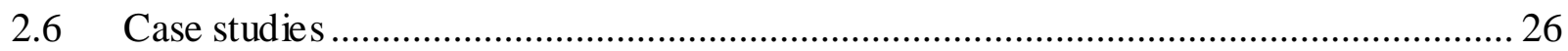

2.6.1 Kitimat LNG Facility, Bish Cove, British Columbia …………………................. 26

2.6.2 Interstate 5 Embankment Support, Tacoma, Washington ....................................... 27

2.6.3 Bangna-Bangpakong Highway, Bangkok, Thailand ............................................... 29

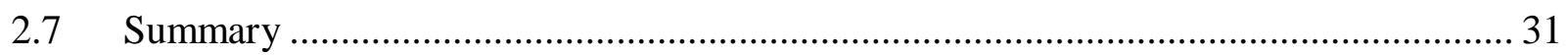

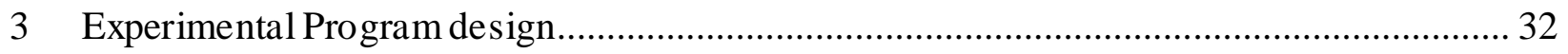

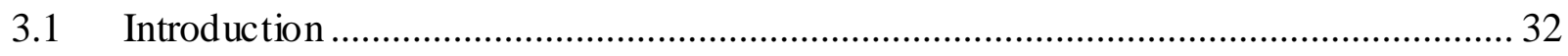

3.2 Experimental Program for Champlain Sea Clay and Organic Silty clay ....................... 32

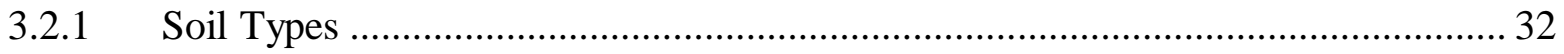

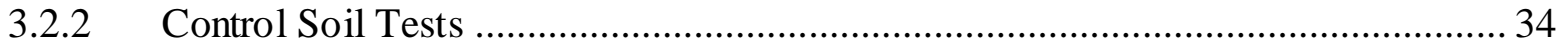

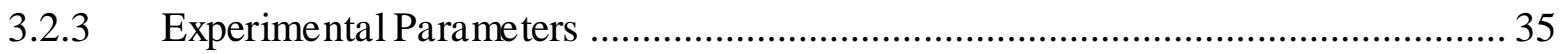

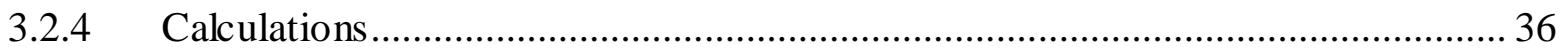

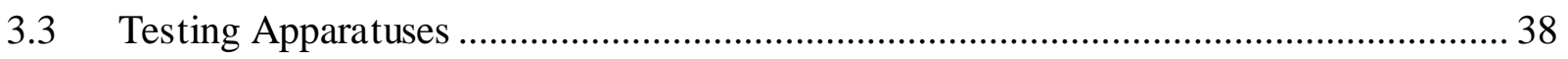

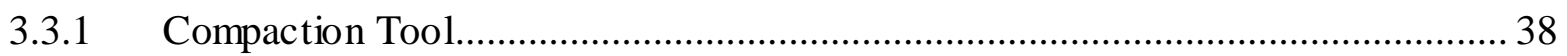

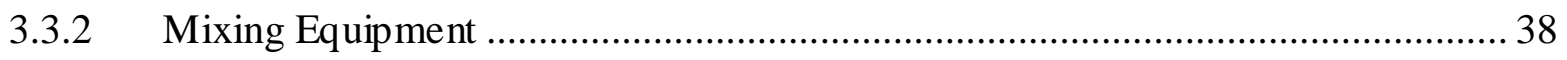

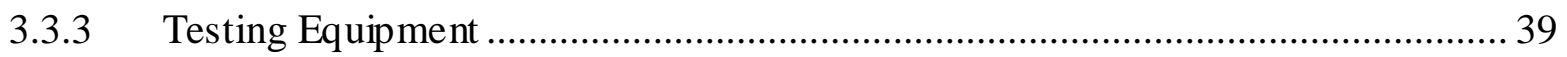

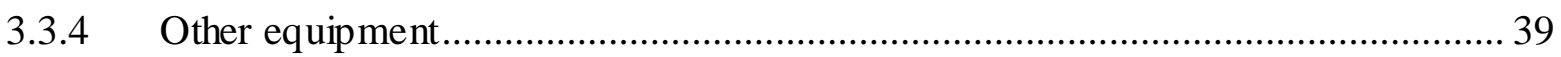

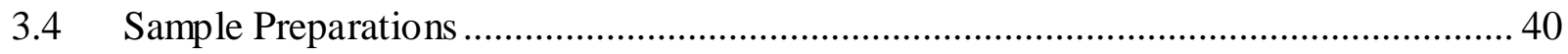

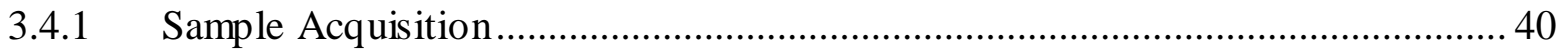

3.4.2 Binder Dosage Design .................................................................................. 40

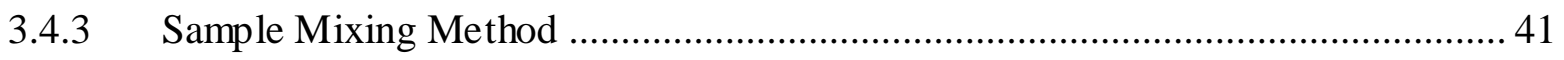

3.4.4 Sample Compaction Procedures ……………….................................................. 43

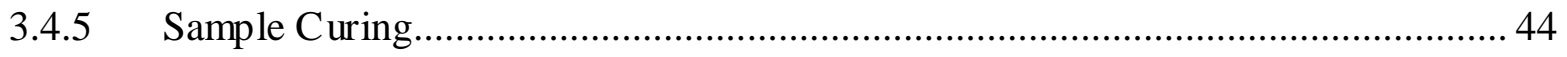




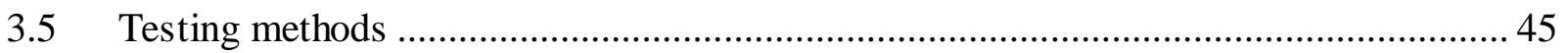

3.5.1 Unconfined Compression Strength Test ............................................................... 45

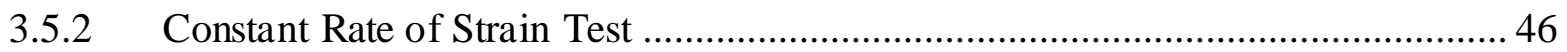

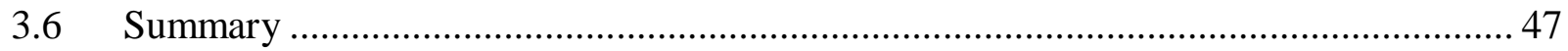

4 Experimental Result Analyses and Discussions ……………………................................... 48

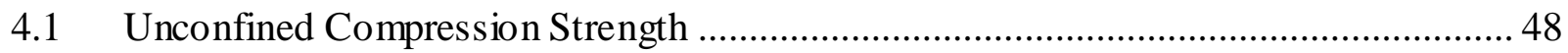

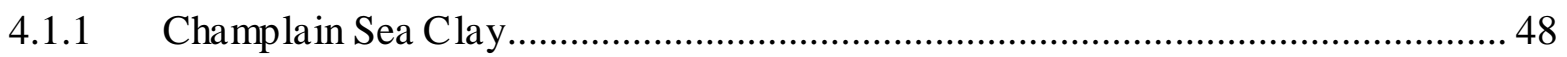

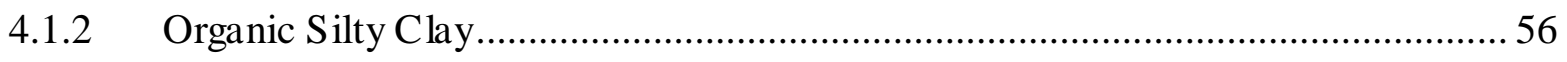

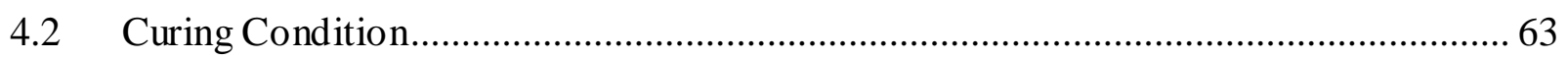

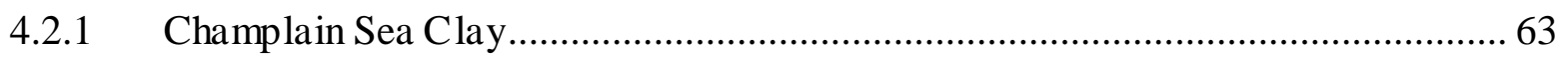

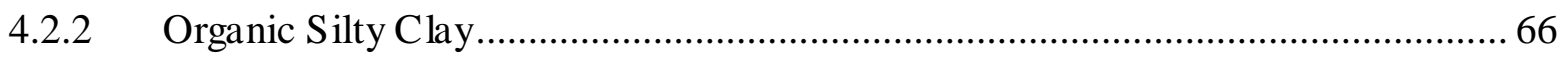

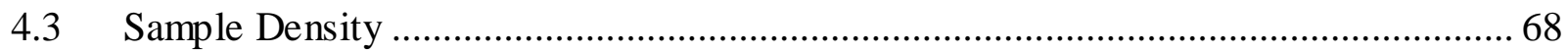

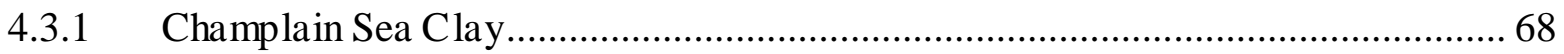

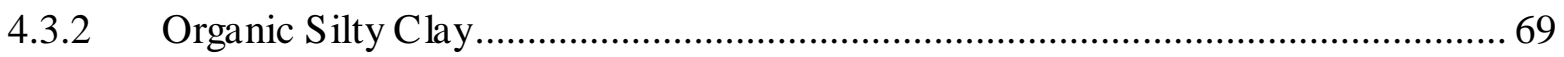

4.4 Sample Height to Diameter Ratio ........................................................................... 71

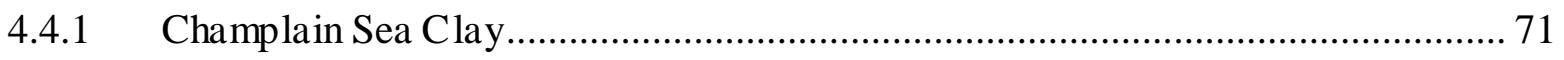

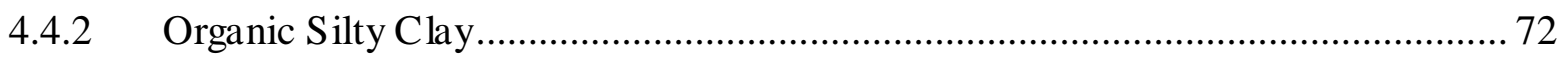

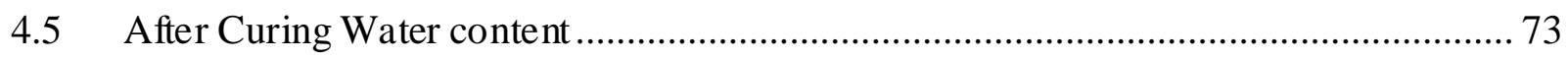

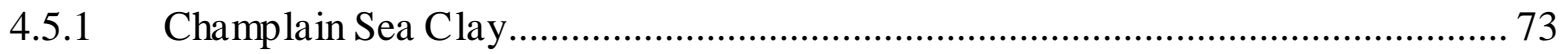

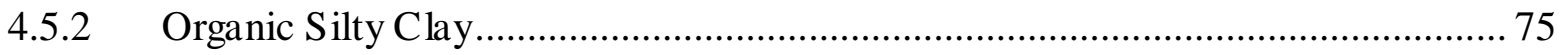

4.6 Elastic Modulus ..................................................................................................... 77

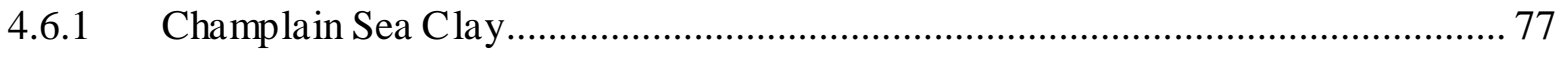

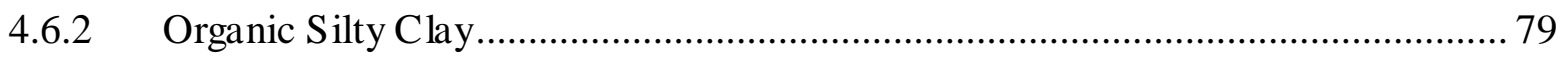

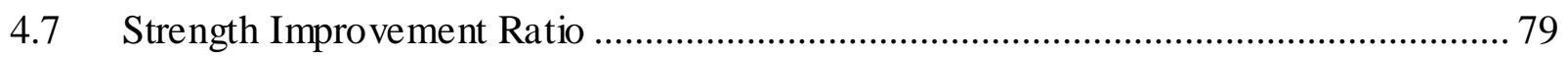

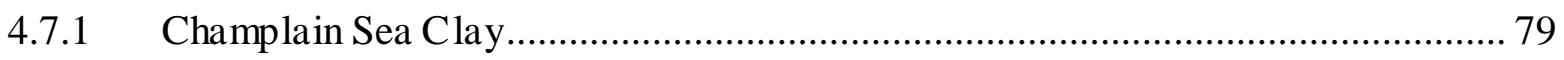




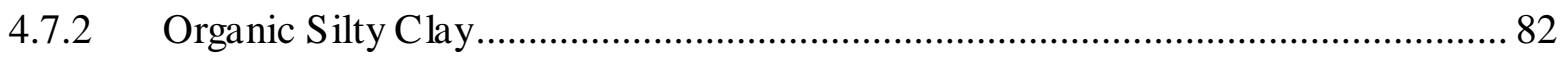

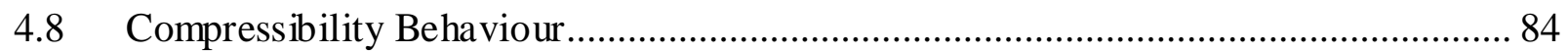

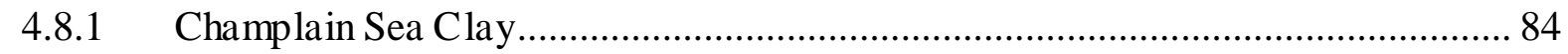

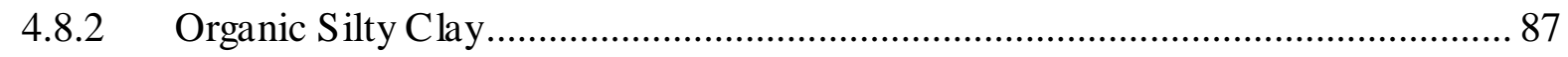

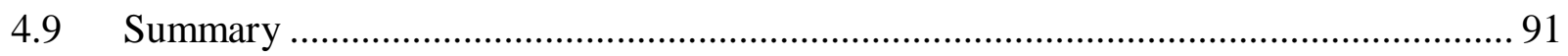

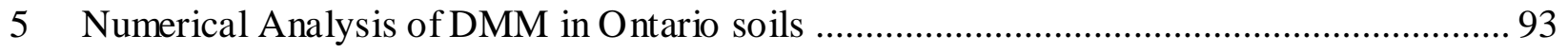

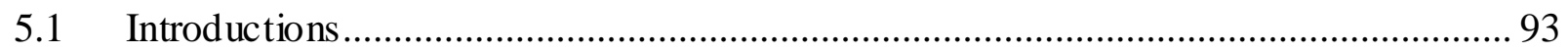

Finite Element Method .................................................................................... 93

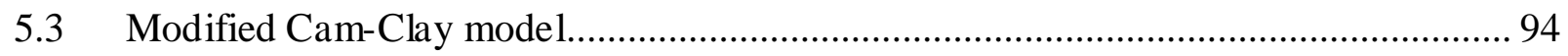

5.4 Plaxis 2D Model based on Chai .......................................................................... 97

5.4.1 Model Geometry and Input Parameters ..................................................... 97

5.4.2 Calculations and Results ..................................................................... 101

5.5 Plaxis 2D Model based on Champlain Sea Clay from Arnprior .............................. 103

5.5.1 Model Geometry and Input Parameters ................................................... 103

5.5.2 Calculations and Results ........................................................................ 106

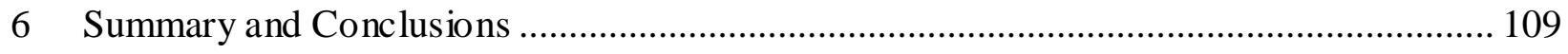

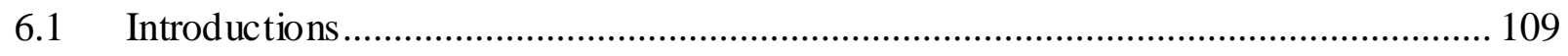

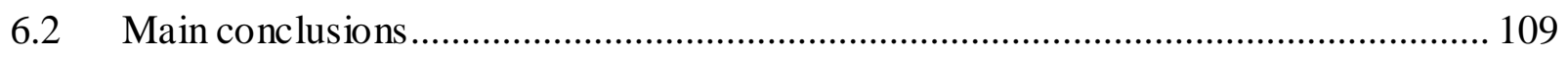

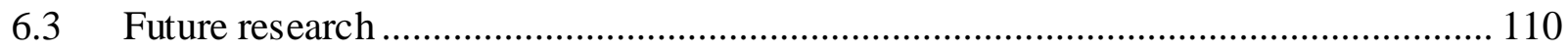

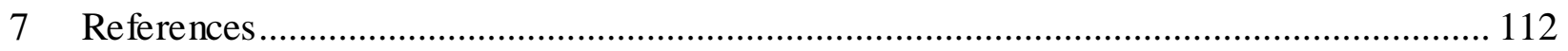




\section{LIST OF TABLES}

Table 2-1 Factors affecting DMM strength increase (Kitazume \& Terashi, 2012) .................... 20

Table 3-1 Soil properties via ASTM standardized tests ..................................................... 34

Table 3-2 Testing variables for Champlain Sea clay experimental program.............................. 35

Table 3-3 Testing variables for organic silty clay experimental program ............................... 36

Table 3-4 Summary of soil and binder design and testing method ........................................ 41

Table 4-1 Maximum UCS values of cement treated Arnprior clay samples ............................ 48

Table 4-2 UCS values for cement treated Kanata clay samples ............................................. 51

Table 4-3 UCS values of slag/cement treated Kanata clay samples ........................................ 53

Table 4-4 UCS test results for untreated clayey organic silt to silty clay from Shelby tubes ...... 56

Table 4-5 UCS Test Results for Cement Treated Soils ........................................................... 58

Table 4-6 UCS Test Results for Lime Treated Soils .......................................................... 61

Table 5-1 MCC model input parameters for soil layers, embankment fill, and soil-cement column

Table 5-2 Soil and cement column input parameters ........................................................... 104

Table 5-3 Input parameters for soil-cement column ......................................................... 104 


\section{LIST OF FIGURES}

Figure 1-1 Distribution of Champlain Sea clay (in gray color) in Canada (Quinn, 2012) ............ 2

Figure 2-1 Champlain Sea formation based on geological survey (Penner \& Burn, 1978) .......... 5

Figure 2-2 Sensitivity versus salt content in terms of specific conductivity (Penner, 1965); high specific conductivity equals to high salt content ................................................................ 7

Figure 2-3 Flow slide site near Casselman, Ontario (Penner \& Burn, 1978) .............................. 7

Figure 2-4 Influence of organic content on soil's mo isture content (Jarrett, 1983) .................... 9

Figure 2-5 Influence of organic content on soil's Atterberg limits (Abdallah, 1999) .................. 9

Figure 2-6 Organic content's influence on soil specific gravity of solids (Radforth et al., 1996) 10

Figure 2-7 Organic content's influence on optimum water content (Abdallah, 1999) ................ 11

Figure 2-8 Organic content's influence on UCS (Abdallah, 1999) ......................................... 11

Figure 2-9 Distribution of soft silty clay in Lake Ontario and Lake Erie (Kemp and Lewis, 1968)

Figure 2-10 Correlations between organic content, clay content, quartz content, and medium grain size of soft silty clay (Kemp and Lewis, 1968) .................................................................. 12

Figure 2-11 Vibro Compaction procedure on granular soil (Keller, 2016) ............................... 14

Figure 2-12 Geo-tube application for Incheon Bridge project in Incheon, Korea (Prakashan, 2015)

Figure 2-13 Dry cement soil column installation at a work site (Hayward Baker, 2016) ........... 16

Figure 2-14 Stages of cement stabilization (Kitazume \& Terashi, 2012).................................. 17

Figure 2-15 Mechanism of pozzolanic reaction (Ingles \& Metcalf, 1972) ............................... 18

Figure 2-16 Chemical reactions between clay, cement, water, and slag (Saitoh et al., 1985)...... 18

Figure 2-17 Mass mixing conducted at Port Everglades, FL (Wet Mixing, 2016) .................... 19

Figure 2-18 Soil columns constructed via DMM technique (Engineering, 2012)..................... 19

Figure 2-19 Influence of binder dosage and curing time on samples' UCS (Pathivada, 2005) .... 22

Figure 2-20 Influence of soil parameters on UCS (Niina et al., 1981) .................................... 23

Figure 2-21 Influence of humic acid on cement treated soil's UCS (Okada et al., 1983) ........... 24

Figure 2-22 Curing time on lime treated marine clays in Japan (Kitazume \& Terashi, 2012) ..... 25

Figure 2-23 Curing time on cement treated marine clays in Japan (Kawasaki et al., 1981) ........ 25

Figure 2-24 CSM cutter head exiting a completed panel (Associates, 2015) ........................... 27

Figure 2-25 Equipment used to conduct DMM at Interstate 5 (Pooranampillai et al., 2012) ...... 29 
Figure 2-26 UCS of samples taken at Section 3 of Bangna-Bangpakong highway (Bergado et al., 1999) 30

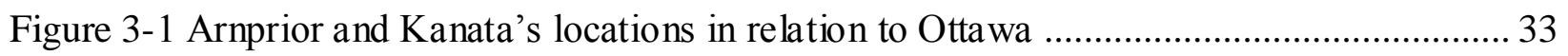

Figure 3-2 Organic silty clay's location relative to Toronto ................................................ 33

Figure 3-3 Different compaction tools used throughout the project ...................................... 38

Figure 3-4 Test apparatuses for mixing and shearing .................................................... 39

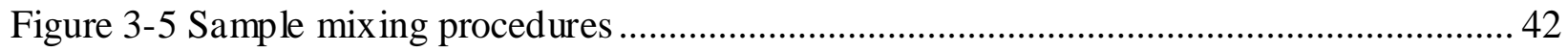

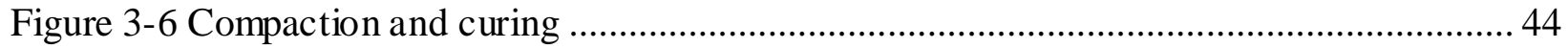

Figure 3-7 Sample trimming and typical failure mode of a sample in UCS test ..................... 46

Figure 4-1 Stress vs. strain curves of cement treated Arnprior soil samples ............................ 50

Figure 4-2 Stress vs. strain curves of cement treated Champlain Sea clay from Arnprior, Ontario 50

Figure 4-3 Stress vs. strain curves of cement treated Kanata soil samples .............................. 53

Figure 4-4 Stress vs. strain curves of slag/cement treated Kanata soil samples ........................ 55

Figure 4-5 UCS vs. Dosage for Cement Treated Champlain Sea clay .................................... 55

Figure 4-6 Stress-strain curves of untreated clayey organic silt to silty clay from Shelby tube ... 57

Figure 4-7 Stress-strain curves of UCS tests for $150 \mathrm{~kg} / \mathrm{m}^{3}$ cement treated soil samples ........... 59

Figure 4-8 Stress-strain curves of UCS tests for $200 \mathrm{~kg} / \mathrm{m}^{3}$ cement treated soil samples ........... 59

Figure 4-9 Stress-strain curves of UCS tests for $250 \mathrm{~kg} / \mathrm{m}^{3}$ cement treated soil samples ........... 60

Figure 4-10 Stress-strain curves of UCS tests for $100 \mathrm{~kg} / \mathrm{m}^{3}$ lime treated soil samples ............ 62

Figure 4-11 Stress-strain curves of UCS tests for $200 \mathrm{~kg} / \mathrm{m} 3$ lime treated soil samples ............. 63

Figure 4-12 Influence of curing duration on UCSs of cement treated Arnprior samples ............ 65

Figure 4-13 Influence of curing duration on UCSs of cement treated samples ........................ 65

Figure 4-14 Influence of curing duration on UCS of slag/cement treated samples .................... 66

Figure 4-15 UCS vs. curing duration plot for cement treated clayey silt with organics to organic

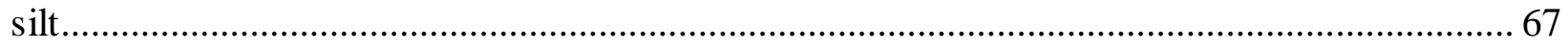

Figure 4-16 UCS vs. curing duration plot for lime treated clayey silt with organics to organic silt 67

Figure 4-17 Effect of sample density on UCS of cement treated samples ...............................6 69

Figure 4-18 Effect of sample density on UCS of slag/cement treated samples ........................ 69

Figure 4-19 UCS vs. wet density of the treated sample for cement treated organic silty clay ..... 70 
Figure 4-20 Effect of sample height to diameter ratio on cement treated samples 71

Figure 4-21 Effect of sample height to diameter ratio on slag/cement treated samples .............. 72

Figure 4-22 UCS vs. height to diameter ratio for cement treated organic silty clay .................. 72

Figure 4-23 Relationship between after curing water content and UCS for cement treated samples 74

Figure 4-24 Relationship between water content and UCS for slag/cement treated samples ...... 74

Figure 4-25 After curing water content vs. curing duration for slag/cement treated Kanata clay 75

Figure 4-26 UCS vs. after curing water content for cement treated organic silty clay................ 76

Figure 4-27 After curing water content vs. curing duration for cement treated organic silty clay 76

Figure 4-28 UCS vs. elastic modulus for cement treated Arnprior clay................................. 77

Figure 4-29 Elastic modulus vs. binder dosage for cement treated clay samples ...................... 78

Figure 4-30 UCS vs. elastic modulus for slag/cement treated Kanata clay .............................. 78

Figure 4-31 UCS vs. elastic modulus for cement treated organic silty clay ............................. 79

Figure 4-32 Strength increase ratio vs. binder dosage for cement treated clay samples ............. 80

Figure 4-33 Strength increase ratio vs. binder dosage for slag/cement treated Kanata clay ........ 81

Figure 4-34 Strength increase with curing duration for cement treated clay samples ................ 82

Figure 4-35 Strength increase with curing duration for slag/cement treated Kanata clay ............ 82

Figure 4-36 Ratio of strength improvement vs. cement dosage for cement treated organic silty clay

Figure 4-37 Ratio of improvement vs. curing duration for cement treated organic silty clay ...... 84

Figure 4-38 e- $\log$ P curve for untreated and cement treated Kanta clay................................... 85

Figure 4-39 Excess pore pressure vs. effective stress for cement treated Champlain Sea clay.... 86

Figure 4-40 Hydraulic conductivity vs. void ratio for cement treated Champlain Sea clay......... 86

Figure 4-41 e vs. $\log \mathrm{p}$ for cement treated clayey silt with organics to organic silt and untreated

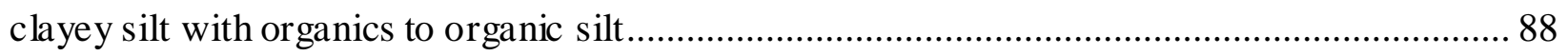

Figure 4-42 Compression index and recompression index for $250 \mathrm{~kg} / \mathrm{m}^{3}$ cement treated clayey silt

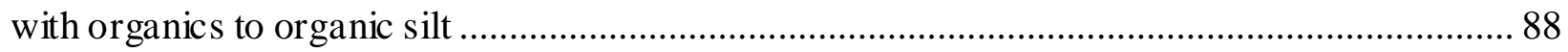

Figure 4-43 Compression index and recompression index for $200 \mathrm{~kg} / \mathrm{m}^{3}$ cement treated clayey silt with organics to organic silt 89

Figure 4-44 Compression index and recompression index for $150 \mathrm{~kg} / \mathrm{m}^{3}$ cement treated clayey silt with organics to organic silt 
Figure 4-45 Compression index and recompression index for untreated clayey silt with organics to

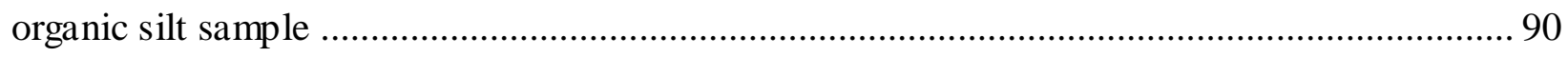

Figure 4-46 Compression index and recompression index for lime treated clayey silt with organics

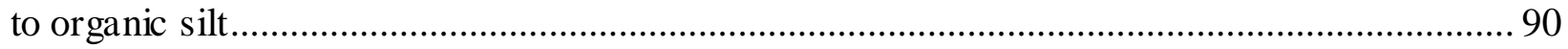

Figure 4-47 Excess pore pressure vs. effective stress for cement treated clayey silt ................. 92

Figure 4-48 Log hydraulic conductivity vs. void ratio for cement treated clayey silt ................. 92

Figure 5-1 MCC model's consolidation profile for soft soil under isotropic conditions (Rocscience,

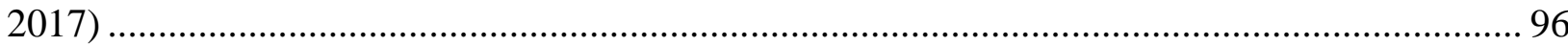

Figure 5-2 Yield curve of Cam-clay model and MCC model ............................................... 97

Figure 5-3 Geometric model of the plane strain model created on Plaxis 2D based on Chai et al.

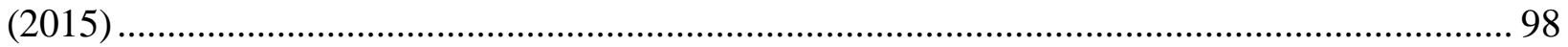

Figure 5-4 Hydraulic boundary conditions of the model................................................... 99

Figure 5-5 Generated mesh of the 2D model............................................................ 100

Figure 5-6 Deformed soil mesh after minimum pore water pressure stage ........................... 102

Figure 5-7 Displacement vs. time graph for Plaxis 2D simulated result and measured result ... 103

Figure 5-8 Model geometry of highway embankment with soil-cement columns ................... 105

Figure 5-9 Generated mesh of the model with columns .................................................... 105

Figure 5-10 Hydraulic boundary condition for the model ............................................... 106

Figure 5-11 Settlement vs. time profile for simulated Champlain Sea clay with DMM piles ... 107

Figure 5-12 Settlement profile of the embankment without DMM piles (top) and with DMM piles (bottom) 108 


\section{INTRODUCTION}

\subsection{General Background}

Champlain Sea clay, also known as Leda clay, is a type of sensitive and fine grained clay commonly found along the St. Lawrence Lowlands region in Ontario and Quebec (Penner, 1965). Figure 1-1 illustrates the distribution of Champlain Sea clay near Ottawa, Montreal, and other high population areas along the St. Lawrence River. Its high sensitivity proves problematic for the region's infrastructure development. Landslides were often triggered in these areas due to its low strength and high sensitivity. It is crucial to establish a cost-effective ground improvement method to deal with this type of clay.

Organic clayey silt to silty clay was found at the intersection between Highway 400 and Side Road $16^{\text {th }}$ in the York Region of Ontario. Soft silty clay can be commonly found in Lake Ontario and Lake Erie, especially along cities near the lakeshore such as Toronto and Detroit (Thomas, 1968). The clay's low strength and high compressibility requires ground improvement prior to construction activity.

Deep mixing method (DMM) is a ground improvement technique established in Japan as early as 1970s. Its unique advantages over other ground improvement methods include quick strength increase, low environmental disturbance, and wide range of soil applicability. Due to DMM's ability to treat difficult soils, it became a popular technique in many parts of the world, including western Canada. However, DMM was rarely used in Ontario due to lack of laboratory test data. Investigations on lime stabilization of sensitive clays are scarce (Locat et al., 1990); however, the results confirm the viability of using DMM to improve strength of soft sensitive clay. Similar studies were performed in the past which verified the viability of using DMM to treat organic clay. 


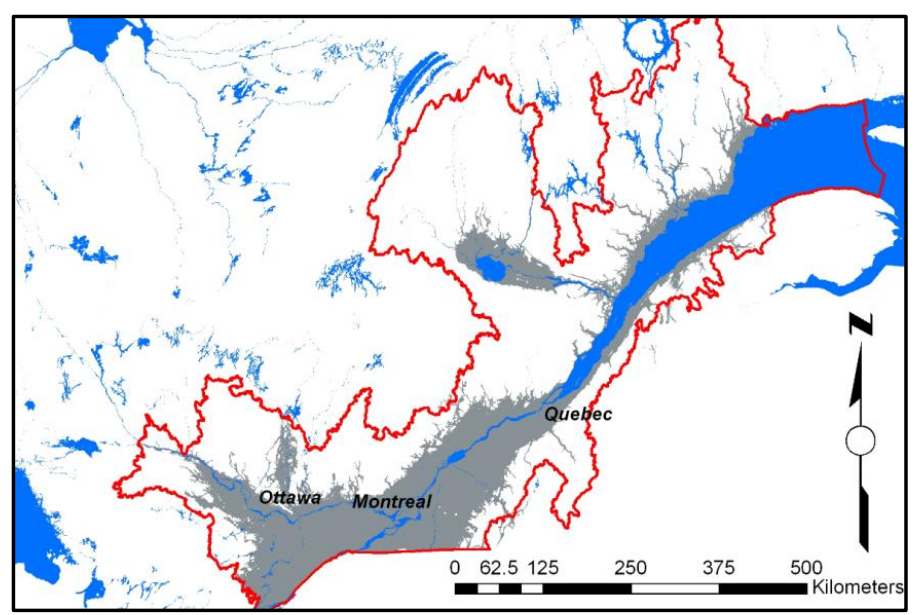

Figure 1-1 Distribution of Champlain Sea clay (in gray color) in Canada (Quinn, 2012)

\subsection{Scope and Research Objective}

The scope of this research is to verify the feasibility of applying DMM to treat two problematic clays in Ontario: Champlain Sea clay and organic silty clay. Soil binder reaction mechanism, while crucial to understanding the soil strengthening process, will be out of the scope of the research. With a clear scope in mind, the main objective of this study is to conduct mechanical test before and after binder treatment to directly measure the effect of DMM. To measure the viability and effectiveness of DMM, the following parameters will be obtained and analyzed against the baseline performance of the untreated soils:

1) Obtain index properties of the untreated clay samples, including unconfined compressive strength (UCS), undrained shear strength, plastic limit, liquid limit, inherent moisture content, and compressibility behaviour

2) Obtain UCS results of binder treated Champlain Sea clay and organic silty clay with varying binder dosage, curing duration, and binder type

3) Evaluate influence of variables on final UCS results

4) Obtain compressibility performance of binder treated Champlain Sea clay and organic silty clay via constant rate of strain (CRS) consolidation tests 
5) Numerical simulation of using DMM to reduce long-term settlement of a hypothetical highway embankment construction on Champlain Sea clay

6) Recommend optimum design dosage, binder type, and mixing condition

\subsection{Methodology}

A series of geotechnical tests will be used in this study. The experimental program will be broken down into two sections based on two soil types. The first section will investigate the application of DMM to Champlain Sea clay. The second section will investigate the application of DMM to organic silty clay.

In the first section, test variables include soil type, binder type, binder dosage, and binder curing duration. Champlain Sea clays from two different locations were used for the test. Next, cement, and slag/cement binders were used as different binder type. Furthermore, binder dosages varying from $57 \mathrm{~kg} / \mathrm{m}^{3}$ to $414 \mathrm{~kg} / \mathrm{m}^{3}$ were applied to the sample. Finally, a wide range of curing duration was examined, varying from 7 days to 56 days.

In the second section, test variables included binder type, binder dosage, and binder curing duration. Cement and lime were applied to the untreated clay. Next, binder dosage varied from $100 \mathrm{~kg} / \mathrm{m}^{3}$ to $250 \mathrm{~kg} / \mathrm{m}^{3}$. Finally, a curing duration range between 7 days to 56 days were used.

\subsection{Thesis Organization}

This thesis study will be organized into six different chapters to discuss the background, objective, methodology, procedure, and results of the experiment. Conclusions and future works will also be covered in the thesis.

Chapter One introduces different types of problematic soils found in Ontario, which include Champlain Sea clay and organic silty clay. The research study's general scope, objective, and methodologies were discussed in chapter one. Chapter Two presents the history of Champlain Sea clay, organic silty clay, and deep soil mixing. Champlain Sea clay's thixotropic properties, organic silty clay's high compression, and deep soil mixing's main advantages are discussed. Chapter Three explains the detailed procedure for the experimental lab program. Soil type, experimental 
schedule, and calculations are all included in this chapter. Sample preparations methods and testing methods, including unconfined compression strength (UCS) test and constant rate of strain (CRS) test, were presented in this chapter. Chapter Four discusses the result of the experimental program including UCS and CRS test results. Chapter Five presents the procedure, construction, and result of the finite element model (FEM). The FEM model was used to predict the settlement before and after applying DMM with case study verification. Finally, Chapter Six summarizes experimental findings from this study along with recommendation for future research. 


\section{LITERATURE REVIEW}

\subsection{Champlain Sea Clay}

Champlain Sea clay, also known as Leda clay, was formed throughout the Ottawa and St. Lawrence River valley via one single marine episode 12000 - 9000 BP (Penner \& Burn, 1978). Figure 2-1 shows the extent of the Champlain Sea in relation to modern day Ottawa and Montreal. The marine episode ended due to "differential uplift of the land and was replaced in progressive stages first by estuarine then by freshwater lacustrine and fluvial ancestors of the present freshwater drainage system" (Gadd, 1963). Fine sediments left behind after the marine period were collectively referred to as Champlain Sea clay. Champlain Sea clay deposits layers have thickness ranging from $10 \mathrm{~m}$ to more than $60 \mathrm{~m}$.

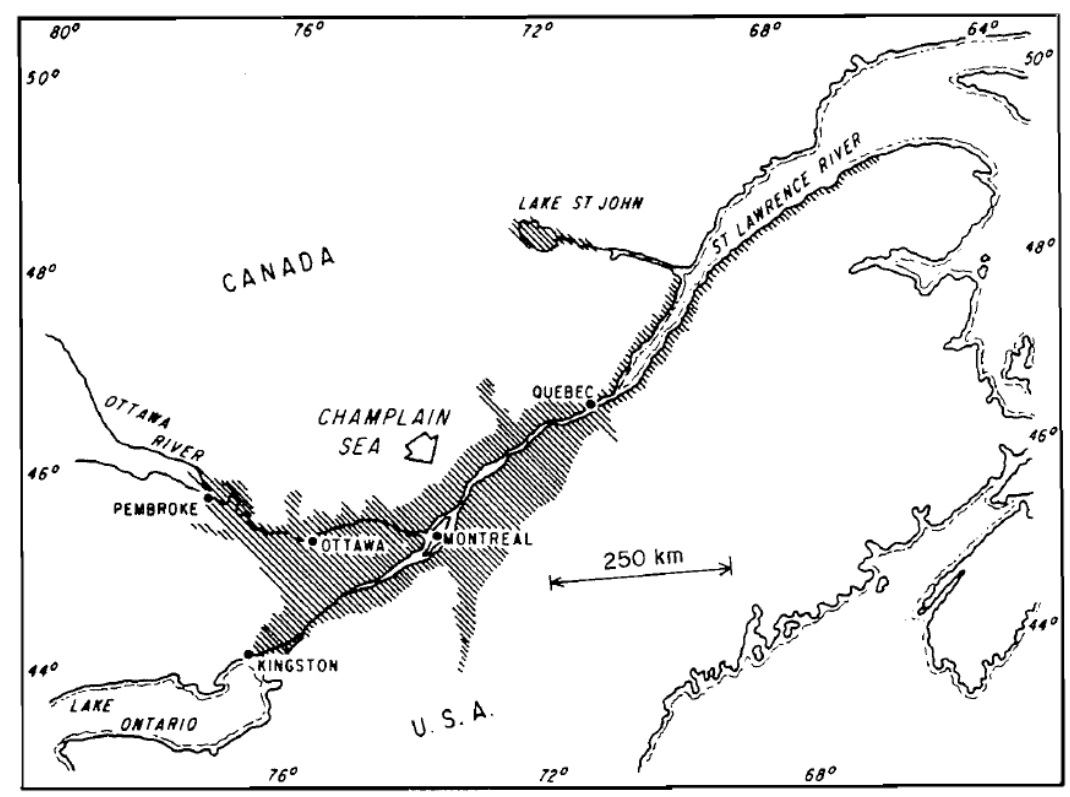

Figure 2-1 Champlain Sea formation based on geological survey (Penner \& Burn, 1978)

Champlain Sea clay consists of fabrics of silt, clay particles, small rock fragments, and clay platelets (Penner \& Burn, 1978). Champlain Sea clays were formed under high salinity water conditions with high electrolyte. The low repulsion forces between particles led to agglome rate formation in the early stages of the deposit. As electrolytes at clay particles' points of contact start to polarize, a weak force of attraction brings particle agglomerates closer to augment the overall strength of the soil. Deposits from above also packs soil layer together. Through this type of soil 
formation, Champlain Sea clays exhibit open fabric structures which are prone to structural disturbance if the electrolyte concentration between each point of contact is reduced (Penner \& Burn, 1978).

One phenomenon which increased the sensitivity of Champlain Sea clay is salt leaching. Leaching reduces the electrolyte concentration at points of contact, causing water release from the pores of the soil fabric, which destroys the soil's bond and structure integrity (Penner \& Burn, 1978). La Rochelle et al. (1970) proposed the valley like substructure underlying the clay deposits created a downward percolation and an upward flow gradient, which actively leached the salt content of the clay. Some Champlain Sea clays have low initial salt contents to begin with, and it is explained by Gadd (1963) as the fresh water phase released via "a sudden influx of fresh water produced either by release of melt-water from glacial sources or, more likely, by the sudden release of large volumes of silt-laden water from the Great Lake region." Penner (1965) utilized an innovative method of using electrical potentials to measure Champlain Sea clay's sensitivity. Champlain Sea clays with low salt contents have a sensitivity range of $10-1000$; while Champlain Seaclays with high salt contents have a sensitivity of up to 75 (Penner, 1965). Figure 2-2 illustrates a distinct inverse relationship that was found between soil sensitivity and pore water salt content in terms of specific conductivity. High specific conductivity reflects high salt content in soil, which produced a low sensitivity. These results confirmed the detrimental effect of a low salt content on marine clay's undrained shear strength. The open and flocculated structure of the Champlain Sea clay causes many engineering problem due to its high sensitivity (Law \& Bozozuk, 1988).

Champlain Sea clay often triggers landslides due to its low shear strength and high sensitivity. Many flow slides, with features such as overspill apron, crater shapes, and spoil ridges, occur once every few years. A study conducted by Mitchell and Markell (1974) found that hundreds of flow occurred over the area of one hectare. Eden and Mitchell (1970) found the "closely spaced planes of weakness existing in the apparently intact clay give rise to dilatant behaviour and predominantly frictional shearing resistance." This mode of failure appears to be consistent with onsite analysis of landslide sites. The dilatant behaviour was attributed to pre-existing discontinuities and cracks, which led to shearing of clay blocks (Eden \& Mitchell, 1970). Slip surfaces also develop simultaneously, which can trigger flow slides in a large area. Figure 2-3 illustrates two flow slides directly opposite of each other on the South Nation River, which is $30 \mathrm{~km}$ east of Ottawa and near 
the village of Casselman in Ontario. One slide happened just two years ago; the other slide happened over 65 years ago.

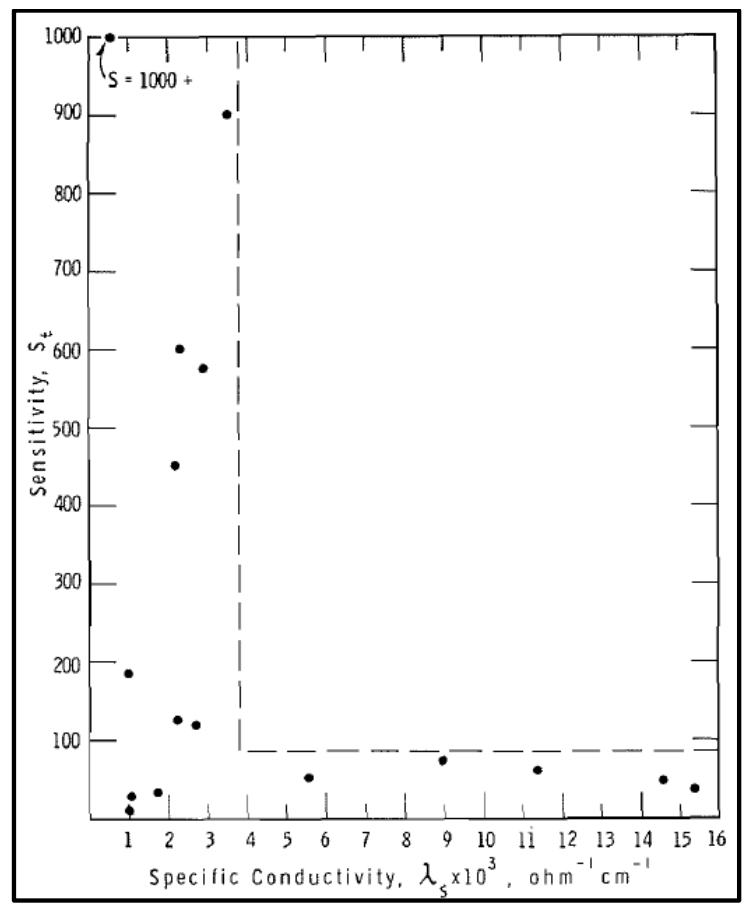

Figure 2-2 Sensitivity versus salt content in terms of specific conductivity (Penner, 1965); high specific conductivity equals to high salt content

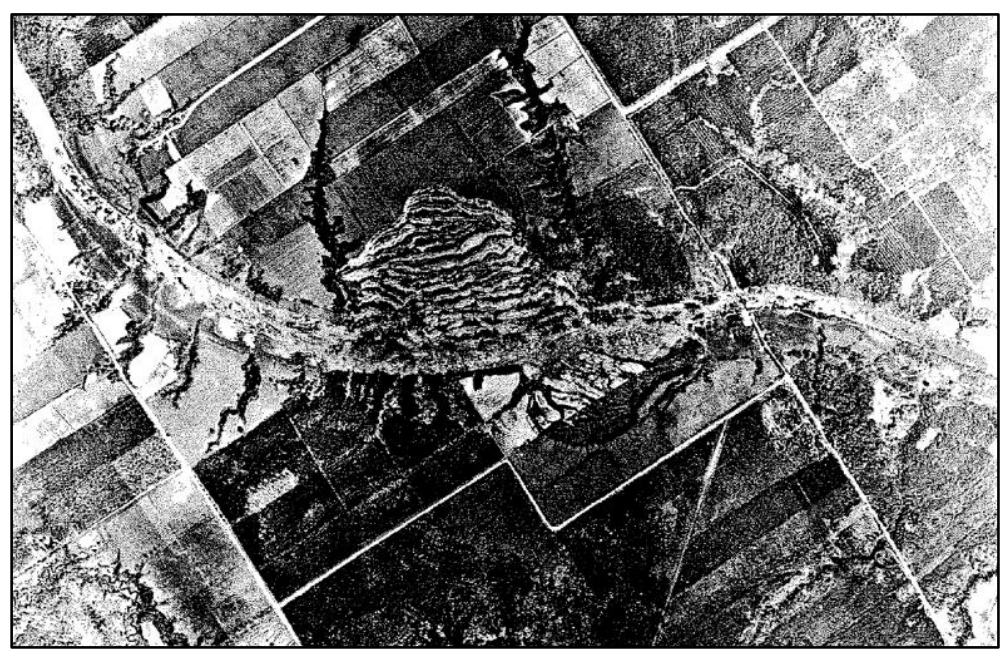

Figure 2-3 Flow slide site near Casselman, Ontario (Penner \& Burn, 1978)

When Champlain Sea clay was subjected to repetitive loading, Raymond (1970) found that permanent deformations continue to increase with the number of stress cycles even at low stresses. 
If stress levels were applied above the critical stress, sudden shear failure of the sample will occur without warning after relatively few stress applications (Raymond, Gaskin, \& Addo-Abedi, 1979). Mitchell and King (1977) reported that cyclic stress can cause failure of Champlain Sea clay with very low loading cycles if the confining pressure is between 50 to $100 \mathrm{kN} / \mathrm{m}^{2}$. The above findings point to a significant secondary consolidation behaviour where consolidation due to pore water

pressure has already completed. The difficulty in determining pre-consolidation stress accurately makes settlement predication difficult for Champlain Sea clay. Construction of engineering structures, such as embankments and mat foundations, will result in excess settlement. Furthermore, LaFleur et al. (1988) described an excavation performed in soft Champlain Sea clay. Steep slope excavation at $45^{\circ}$ collapsed after one day, and a $34^{\circ}$ excavation collapsed two weeks later. These findings prove the difficult nature of working with Champlain Sea clay, especially in a pavement construction context where repetitive loading from large construction equipment would be applied to the subgrade on a daily basis.

In conclusion, Champlain Sea clay's high sensitivity and low undrained shear strength increases the difficulty of conducting construction activity. Ground improvement prior to construction is required in most cases. A deeper understanding of the clay's interaction with external and internal load is required.

\subsection{Organic Silty Clay}

Organic sediment is a common place soil subtype commonly found around the world. The biggest problem encountered by organic deposit is its high compressibility. In geotechnical design, it is often difficult to accurately predict the secondary compression behaviour of organics deposits on undergoing load. Prolonged structure settlement due to creep can cause a major problem for designers and engineers. In addition, the low unit weight and the poor engineering properties of organic deposits contribute to the difficulty of working with organic soil (Huang et al., 2009).

Organic soil's poor engineering properties can be attributed to the organic content's soil structure and its soil-organic interaction, which greatly influences many key soil properties. Properties such as water content, specific gravity, bulk density, optimum water content, unconfined compressive strength, and permeability all depend on the inherent organic content of the soil. With increasing organic content, water content, Atterberg limits, and permeability all increase. The fibrous structure of the organic deposit facilitates cation exchange among soil particle and attracts water 
molecule to its surface via adsorption (Huang et al., 2009), which increases the inherent water content of the soil. Figure 2-4 illustrates an increase in water content with increasing organic content. The increased organic adsorption also increases the liquid limit and plastic limit of the soil (Figure 2-5). Furthermore, the open fibrous structure of the organic deposit increases the voids of the soil, which in turn increases permeability.

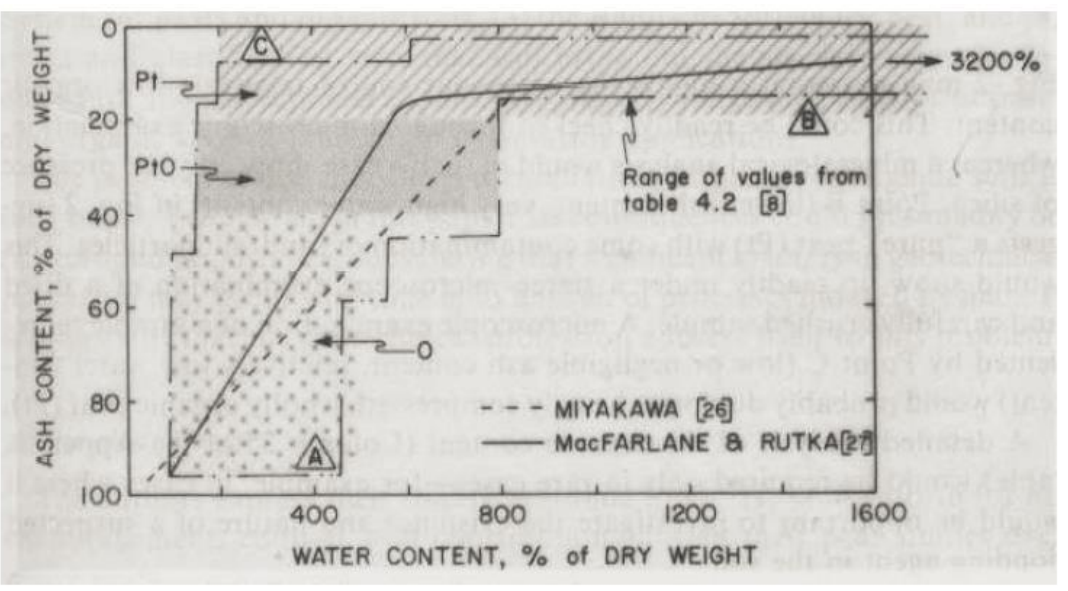

Figure 2-4 Influence of organic content on soil's moisture content (Jarrett, 1983)
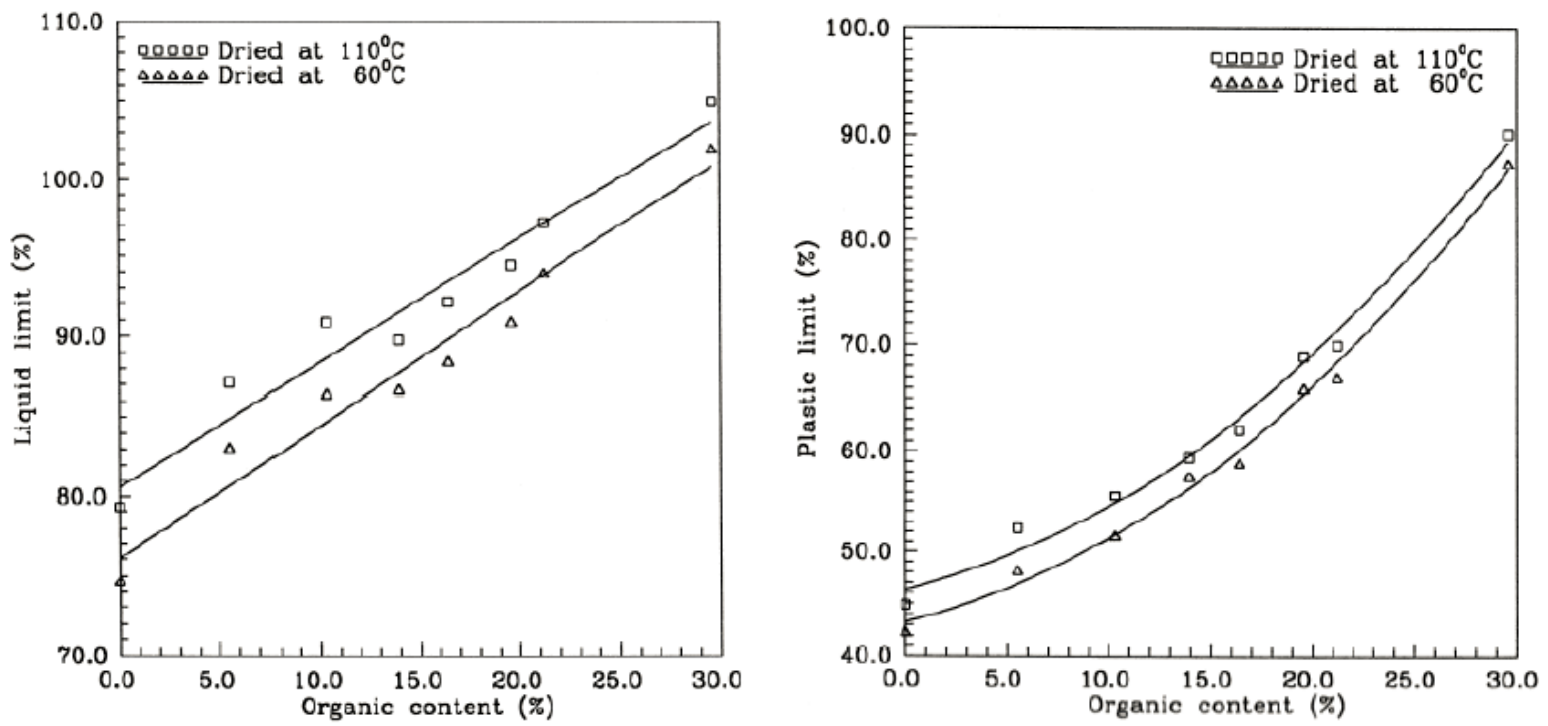

Figure 2-5 Influence of organic content on soil's Atterberg limits (Abdallah, 1999)

With an increase in organic content, the soil's strength properties often decrease. Bulk density of the soil decreases with increasing organic content due to the soil's increased voids. Figure 2-6 
displays a trend of decreasing specific gravity with increasing organic content. Compaction strength of soils, denoted by maximum dry density, decreases with soil's increasing organic content (Figure 2-7). This is consistent with the trend of organic content's tendency to absorb water (Abdallah, 1999). Peak unconfined compressive strength (UCS) also decreases with soil's increasing organic content. This trend is expected because of the UCS's high dependency on inherent moisture content, unit weight, and specific gravity (Abdallah, 1999). Since organic content increases moisture, lowers unit weight and specific gravity, UCS also experiences reduction with increasing organic content. Figure 2-8 clearly illustrates a decreasing UCS with increasing soil organic content. Finally, organic content increases soil's compressibility due to organic content's fibrous and open structure, which creates high water content, large void ratios, and low specific gravity (Mesri et al, 1997). Large compression index can be observed. All this evidence point to a need to improve organic soil's engineering properties.

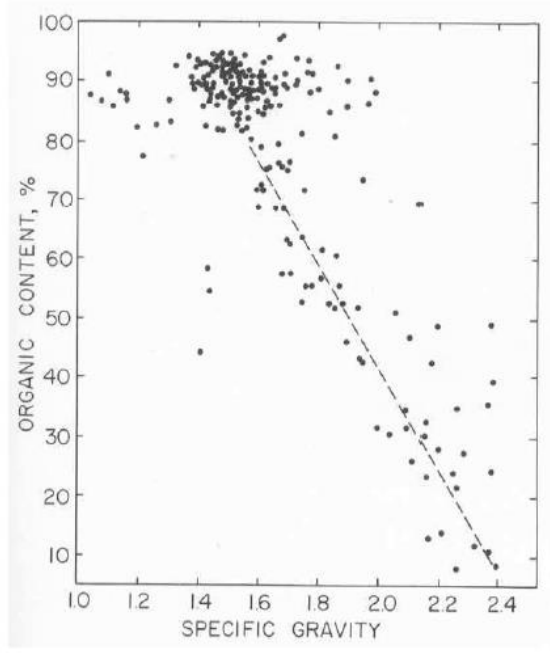

Figure 2-6 Organic content's influence on soil specific gravity of solids (Radforth et al., 1996) 


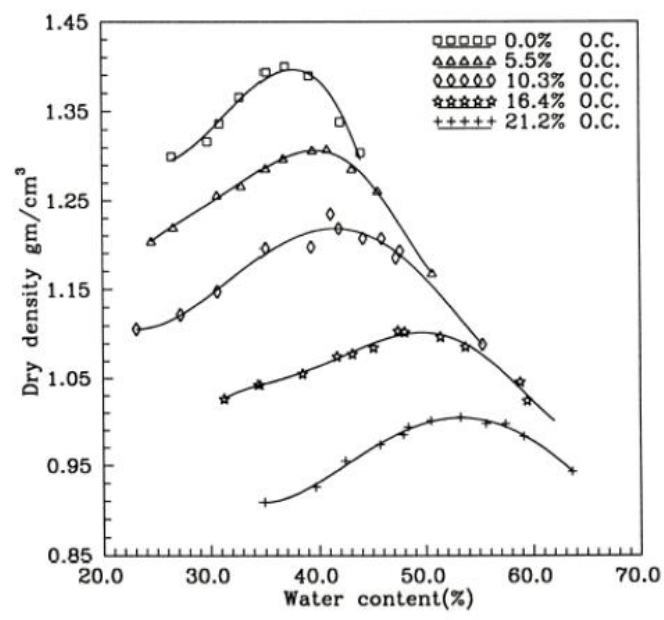

Figure 2-7 Organic content's influence on optimum water content (Abdallah, 1999)

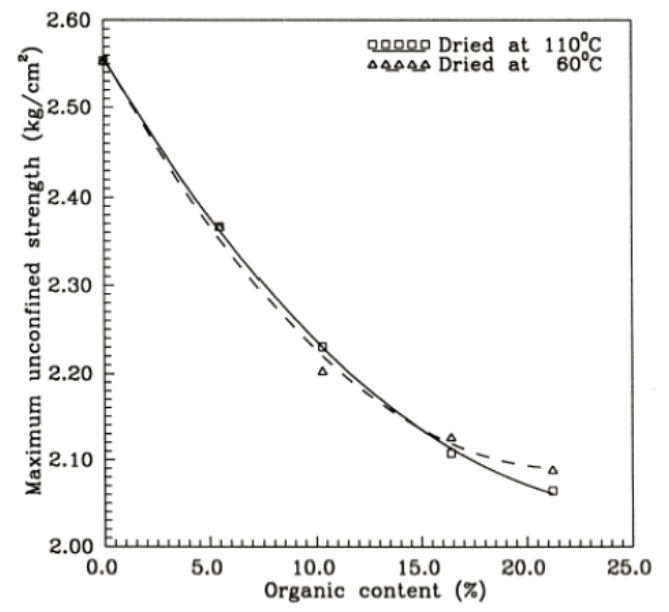

Figure 2-8 Organic content's influence on UCS (Abdallah, 1999)

In Ontario, soft silty clay sediments can be commonly in Lake Erie, Lake Ontario, and the shorelines along the lakes. Cities such as Toronto, Hamilton, and Cleveland contain high amounts of soft silty clay (Thomas, 1968). Figure 2-9illustrates the distribution of soft silty clay along Lake Onatrio and Lake Erie. 


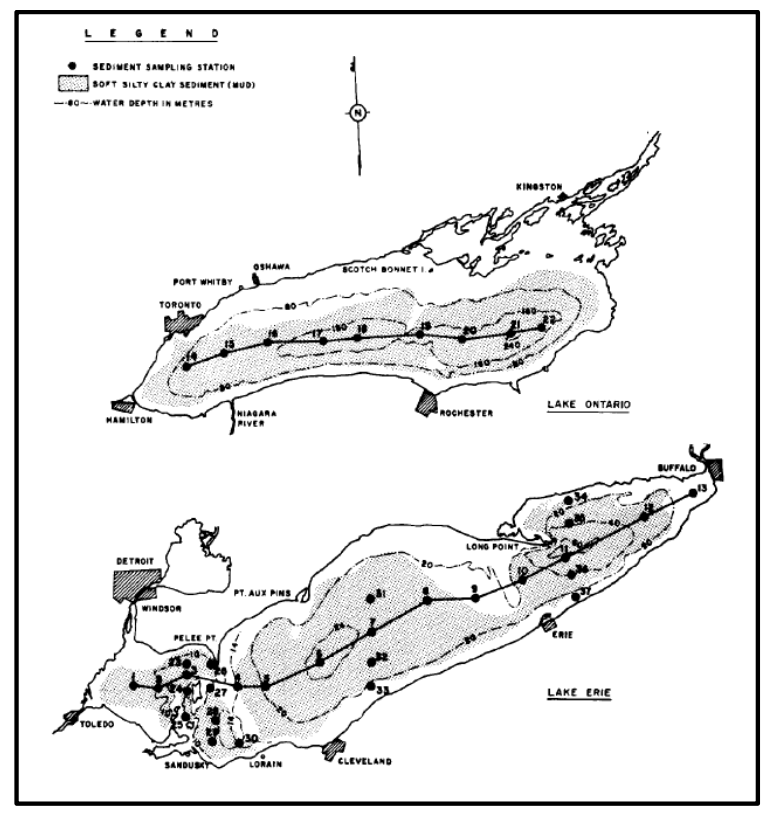

\section{Figure 2-9 Distribution of soft silty clay in Lake Ontario and Lake Erie (Kemp and Lewis, 1968)}

Based on Kemp and Lewis' (1968) analysis of 16 different clay samples extracted from Lake Erie and Lake Ontario, correlation between organic content, clay content, and quartz were obtained as well as clay's basic properties. Average organic content was found to be $4.91 \%$ and average clay content was $46.8 \%$. Kemp and Lewis also found multiple correlations between quartz, median grain size, organic carbon content, and clay content. With a decrease in quartz content, the median grain size increases (Figure 2-10). With an increase in organic carbon content, the clay content also increases (Figure 2-10).
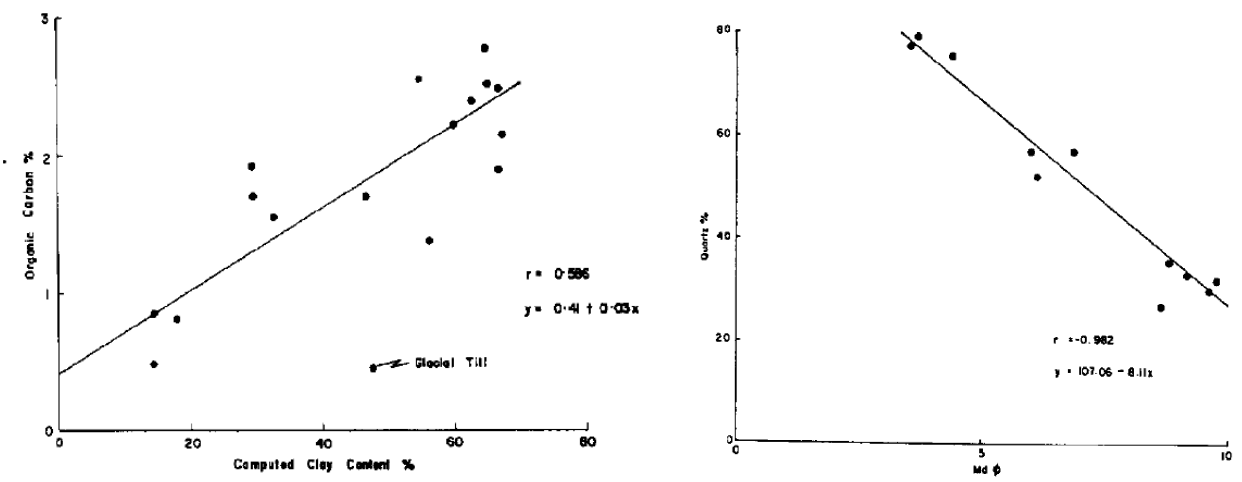

Figure 2-10 Correlations between organic content, clay content, quartz content, and medium grain size of soft silty clay (Kemp and Lewis, 1968) 
While the average organic content of the clay samples were less than $5 \%$, soils found at deeper depth, may have higher organic contents. With even one layer of weak organic soil, engineering structure can expect severe long term settlements.

In conclusion, organic soils have large void ratios, high water content, low unit weight, and low specific gravity. Its large voids contribute to high compressibility, low UCS, and high permeability. Secondary compression and continue settlement can be expected if structures were built on top of organic soils without ground improvement.

\subsection{Ground Improvement Techniques}

Currently, there are a wide variety of techniques available for engineers to treat soft soil unsuitable for load bearing structures, which densification, consolidation dewatering, grouting, reinforceme nt, replacement, soil nailing, micropile, and admixture reinforcement (Kitazume \& Terashi, 2012; Hussin, 2013, Tiwari \& Kumawat, 2014).

Replacement is a simple and reliable process that excavates soft and organic soil at a project site and replaces them with improved foreign materials. A popular choice of replacement material includes natural sand and gravel. This method is popular due to its low complexity and ease of execution, especially when a thin layer of soft clay is located in a shallow depth. However, if gravel and natural sand are saturated with water, the replaced soil becomes weak during seismic activity (Kitazume \& Terashi, 2012). Furthermore, natural material, such as sand and gravel, is very expensive to extract and transport onto the job site (Gonzales \& Moo-Young, 2004).

Another solution to treat soft soil is densification through dynamic compaction. Invented and promoted by Louis Menard, dynamic compaction improves soil's bearing capacity by transmitting high energy to the soil through a heavy weight dropped from heights of 20 to $30 \mathrm{~m}$ (Tiwari \& Kumawat, 2014). Currently, applications used to treat soft and granular soils include vibrodensification, vibroflotation, sand compaction pile, and compaction grouting (Kitazume \& Terashi, 2012). Figure 2-11 illustrates the procedure of vibroflotation compaction where densification was achieved through the mechanical vibration of the probe. However, this method produces large noise and vibration, which are not well received by residential areas in urban settings. The required large equipment may also be difficult for construction site with restricted access. Furthermore, wet 
vibro-compaction utilize water to jet the vibrator, which can increase the spread of contaminants if the work is being performed at a contaminated site (NYSDOT, 2013).

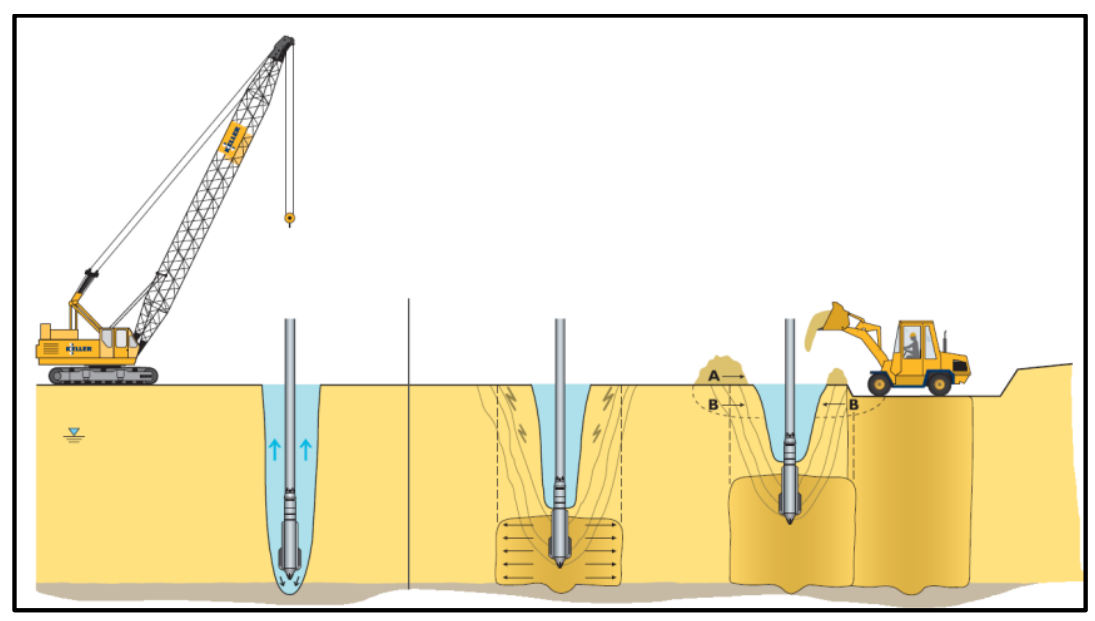

\section{Figure 2-11 Vibro Compaction procedure on granular soil (Keller, 2016)}

Consolidation and dewatering follows the same fundamental mechanism as densification, where soft embankment fill are preloaded and dewatered to increase soil's final bearing capacity. At the same time, dewatering can be applied to consolidate compressible soil with low permeability (Blake et al., 1987). Specific techniques include prefabricated vertical drains, Geo-tube dewatering, and surface preloading (Tiwari \& Kumawat, 2014). However, it is not possible to preload the soil in a one-step fashion. Most applications utilize staged construction, which is time consuming and unfit for projects with a restricted schedule (Kitazume \& Terashi, 2012). Other disadvantages include limited hydrogeological setting for dewatering applications and higher than normal maintenance cost (Blake, Hockman, \& Martin, 1987). Figure 2-12 illustrates a Geo-tube application where solids are dewatered and consolidated for up to twelve months (Prakashan, 2015). 


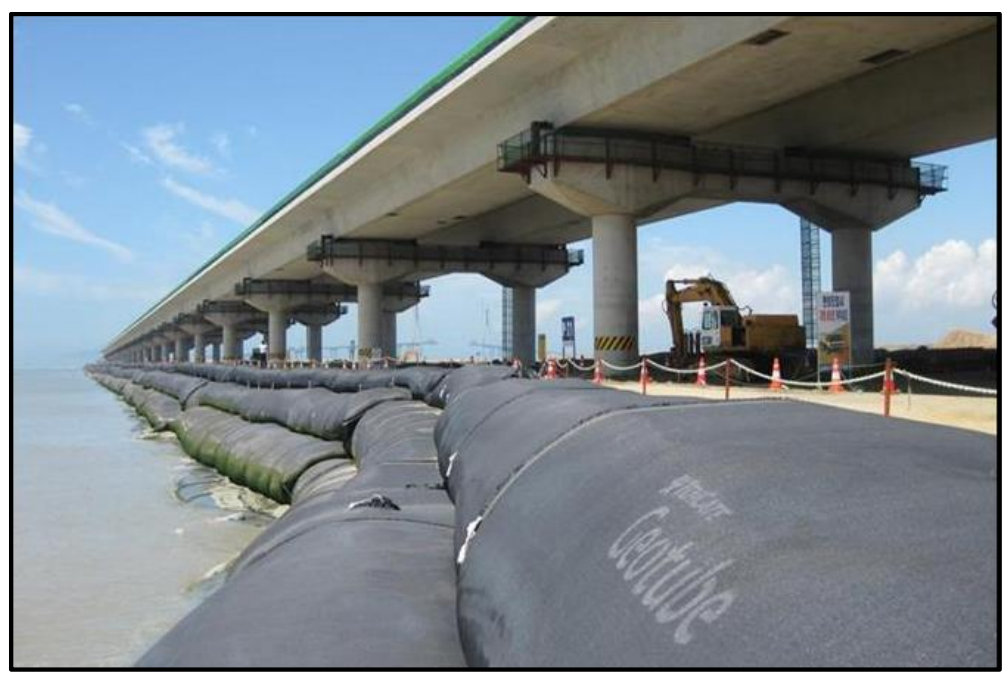

Figure 2-12 Geo-tube application for Incheon Bridge project in Incheon, Korea (Prakashan, 2015)

Grouting is another ground improvement method which introduces viscous material into a natural opening of the soil (or man-made borehole) to increase its strength and retard water seepage (Kitazume \& Terashi, 2012). Grouting is very similar to deep soil mixing where both methods introduce a binder material into the soil. The discerning difference between the two techniques can be distinguished by the un-probing nature of grouting where the injection point is placed outside of the grouting zone. Common grouting applications include compaction grouting, penetration grouting, void grouting and displacement grouting (Tiwari \& Kumawat, 2014). Depending on the scope of the project, grouting can be expensive when chemicals are required to treat special ground conditions.

\subsection{Deep soil mixing}

Deep mixing method (DMM) is a ground improvement technique which introduces a cementitious binder material to the target soil. Throughout the introduction, the binder will be thoroughly distributed among the improvement zone through means of rotary mixing at various geometries. This in-situ mixing technique is achieved through a specialized auger with mixing paddles and injection tubing (Wet Soil Mixing, 2015). The physical mixing motion, either done by auger mixing blade at the end or along the mixing shaft, promotes chemical reaction between the binder and the moisture in soil to allow dewatering, volume reduction of soil, and general increase in bearing capacity. Figure 2-13 shows a typical dry mixing cement soil column being installed. For 
mass deep mixing, a horizontal mixer/cutter is attached to the arm of a backhoe and performs mixing horizontally (Wet Soil Mixing, 2015).

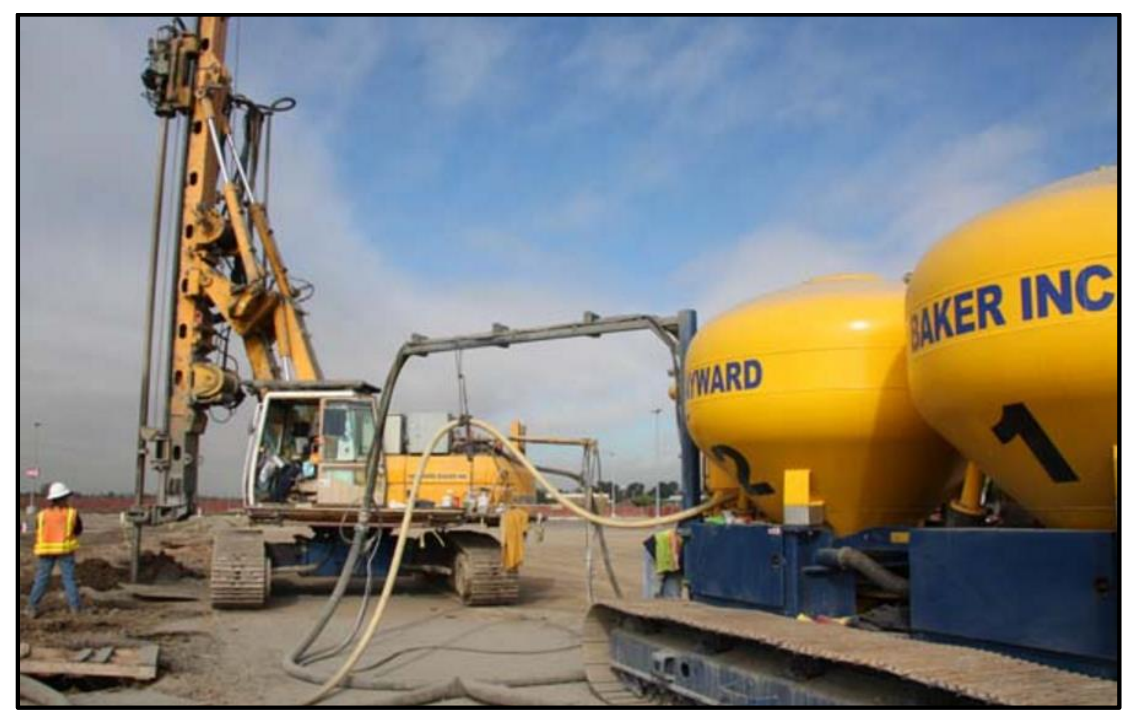

Figure 2-13 Dry cement soil column installation at a work site (Hayward Baker, 2016)

Deep mixing has disadvantages that may be not applicable to all situations, such as large mobilization cost, large work footprint, and impact on high density underground utilities; however, deep mixing becomes advantageous if it applied to large infrastructure development projects. These advantages include low cost per unit volume of treated soil, low soil vibration, effective treatment strength, high spoil reuse rate, quick performance verification, and good execution pace (Kitazume \& Terashi, 2012).

\subsubsection{Mechanism of binder strength improvement}

The mechanisms of DMM stabilization consists of four stages: hydration of binder, ion exchange reaction, formation of cement hydration product, and formation of pozzolanic product (Kitazume and Terashi 2012).

The four stages of cement stabilization, which is presented in Figure 2-14, can be divided into short term and long term phases. Initial cement hydration will lead to reduction of water content and the production of calcium silicate hydrate $(\mathrm{C}-\mathrm{S}-\mathrm{H})$, which improves the soil's strength over a short period of time. As more and more calcium hydroxide is released, long term pozzolanic reaction is triggered and produces calcium aluminate and/or calcium silicate to improve soil matrix's strength. The alkaline environment enables continuous pozzolanic reaction. 


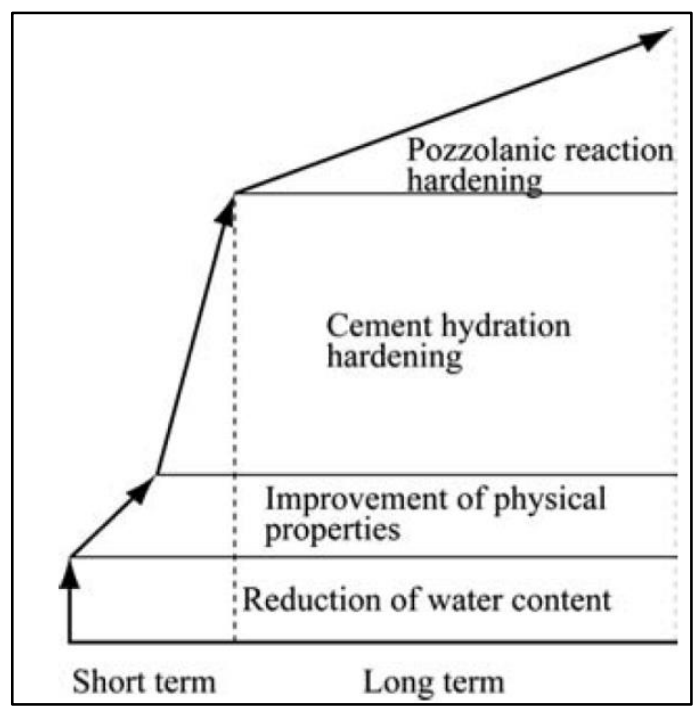

Figure 2-14 Stages of cement stabilization (Kitazume \& Terashi, 2012)

When ordinary Portland cement becomes hydrated, calcium hydroxide $\left(\mathrm{Ca}(\mathrm{OH})_{2}\right)$ and calcium silicate hydrate $(\mathrm{C}-\mathrm{S}-\mathrm{H})$ are produced and released into the environment. C-S-Hacts as a strength improvement material (Wang, 2002). Calcium hydroxide also promotes flocculation and agglomeration of the soil, further improving its strength. Since hydration can continue for a long time, calcium hydroxide will be produced continuously to supply the calcium ions for the formation of C-S-H. Equation 2-1 illustrates tricalcium silicate's and water's reaction to produce C-S-H and calcium hydroxide.

$2\left(3 \mathrm{CaO} \cdot \mathrm{SiO}_{2}\right)+6 \mathrm{H}_{2} \mathrm{O}=3 \mathrm{CaO} \cdot 2 \mathrm{SiO}_{2} \cdot 3 \mathrm{H}_{2} \mathrm{O}+3 \mathrm{Ca}\left(\mathrm{OH}_{2}\right)$

When a high concentration of calcium ions $\left(\mathrm{Ca}^{+}\right)$and hydroxyl ions $\left(\mathrm{OH}^{-}\right)$are present at the surface of clay minerals, the mineral's silica and aluminum dissolve into the pore water and react with the calcium ions to form calcium-silicate and/or calcium-aluminate (Kitazume \& Terashi, 2012). This reaction, known as pozzolanic reaction, produces tough water insoluble gel which improves the long term strength of soil. Calcium hydroxide, which is slowly released through cement soil hydration, maintains a high soil $\mathrm{pH}$ environment. An alkaline soil environment allows the pozzolanic reaction to occur, which is beneficial for long term soil strength improvement. Figure 2-15 illustrates a soil particle under pozzolanic reaction. 


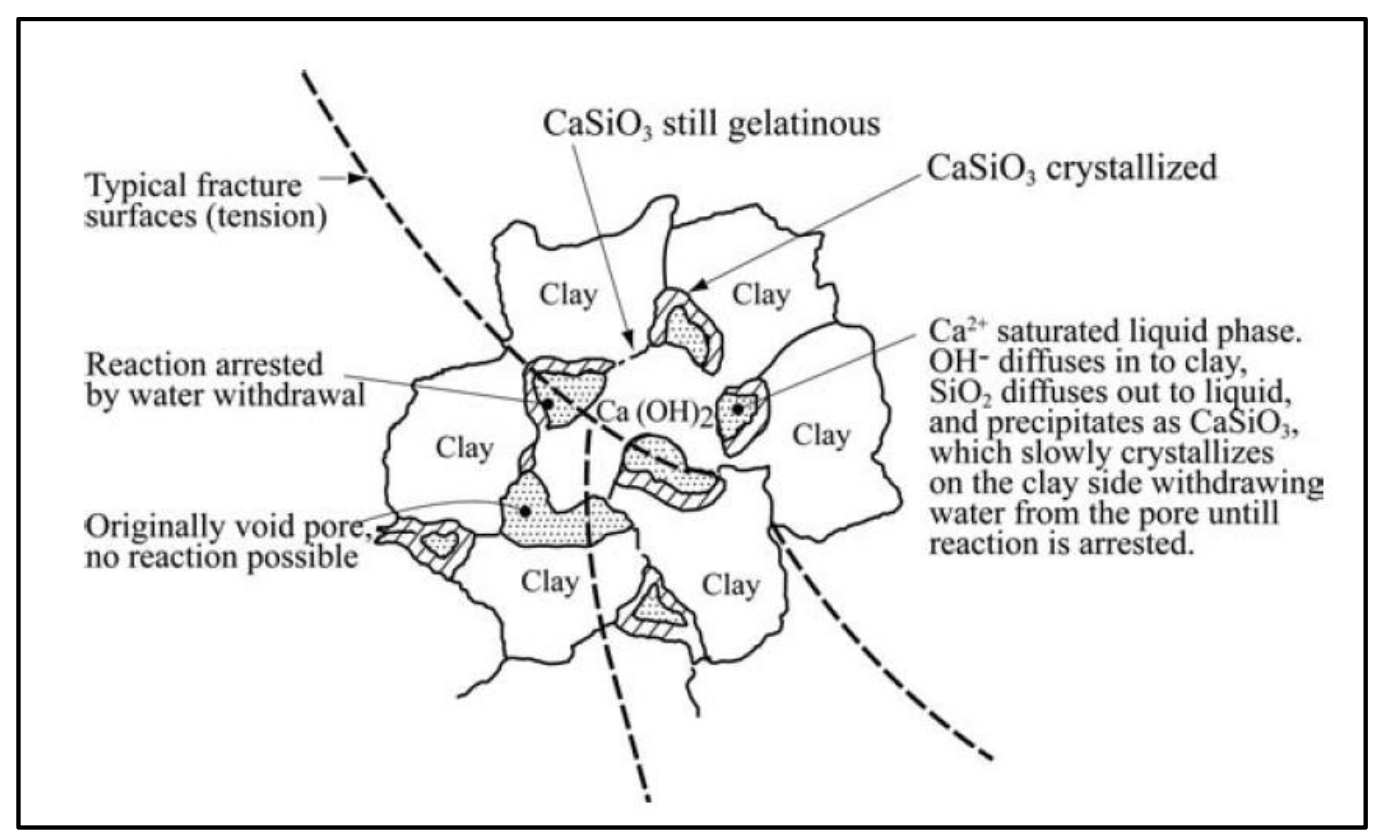

Figure 2-15 Mechanism of pozzolanic reaction (Ingles \& Metcalf, 1972)

Blast furnace slag can also be added to the cement mixture to enhance soil strength improvement. While slag does not directly react with water, slag can actively release silicon dioxide and aluminum oxide under high concentrations of $\mathrm{Ca}^{2+}$ ions, which allows the formation of silicate hydration products to improve strength. Figure 2-16 explains the complex mechanism of cement hydration reaction.

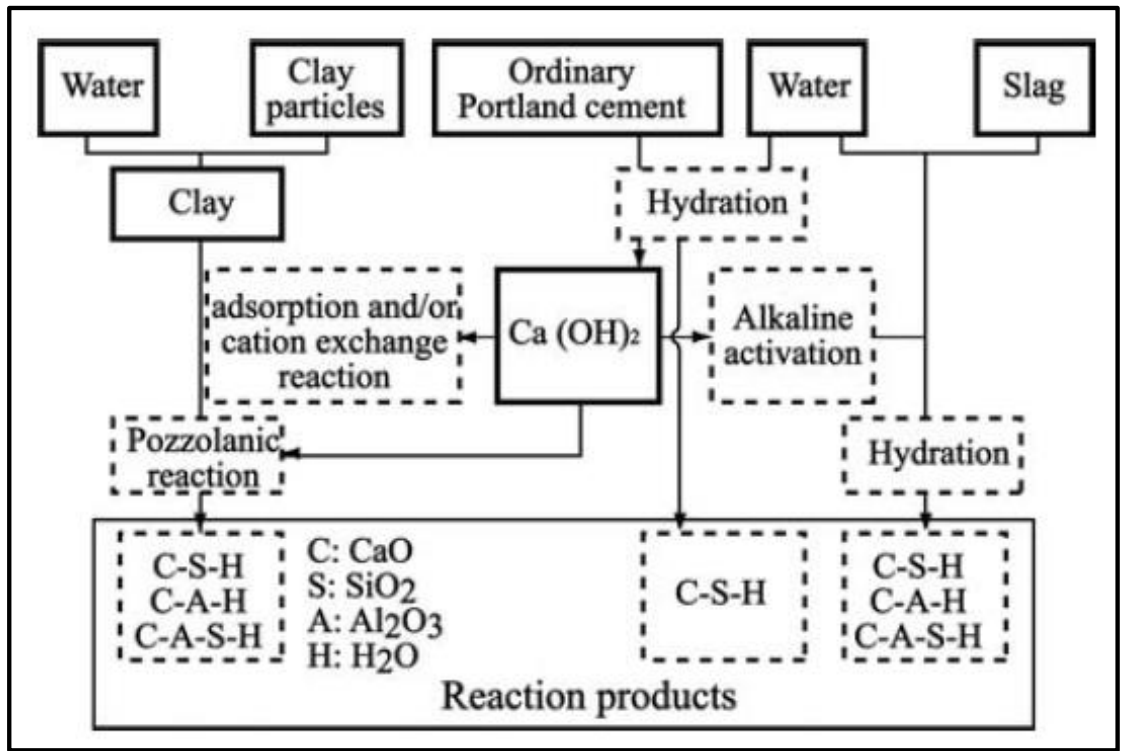

Figure 2-16 Chemical reactions between clay, cement, water, and slag (Saitoh et al., 1985) 


\subsubsection{Deep mixing method classifications}

The most popular DMM classifications mentioned in the practice is mass mixing and column mixing. Mass mixing is the treatment of a large body of soft soil (Figure 2-17), whereas column mixing solidifies the soil in a column like fashion, penetrating the earth in a vertical motion. Mass mixing utilizes a horizontal cutter attached to the arm of a backhoe. Column mixing utilizes a specialized drill rig which mixes the soil into the column shotcrete (Deep Soil Mixing, 2016), as seen in Figure 2-18.

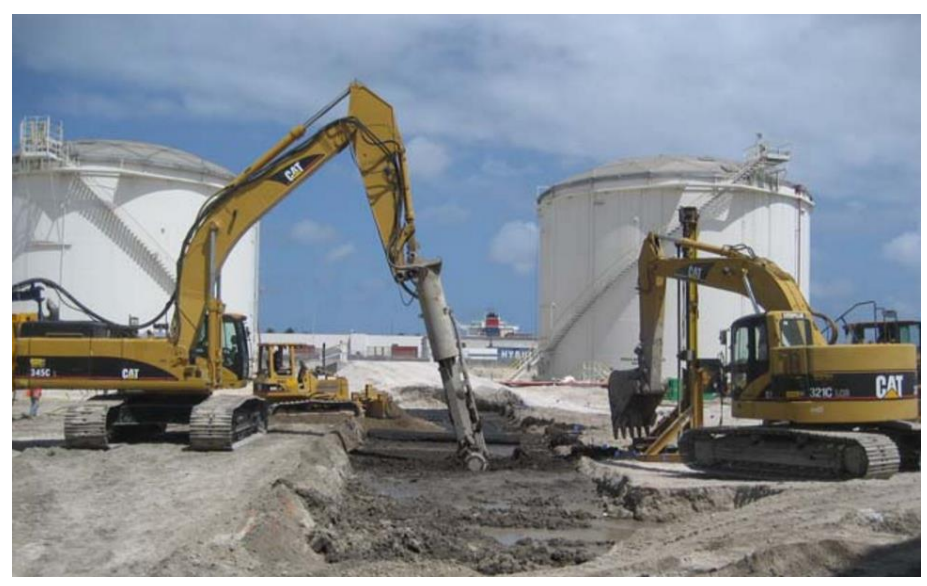

Figure 2-17 Mass mixing conducted at Port Everglades, FL (Wet Mixing, 2016)

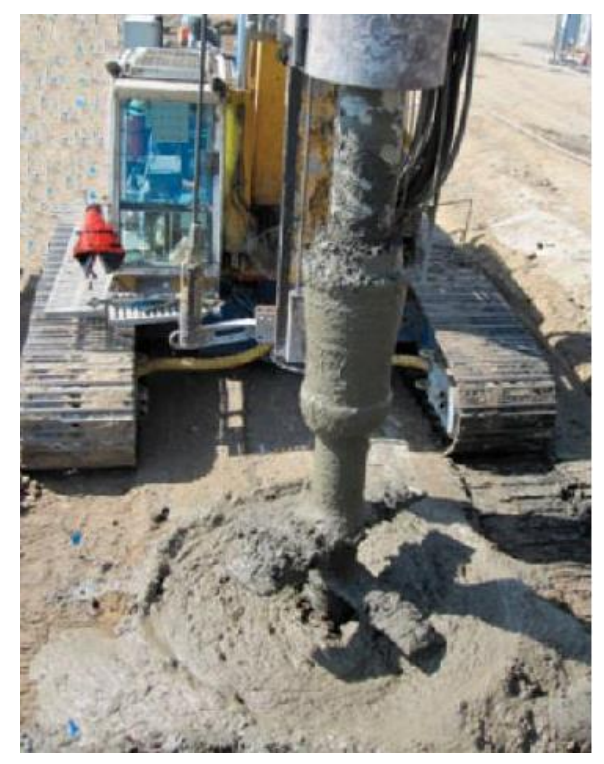

Figure 2-18 Soil columns constructed via DMM technique (Engineering, 2012)

The US Federal Highway Association further classifies deep mixing into dry and wet mixing. The dry mixing method is mostly applied when the moisture content of the soil is higher than $60 \%$; 
therefore, dry mixing utilizes a powder which reacts strongly with water already present in the soil. The wet mixing method utilizes wet cementitious binder slurry which is mixed into soil with moisture content up to $60 \%$ (Bruce et al., 2013).

Finally, this classification can be further refined by adding in the mixing and binder injecting methods. Bruce et al. (1998) provide a convenient summary of classifications according to the following criteria.

1. Is the binder material a wet slurry $(\mathbf{W})$ or dry $(\mathbf{D})$

2. Is the binder being mixed with rotary energy $(\mathbf{R})$ or high pressure jet $(\mathbf{J})$

3. Does the mixing occur near the end of the mixing auger $(\mathbf{E})$ or along the shaft of the auger $(\mathbf{S})$

According to this classification system, various techniques can be summarized under this grouping with a simple three letter code for unifying definition. Many of the deep mixing methods can be categorized under WRS, WRE, WJE, and DRE (Bruce et al., 1998). There are no DRS, DJE, and DJS because dry mixing method is limited to rotary mixing at the end of the shaft at this point.

\subsection{Past Investigations}

According to Kitazume and Terashi (2012), factors affecting soil strength increase can be divided into four categories: binder characteristics, soil characteristics, mixing conditions, and curing conditions. The Federal Highway Administration's design manual on deep soil mixing agrees with this approach, with loading condition as an additional factor (Bruce et al., 2013). Table 2-1 illustrates a list of variables and factors which affect the performance of DMM.

Table 2-1 Factors affecting DMM strength increase (Kitazume \& Terashi, 2012)

\begin{tabular}{l|l}
\hline 1. Characteristics of binder & $\begin{array}{l}\text { 1. Type of binder } \\
\text { 2. Quality } \\
\text { 3. Mixing water and additives }\end{array}$ \\
\hline $\begin{array}{l}\text { 2. Characteristics and conditions } \\
\text { of soil }\end{array}$ & $\begin{array}{l}\text { 1. Physical, chemical and mineralogical properties of } \\
\text { soil }\end{array}$ \\
& 2. Organic content \\
\hline
\end{tabular}




\begin{tabular}{l|l}
\hline & $\begin{array}{l}\text { 3. Potential Hydrogen }(\mathrm{pH}) \text { of pore water } \\
\text { 4. Water content }\end{array}$ \\
\hline 3. Mixing conditions & $\begin{array}{l}\text { 1. Degree of mixing } \\
\text { 2. Timing of mixing/re-mixing } \\
\text { 3. Quantity of binder }\end{array}$ \\
\hline \multirow{3}{*}{ Curing conditions } & $\begin{array}{l}\text { 1. Temperature } \\
\text { 2. Curing period } \\
\text { 3. Humidity } \\
\text { 4. Wetting, drying, freezing and thawing, etc. } \\
5 . \text { Overburden pressure }\end{array}$ \\
\hline
\end{tabular}

\subsubsection{Binder Dosage}

Binder dosage was commonly used as variable by researchers to gauge strength improvement of treated clay samples (Pathivada, 2005; Ramirez, 2009; Baker, 2015; Hwang, 2006; Das, 2012). Pathivada (2005) utilized a low binder dosage between $6 \%$ to $12 \%$ binder content by dry mass $\left(100 \mathrm{~kg} / \mathrm{m}^{3}\right.$ to $\left.200 \mathrm{~kg} / \mathrm{m}^{3}\right)$ to treat expansive clay. Das (2012) also utilized a similar binder dosage range between $2 \%$ to $10 \%$ cement by mass to treat clay minerals. A higher binder dosage was used by many researchers to treat organic to highly organic soils, sometimes the binder dosage can go up to $100 \%$ by mass (Hwang 2006; Ramirez 2009; Baker 2015).

The results of aforementioned studies showed that an increase in soil strength is directly related to an increase in binder dosage. Figure 2-19 illustrates a direct increase in sample UCS with increasing binder dosage (Pathivada, 2005).

\subsubsection{Binder Type}

Based on current industry standards and past research studies, Ordinary Portland cement is the most common binder used for research and field applications (Pathivada, 2005; Kitazume \& Terashi, 2012; Pooranampillai, 2012; Ramirez, 2009). Lime was also commonly used by contractors. It was shown to be an effective binder to improve Champlain Sea clay's strength according to Locat et al. (1990) due to lime's high reactivity towards pozzolanic reaction. If a soil has low pozzolanic reactivity, Little and Nair (2009) recommended using a combination of lime and cement to continue the strength improvement process. Pathivada (2005) also tested a 
combination of lime and cement to examine the strength improvement of expansive clay. Figure 3-1 illustrates that the best strength improvement comes from a 100\% cement binder type instead of a lime-cement mixture in Pathivada's study (Pathivada, 2005).

Slag, a pozzolanic reagent, promotes the hydration of calcium hydroxide to produce pozzolanic compounds for further strength improvement (Kitazume \& Terashi, 2012; Baker, 2015). This compound is often used in combination with cement to promote pozzolanic reaction of clay. Cost and Ahlrich (2003) utilized slag/cement as strengthening binder for a specific soil. Slag/cement mixture was found to have more than twice the strength compared to lime-fly ash mixture.

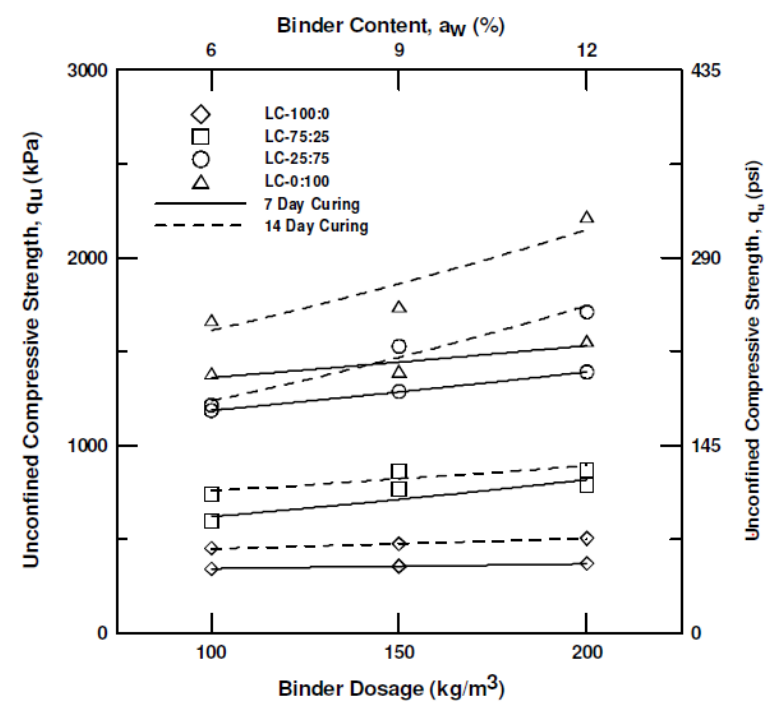

Figure 2-19 Influence of binder dosage and curing time on samples' UCS (Pathivada, 2005)

\subsubsection{Soil Type and Parameters}

Currently, the admixture stabilization research on Champlain Sea clay is limited. Locat et al. (1990) conducted laboratory tests on Champlain Sea clay with lime as the primary stabilization agent. Locat et al. (1990) confirmed the viability of using lime to develop strength improvement for Champlain Sea clay at a binder content up to $10 \%$ quicklime by mass. However, treated Champlain Sea clay's UCS was affected by many factors, including inherent water content, curing time, and dispersion mechanism.

Pathivada (2005) conducted research on expansive clay found in Fort Worth, Texas with medium to high plastic indices with positive results. In field applications and verifications using cement mixing on Bangkok soft clay (Bergado et al., 1999; Lorenzo \& Bergado, 2004) were conducted. 
Embankment settlements were successfully reduced using cement columns. Organic soils were also frequently used by researchers to conduct tests (Hwang, 2006; Ramirez, 2009; Baker, 2015).

Niina et al. (1981) conducted cement stabilization tests on 20 different types of clays in Japan to find the most influential factors on peak unconfined compression strength (UCS). Parameters for this study include $\mathrm{pH}$, humic acid content, organic carbon content, ignition loss, natural water content, and specific gravity. The results indicate that $\mathrm{pH}$ and humic acid content were the most dominant factors influencing UCS (Figure 2-20). Further studies conducted by Okada et al. (1983) verified the effect of humic acid on cement treated soil. Drastic decrease in UCS can be found after $2 \%-5 \%$ of humic acid in soil (Figure 2-21).

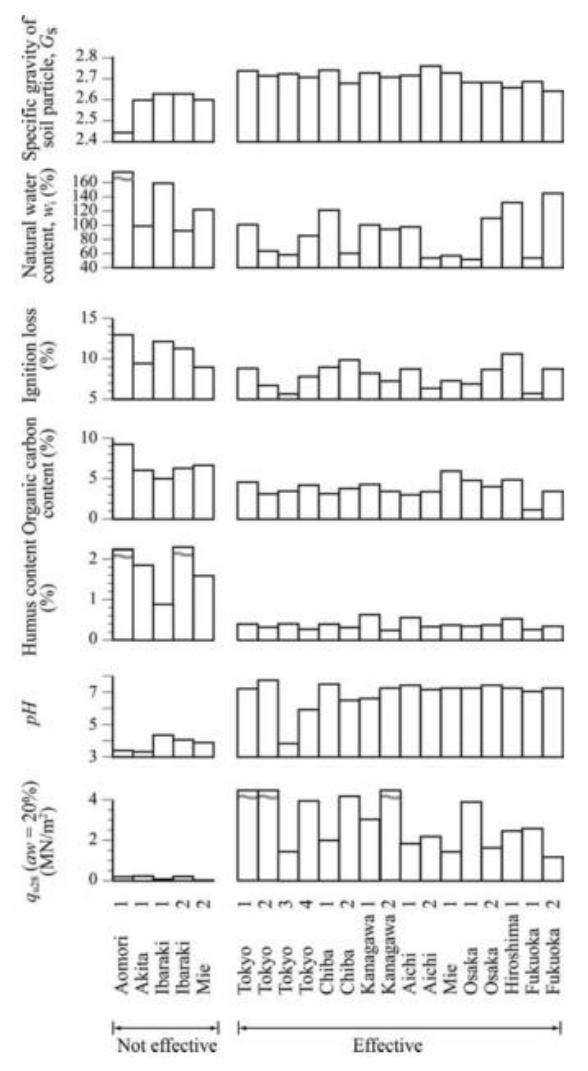

Figure 2-20 Influence of soil parameters on UCS (Niina et al., 1981) 


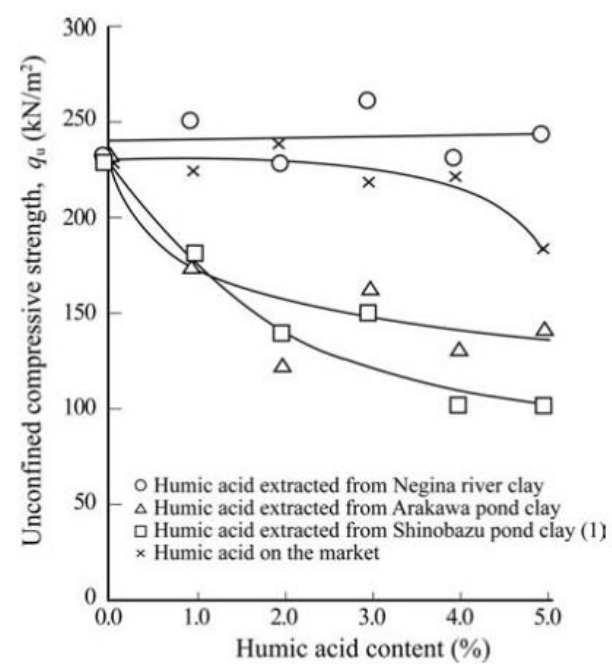

Figure 2-21 Influence of humic acid on cement treated soil's UCS (Okada et al., 1983) 2.5.4 Curing Period

Sample curing remains a fundamental part of the experimental program. Most studies cure samples for a period of 7, 14, and 28 days. Baker (2015) cured treated samples for up to 61 days to fully observe long term effect of curing on samples compared to 14 and 28 days. Ramirez (2009), Pathivada (2005), and Das (2012) only cured treated samples for 7 and 14 days due to experimental design program. The field DMM quality control normally require testing at 7 day curing and 28day curing (Little \& Nair, 2009). Increasing curing period is directly related to increasing sample UCS for lime treated samples and cement treated samples. Figure 2-22 illustrates the effect of increasing curing time on lime treated marine clays in Japan (Kitazume \& Terashi, 2012) and Figure 2-23 illustrates a similar increasing UCS with an increasing curing of cement treated marine clays.

\subsubsection{Experimental Methodology}

The fundamental experimental program utilized by past research favoured an inductive approach. Based on existing conditions, usage, and limited understanding, researchers aimed to understand the mechanism of admixture stabilization under different conditions. Das (2012) focused his research on improving stiffness and shear strength of clay minerals with cement . Other researchers (Ramirez, 2009; Pathivada, 2005; Lorenzo \& Bergado, 2004) aimed to observe a strength improvement of soil with altered experimental parameters. They have also established a correlation relationship between these parameters to the strength improvement. 


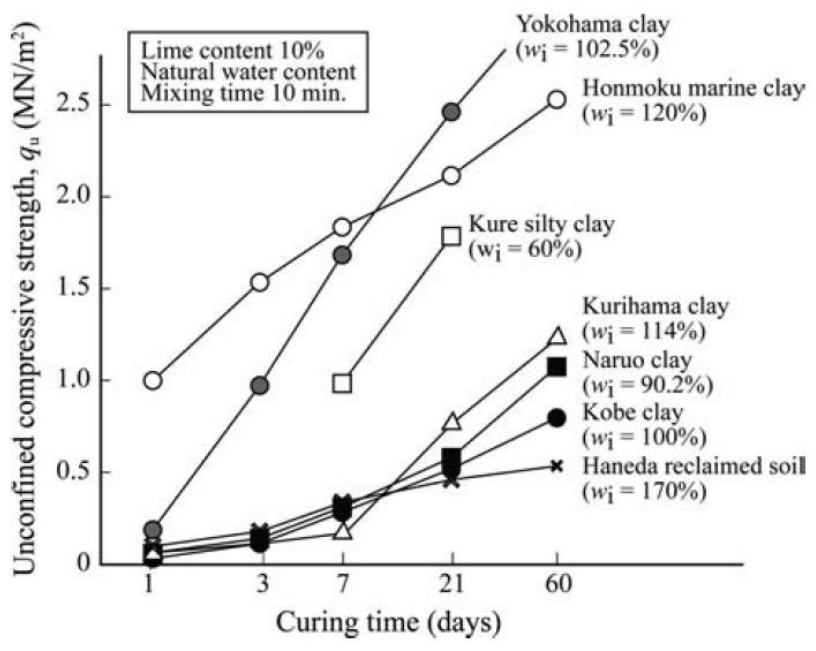

Figure 2-22 Curing time on lime treated marine clays in Japan (Kitazume \& Terashi, 2012)

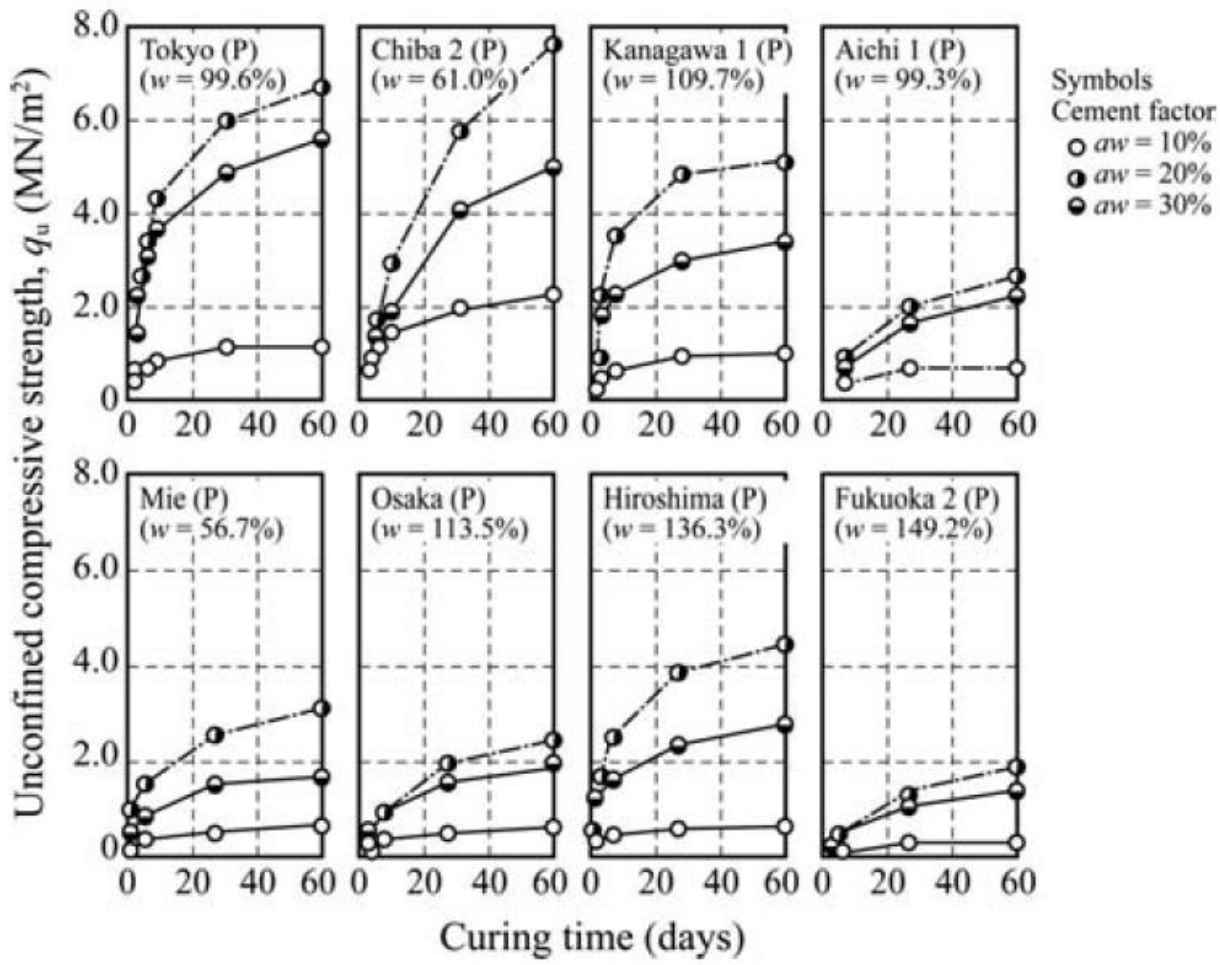

Figure 2-23 Curing time on cement treated marine clays in Japan (Kawasaki et al., 1981) 


\subsubsection{Testing Methods}

To evaluate the strength improvements of treated samples, unconfined compression strength (UCS) test is most commonly used by researchers to measure strength improvements of treated samples (Ramirez, 2009; Pathivada, 2005; Locat, 1990; Bergado, 1999). UCS can be directly correlated to undrained shear strength of a treated clay sample. UCS tests are conducted at 7, 14, and 28 days of curing. Other testing procedures include Swedish fall cone tests and shear wave velocity to develop undrained shear strength (Locat et al., 1990). Consolidation tests were conducted (Ramirez, 2009) to examine primary and secondary compression behaviours of treated soil samples. Hwang (2006) utilized a constant rate of strain (CRS) device to conduct 1-D consolidation on binder treated samples. Furthermore, different types of triaxial tests were conducted (Das, 2012) to examine the reaction to different force application of the treated sample.

\subsection{Case studies}

DMM has been successfully implemented in the past in the United States, Japan, Norway, and many other parts of the world. Poor soil compositions such as clay, marine, silt, organic soils, peat, and fill have been successfully treated with DMM. The following cases will illustrate the wide and successful applications of DMM.

\subsubsection{Kitimat LNG Facility, Bish Cove, British Columbia}

The Kitimat Liquefied Natural Gas (LNG) project required ground improvement at a remote area in Bish Cove, British Columbia before a processing facility can be constructed on top. Golder Associates Construction proposed Cutter Soil Mixing (CSM), a DMM technique, to improve the clayey silt and sandy gravel soil prior to construction of two Mechanical Stabilized Earth (MSE) retaining walls (Associates, 2015). The MSE walls are $165 \mathrm{~m}$ to $300 \mathrm{~m}$ in length, and $5.5 \mathrm{~m}$ to 20 $\mathrm{m}$ in height. CSM was chosen because it uses local soil as a construction material to perform ground reinforcement. Since the work site can only be accessed via marine channels, it was imperative to minimize the amounts of materials delivered to and removed from site.

Construction using the CSM technique involves building soil panels by drilling a mixing head armed with two cutter wheels into the ground. The cutter wheel loosens the soil during its way down and mixes ejected cement slurry with soil particles on its way up to form a uniform column or panel like structure. Figure 2-24 illustrates a rig's cutter head exiting the soil panel. 
CSM panels were embedded throughout the soil layer. A total volume of $73900 \mathrm{~m}^{3}$ of soil was treated with cement to yield an average UCS of $2.5 \mathrm{MPa}$. The applied wet slurry water to cement ratio (w/c) was between 0.6 and 0.75 ; and the cement dosage was between $250 \mathrm{~kg} / \mathrm{m}^{3}$ to $450 \mathrm{~kg} / \mathrm{m}^{3}$. Trial panels were cured for 7, 14, 28, and 56 days and tested for their UCSs. Additional coring samples were extracted and tested from trials panels cured for 21 days.

To ensure testing authenticity and reliability, two specimens were tested at the same depth, curing age, and panel. The variation was $0.25 \mathrm{MPa}$ or less for forty percent of the samples; and $0.5 \mathrm{MPa}$ or less for $63 \%$ of the samples.

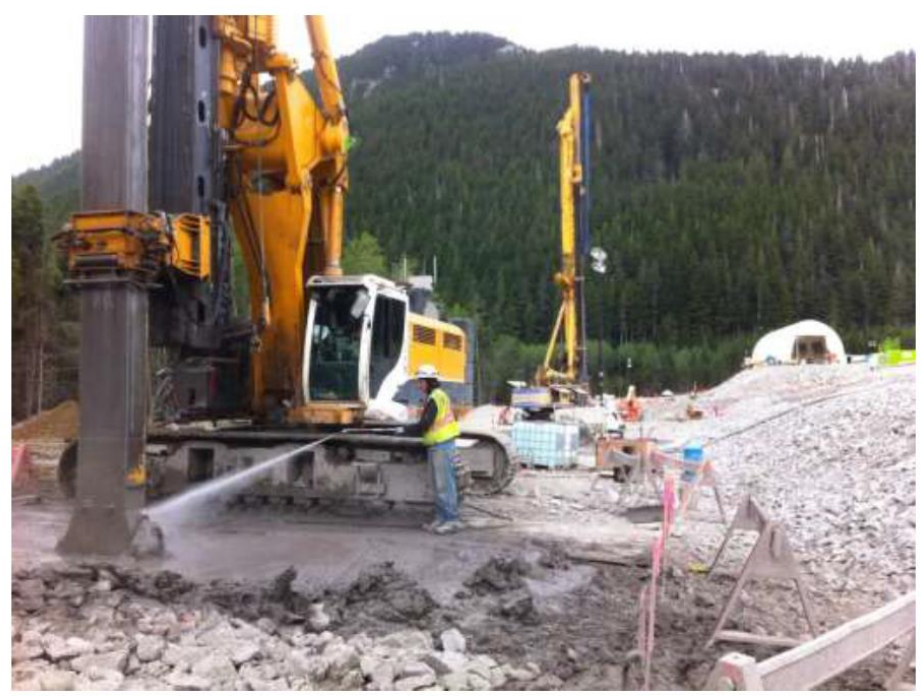

Figure 2-24 CSM cutter head exiting a completed panel (Associates, 2015)

\subsubsection{Interstate 5 Embankment Support, Tacoma, Washington}

Tacoma's Interstate 5 expressway required road widening to construct high occupancy vehicle (HOV) lanes. During soil investigation, the soil was found to be poor in strength and unsuitable for embankment support. The soil contained low plasticity silts, organic silts, and silty sands. This soil condition is potentially liquefiable. The presence of organic also indicated high soil compressibility.

To solve this problem, local contractor Condon Johnson proposed using DMM to strengthen ground condition for embankment support. The designed UCS was initially set at $1032 \mathrm{kPa}$. Constructed soil mixed columns should also allow for the construction of trenchless utilities beneath the embankment (Pooranampillai et al., 2012). However, during on-site soil testing, 
samples extracted on-site yielded lower UCS than anticipated; therefore, the target UCS was reduced to $517 \mathrm{kPa}$. The reduction of UCS prompted an increase in soil replacement ratio to maintain an overall integrity.

Soil-mixed columns were constructed using auger tools and mixing blades attached to a Kelly bar (Figure 2-25). The average diameter of the columns was $1.8 \mathrm{~m}$. Columns were spaced at $3 \mathrm{~m}$ distance in a triangular fashion; and installed depths range from 24 to $26 \mathrm{~m}$.

During construction, various parameters were monitored to maintain consistent qualities. Condon Johnson also maintained consistent lab testing of wet mix samples extracted from columns for strength verification. Sonic coring of the columns was also performed at a high frequency of 1 in 5 columns. However, Condon Johnson's project produced a lot of spoil which were $50 \%$ of the total treatment volume. These spoils were stored on site and later shipped away.

Condon Johnson was able to finish the project with all columns meeting designed strength. Daily sample extraction and testing verified consistent strength. However, extraction of intact coring samples proved to be challenging. Condon Johnson recommended the following steps to improve the coring process (Pooranampillai et al., 2012).

1. Incorporate strength loss in the sample due to sonic coring

2. Methods in assessing strength before cement curing

3. Repeatable and quantifiable methods to assess uniformity of the sonic coring sample 


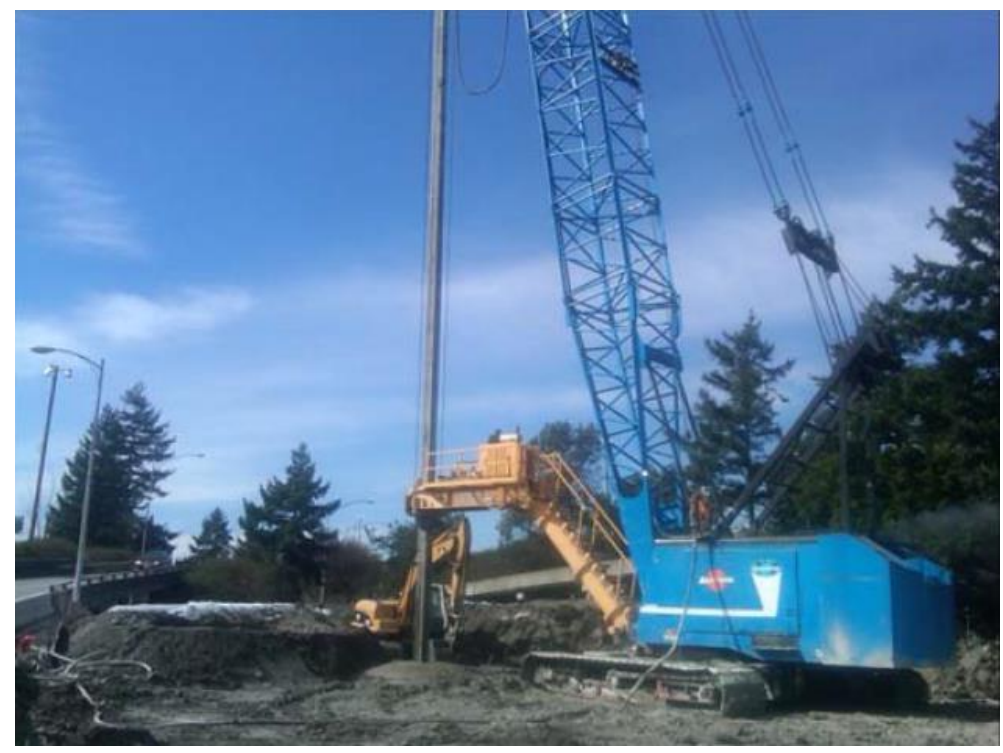

Figure 2-25 Equipment used to conduct DMM at Interstate 5 (Pooranampillai et al., 2012)

\subsubsection{Bangna-Bangpakong Highway, Bangkok, Thailand}

Bangna-Bangpakong highway is an arterial highway connecting the suburb of Bangna to the industrial park district of Bang Pakong in Thailand. Severe settlement was observed on a section of this $55 \mathrm{~km}$ long highway, which was built on top of soft Bangkok clay. Settlement was measured at $400 \mathrm{~mm}-700 \mathrm{~mm}$ a year. Bangna area also has a high subsidence rate of $100-150 \mathrm{~mm} / \mathrm{year}$ (Bergado et al., 1999).

To combat settlement along the highway, DMM was considered as one of the ground improve me nt methods due to its previous local applications in settlement control for highway embankment, buildings, and other lightly loaded small structures (Bergado et al., 1999). Initial trial mix was performed at one section of the highway. Samples of cement treated soil were taken at various depths with a cement dosage of $125 \mathrm{~kg} / \mathrm{m}^{3}$ to $250 \mathrm{~kg} / \mathrm{m}^{3}$. The samples were then allowed to cure for $3,7,14$, and 28 days. UCSs of samples were collected and a minimum cement dosage of 150 $\mathrm{kg} / \mathrm{m}^{3}$ was found. Figure 2-26illustrates sample UCS strength at different curing stage and dosage. 


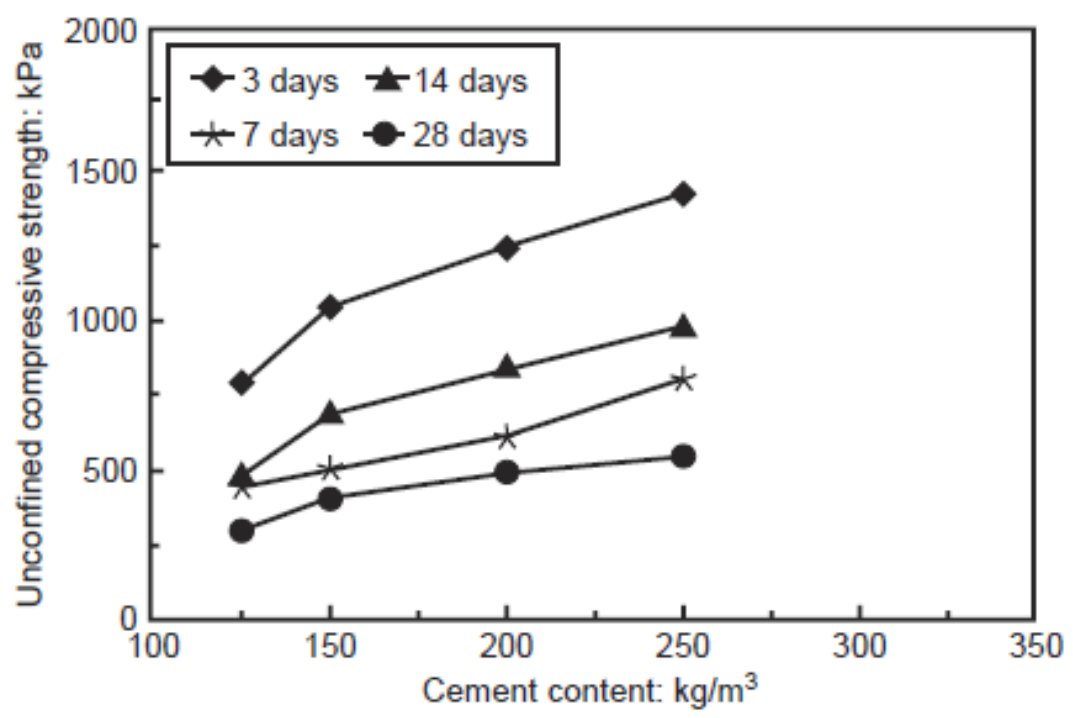

Figure 2-26 UCS of samples taken at Section 3 of Bangna-Bangpakong highway (Bergado et al., 1999)

After initial success with the trial experiment, cement piles were then installed via in situ wet mixing. The piles satisfied the following criteria:

- Diameter $=0.6 \mathrm{~m}$

- $\quad$ Pile centre to centre spacing $=1.5 \mathrm{~m}$

- Cement pile length $=14-16 \mathrm{~m}$

- Cement dosage $=150 \mathrm{~kg} / \mathrm{m}^{3}$

- Unconfined compressive strength $=600 \mathrm{kPa}$

- $\quad$ Water to cement ratio $=1.5: 1$

Quality control devices were in operation to monitor the slurry content, grouting slurry pressure, flow rate, blade rotation speed, and withdrawal rate (Bergado et al., 1999).

When DMM piles were installed in place, settlement analysis was conducted at sections of the highway. According to Bergado's calculations, the untreated highway embankment would expect a long-term settlement between $1.35-1.62 \mathrm{~m}$. With DMM treatment, short term settlement would be $0.2 \mathrm{~m}$ while the total long term settlement would be $0.56 \mathrm{~m}$. Observations made one year after treatment recorded settlements between $0.15-0.35 \mathrm{~m}$, which agrees reasonably well with Bergado's predicted value of $0.20 \mathrm{~m}$ settlement. 


\subsection{Summary}

This chapter introduced the composition of sensitive marine clay and organic silty clay in Ontario. The inherent mechanisms which led to the poor strengths of sensitive Champlain Sea clay and organic silty were discussed. Next, various ground improvement techniques for improving soil strengths were introduced, with a focus on DMM. Furthermore, DMM's strengthening mechanis m and its different types were presented. Finally, successful cases of using DMM to treat various problematic soil conditions were introduced. DMM is an effective ground improvement technique which can signific antly improve operating efficiency. The next chapter describes the experimental implemented to test small scale stabilisation of Champlain Sea clay 


\section{EXPERIMENTAL PROGRAM DESIGN}

\subsection{Introduction}

This chapter introduces the experimental program utilized to test the feasibility of DMM to treat sensitive marine clay and organic silty clay. First, the calculations used to quantify dosage will be discussed. Next, sample preparation procedures along with testing apparatuses were presented. Finally, the testing methods used to evaluate sample performance were presented.

\subsection{Experimental Program for Champlain Sea Clay and Organic Silty clay}

Experimental studies were conducted in the laboratory to verify the validity of using cement, slag/cement, and lime binder to treat sensitive Champlain Sea clay and organic silty clay. The following sections describe the experimental approach taken in this study.

\subsubsection{Soil Types}

Champlain Sea clays were obtained from two different locations near Ottawa: Arnprior and Kanata, as shown in Figure 3-1. Arnprior soils were delivered as undisturbed Laval samples and Shelby tube samples. Kanata soils were delivered in a disturbed state by Geo-Foundations Contractors Inc.

Silty clay and organic clay soils were provided by Golders Associates. The soil samples were provided in disturbed form (bucket) and undisturbed form (Shelby tube). The samples were collected from a project site near the intersection between Highway 400 and Side Road $16^{\text {th }}$ in the York Region. Figure 3-2 illustrates the site's location relative to Toronto. 


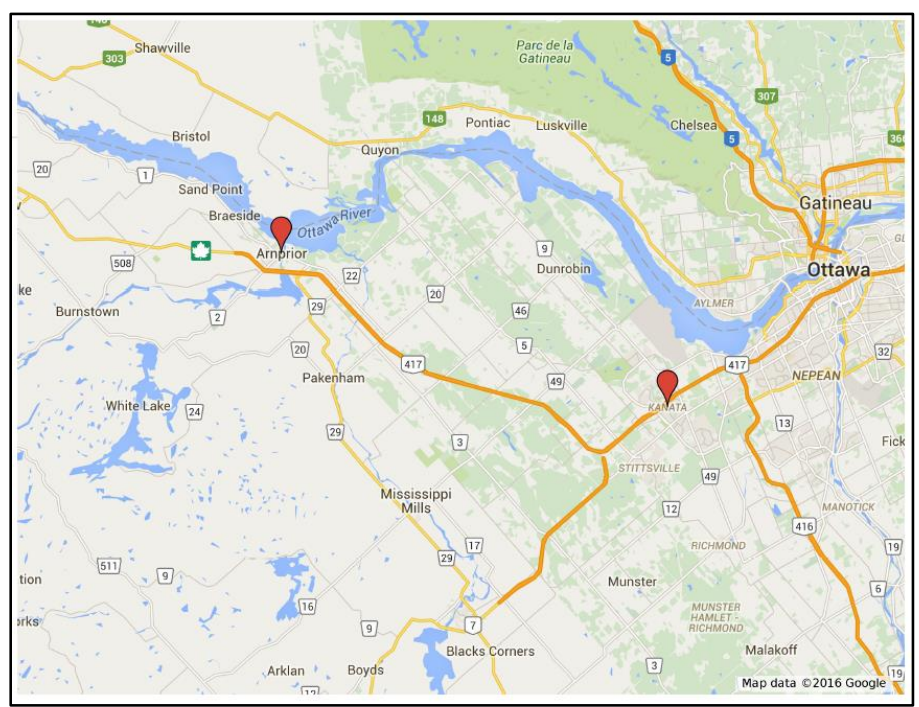

Figure 3-1 Arnprior and Kanata's locations in relation to Ottawa

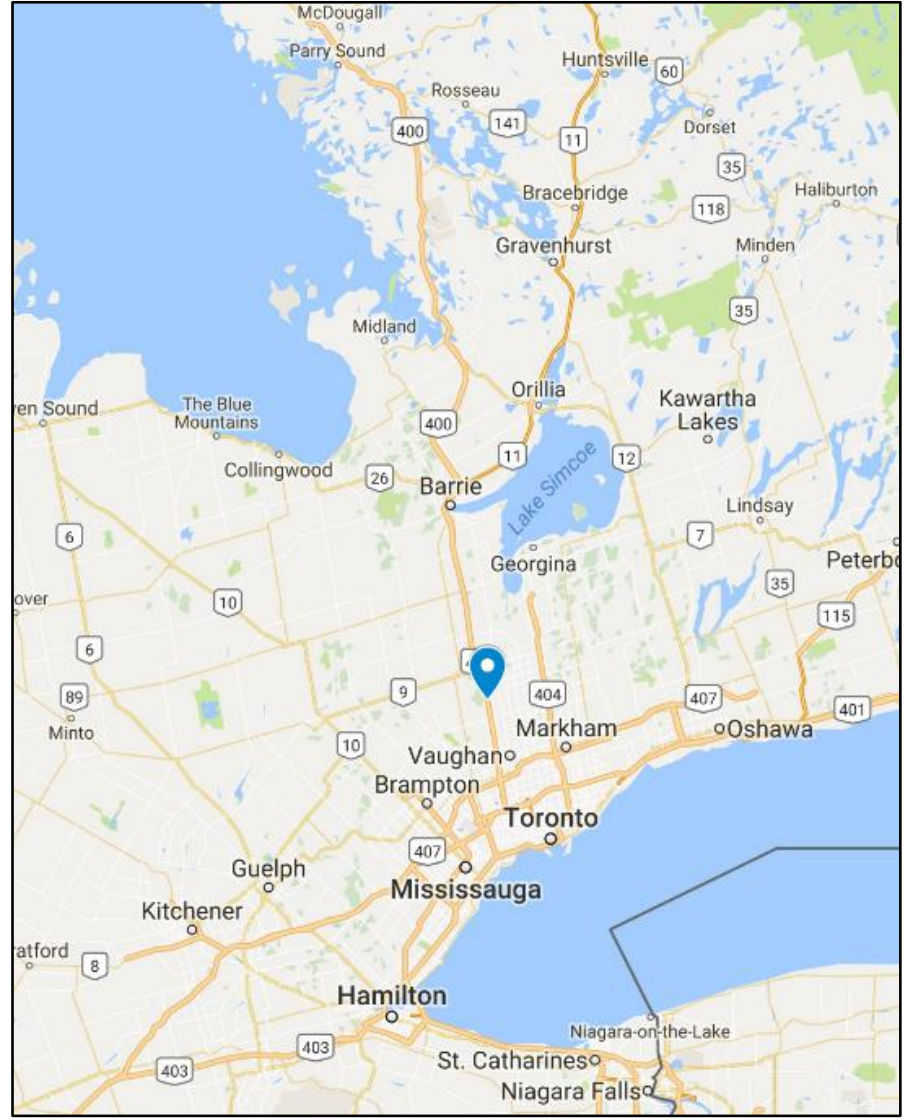

Figure 3-2 Organic silty clay's location relative to Toronto 


\subsubsection{Control Soil Tests}

Untreated soils were thoroughly tested so reliable benchmarks could be established to observe the efficiency of DMM treatment. Table 3-2 illustrates the tests conducted on untreated soil with the subsequent values. Tests such as Atterberg limits test, mini-vane shear test, and unconfined compression strength (UCS) test were systematically conducted in accordance with ASTM standards.

Table 3-1 Soil properties via ASTM standardized tests

\begin{tabular}{|c|c|c|c|c|}
\hline Soil Characteristics & Standards & $\begin{array}{l}\text { Arnprior } \\
\text { Samples }\end{array}$ & $\begin{array}{l}\text { Kanata } \\
\text { Samples }\end{array}$ & $\begin{array}{l}\text { Silty clay } \\
\text { Samples }\end{array}$ \\
\hline USCS Symbol & & $\mathrm{CH}$ & $\mathrm{CL}$ & \\
\hline Moisture content $(\%)$ & ASTM D 2216 - 98 & 49.1 & 60.5 & 43 \\
\hline Liquid Limit (\%) & ASTM D 4318 - 00 & 57.3 & 29.3 & 50 \\
\hline Plastic Limit (\%) & ASTM D 4318 - 00 & 26.9 & 21.8 & 21 \\
\hline $\begin{array}{l}\text { Mini-vane undisturbed } \\
\text { undrained shear strength } \\
(\mathrm{kPa})\end{array}$ & ASTM D 4648 - 00 & 78.7 & 20.2 & 25 \\
\hline $\begin{array}{l}\text { Remolded undrained shear } \\
\text { strength }(\mathrm{kPa})\end{array}$ & ASTM D 4648 - 00 & 5.72 & 1.8 & 10 \\
\hline Sensitivity & ASTM D 4648 - 00 & 13.7 & 11 & 2.5 \\
\hline $\begin{array}{l}\text { Unconfined compression } \\
\text { strength }(\mathrm{kPa})\end{array}$ & ASTM D 2166 - 00 & 132 & -- & 62 \\
\hline
\end{tabular}

Soils from Arnprior and Kanata were both classified as Champlain Sea clay. They are highly sensitive in nature. Soils extracted from Arnprior have an average moisture content of 50\%. It has an average liquid limit of $62 \%$ and a plastic limit of $28 \%$. The undrained shear strength of Arnprior soil is $84.10 \mathrm{kPa}$ with a sensitivity of 11 . Kanata soils have a natural water content of $60 \%$ on average. It has a plastic limit between 20.6 to 24, and a liquid limit between 25.5 and 33.8. The 
UCS of Kanata soil is $20.2 \mathrm{kPa}$ with a sensitivity of 11 . The low strength and high sensitivity indicates the difficulty of working with Kanata soil on site.

Silty clay and organic silty clay samples were obtained for DMM treatment as well. Average moisture content of the soil is $43 \%$. It has an average liquid limit of $50 \%$ and an average plastic liquid limit of $21 \%$ (Golder, 2016). The average undrained shear strength of silty clay is $25 \mathrm{kPa}$ with a sensitivity of 2.5. Average UCS of untreated silty clay samples was $62 \mathrm{kPa}$. Soil samples with high organic contents of up to $40 \%$ were tested with triaxial tests; however, due to the shortage of available soils, they were not treated cement or other binders.

\subsubsection{Experimental Parameters}

Based on past studies on cement treated soil, many factors can contribute to the influence of the final strength of the treated soil. They include the soil type, binder type, binder content, binder proportion, curing period, curing condition, and water cement ratio for wet soil mixing slurry (Pathivada 2005; Lorenzo 2004). In this study, the effects of different binder types, binder dosages, and curing conditions on the final strength of the treated soil are examined. Table 3-2 shows the different type variables used for the Champlain Sea clay study.

Table 3-2 Testing variables for Champlain Sea clay experimental program

\begin{tabular}{ccc}
\hline Parameters & Number of Variables & Variable Descriptions \\
\hline Soil types & 2 & Arnprior and Kanata Clay \\
Binder types & 2 & Cement and Slag/cement \\
Binder dosage $\left(\mathrm{kg} / \mathrm{m}^{3}\right)$ & 9 & $\begin{array}{c}57,72,100,144,200,400 \text { for } \\
\text { cement; 290, 414, 828 for slag/cement }\end{array}$ \\
Curing duration (days) & 4 & $7,14,28,56$ \\
Mixing types & 2 & dry, wet \\
\hline
\end{tabular}

The compaction method of all samples was kept constant as a control parameter. However, modifications to compaction method occurred throughout the research program. 
For organic silty clay, a similar approach was designed to follow an experimental program and reveal the effect of binder treatment on organic silty clay. Table 3-3 illustrates the different types of parameters.

Table 3-3 Testing variables for organic silty clay experimental program

\begin{tabular}{lcc}
\hline Parameters & Number of Variables & Variable Descriptions \\
\hline Soil types & 2 & $\begin{array}{c}\text { Disturbed silty clay and undisturbed } \\
\text { organic silty clay }\end{array}$ \\
Binder types & 3 & Cement, slag cement, and lime \\
Binder dosage $\left(\mathrm{kg} / \mathrm{m}^{3}\right)$ & 6 & $150,200,250$ for cement \\
& & 100,200 for lime \\
Curing duration (days) & 4 & 300 for slag/cement \\
Mixing types & 1 & $7,14,28,56$ \\
\end{tabular}

\subsubsection{Calculations}

The equations below were used to perform calculations for water content, cement dosage, and strength performance index.

Water content of soil sample

$w=\frac{W_{w}}{W_{d}}$

(Equation 3-1)

Where $\mathrm{w}_{\mathrm{w}}$ is weight of water in soil, and $\mathrm{w}_{\mathrm{d}}$ is weight of dry soil sample

Dry soil mass

$M_{d}=\frac{M_{t o t}}{1+w}$

(Equation 3-2)

Where $\mathrm{M}_{\mathrm{tot}}$ is mass of total batch soil weight, and $\mathrm{w}$ is water content of soil 
Binder dosage by percent

$D_{p}=M_{d} \times \alpha$

(Equation 3-3)

Where $\mathrm{M}_{\mathrm{d}}$ is dry soil mass of total batch, and $\alpha$ is predetermined cement dosage (\%)

Cement dosage by $\mathrm{kg} / \mathrm{m}^{3}$

$D_{k}=\frac{M_{t o t}}{\rho_{s}} \times \alpha$

(Equation 3-4)

Where $\rho_{s}$ is the soil's wet density and $\alpha$ is the predetermined cement dosage $\left(\mathrm{kg} / \mathrm{m}^{3}\right)$

Water addition to slurry by weight

$D_{w}=w c \times D_{c}$

(Equation 3-5)

Where wc is water cement ratio based on past references.

Strength increase ratio

$\beta=\frac{Q_{u}}{q_{u}}$

(Equation 3-6)

Where $\beta$ is the ratio of improvement, $\mathrm{q}_{\mathrm{u}}$ is the unconfined compressive strength (UCS) of the untreated soil and $\mathrm{Q}_{\mathrm{u}}$ is the UCS of treated sample.

Modulus Factor

$M=\frac{Q_{u}}{E}$

(Equation 3-7)

Where $\mathrm{M}$ is the modulus factor, and $\mathrm{E}$ is the elastic modulus of sample. 


\subsection{Testing Apparatuses}

\subsubsection{Compaction Tool}

Different compaction tools have been used to test compaction effectiveness. At first, a heavy proctor compaction rod was used to compact our samples into the curing tube; however, this iteration of compaction tool caused clay to stick to the side tube, making compaction difficult.

A smaller compaction rod was then utilized to allow more control during compaction; however, the end revealed inconsistencies between compaction layers.

A thin steel rod was then incorporated in the compaction procedure to puncture air-holes in between layers. The air-holes were created to facilitate compaction effectiveness in between the layers and to ensure compaction consistency; however, inconsistent compaction results were still found.

Finally, a plated rod melded with nails was incorporated in the compaction procedure. This tool is light, medium length, and easy to control during compaction. Figure 3-3 illustrates different compaction tools used in the experiment.
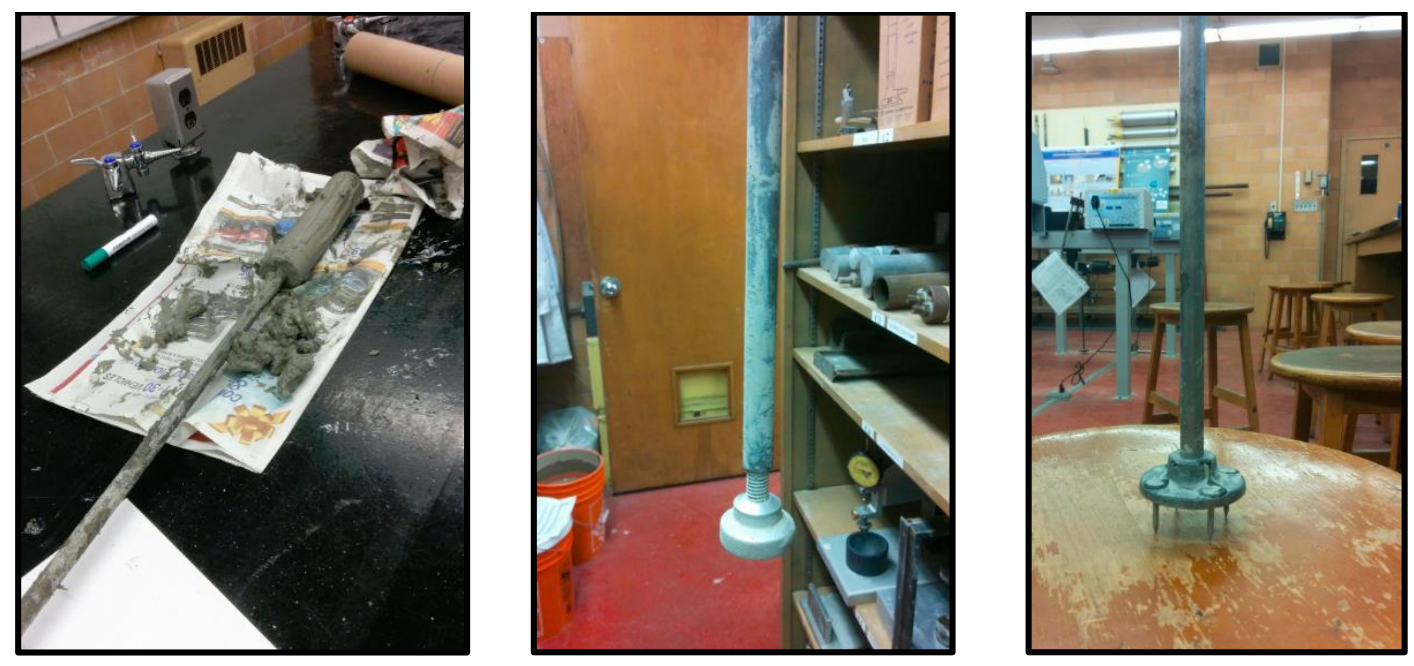

Figure 3-3 Different compaction tools used throughout the project

\subsubsection{Mixing Equipment}

A standard Hobart A200 Mixer was used for all mixing and homogenizing operations in this research, as shown in Figure 3-9a. The mixer's standard revolutions per minute (RPM) ratings are 
61RPM, 113RPM, and 205RPM (Hobart, 2005). Unreinforced marine clay was mixed thoroughly at 61 RPM first. After the addition of cement, reinforced clay was then mixed at 61 RPM and 113 RPM depending on the clay properties.
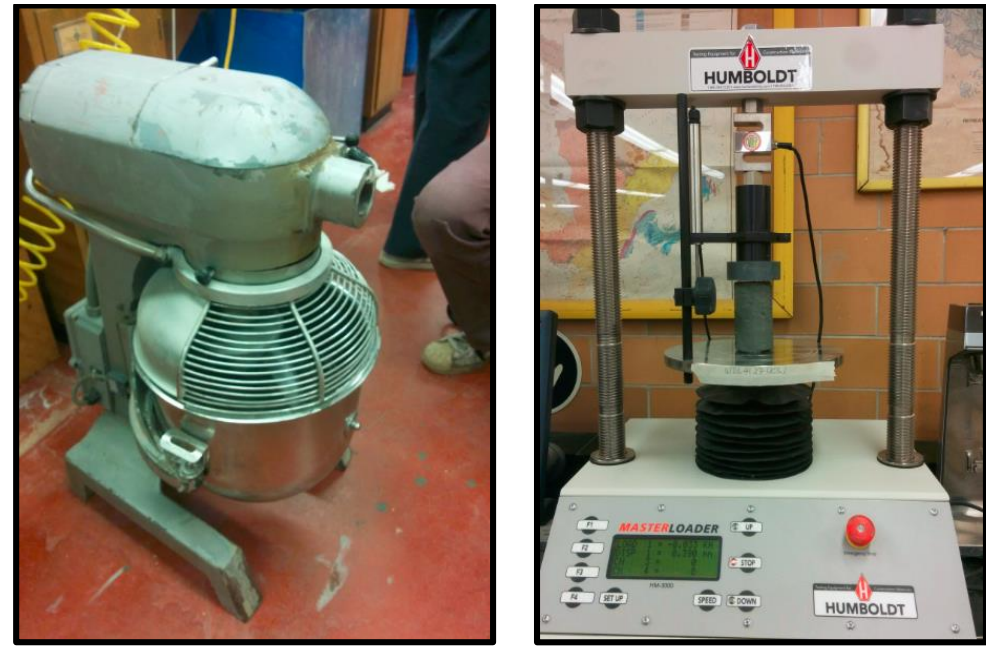

a. mixer b. Humboldt testing frame

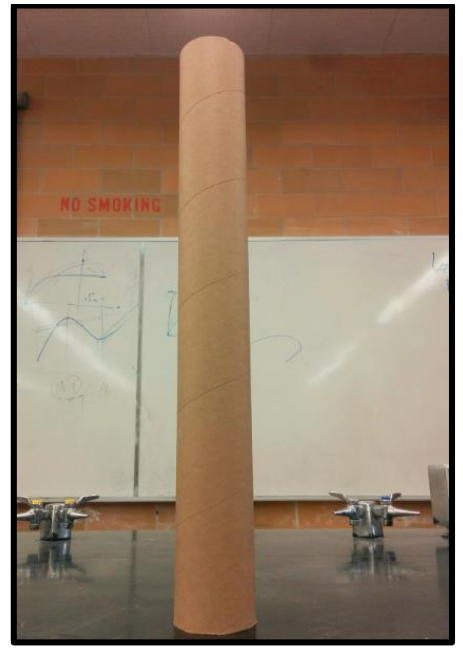

c. Sample curing tube

Figure 3-4 Test apparatuses for mixing and shearing

\subsubsection{Testing Equipment}

Humboldt Masterloader 3000 (HM3000) was used to conduct all UCS tests for this research, as shown in Figure 3-9b. Constant rate of strain (CRS) device manufactured by GeoTac was used to obtain compressibility properties of the untreated and treated samples.

\subsubsection{Other equipment}

Blue M Stabil-Therm lab oven was used for drying wet samples to obtain soil moisture content. Water content tests were conducted using this oven according to ASTM standard.

Paper tubes purchased from Staples were used as curing containers, see Figure 3-9c. These tubes are 3 inches in diameter and 12 inches in length. Normally plastic tubes were used by other researchers. The paper tube has advantages over plastic tube because it is convenient to extrude samples, low in cost, and easy for water to permeate for a better sample curing.

Plastic tubs purchased from Home Depot were used as water curing environment for sample water curing. Compacted soil tubes were sealed with caps and placed into the water tub to allow curing. 


\subsection{Sample Preparations}

\subsubsection{Sample Acquisition}

Champlain Sea clays from two different locations in Ontario were used for this study: Arnprior, $\mathrm{ON}$ and Kanata, ON. The differences between the two marine clay samples are not only sample location, but also sample preparation methods and sample extraction depth. Arnprior marine clay was prepared from undisturbed Laval samples obtained at $40 \mathrm{~m}$ below ground. Kanata marine clay was obtained at a shallower depth from a construction site of Geo-Foundations Contractors Inc. as disturbed samples.

Undisturbed organic silty clay samples and disturbed silty clay samples were obtained from Highway 400 and Side Road $16^{\text {th }}$ in King County, Ontario. Undisturbed soil samples were extracted from the ground via Shelby tube method and delivered to the geotechnical lab at Ryerson University. The depth below ground ranged from 6.7 meters to 12.5 meters. Disturbed soil samples were obtained in a test pit and delivered to the geotechnical lab at Ryerson University via pails. The soil samples were obtained from a depth of 3 meters below ground.

\subsubsection{Binder Dosage Design}

Two types of binder, cement and slag/cement, were chosen for the Champlain Sea clay study. Cement has long been used as a binding agent to strengthen marine clay. Slag/cement binder is a specialty mix at slag to cement ratio of $3: 1$ by weight. The purpose of testing slag/cement binder is to determine if slag contributes to any positive reinforcement of marine clay. Slag is a by-product during steel production and there is an increasing interest in utilizing and recycling slag for different construction purposes, such as pavement material and reinforcement agent.

For the organic silty clay study, three different binders were used to test their effectiveness. Cement, lime, and slag/cement were tested with silty clay from Ontario for its effect on strength improvement. Lime was selected as a testing binder because high strength improvements were reported by Bell (1996) after lime was added to clay of different mineralogical contents. Locat et al. (1990) also reported moderate strength increase to lime treated Champlain Sea clay. Balasubramaniam and Bergado (1989) reported a ten-fold increase in strength with just 5\% of lime dosage. 
Two different cement dosages, $5 \%$ and $12.5 \%$ by weight, were utilized for samples using Arnprior soil compared to three cement dosage, $7 \%, 10 \%$, and $20 \%$ by weight, for Kanata soil samples. Two additional dosages, $100 \mathrm{~kg} / \mathrm{m}^{3}$ and $200 \mathrm{~kg} / \mathrm{m}^{3}$, were added to Arnprior soil's experimental program. Two different slag/cement dosage, $40 \%$ and $80 \%$ by weight, was utilized for Kanata soil samples. Table 3-5 illustrates the types and dosages of binders used on Champlain Sea clay. The purpose of having multiple dosage levels was to verify the effectiveness of using cement to improve Champlain Sea clay's strength. Multiple dosage levels also allow optimization of the binder dosage for DMM.

Table 3-4 Summary of soil and binder design and testing method

\begin{tabular}{cccc}
\hline Soil Type & Binder & Dosage & Dosage (kg/m $\left.\mathbf{m}^{\mathbf{3}}\right)$ \\
\hline Arnprior & Cement & $5.0 \%$ & 57 \\
\hline Arnprior & Cement & & 100 \\
Arnprior & Cement & $12.5 \%$ & 144 \\
Arnprior & Cement & & 200 \\
Kanata & Cement & $7.0 \%$ & 72 \\
Kanata & Cement & $10.0 \%$ & 103 \\
Kanata & Cement & $20.0 \%$ & 207 \\
Kanata & Slag/Cement & $40.0 \%$ & 414 \\
Kanata & Slag/Cement & $80.0 \%$ & 828 \\
\hline
\end{tabular}

Kitazume and Terashi (2012) proposed a minimum binder dosage of $50 \mathrm{~kg} / \mathrm{m}^{3}$ for organic soil. This dosage was used as a starting point in this study, which roughly translates to $5 \%$ dosage by soil dry weight. The binder dosage was then increased at increments of $5 \%$ dosage for Arnprior clay, and doubled for Kanata clay.

\subsubsection{Sample Mixing Method}

Initially, dry mixing was attempted when the water content of our soil sample was higher than $75 \%$; however, most of the samples were found to be at $50 \%$ water content. Wet mixing was then applied as the primary mixing method this study. Dry mixing was not attempted for organic silty clay due to the soil's low inherent moisture content. 
First, wet cement slurry was prepared by mixing cement with water according to a $0.8: 1$ water to cement ratio based on the optimum water to cement ratio (w/c) finding by Pathivada (2005). Water was added in three separate batches into the cement to allow maximum slurry homogenization. The slurry was mixed with two spoon spatula by hand for one minute when first half of water was poured in. Clumps and aggregates could be observed during this step. It is important to break the clumps and mix thoroughly to make sure consistent slurry is prepared. Next, remaining water were poured into the container and mixed for one minute with two spoon spatula by hand. The final state of the slurry should be liquid and runny, with no visible clumps or sludge. Figure 3-5 illustrates the slurry mixing and sample mixing procedures.
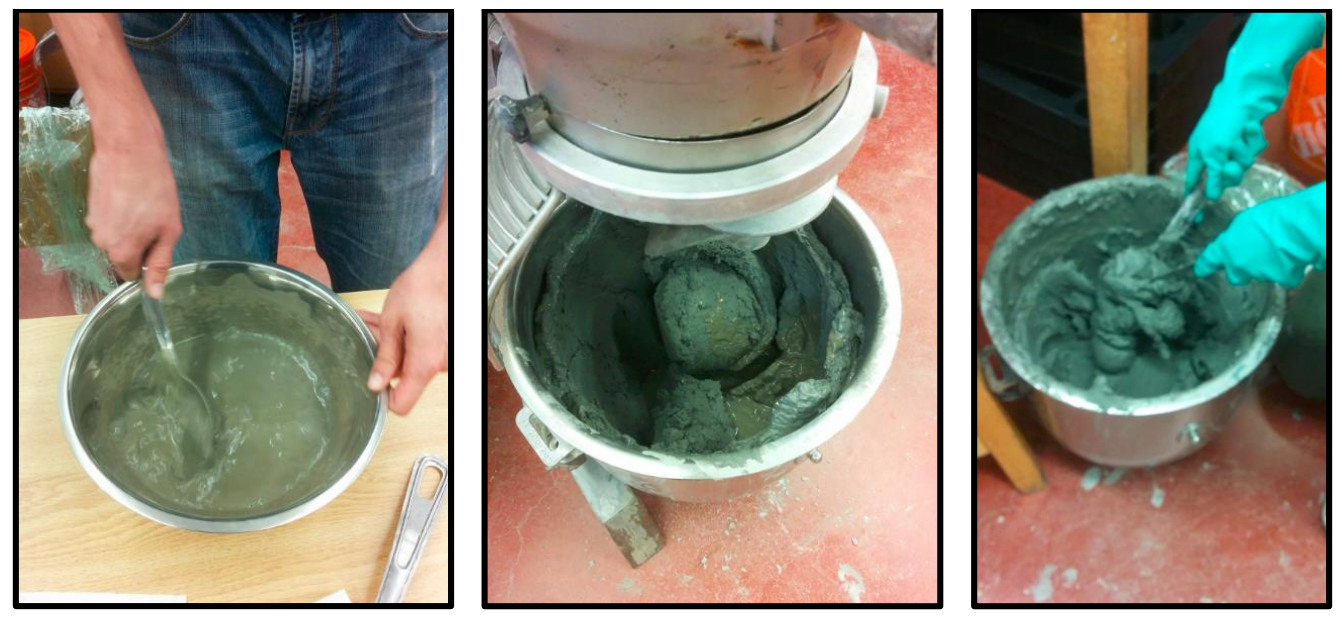

Figure 3-5 Sample mixing procedures

Second, clay soils were homogenized under the Hobart mixer. Soils were transferred to the mixer's metal bowl and placed under the mixer's mechanical mixing hook. A mixing speed setting of one, or 60 RPM, was used to homogenize the clay soil before cement addition. The soil is homogenized between 10 to 20 minutes at the speed level of 1 (Figure 3-5). Arnprior soil tends to be clumpy and exhibit a high viscosity during the homogenization process. Kanata soil tends to be liquid and runny due to the thixotropic nature of Champlain Sea clay. During the homogenization process, organic silty clay tends to stick to the side of the mixing bowl; therefore, the mixer was turned off every five minutes to scrape unmixed soil into the center of the bowl to allow maximum homogenization.

Next, clay samples were mixed with the slurry binder. Binder was added to clay in three to four batches. The mixer was turned off, and the first batch of binder slurry was poured into the mixture. 
Then the mixture was allowed to mix for one minute at the speed level 1. After one minute, the second batch was added with the same mixing procedure until all binders were added. During the intervals, mixing bowl was scraped by spatula, as shown in Figure 3-4, to manually homogenize the mixture. Mixing speed was switched to 2 after adding the last batch of binder slurry to further homogenize the mixture as required. This method was an improved version of Ramirez's (2009) disclosed method used to evaluate the effect of cement stabilization of organic soils.

\subsubsection{Sample Compaction Procedures}

Sample compaction initially followed Pathivada and Ramirez's procedure. Cement treated soil were compacted into a paper tube $76 \mathrm{~mm}$ in diameter and $610 \mathrm{~mm}$ in length. Treated soil was poured into the tube in 5 layers. Compaction was made with a ball-peen hammer in between each pour of soil layer. The layer was compacted down to half of its original height. This process was repeated until all soils were compacted evenly in the tube.

Pathivada and Ramirez's procedure was dictated by compaction with pre-determined amount of compacting blows, compacting height, and layers. Efforts in replicating Pathivada and Ramirez's compaction procedures led to undesirable results when applied to treat Arnprior soil samples. The main causes of incompatibility can attribute to the following:

1. Arnprior soil, high in water content, is very viscous and low in rigidity even after immediate addition of cement binder; the remoulded soft soil led to a difficult compaction process with soil often dragging up on the side of the tube and out along with the hammer

2. Pathivada and Ramirez's procedure were done on much smaller moulds with only $70 \mathrm{~mm}$ diameter and $156 \mathrm{~mm}$ length. The smaller moulds allowed greater ability for compaction control, which is not applicable in our case.

To mitigate the issues in compaction, a different compaction procedure was implemented to create samples better suited to our needs. The steps are described as follows:

1. Cut paper tubes into $381 \mathrm{~mm}$ segments. The smaller paper tube gave experimenters more accuracy in compaction. $381 \mathrm{~mm}$ in length also leaves enough margin of error for sample preparations of the UCS test 
2. Mould the treated clay into a ball by hand with a diameter of $70 \mathrm{~mm}$. This action prevented soil from sticking to the side of the tube

3. After the ball was dropped, use the nail hammer to compact the dropped ball 30 times. This action would puncture air holes within the soil to facilitate pressure compaction, while als o applying force to the soil. This step is a modified procedure from Pathivada's disclosed procedure (Pathivada 2005)

4. Repeat steps 2 and 3 until the tube was filled to the top

5. Seal the soil tube with caps and get it ready for curing

Figure 3-6 illustrates compaction method used in experiment.
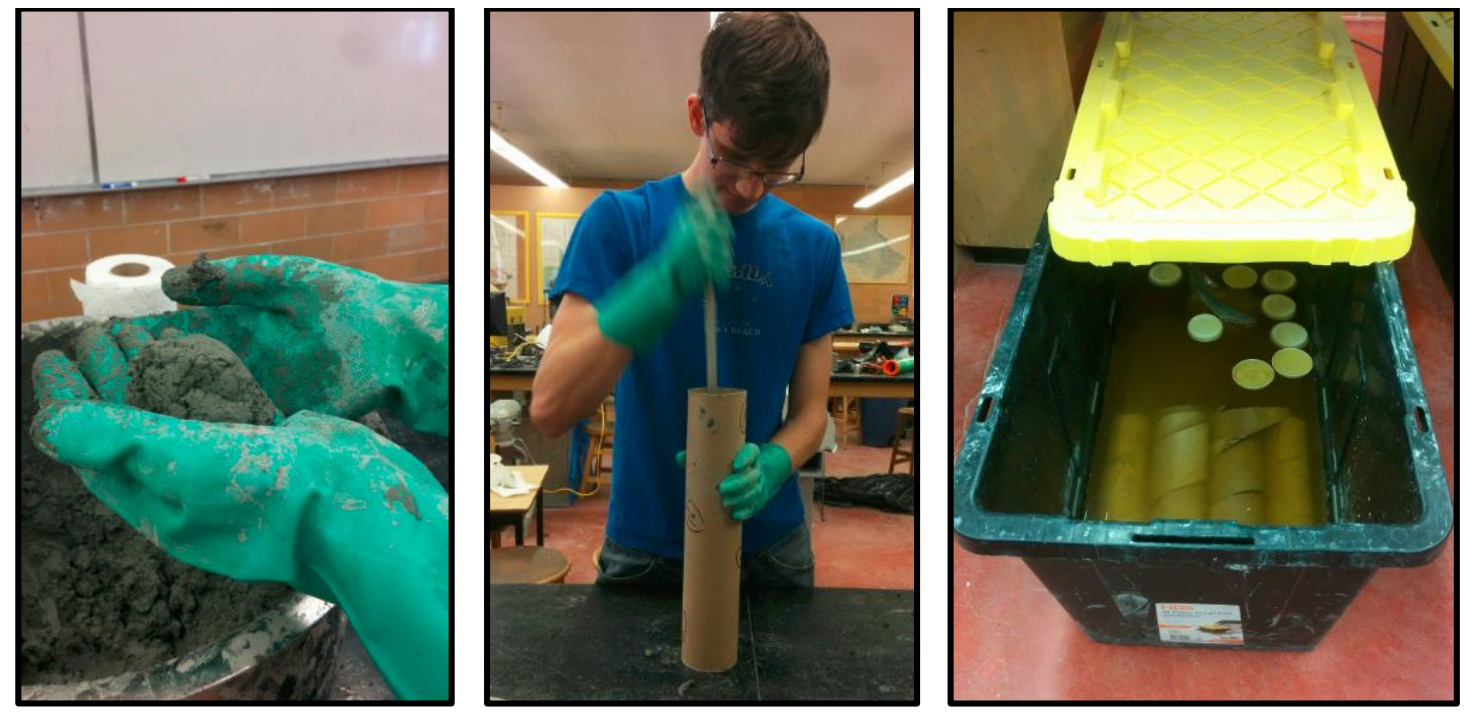

Figure 3-6 Compaction and curing

For organic silty clay, the sample compaction procedure remains the sample with one minor modification. Paper tube used to mould the sample was reduced to a diameter of $64 \mathrm{~mm}$ and a length of $305 \mathrm{~mm}$. The reduction in tube dimensions was due to low quantities of soil sample to work with.

\subsubsection{Sample Curing}

Each paper tube was sealed with caps after compaction was completed. The sealed samples were placed into a plastic tub filled with $400 \mathrm{~mm}$ of water, as shown in Figure 3-5. The plastic tub was sealed on the sides with openings on top near the lid. The water bath completely submerged the 
paper tube. Curing of the samples took $7,14,28$, or 56 days depending on the designation of the experiment. After two weeks, putrid odours could be detected from the water bath. This may be caused by amoeba or other bacteria fermenting in the water bath. The effect of this on the UCS of sample is unknown and needs future investigation.

The curing procedure disclosed by Pathivada described samples cured in 100\% relative humidity with temperature control at $20^{\circ} \mathrm{C}$ (Pathivada, 2005). Our research's curing method of dunking samples in water bath may be a disadvantage and could lead to different results; however, Ramirez discloses a curing procedure of "putting samples into water filled bath and allowed to cure 7 days" (Ramirez, 2009). The purpose of the curing process is to allow cement hydration to take place and increase the strength of soil. The goal of curing is always to maximize strength improvement while simulating field conditions. Further investigation and comparison between curing methods can be done to verify if there is any significant influence from these curing conditions.

\subsection{Testing methods}

\subsubsection{Unconfined Compression Strength Test}

Unconfined compression strength (UCS) test was used in this research as the main benchmark test to determine the strength improvement of sample when different variables of the experiment were applied. The test follows all standards and procedures per ASTM D2166. The water content of the sample right before shearing was recorded using oven drying method per ASTM standards. The sample preparation procedure for the UCS test was modified to best suit the paper mould:

1. Retrieve wet soil sample from curing bath

2. Mark desired sample length based on mould diameter; $152.4 \mathrm{~mm}$ for 3" tubes and $127 \mathrm{~mm}$ for 2.5 " tubes

3. Trim cured samples into desired lengths without peeling the mould paper; trimmed material was used to measure after-curing moisture content of the sample

4. Measure the height, diameter, and weight of the sample

5. Place trimmed sample onto the Humboldt testing frame, carefully peel off the wet paper mould from the sample

6. Weigh the wet paper to obtain the actual wet weight of the sample

7. Perform UCS test 
In some instances of sample testing, the height vs. diameter ratio cannot adhere to the specified 2:1 ratio per ASTM D2166. Sometimes samples were trimmed with a height of $140 \mathrm{~mm}$ and a diameter of $76 \mathrm{~mm}$. Due to the brittleness of the sample, the sample height was kept at the minimum range of allowable H/D ratio to prevent any snaps or breakages off the sample.

Samples were initially trimmed with mitter saw by hand. After an increase in binder dosage and curing duration, the increase in shear strength made manually cutting extremely difficult. Manual trimming also produces an inconsistent loading surface of the sample, which is highly undesirable for accurate results. To mitigate this problem, a mechanical table saw was acquired to cut the cured samples into desired lengths (Figure 3-7). Loading surface consistency saw a marked improvement after using the power saw. Typical failure modes for binder treated samples are brittle failures with a conical failure plane or splitting failure plane. Untreated samples often display a shear failure plane.

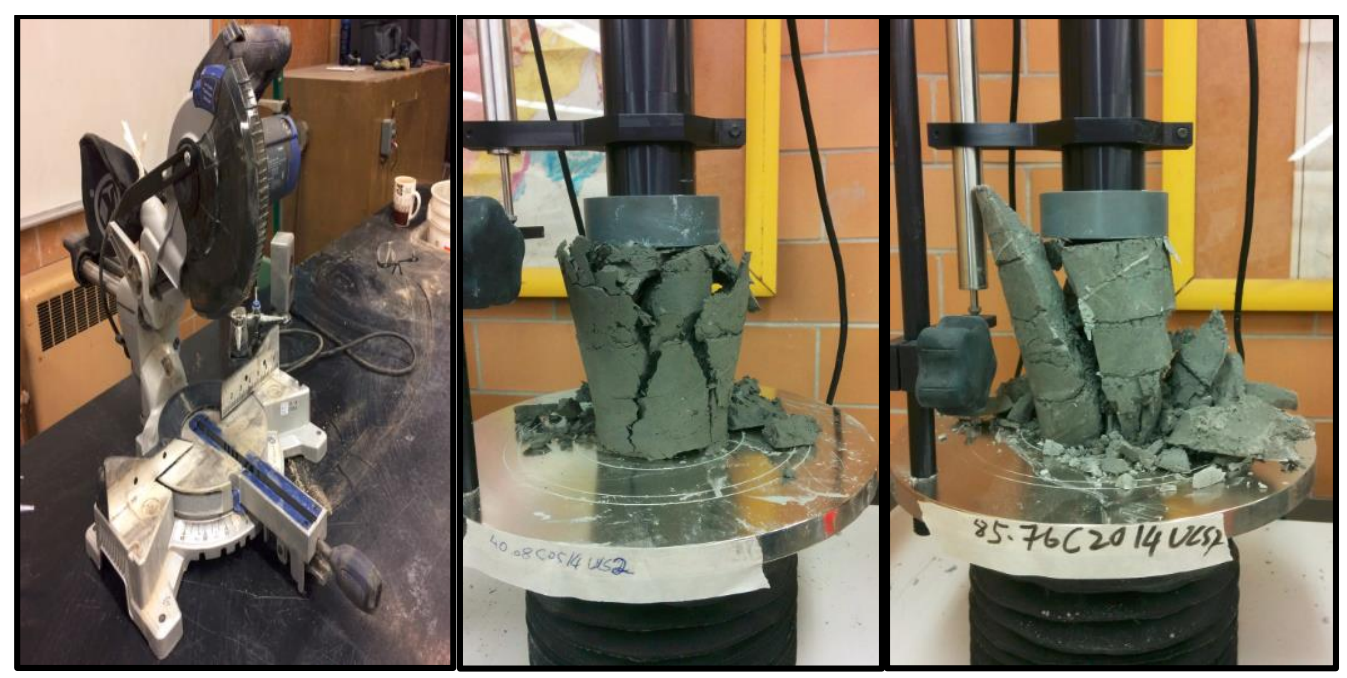

Figure 3-7 Sample trimming and typical failure mode of a sample in UCS test

\subsubsection{Constant Rate of Strain Test}

Constant rate of strain test was utilized to evaluate the compressibility parameters of the treated samples according to ASTM D4168. To prepare the samples for this test, treated soil must be cored into the consolidation ring right after mixing. The soil is allowed to cure inside the ring for 7 days to 14 days before starting the actual CRS test. Sample preparations procedure for this test is described below:

1. Take a large piece of mixed sample and mould it into a flat cylindrical blob 
2. Push the consolidation ring upside down into the mixed sample

3. Use a slow advance rate for pushing the samples into the ring

4. Trim off the sides of the soil as you push the soil into the ring

5. When the consolidation ring is filled, trim off the protruding soil on top

6. Flip the consolidation ring over and trim off any extra soil

7. Fill the surface voids of the ring with soil and pat down with a spatula

\subsection{Summary}

This chapter presented the experimental program and the sample preparation procedures undertaken to investigate the feasibility of using DMM to treat problematic soils. First, past experimental programs proposed by previous researchers were examined. Important parameters, such as binder dosage, binder type, curing duration, and soil type, were identified as great influencer to the final strength. Next, the experimental program was proposed including key parameters such as binder dosage and curing duration. Furthermore, the sample preparation was explained in great details along with the type of equipment used. Finally, the major testing methods for this experimental program were presented. The next chapter will discuss the results from the experiment. 


\section{EXPERIMENTAL RESULT ANALYSES AND DISCUSSIONS}

\subsection{Unconfined Compression Strength}

\subsubsection{Champlain Sea Clay}

After applying cement binders to Champlain Sea clay samples, strength improvements were observed; however, initial strength improvements were inconsistent due to inexperienced compaction methods. Table 4-1 illustrates strength improvement for cement treated Arnprior clay samples.

Table 4-1 Maximum UCS values of cement treated Arnprior clay samples

\begin{tabular}{ccccccc}
\hline $\begin{array}{c}\text { Soil Depth } \\
\text { (meters below } \\
\text { ground surface) }\end{array}$ & Binder & $\begin{array}{c}\text { Water to } \\
\text { cement } \\
\text { ratio }(\mathbf{w} / \mathbf{c})\end{array}$ & $\begin{array}{c}\text { Dosage } \\
\text { (percent by } \\
\text { weight) }\end{array}$ & $\begin{array}{c}\text { Dosage } \\
\left(\mathbf{k g} / \mathbf{m}^{3}\right)\end{array}$ & $\begin{array}{c}\text { Curing } \\
\text { Duration } \\
(\mathbf{d a y s})\end{array}$ & $\begin{array}{c}\text { Max } \\
\text { UCS } \\
(\mathbf{k P a})\end{array}$ \\
\hline 40.9 & $\mathrm{n} / \mathrm{a}$ & $\mathrm{n} / \mathrm{a}$ & 0 & 0 & 0 & 132 \\
40.08 & $\mathrm{n} / \mathrm{a}$ & $\mathrm{n} / \mathrm{a}$ & 0 & 0 & 28 & 7 \\
40.08 & $\mathrm{C}$ & 11.6 & 5 & 57 & 7 & 190 \\
40.08 & $\mathrm{C}$ & 11.6 & 5 & 57 & 14 & 81 \\
40.08 & $\mathrm{C}$ & 11.6 & 5 & 57 & 28 & 134 \\
40.9 & $\mathrm{C}$ & 3.8 & 12.5 & 144 & 7 & 312 \\
41.28 & $\mathrm{C}$ & 3.8 & 12.5 & 144 & 7 & 273 \\
40.9 & $\mathrm{C}$ & 3.8 & 12.5 & 144 & 14 & 1050 \\
41.28 & $\mathrm{C}$ & 3.8 & 12.5 & 144 & 14 & 611 \\
41.28 & $\mathrm{C}$ & 3.8 & 12.5 & 144 & 28 & 239 \\
41.28 & $\mathrm{C}$ & 3.8 & 12.5 & 144 & 28 & 278 \\
23.0 & $\mathrm{C}$ & 7.2 & 11 & 100 & 7 & 357 \\
23.0 & $\mathrm{C}$ & 7.2 & 11 & 100 & 14 & 597 \\
23.0 & $\mathrm{C}$ & 4.0 & 22 & 200 & 9 & 908 \\
23.0 & $\mathrm{C}$ & 4.0 & 22 & 200 & 14 & 964 \\
\hline
\end{tabular}


Initial trials at low cement dosage of $5 \%$ by weight or $57 \mathrm{~kg} / \mathrm{m}^{3}$ by volume, yielded marginal improvements for Arnprior clay. UCS tests yielded a UCS of 190, 81, and $134 \mathrm{kPa}$ for samples cured at 7, 14, 28 days, respectively. The low UCS can be attributed to low cement dosage, high water to cement ratio, and inconsistent compaction method applied at the beginning of the study. Inappropriate compaction caused deep cracks and discontinuities on the samples, which weakened the structural integrity of the sample and lowers the UCS of samples. Long curing time in water would further disintegrate poorly compacted samples, creating layers and discs. Therefore, it is possible for a sample to have a lower UCS with a longer curing time compared to a shorter curing time. Another explanation for the decrease in UCS with prolonged curing is the leaching of the salt content from the Champlain Sea clay. The curing bath was filled with fresh water, which would permeate into the paper tube and allow the salt content to migrate away from the sample. Salinity test need to be conducted to verify this hypothesis in future tests.

When cement dosage for Arnprior clay was increased to $12.5 \%$ by weight or $144 \mathrm{~kg} / \mathrm{m}^{3}$ by volume, UCS increased substantially. The UCS values of 312, 1050, 278 were recorded for treated Arnprior clay samples cured at 7, 14, and 28 days. The increase in UCS can be caused by an increase in cement dosage and decrease in water to cement ratio (from 11.6 to 3.8). The maximum UCS of $1050 \mathrm{kPa}$ was recorded on one treated sample cured at 14 days (Figure 4-1). However, the second treated sample with the same curing condition and dosage only achieved a UCS value of $611 \mathrm{kPa}$. As illustrated in Figure 4-1, the inconsistent peak strength problem was frequently encountered in the early stages of the experiment. Poor compaction method may be the main contributing factor.

Additional tests were also conducted on Arnprior clay at a higher elevation of $23 \mathrm{~m}$ below. The inherent moisture content of the clay, measured at 71\%, was higher than lower elevation Arnprior clay. Samples treated with $11 \%$ cement, or $7.2 \mathrm{w} / \mathrm{c}$, yielded UCS of $357 \mathrm{kPa}$ and $597 \mathrm{kPa}$ for 7 days and 14 days of curing respectively. Relatively high water to cement ratio could have contributed to the low UCS. An increase in UCS was observed with increasing curing duration for the samples. Earlier samples treated with a dosage of $12.5 \%$ cement had a water to cement ratio of 4.0 , which resulted in high UCS of $1000 \mathrm{kPa}$. Samples treated with $22 \%$ cement, or 4.0 water to cement ratio produced a consistent UCS of $908 \mathrm{kPa}$ for 9 days of curing. If the sample was allowed to cure for 14 days, UCS increased to $964 \mathrm{kPa}$. Improved compaction methods and low water to 
cement ratio contributed to the high UCS. Figure 4-2 illustrates the strength vs. strain profile for the cement treated upper clay.

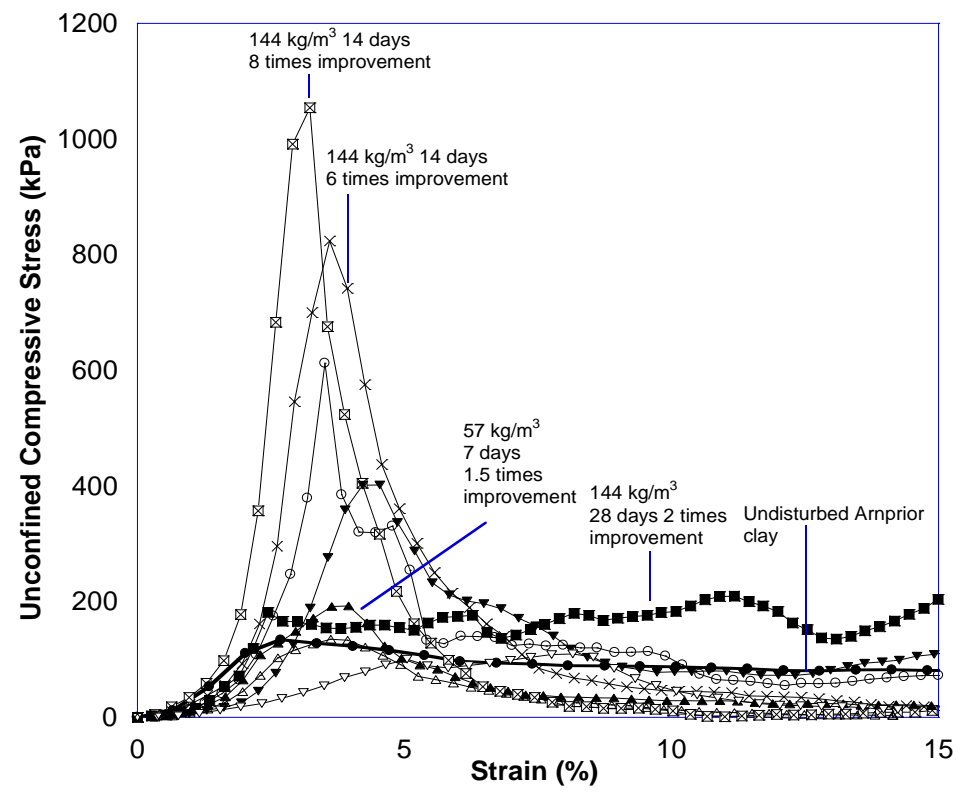

Figure 4-1 Stress vs. strain curves of cement treated Arnprior soil samples

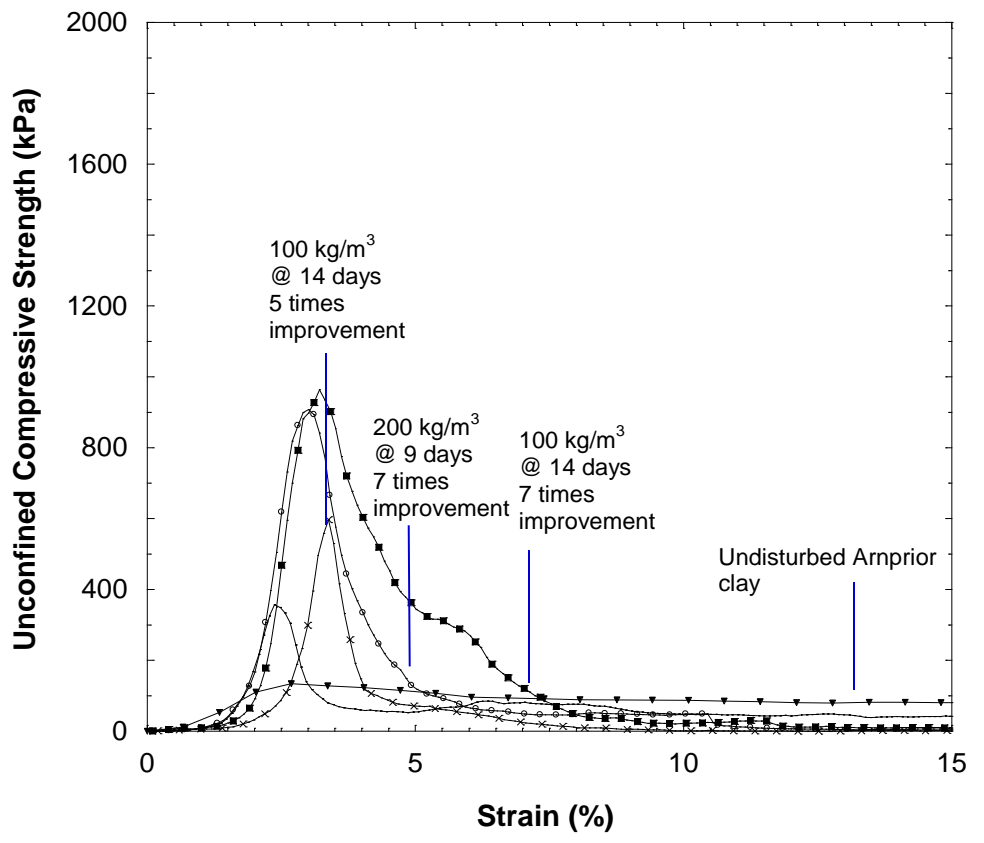

Figure 4-2 Stress vs. strain curves of cement treated Champlain Sea clay from Arnprior, Ontario 
After adjusting the compaction method, a significant improvement in peak strength consistency was observed with Kanata clay. The improvement in compaction method came from shortened paper tubes, self-fabricated puncturing tools, standardized compaction strokes, and minimized layer volume. The improved compaction method produced more homogeneous samples and produced more consistent test results.

Initially, cement dosages of $10 \%$ and $20 \%$ by weight $\left(103 \mathrm{~kg} / \mathrm{m}^{3}\right.$ and $207 \mathrm{~kg} / \mathrm{m}^{3}$ respectively) were designed for Kanata soil. Desirable results were immediately observed when a UCS of $718 \mathrm{kPa}$ was recorded for a sample treated with $103 \mathrm{~kg} / \mathrm{m}^{3}$ of cement and cured for 7 days. For a sample treated with $203 \mathrm{~kg} / \mathrm{m}^{3}$ of cement and cured for 7 days, a UCS of $822 \mathrm{kPa}$ was recorded. Samples treated with $203 \mathrm{~kg} / \mathrm{m}^{3}$ of cement and cured for 28 days reached a UCS of $1323 \mathrm{kPa}$. Binder dosage was further increased to $40 \%$ cement by weight $\left(414 \mathrm{~kg} / \mathrm{m}^{3}\right)$ to verify its effectiveness. A UCS value of $939 \mathrm{kPa}$ was recorded for samples treated with $40 \%$ cement and cured for 7 days; a UCS of $2071 \mathrm{kPa}$ was recorded for a sample treated with $40 \%$ cement and cured for 28 days. The increase in UCS was due to increase in cement dosage and decrease in water to cement ratio. Table 4-2 summarizes the UCS values of cement treated Kanata Champlain Sea clay samples under different cement dosage and curing time conditions.

Table 4-2 UCS values for cement treated Kanata clay samples

\begin{tabular}{cccccccc}
\hline $\begin{array}{c}\text { Soil Depth }(\mathbf{m} \\
\text { below } \\
\text { ground) }\end{array}$ & Binder & Mix & $\begin{array}{c}\text { Water to } \\
\text { cement } \\
\text { ratio }\end{array}$ & $\begin{array}{c}\text { Dosage } \\
\text { (percent } \\
\text { by weight) }\end{array}$ & $\begin{array}{c}\text { Dosage } \\
\left(\mathbf{k g} / \mathbf{m}^{3}\right)\end{array}$ & $\begin{array}{c}\text { Curing } \\
\text { Condition } \\
\text { (days) }\end{array}$ & $\begin{array}{c}\text { Max } \\
\text { UCS } \\
\text { (kPa) }\end{array}$ \\
\hline 9.24 & $\mathrm{C}$ & Wet & 8.7 & 7 & 72 & 7 & 361 \\
9.24 & $\mathrm{C}$ & Wet & 8.7 & 7 & 72 & 14 & 284 \\
9.24 & $\mathrm{C}$ & Wet & 8.7 & 7 & 72 & 28 & 330 \\
9.24 & $\mathrm{C}$ & Wet & 6.3 & 10 & 103 & 7 & 718 \\
9.24 & $\mathrm{C}$ & Wet & 6.3 & 10 & 103 & 14 & 546 \\
9.24 & $\mathrm{C}$ & Wet & 6.3 & 10 & 103 & 28 & 697 \\
9.24 & $\mathrm{C}$ & Wet & 6.3 & 10 & 103 & 56 & 391 \\
9.24 & $\mathrm{C}$ & Wet & 3.5 & 20 & 207 & 7 & 822
\end{tabular}




\begin{tabular}{lllllllc}
9.24 & C & Wet & 3.5 & 20 & 207 & 14 & 704 \\
9.24 & C & Wet & 3.5 & 20 & 207 & 28 & 1323 \\
9.24 & C & Wet & 2.0 & 40 & 414 & 7 & 939 \\
9.24 & C & Wet & 2.0 & 40 & 414 & 14 & 1173 \\
9.24 & C & Wet & 2.0 & 40 & 414 & 28 & 2071 \\
9.24 & C & Dry & 5.0 & 10 & 103 & 7 & 694 \\
9.24 & C & Dry & 5.0 & 10 & 103 & 14 & 954 \\
9.24 & C & Dry & 5.0 & 10 & 103 & 28 & 731 \\
\hline
\end{tabular}

For wet mixing methods, a pre-determined water to cement ratio of $0.8: 1$ was first added to cement to turn the binder into workable slurry (Pathivada, 2005). The reason behind using wet mixing was due to the slightly low water contents in these two site soils. However, a trial test was performed to utilize dry mixing to investigate any advantage over wet mixing. With the same dosage of $10 \%$ cement $\left(103 \mathrm{~kg} / \mathrm{m}^{3}\right)$, a UCS value was recorded at $694 \mathrm{kPa}$ and $954 \mathrm{kPa}$ for 7 days cured and 14 days cured samples respectively. The result suggests dry mixing method yields a higher UCS than wet mixing method due to decreased water to cement ratio. Further investigation is required to investigate the influence of the mixing method on Champlain Sea clay. The stress-strain curves of these cement treated Kanata clay samples are shown in Figure 4-2.

Slag/cement binder was also investigated for binder type influence. Slag is a by-product of iron ore smelting and is often included in Portland cement as ground granulated blast slag (GGBS) to reduce alkali-silica attack. Slag also has the potential to produce a pozzolanic reaction under alkaline conditions (Kitazume and Terashi 2012). In this application, slag was mixed with cement in a 3:1 ratio by weight as a strength improvement binder for quick clay. A slag/cement binder, if verified as a suitable binder, can reduce the amount cement used and improve cost-efficiency for large ground improvement projects. Table 4-3 summarizes the UCS values of slag/cement treated Kanata clay samples. 


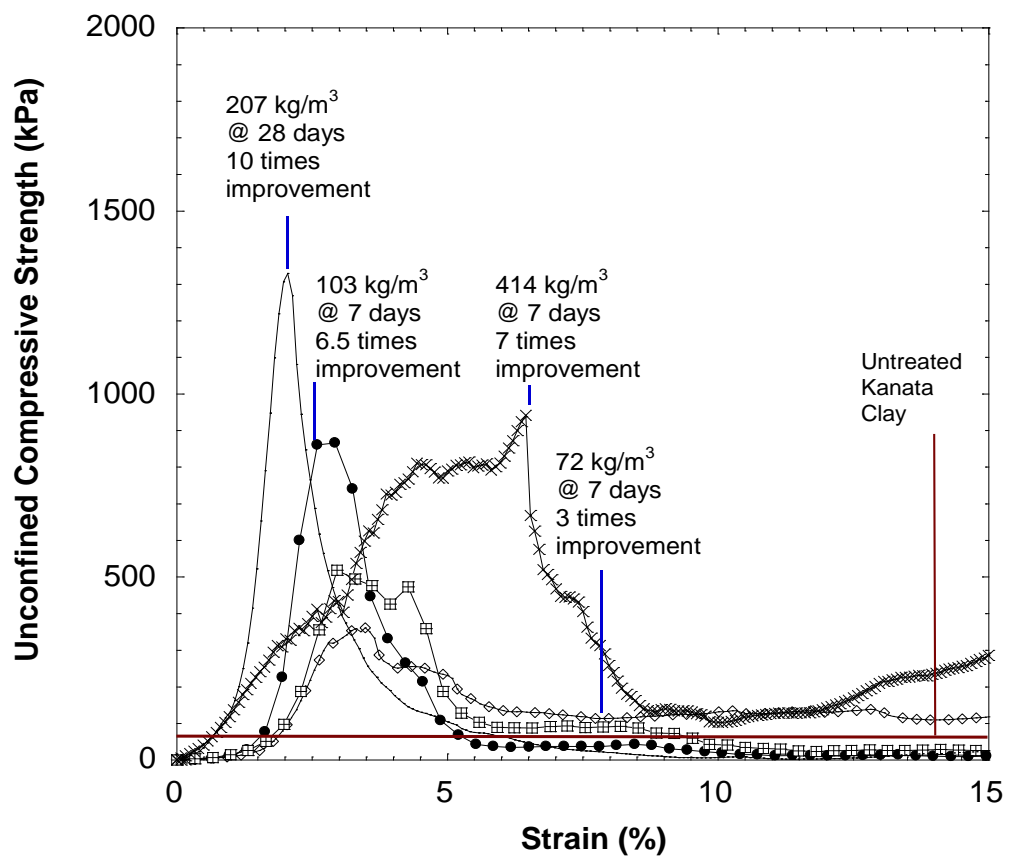

Figure 4-3 Stress vs. strain curves of cement treated Kanata soil samples

Table 4-3 UCS values of slag/cement treated Kanata clay samples

\begin{tabular}{ccccccc}
\hline $\begin{array}{c}\text { Soil Depth (m } \\
\text { below ground) }\end{array}$ & Binder & $\begin{array}{c}\text { Water to } \\
\text { cement } \\
\text { ratio }\end{array}$ & $\begin{array}{c}\text { Dosage } \\
\text { (percent by } \\
\text { weight) }\end{array}$ & $\begin{array}{c}\text { Dosage } \\
\left(\mathbf{k g} / \mathbf{m}^{3}\right)\end{array}$ & $\begin{array}{c}\text { Curing } \\
\text { Condition } \\
\text { (days) }\end{array}$ & $\begin{array}{c}\text { Max } \\
\text { UCS } \\
(\mathbf{k P a})\end{array}$ \\
\hline 6.1 & SC & 2.5 & 28 & 290 & 7 & 1052 \\
6.1 & SC & 2.5 & 28 & 290 & 14 & 909 \\
6.1 & SC & 2.5 & 28 & 290 & 28 & 1354 \\
6.1 & SC & 2.5 & 28 & 290 & 56 & 1593 \\
6.1 & SC & 2.2 & 40 & 414 & 7 & 632 \\
6.1 & SC & 2.2 & 40 & 414 & 14 & 1178 \\
6.1 & SC & 2.2 & 40 & 414 & 28 & 828
\end{tabular}




\begin{tabular}{lcccccc}
6.1 & SC & 1.4 & 80 & 828 & 7 & 1626 \\
6.1 & SC & 1.4 & 80 & 828 & 14 & 1644 \\
6.1 & SC & 1.4 & 80 & 828 & 28 & 2085 \\
6.1 & SC & 1.4 & 80 & 828 & 28 & 2068 \\
\hline
\end{tabular}

Samples treated with $28 \% \mathrm{slag} / \mathrm{cement}\left(290 \mathrm{~kg} / \mathrm{m}^{3}\right)$ recorded a UCS of $1052 \mathrm{kPa}$ for only 7 days of curing; after 28 days of curing, the UCS reached $1354 \mathrm{kPa}$. In $28 \%$ of slag/cement dosage, only $7 \%$ cement by weight was added to soil. Compared to an approximately $300 \mathrm{kPa}$ UCS value for purely $7 \%$ cement dosage from previous experiments, these significant UCS increases demonstrated the efficiency of slag in treating Champlain Sea clay.

Samples treated with $40 \%$ slag/cement $\left(414 \mathrm{~kg} / \mathrm{m}^{3}\right)$ recorded a UCS of $994 \mathrm{kPa}$ for 14 days of curing. Dosage was later increased to $80 \%$ slag/cement $\left(828 \mathrm{~kg} / \mathrm{m}^{3}\right)$ and a UCS of $1626 \mathrm{kPa}$ was recorded for 7 days of curing. A sample treated with $80 \%$ slag/cement $\left(828 \mathrm{~kg} / \mathrm{m}^{3}\right)$ and cured for 28 days reached the load limit of loading frame, which meant that its UCS value was more than $2000 \mathrm{kPa}$. The stress-strain curves of these slag/cement treated Kanata clay samples are shown in Figure 4-4. The effective increase in UCS for slag/cement treated samples could be due to the low water to binder ratio and slag/cement's effective binding reaction with soil.

In conclusion, UCS of the treated sample is directly related to the dosage quantity of the binder. Figure 4-5 illustrates an upward trend where increasing binder dosage also increases the UCS of the sample. Another way to interpret dosage is via water to cement ratio. Total water mass includes the inherent moisture of the soil sample with water in the binder slurry. Total cement mass includes the total amount of cement added to the sample. 


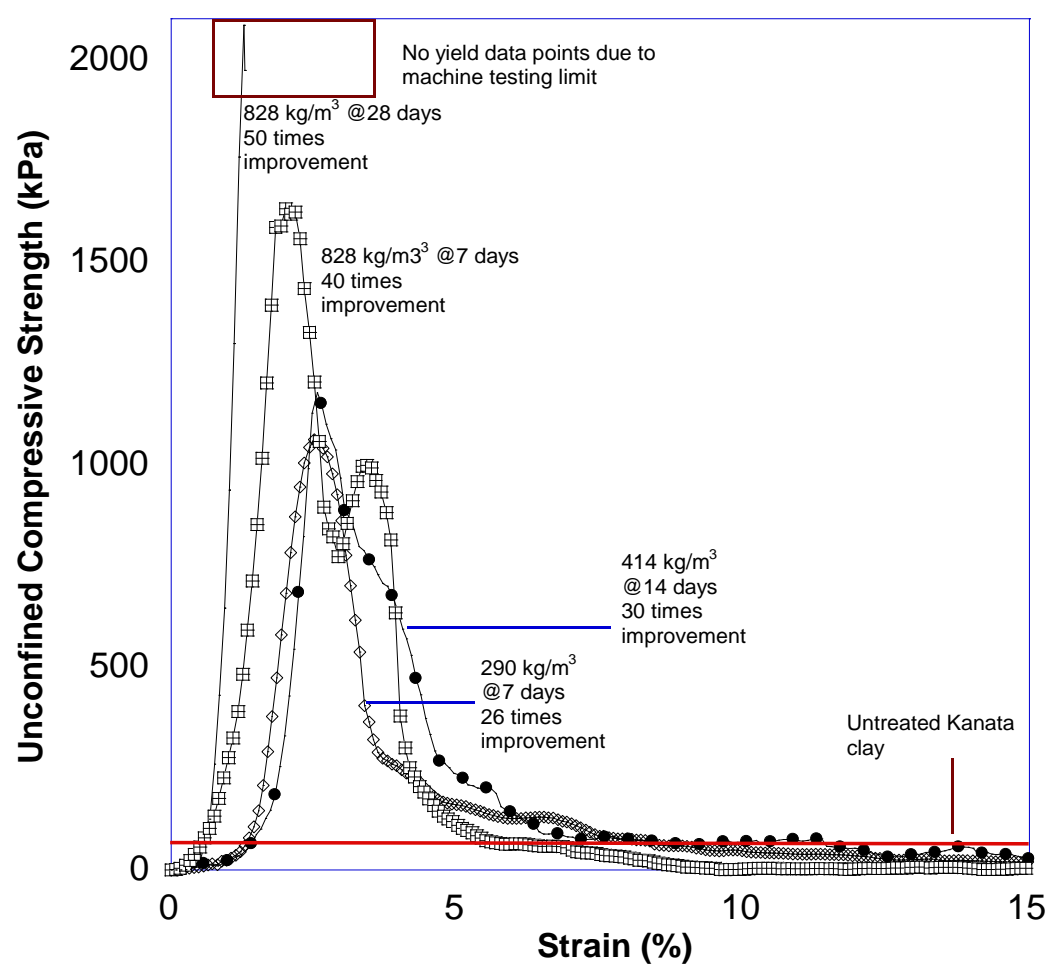

Figure 4-4 Stress vs. strain curves of slag/cement treated Kanata soil samples

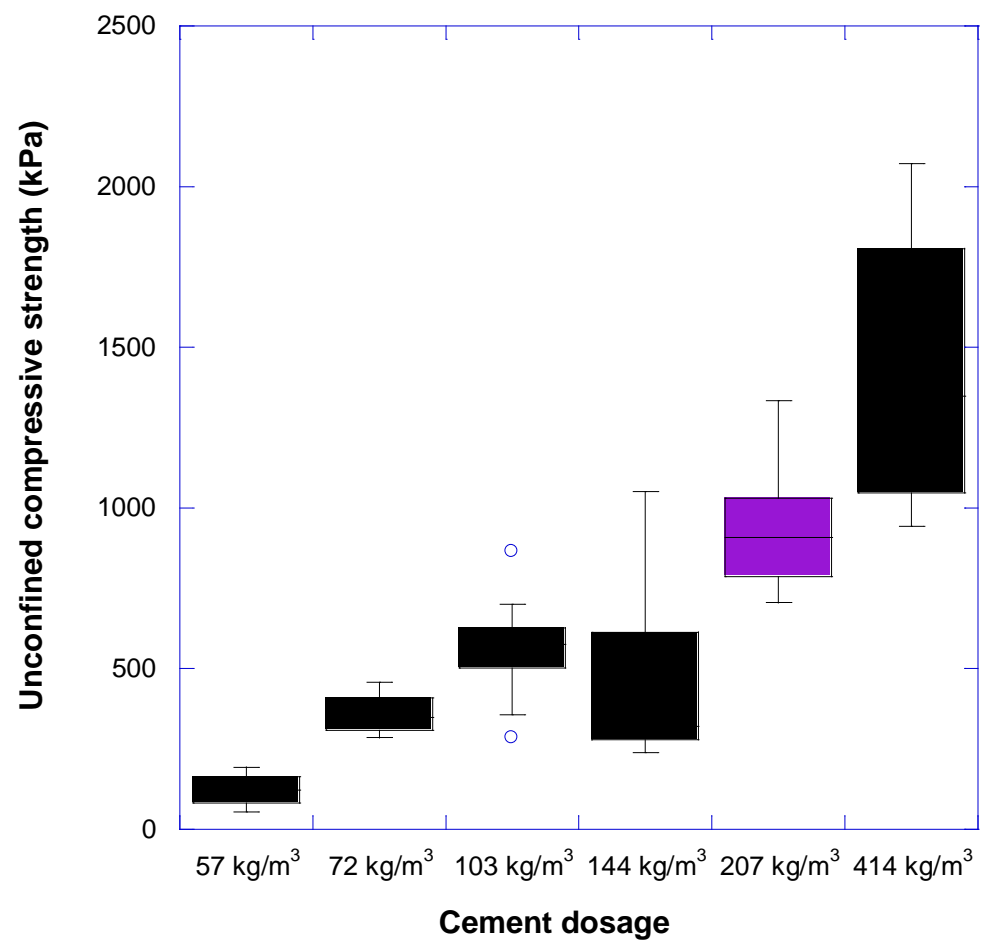

Figure 4-5 UCS vs. Dosage for Cement Treated Champlain Sea clay 


\subsubsection{Organic Silty Clay}

UCS tests were performed on both untreated organic silty clays and cement or lime treated organic silty clays. The $76 \mathrm{~mm}$ curing paper tubes were changed in the middle of test program to $64 \mathrm{~mm}$ tubes due to the limited quantity of soil samples received from the site. Samples treated with 150 $\mathrm{kg} / \mathrm{m}^{3}$ and $200 \mathrm{~kg} / \mathrm{m}^{3}$ of cement were prepared using $76 \mathrm{~mm}$ paper tubes. Samples treated with 250 $\mathrm{kg} / \mathrm{m}^{3}$ of cement, $100 \mathrm{~kg} / \mathrm{m}^{3}$ and $200 \mathrm{~kg} / \mathrm{m}^{3}$ of lime were prepared with $64 \mathrm{~mm}$ paper tubes.

To evaluate the untreated organic silty clay's UCS, a portion of the soil was extracted from the Shelby to conduct the UCS test. GS25 corresponds to Shelby tube No. 4 with a depth of $7.6 \mathrm{~m}$ below ground, GS31 corresponds to Shelby tube No. 6 with a depth of $9.4 \mathrm{~m}$ below ground, and GS34 corresponds to Shelby tube No. 7 with a depth of $10.4 \mathrm{~m}$ below ground. Measured UCS ranged from $26.9 \mathrm{kPa}$ to $55.7 \mathrm{kPa}$ with an average value of $42.7 \mathrm{kPa}$. The UCS tests are shown in Figure 4-6 and summarized in Table 4-4.

Table 4-4 UCS test results for untreated clayey organic silt to silty clay from Shelby tubes

\begin{tabular}{cccc}
\hline No. & Experiment No. & UCS (kPa) & $\begin{array}{c}\text { Approximate Secant } \\
\text { Modulus }(\mathbf{k P a})\end{array}$ \\
\hline 1 & GS25UCS1 & 43.7 & 542 \\
2 & GS31UCS1 & 47.9 & 591 \\
3 & GS31UCS2 & 26.9 & 128 \\
4 & GS34UCS1 & 27.1 & 219 \\
5 & GS34UCS2 & 55.1 & 498 \\
6 & GS34UCS3 & 55.7 & 619 \\
\hline
\end{tabular}

Clayey silt with organics to organic silt were used to perform cement treatment mixing. Cement dosages ranged from $150 \mathrm{~kg} / \mathrm{m}^{3}$ to $250 \mathrm{~kg} / \mathrm{m}^{3}$ with $7,14,28$, and 56 day curing durations. The UCS tests of cement treated soil are summarized in Table 4-5. The notation of sample number is designed as Golder Test Pit (GTP) soil treated with Cement at a dosage of $150 \mathrm{~kg} / \mathrm{m}^{3}$ and cured at 7 days (C1507) for Unconfined Compression Test number 1 (UCS-1). In similar way, GS33C2507UCS1 represents Golder Shelby 33 feet (GS33) below ground sample treated with 
Cement at a dosage of $250 \mathrm{~kg} / \mathrm{m}^{3}$ dosage and cured at 7 days for Unconfined Compression Test number 1.

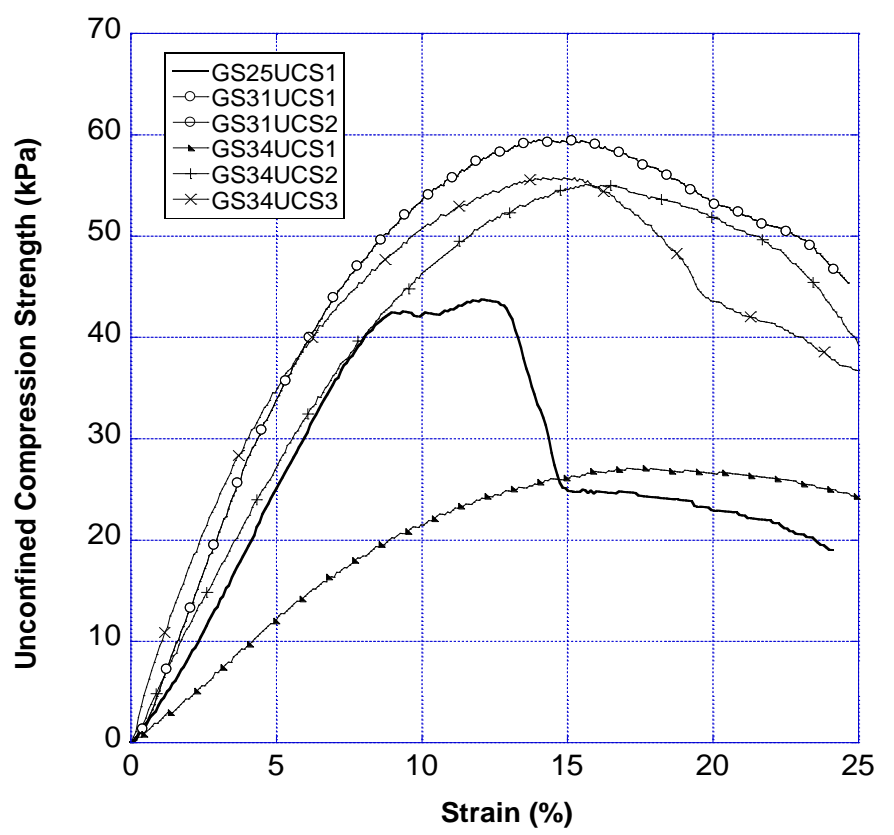

\section{Figure 4-6 Stress-strain curves of untreated clayey organic silt to silty clay from Shelby tube}

The General Use Type 10 cement produced by Holcim was used. After cement treatment, a significant increase was observed in both the UCS and Young's modulus of samples. Cement treatment of $250 \mathrm{~kg} / \mathrm{m}^{3}$ was also performed on clayey organic silt to silty clay (GS33). A similar strength increase was also found in cement treated clayey organic silt to silty clay soil sample. The stress-strain curves of UCS tests for cement treated soils at different dosages and curing time are shown in Figures 4-7 to 4-9. UCS vs. curing duration plots were displayed below to illustrate the effect of cementious strengthening. Residual UCS vs. curing duration plots were also displayed below. Note that residual UCS of a sample was selected at $15 \%$ strain of the corresponding stress vs. strain curve. 
Table 4-5 UCS Test Results for Cement Treated Soils

\begin{tabular}{|c|c|c|c|c|c|}
\hline Experiment No. & Binder & $\begin{array}{c}\text { Dosage } \\
\left(\mathrm{kg} / \mathrm{m}^{3}\right)\end{array}$ & $\begin{array}{l}\text { Curing } \\
\text { Duration } \\
\text { (days) }\end{array}$ & UCS (kPa) & $\begin{array}{c}\text { Approximate } \\
\text { Secant Modulus } \\
(\mathrm{kPa})\end{array}$ \\
\hline GTPC1507 UCS - 1 & $\mathrm{C}$ & 150 & 7 & 407 & 12942 \\
\hline GTPC1507 UCS - 2 & $\mathrm{C}$ & 150 & 7 & 287 & 10037 \\
\hline GTPC15028 UCS - 1 & $\mathrm{C}$ & 150 & 28 & 280 & 12887 \\
\hline GTPC15028 UCS - 2 & $\mathrm{C}$ & 150 & 28 & 397 & 25951 \\
\hline GTPC15056 UCS - 1 & $\mathrm{C}$ & 150 & 56 & 342 & 14045.6 \\
\hline GTPC15056 UCS - 2 & $\mathrm{C}$ & 150 & 56 & 211 & 9658.1 \\
\hline GTPC2007UCS -1 & $\mathrm{C}$ & 200 & 7 & 375 & 23112 \\
\hline GTPC2007UCS -2 & $\mathrm{C}$ & 200 & 7 & 315 & 18954 \\
\hline GTPC20014UCS -1 & $\mathrm{C}$ & 200 & 14 & 275 & 39680 \\
\hline GTPC20028UCS -1 & $\mathrm{C}$ & 200 & 28 & 152 & 6030 \\
\hline GTPC 20028UCS -2 & $\mathrm{C}$ & 200 & 28 & 390 & 29410 \\
\hline GTPC20056UCS -1 & $\mathrm{C}$ & 200 & 56 & 295 & 17850 \\
\hline GTPC20056UCS -2 & $\mathrm{C}$ & 200 & 56 & 497 & 22657 \\
\hline GTPC2507UCS -1 & $\mathrm{C}$ & 250 & 7 & 385 & 37649 \\
\hline GTPC2507UCS -2 & $\mathrm{C}$ & 250 & 7 & 395 & 29614 \\
\hline GTPC 25014UCS -1 & $\mathrm{C}$ & 250 & 14 & 600 & 29146 \\
\hline GTPC25014UCS -2 & $\mathrm{C}$ & 250 & 14 & 609 & 57916 \\
\hline GTPC25028UCS -1 & $\mathrm{C}$ & 250 & 28 & 518 & 59971 \\
\hline GTPC25028UCS -2 & $\mathrm{C}$ & 250 & 28 & 422 & 56076 \\
\hline GTPC 25056UCS -1 & $\mathrm{C}$ & 250 & 56 & 489 & 23169 \\
\hline GTPC25056UCS -2 & $\mathrm{C}$ & 250 & 56 & 475 & 23133 \\
\hline GS33C2507UCS - 1 & $\mathrm{C}$ & 250 & 7 & 404 & 22118 \\
\hline GS33C2507UCS - 2 & $\mathrm{C}$ & 250 & 7 & 571 & 34840 \\
\hline GS33C25014UCS - 1 & $\mathrm{C}$ & 250 & 14 & 378 & 17860 \\
\hline GS33C25014UCS - 2 & $\mathrm{C}$ & 250 & 14 & 601 & 29682 \\
\hline
\end{tabular}

Note: C-cement 


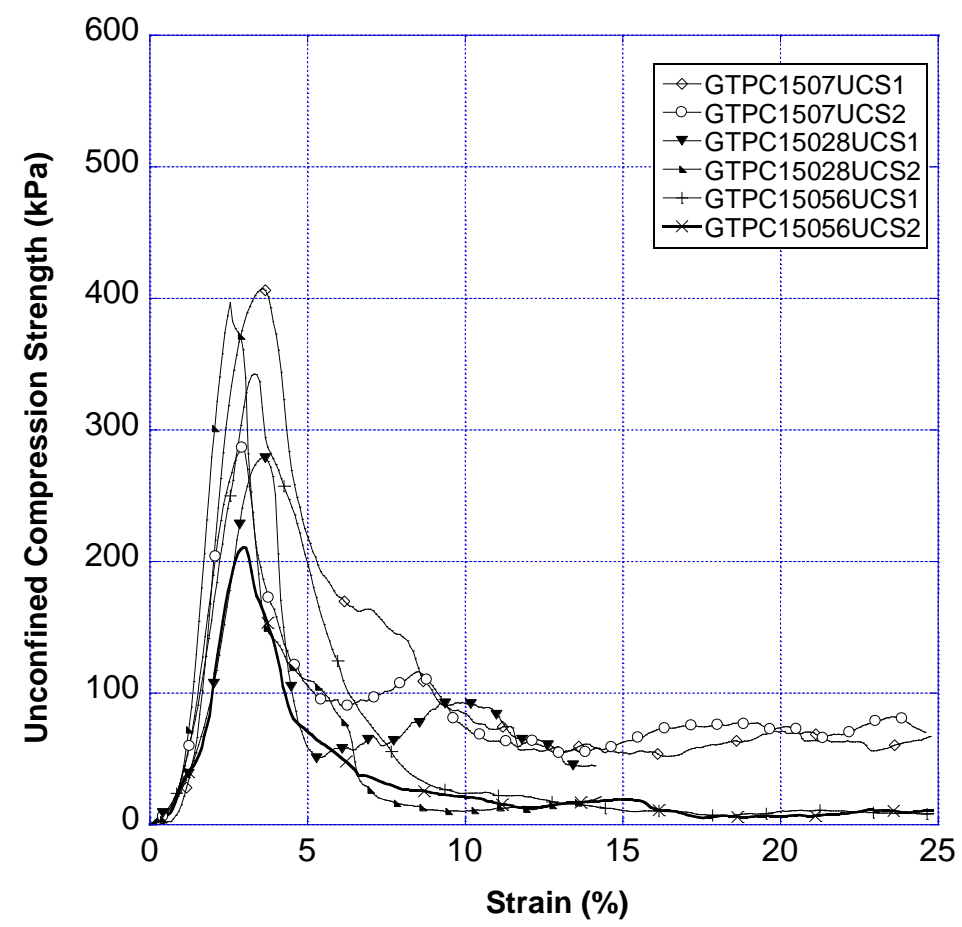

Figure 4-7 Stress-strain curves of UCS tests for $150 \mathrm{~kg} / \mathrm{m}^{3}$ cement treated soil samples

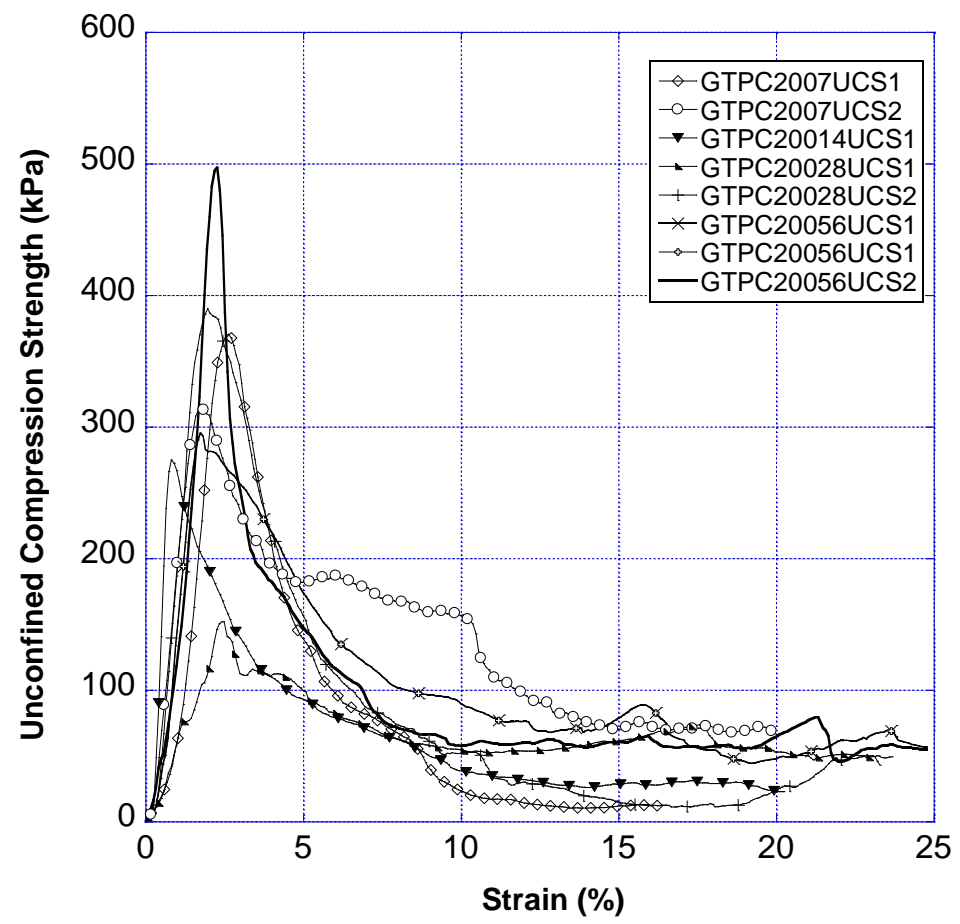

Figure 4-8 Stress-strain curves of UCS tests for $200 \mathrm{~kg} / \mathrm{m}^{3}$ cement treated soil samples 


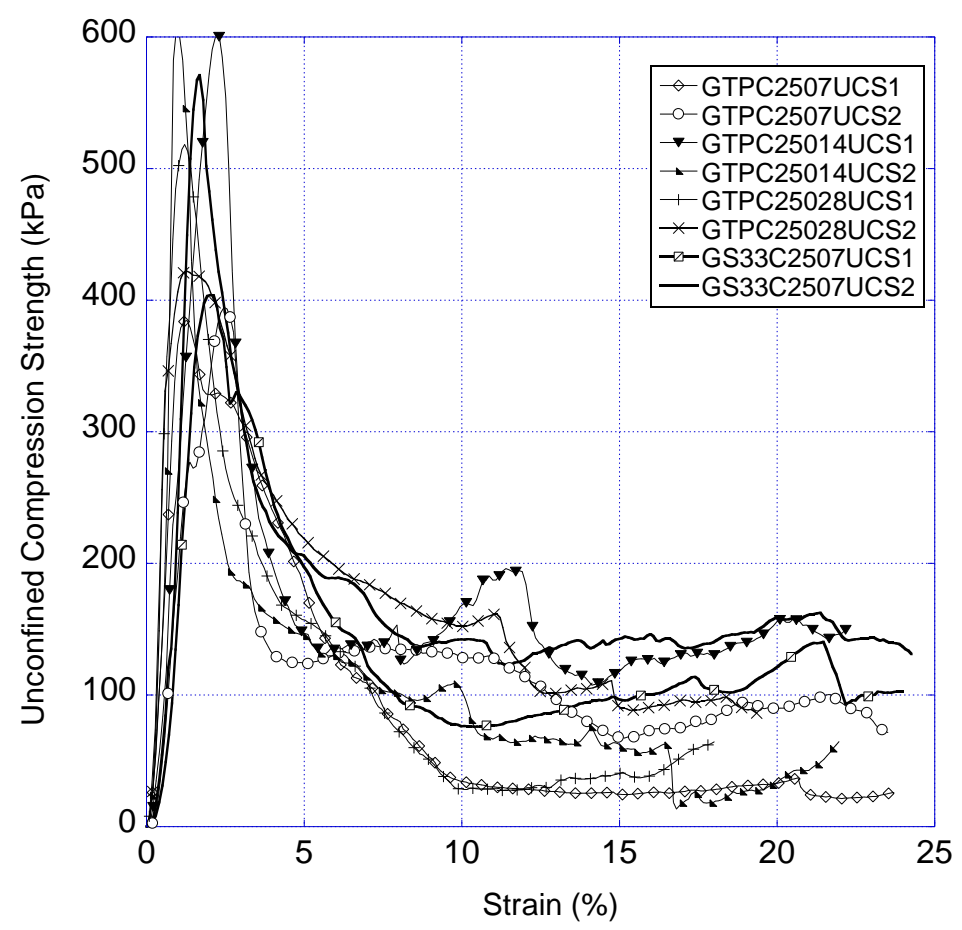

Figure 4-9 Stress-strain curves of UCS tests for $250 \mathrm{~kg} / \mathrm{m}^{3}$ cement treated soil samples

An increase in UCS was observed for all three dosages of cement. UCS increased the most with a cement dosage of $250 \mathrm{~kg} / \mathrm{m}^{3}$ while a cement dosage of $150 \mathrm{~kg} / \mathrm{m}^{3}$ did not produce a significant improvement in UCS. Compared to the strength improvements acquired by cement treated Champlain Sea clay, organic silty clay's strength improvement was significantly less after receiving cement treatment. Some possible reasons behind this phenomenon could be different curing container and physicochemical interaction between organics and cement. The switch from a larger mould to a smaller mould could have impacted the strength improvement in a negative way. Tremblay et al.'s (2002) findings indicate that organic compound can negatively influence the cementation process. Organic compounds which produce a $\mathrm{pH}$ of 9 or lower is highly likely to inhibit the cementation process. Other types of organic compounds, such as oil or nonmiscible hydrocarbons, can delay the cementation process. It is important to monitor the type of organic compound in the soil and measure the soil's pH values in order to determine the suitability of using this technique. Residual strengths of the cement treated sample vary greatly between each test. Post yield strength decreases rapidly for most sample. This is due to the brittle failure mode of the samples. Since no confining pressure was applied to the sample during the unconfined 
compression tests, the accuracy of the residual strength interpretation is questionable. Triaxial can be conducted on cylindrical samples to better evaluate post yield behaviors.

The efficiency of lime treatment of clay was tested with clayey silt with organics to organic silt samples taken from the test pits. Lime stabilisation was reported to be effective in strengthe ning soft clay and marine clay (Balasubramaniam \& Bergado, 1989; Locat, 1990). High calcium quicklime donated from Graymont in Boucherville, QC was used in this study. The lime dosages were $100 \mathrm{~kg} / \mathrm{m}^{3}$ and $200 \mathrm{~kg} / \mathrm{m}^{3}$ and the curing durations are 7, 14, 28, and 56 days. Based on the UCS test results, the efficiency of lime in treating the site clay is very low. Normally lime is not efficient in treating organic clays though it may be excellent for other problematic clays (Eades \& Grim, 1960). Another reason for lime's low reaction with organic silty clay is the lime slurry's preparation. A water to lime ratio of $3: 1$ and $1.6: 1$ for $100 \mathrm{~kg} / \mathrm{m}^{3}$ and $200 \mathrm{~kg} / \mathrm{m}^{3}$ dosage was applied respectively due to lime's high exothermic properties. The summary of UCS tests for lime treated soils is shown in Table 4-6. The stress-strain curves of UCS tests on the lime treated samples for two dosages are shown in Figure 4-10 and Figure 4-11, respectively.

Table 4-6 UCS Test Results for Lime Treated Soils

\begin{tabular}{cccccc}
\hline Experiment No. & Binder & $\begin{array}{c}\text { Dosage } \\
\left(\mathbf{k g} / \mathbf{m}^{\mathbf{3}}\right)\end{array}$ & $\begin{array}{c}\text { Curing } \\
\text { Duration } \\
\text { (days) }\end{array}$ & UCS (kPa) & $\begin{array}{c}\text { Approximate Secant } \\
\text { Modulus (kPa) }\end{array}$ \\
\hline GTPL1007UCS -1 & L & 100 & 7 & 20 & 187 \\
GTPL1007UCS -2 & L & 100 & 7 & 20 & 178 \\
GTPL10014UCS -1 & L & 100 & 14 & 19 & 175 \\
GTPL10014UCS -2 & L & 100 & 14 & 17 & 180 \\
GTPL10028UCS -1 & L & 100 & 28 & 18 & 149 \\
GTPL10028UCS -2 & L & 100 & 28 & 21 & 665 \\
GTPL2007UCS-1 & L & 200 & 7 & 37 & 520 \\
GTPL2007UCS-2 & L & 200 & 7 & 35 &
\end{tabular}




\begin{tabular}{lccccc} 
GTPL20014UCS-1 & L & 200 & 14 & 29 & 450 \\
GTPL20014UCS-2 & L & 200 & 14 & 28 & 334 \\
GTPL20028UCS-1 & L & 200 & 28 & 6 & 36 \\
GTPL20028UCS-2 & L & 200 & 28 & 5 & 42 \\
\hline
\end{tabular}

Note: L-Lime

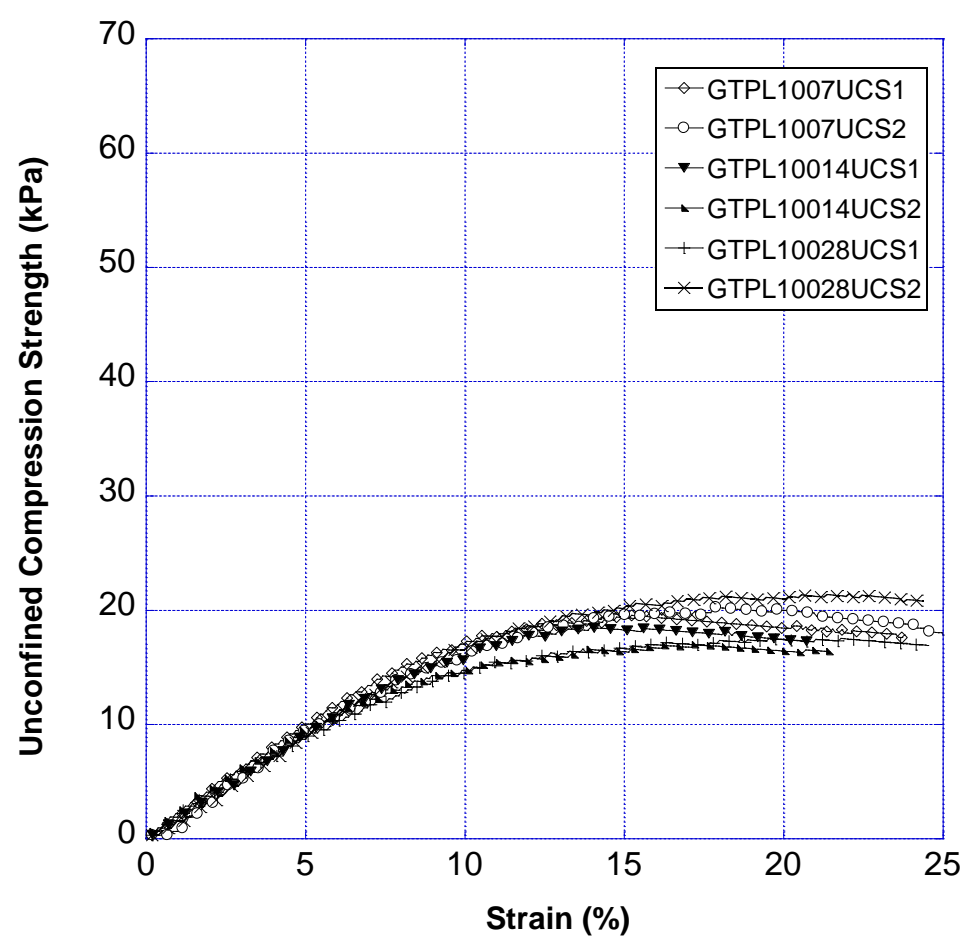

Figure 4-10 Stress-strain curves of UCS tests for $100 \mathrm{~kg} / \mathrm{m}^{3}$ lime treated soil samples 


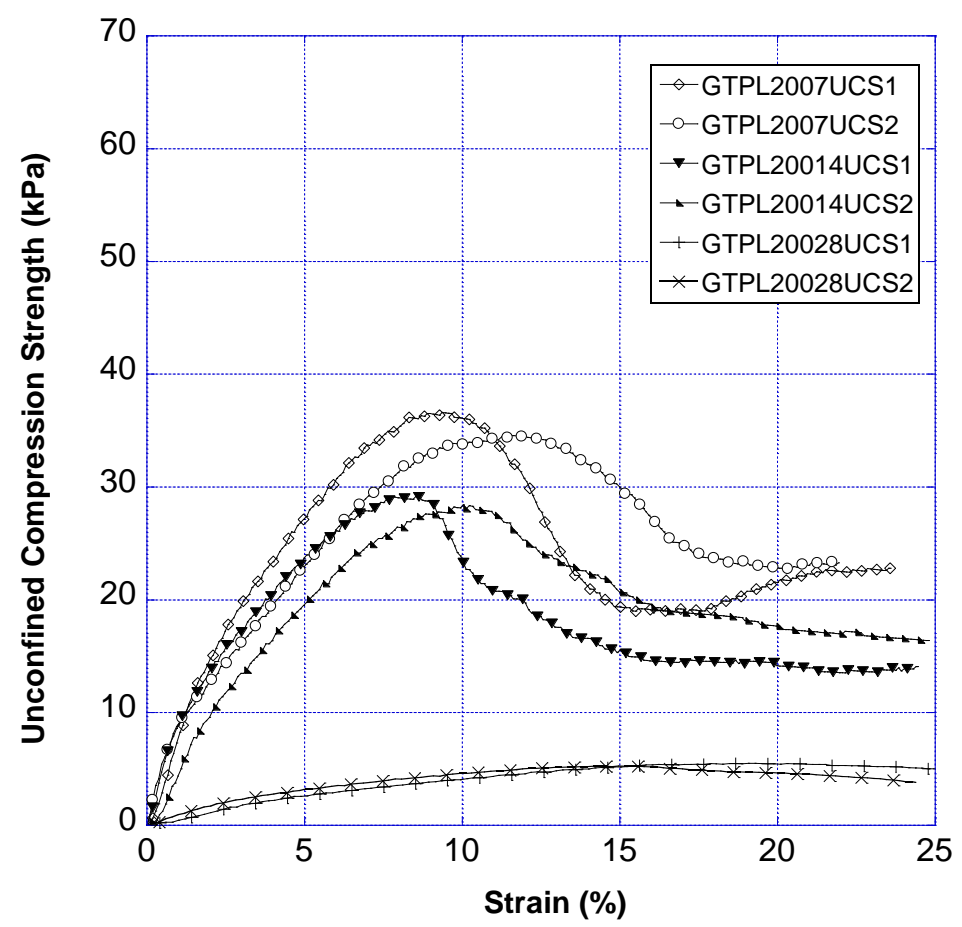

\section{Figure 4-11 Stress-strain curves of UCS tests for $200 \mathrm{~kg} / \mathrm{m3}$ lime treated soil samples}

UCS for lime treated samples did not exceed the untreated clay's UCS. In some cases, the UCS even decreased to a much lower level, such as $200 \mathrm{~kg} / \mathrm{m}^{3}$ lime treated clays cured for 28 days. One of the possible explanation for this result could be due high water to lime ratio. Lime is highly exothermic when in contact with water. Therefore, to produce a mixable lime slurry, extra water was added to the quicklime powder. The high water to lime ratio may have resulted in a low strength treated sample. For future studies, cement and lime could be included as a combination to stimulate better strength improvement.

\subsection{Curing Condition}

\subsubsection{Champlain Sea Clay}

Curing duration is an important influencing factor. Previous research showed that treated soil strength improves with increasing curing duration as cement hydrates and pozzalonic reaction takes place to form pozzalonic compound (Pathivada, 2005). 
Figure 4-12 shows the UCS values vs. curing durations for cement treated Arnprior clay samples. However, there is no clear trend observed for Arnprior clay samples due to poor compaction method used at the beginning of tests. Continuous leaching of the marine clay sample may have also caused the reduction in UCS from 14 days of curing to 28 days of curing. A consistent monitor of the water bath's salinity with increasing time can help quantify the degree of leaching for future tests. Furthermore, the increase in water to cement ratio may also affect the reduction in UCS after 14 days. Although after curing water content does not show significant deviations between 7 days, 14 days, and 28 days cured samples.

Once the improved compaction method was implemented for Kanata soil, an positive correlation for strength increase can be observed with increasing curing duration (Figure 4-13). The prolonged curing allows cement to fully hydrate and react with soil (Kitazume \& Terashi, 2012). However, for samples treated with low binder dosages between $7 \%$ and $10 \%\left(72 \mathrm{~kg} / \mathrm{m}^{3}\right.$ and $103 \mathrm{~kg} / \mathrm{m}^{3}$ respectively), there is no significant strength increase with curing duration. The low cement dosage may not be enough to overcome the leaching effect and the increased water to cement ratio. For slag/cement treated samples, an increase in curing duration resulted in an increase in UCS. However, for $414 \mathrm{~kg} / \mathrm{m}^{3}$ cement treated samples, UCS increased with increasing curing duration until the $14^{\text {th }}$ day. Insufficient compaction, prolonged leaching, and improper UCS sample preparation can be contributing factors.

While the findings are preliminary at the moment, the result still confirm the reaction of binders with soil. A more thorough study is required in the future to establish the relationship between the UCS increase and an increasing curing duration for Champlain Sea clay. To improve the accuracy of evaluating curing duration's influence on UCS, curing can be conducted in a $100 \%$ moisture environment instead of submerging underwater. 


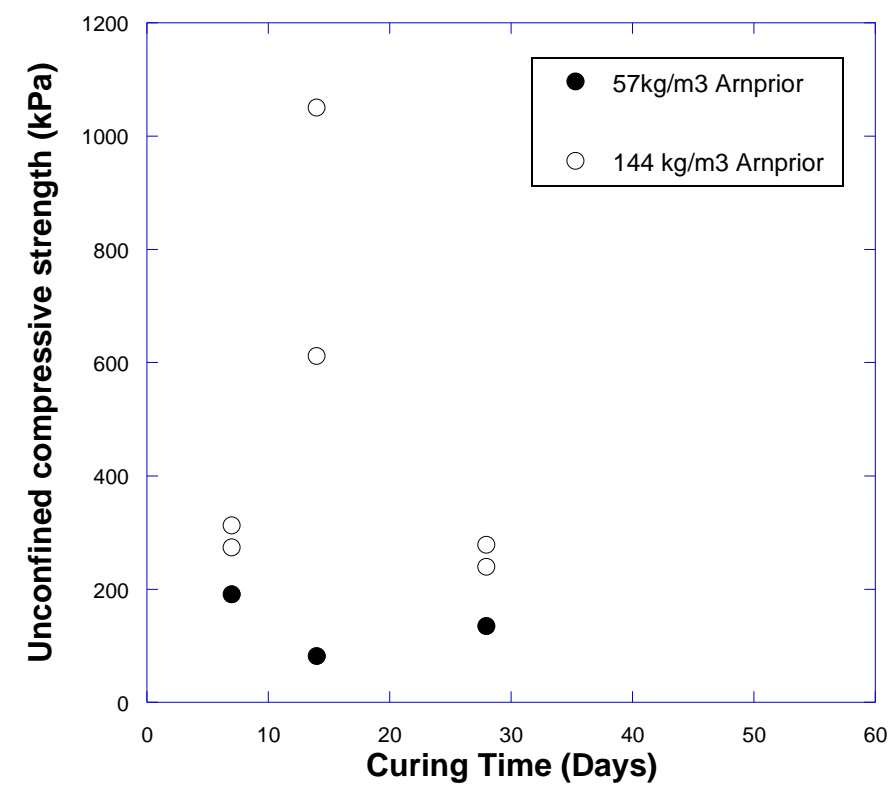

Figure 4-12 Influence of curing duration on UCSs of cement treated Arnprior samples

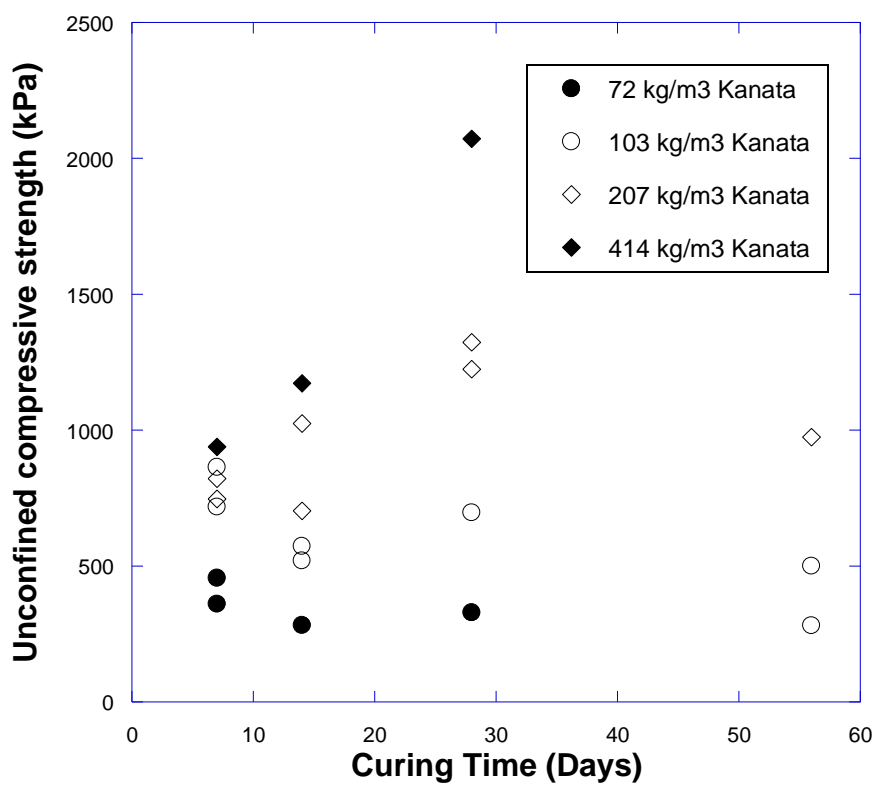

Figure 4-13 Influence of curing duration on UCSs of cement treated samples 


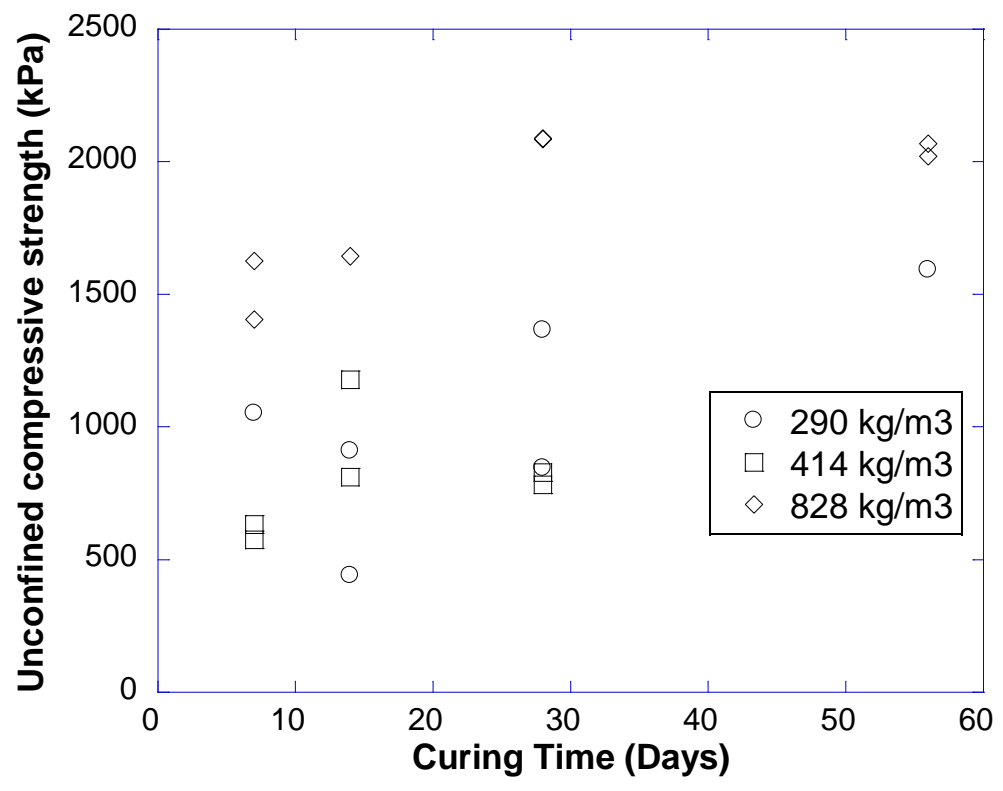

Figure 4-14 Influence of curing duration on UCS of slag/cement treated samples

\subsubsection{Organic Silty Clay}

For cement treated organic silty clay, significant improvement in UCS with prolonged curing was not observed. For $150 \mathrm{~kg} / \mathrm{m}^{3}$ and $200 \mathrm{~kg} / \mathrm{m}^{3}$ cement treated samples, increasing curing duration caused UCS of the treated samples to decline slightly in certain instances. Possible explanations for this phenomenon could be cement's ineffective reaction with organic silty clay and insuffic ient cement dosage. Prolonged submersion underwater can cause structural disintegration of the compacted sample, leading to large cracks and layers on the surface of sample. Finally, the water to binder ratio could also decrease with increasing water curing durations. For samples treated with $250 \mathrm{~kg} / \mathrm{m}^{3}$ of cement, UCS increased from 7 days of curing to 14 days of curing. However, UCS started to decrease after 28 days of curing and 56 days of curing. For future studies, a larger dosage may be required to fully visualize the effect of curing duration on binder treated organic silty clay.

For lime treated organic silty clays, the effect of curing on UCS was not very relevant. For both $100 \mathrm{~kg} / \mathrm{m}^{3}$ and $200 \mathrm{~kg} / \mathrm{m}^{3}$ lime treated samples, UCS decreased after 14 days curing. For $200 \mathrm{~kg} / \mathrm{m}^{3}$ lime treated sample, UCS decreased with increasing curing duration. This is phenomenon can be attributed to lime's poor interaction with organic silty clays (Tremblay et al, 2002). Strength improvement was not apparent in the first place, which makes observation difficult to discern any change in UCS with respect to curing duration. 


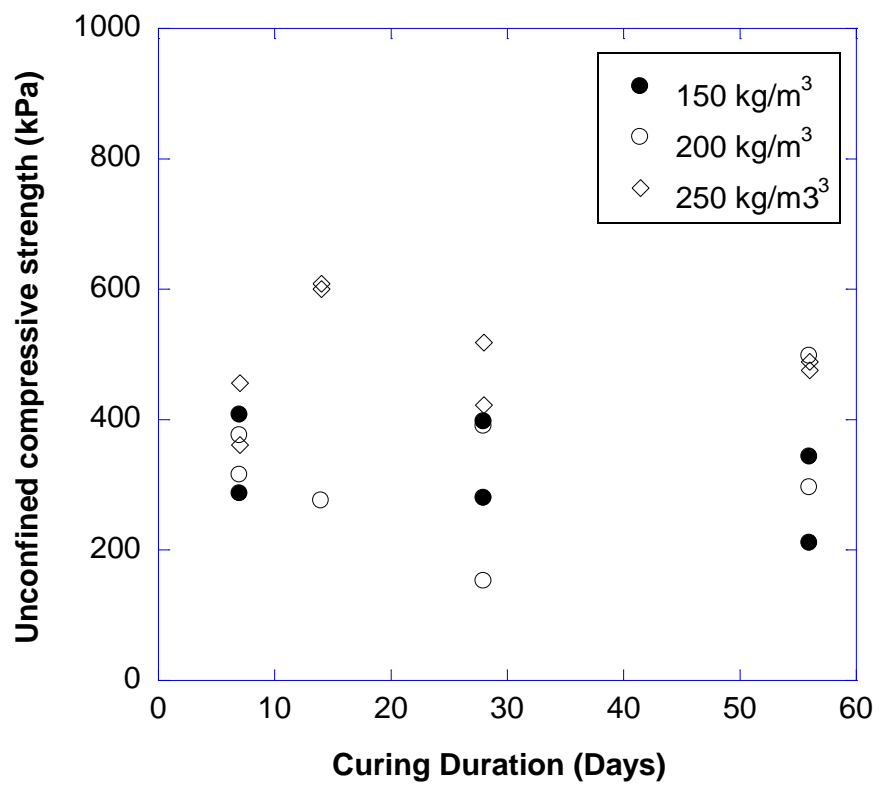

Figure 4-15 UCS vs. curing duration plot for cement treated clayey silt with organics to organic silt

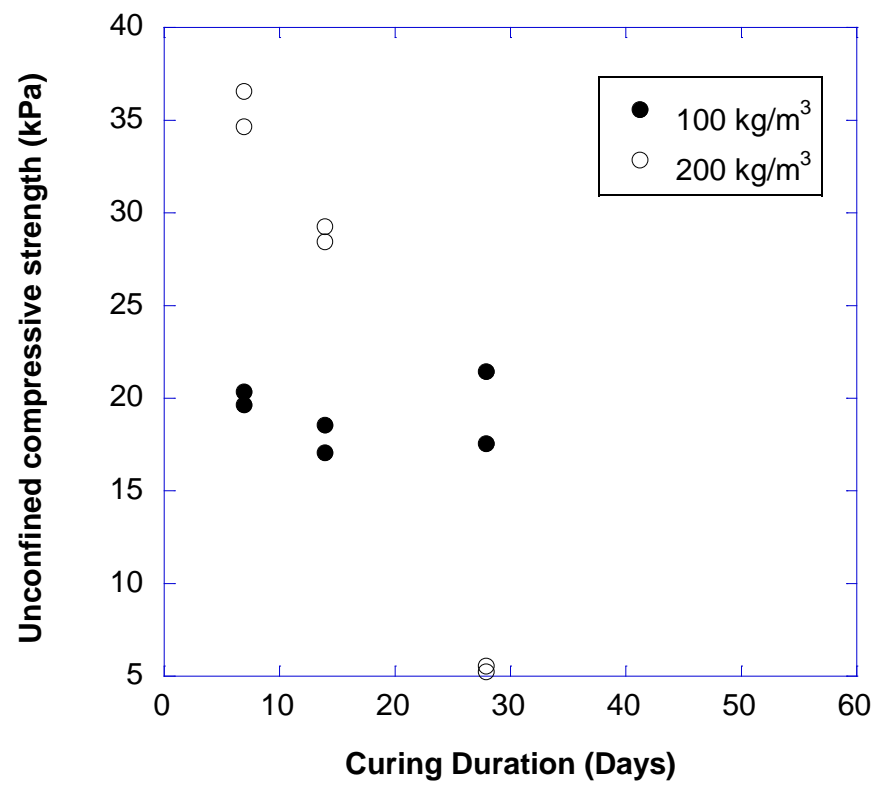

Figure 4-16 UCS vs. curing duration plot for lime treated clayey silt with organics to organic silt 


\subsection{Sample Density}

\subsubsection{Champlain Sea Clay}

Sample density can influence treated soil's UCS. Figure 4-17 shows the relationship between UCS and density values of cement treated samples. A sample with poor compaction would have a low density, which would likely produce a lower than average UCS. Improved sample compaction often led to a higher sample density and higher UCS.

For Kanata clay, most samples had density values within a narrow range of around $1.6 \mathrm{~g} / \mathrm{cm}^{3}$, which is an indication of a consistent compaction effort. For cement treated Kanata clays, strength increase also strongly correlates to increasing sample density. The main contribution factor is still believed to be the poor compaction method used at the beginning of tests.

For Kanata clay treated with slag/cement, a similar relationship is also observed between the UCS and sample density, as shown in Figure 4-18. A higher density may result in higher UCS. However, high sample density can also result in reduced UCS. This can be attributed to high brittleness and structural discontinuities of the samples. Samples which received high binder dosage, such as 414 $\mathrm{kg} / \mathrm{m}^{3}$ of slag/cement, often display this trend.

In conclusion, increasing sample density correlates with increasing UCS. However, higher sample density did not guarantee an increase in UCS. Brittle samples with cracks and discontinuities often have high density but low UCS, which contribute to the scatter on the graphs. 


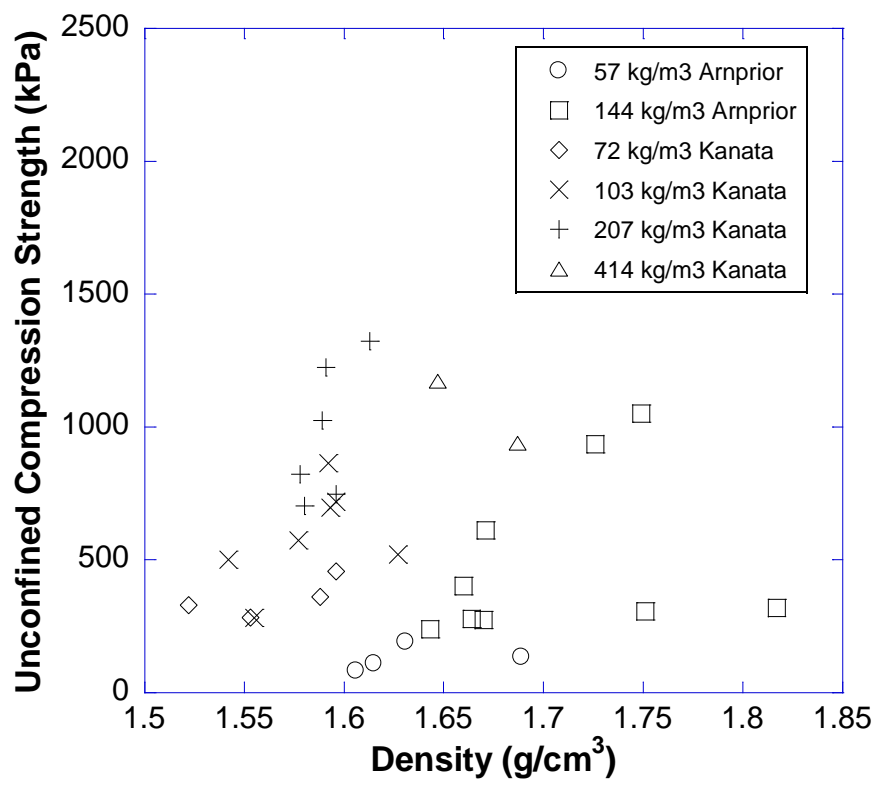

Figure 4-17 Effect of sample density on UCS of cement treated samples

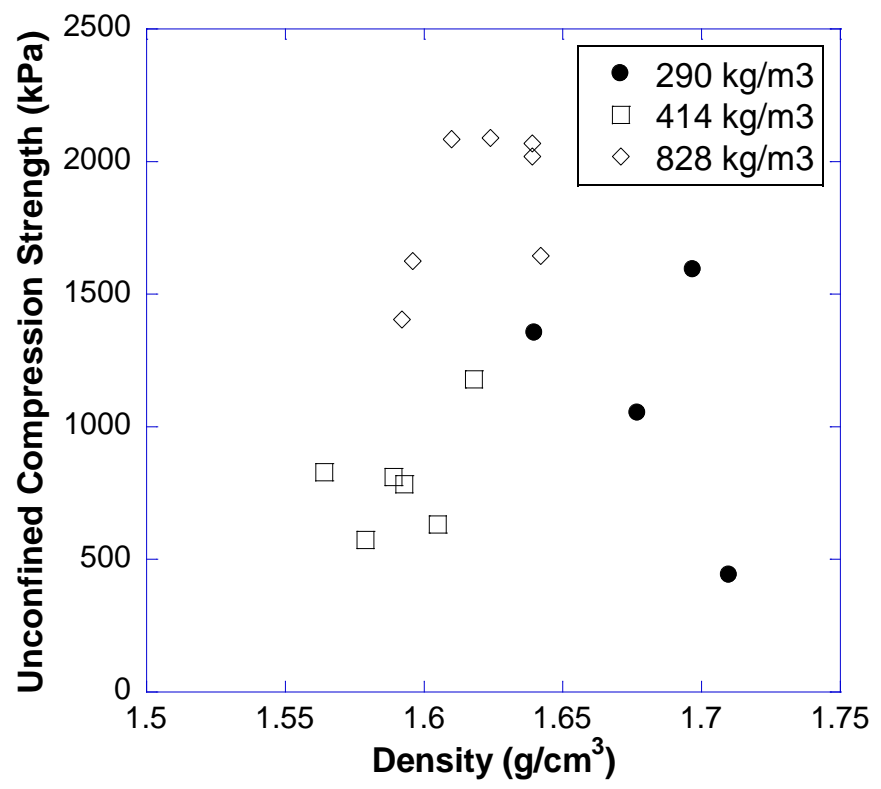

Figure 4-18 Effect of sample density on UCS of slag/cement treated samples

\subsubsection{Organic Silty Clay}

For cement treated organic silty clay, increasing wet sample density correlates to increasing UCS (Figure 4-19). However, if the sample density is higher than 1.75 or $1.8 \mathrm{~g} / \mathrm{cm}^{3}$, UCS may start to decrease. For $150 \mathrm{~kg} / \mathrm{m}^{3}$ cement treated sample, increasing wet sample density resulted in 
increasing UCS. However, after sample density reached $1.8 \mathrm{~g} / \mathrm{cm}^{3}$, increasing sample density no longer guarantees an increase in UCS. This trend is also found for $200 \mathrm{~kg} / \mathrm{m}^{3}$ cement treated samples where sample with highest density recorded the lowest UCS; however, increasing sample density resulted in increasing UCS for samples with a density of less than $1.75 \mathrm{~g} / \mathrm{cm}^{3}$. For 250 $\mathrm{kg} / \mathrm{m}^{3}$ cement treated samples, there is no obvious correlation between UCS and wet sample density.

The reason behind the inconsistency between sample density and UCS could be cement's ineffective performance to improve organic silty clay's strength. Tremblay et al. (2002)'s studies indicated organic content's impediment to the cementation process. Some organic compounds may inhibit the hydration process to varying degree of effect. Low $\mathrm{pH}$ level and high concentration of sulfate $\left(\mathrm{SO}_{4}\right)$ can strongly affect the level of strength improvement where no strength gain may be possible. It is prudent to conduct additional tests to evaluate the $\mathrm{pH}$ level of the soil sample.

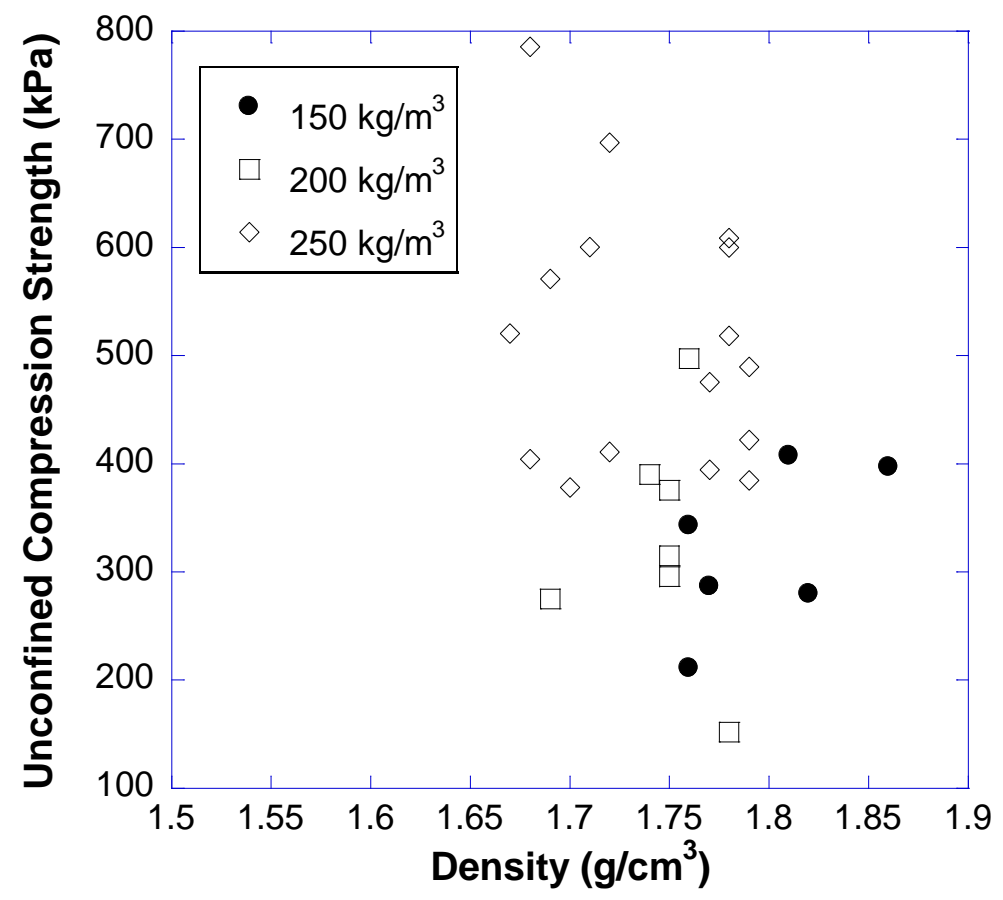

Figure 4-19 UCS vs. wet density of the treated sample for cement treated organic silty clay 


\subsection{Sample Height to Diameter Ratio}

\subsubsection{Champlain Sea Clay}

According to ASTM Standard D2166-00, an optimum range of height to diameter (H/D) ratio is recommended to be $2-2.5$ for the UCS tests. Based on data collected for cement treated clay samples in Figure 4-20 and slag/cement treated samples in Figure 4-21, a height to diameter ratio of 2.0 correlates to the highest UCS from samples. Deviation from a H/D ratio of 2.0 results in drastic UCS reduction. While $2.0 \mathrm{H} / \mathrm{D}$ may correlate to a higher UCS, the lack of test data on other $\mathrm{H} / \mathrm{D}$ ratio can result in statistical bias toward $2.0 \mathrm{H} / \mathrm{D}$.

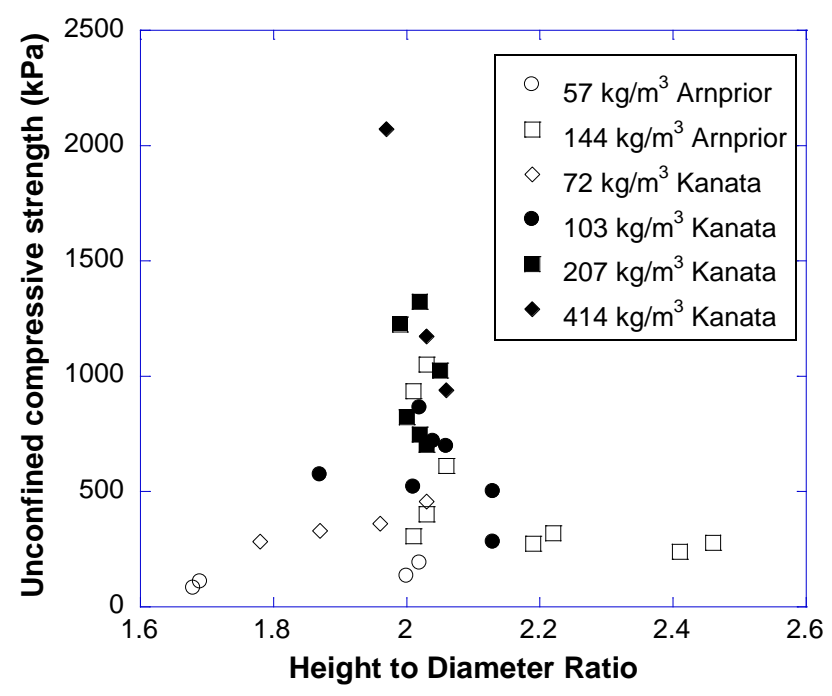

Figure 4-20 Effect of sample height to diameter ratio on cement treated samples 


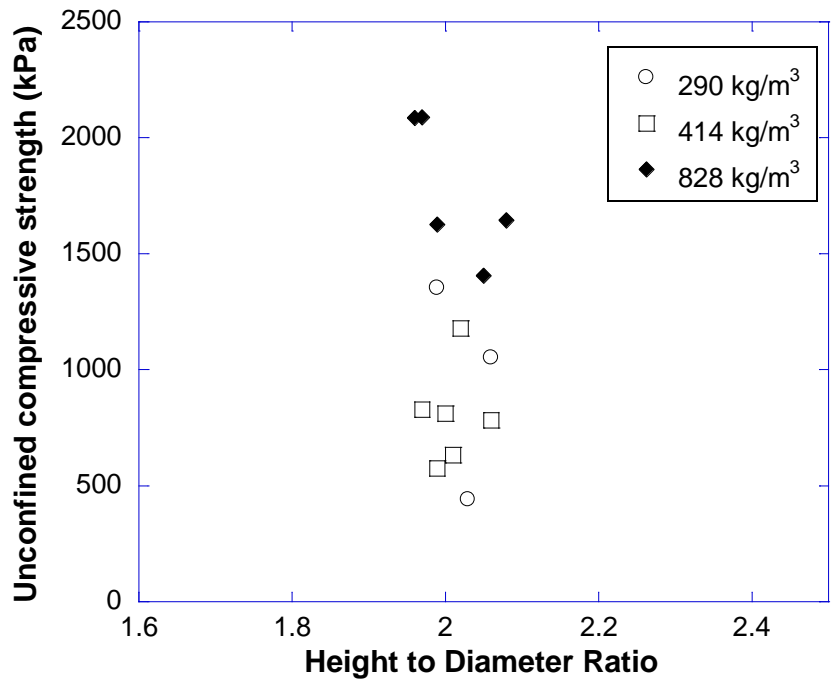

Figure 4-21 Effect of sample height to diameter ratio on slag/cement treated samples

\subsubsection{Organic Silty Clay}

For cement treated organic silty clay, the correlation between UCS and height to diameter ratio was not very clear. The recorded height to diameter ratio for cement treated organic silty clay ranged from 1.90 to 2.10, which is a much smaller range compared to cement treated Arnprior samples. The small range in height to diameter ratio could have contributed its decorrelation to UCS. On the other hand, a consistent sample to height diameter ratio indicates improved quality control for sample preparation. Figure 4-22 presents UCS vs. height to diameter ratio for cement treated organic silty clay.

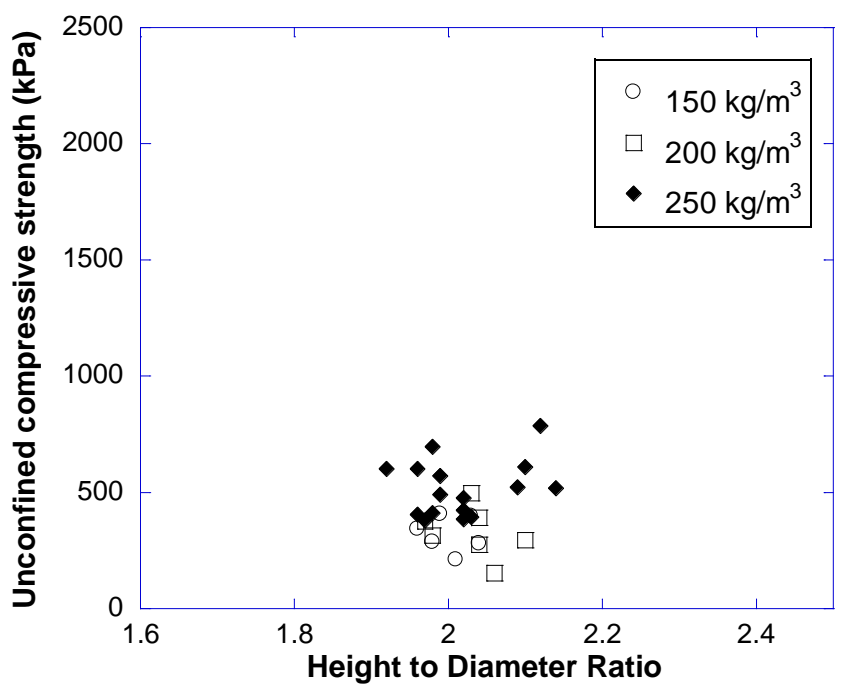

Figure 4-22 UCS vs. height to diameter ratio for cement treated organic silty clay 


\subsection{After Curing Water content}

\subsubsection{Champlain Sea Clay}

Throughout this experiment, after curing water content was not used as a control parameter. Dosage was calculated based on the inherent moisture content of the sample before treatment. However, a small variation of water content between each sample still exists. Water content of cured samples was taken right before the UCS test. Based on Figure 4-23, some samples with a lower water content will often have a higher UCS, and vice versa. This result agree with the basic mechanism of cement stabilization (Kitazume \& Terashi, 2012) where reduction of water content serves as a short term strength increase for the target soil. For samples treated with 5\% cement (57 $\mathrm{kg} / \mathrm{m}^{3}$ ), the correlation between water content and UCS is not very clear. This can be contributed to the small sample size of the experiments.

For Kanata clay treated with cement, UCS decreases with increasing water content for lower dosages of $7 \%\left(72 \mathrm{~kg} / \mathrm{m}^{3}\right)$ and $10 \%\left(103 \mathrm{~kg} / \mathrm{m}^{3}\right)$ cement. However, samples treated with a higher dosage of cement were less obvious to correlate with after curing water content, as seen in Figure 4-23. The reasons behind the weak correlation between after curing water content and UCS could be improper compaction procedure, poor sample preparation, and prolonged curing.

For Kanata clay treated with slag/cement binder, an increase in water content was associated with a UCS increase (Figure 4-24). This contradicts conventional mechanism where an increasing sample water content lowers the UCS of the sample. High quantity of slag/cement with an increased curing duration could have increased the UCS of the sample, neglecting the salt leaching effect altogether. Figure 4-25 illustrates an increase of after curing water content with increasing curing duration, which may support this theory. It is noted that there are only a few data points displayed this trend. More test data are required to confirm the trend and draw conclusive statements of the correlation between UCS and after curing water content. 


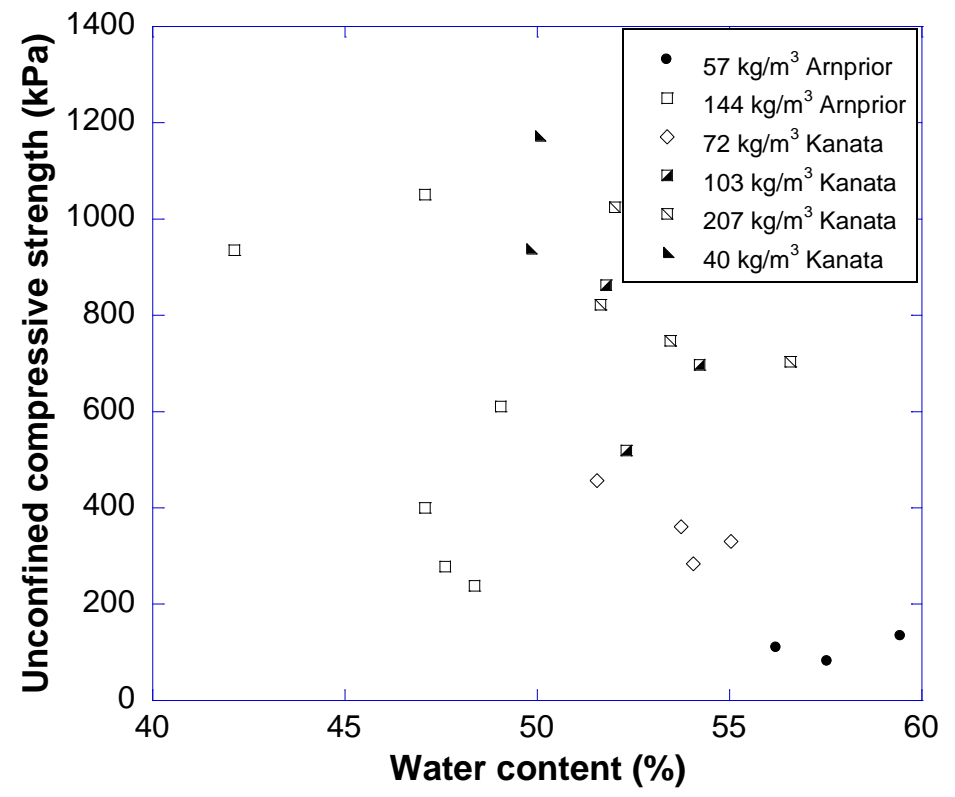

Figure 4-23 Relationship between after curing water content and UCS for cement treated samples

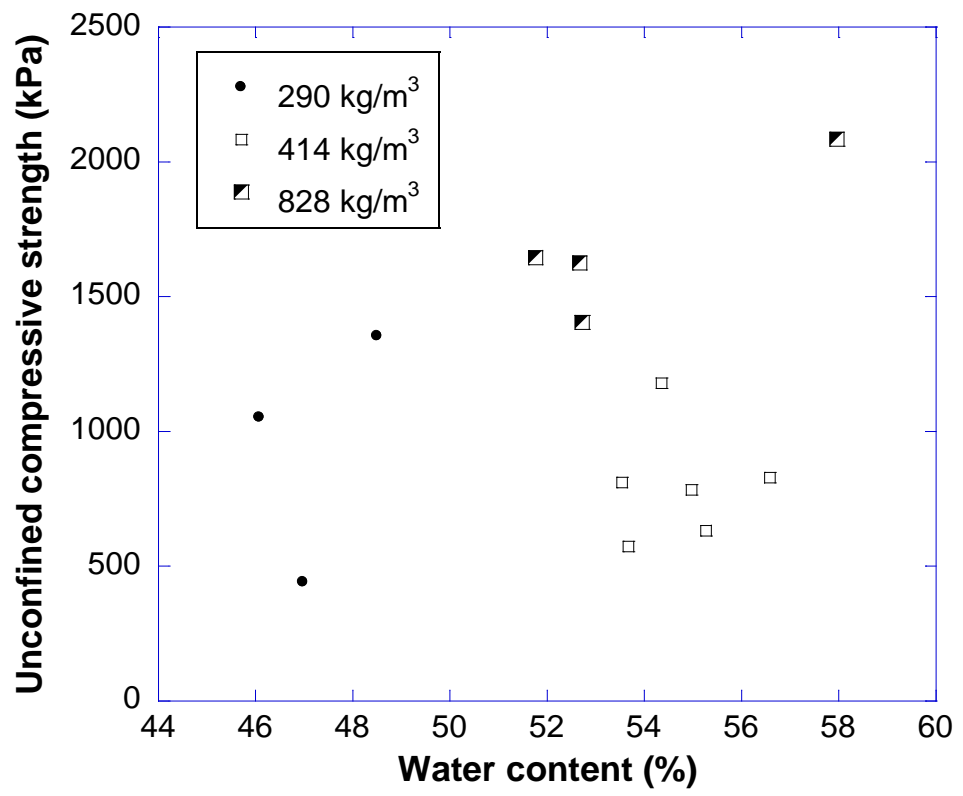

Figure 4-24 Relationship between water content and UCS for slag/cement treated samples 


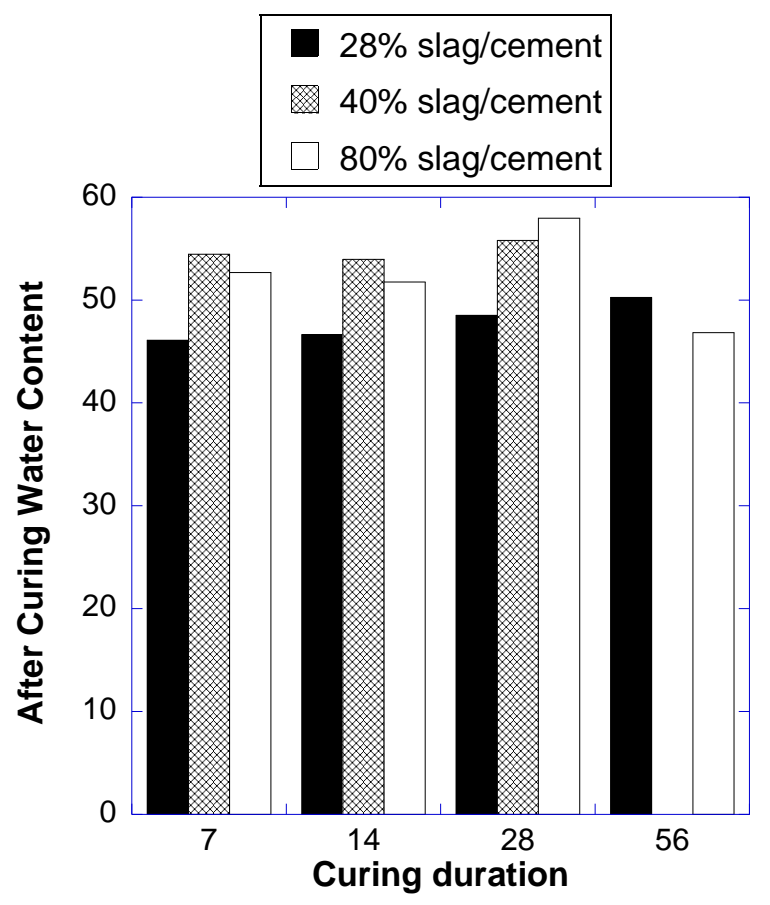

Figure 4-25 After curing water content vs. curing duration for slag/cement treated Kanata clay

\subsubsection{Organic Silty Clay}

For cement treated organic silty clay, increasing after curing water content does not affect UCS significantly. According to Figure 4-26, increasing water content resulted in increasing, decreasing, and neutral UCS, which indicates after curing water content has little to no effect on organic silty clay's UCS. Based on Figure 4-27, a small decrease in after curing water content can be observed for cement treated samples with increasing curing duration; however, water content often starts to increase after 28 days of curing. This phenomenon can be explained by the method of curing applied to the samples. After compacting the mixed samples into the paper tube, the whole tube is submerged in water to promote cement hydration. This curing method could negatively affect the cement hydration process and hamper strength improvement. 


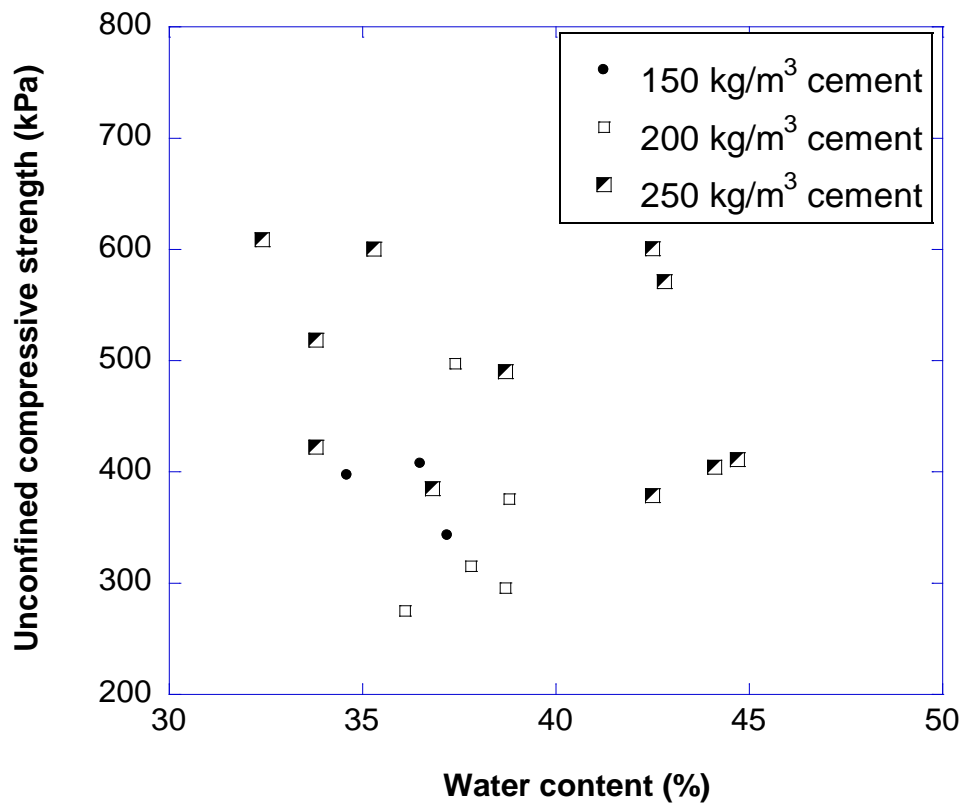

Figure 4-26 UCS vs. after curing water content for cement treated organic silty clay

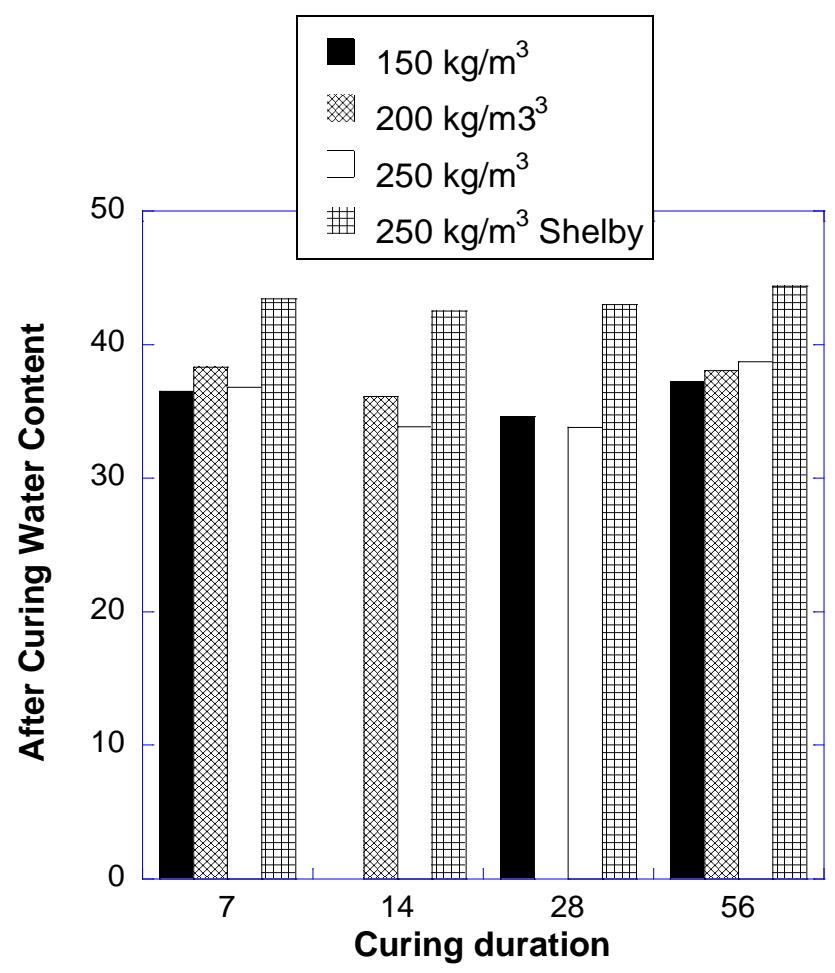

Figure 4-27 After curing water content vs. curing duration for cement treated organic silty clay 


\subsection{Elastic Modulus}

\subsubsection{Champlain Sea Clay}

Elastic modulus is an important design parameter in DMM, particularly in case of settlement control application. Elastic modulus is obtained by using the peak secant modulus method. At half the strength of the UCS of the sample, a stress and strain point is chosen to calculate the modulus from zero stress and zero strain. A comparison between the UCS of the sample and its elastic modulus revealed a linear relationship. The higher the UCS of the sample, the higher its elastic modulus, as shown in Figure 4-28. The relationship between elastic modulus and binder dosage is shown in Figure 4-29. A linear relationship can also be found between the elastic modulus and binder dosage though its relationship is not as strong as the one for elastic modulus with UCS.

For Kanata clay treated with slag/cement, increasing UCS correlates to increasing elastic modulus. Figure 4-30 illustrates the relationship between UCS and elastic modulus. However, UCS starts to level off for $828 \mathrm{~kg} / \mathrm{m}^{3}$ slag/cement treated samples while modulus continues to climb. This can be attributed to limited load applied by the test frame, which prevented the sample from reaching the yield point before testing stopped.

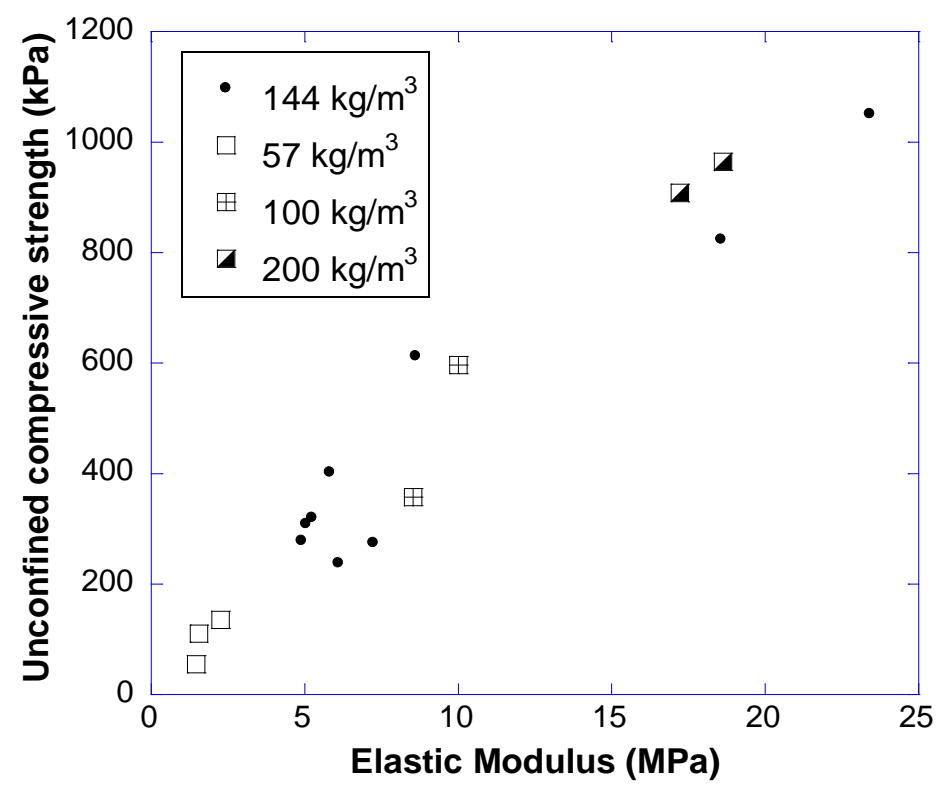

Figure 4-28 UCS vs. elastic modulus for cement treated Amprior clay 


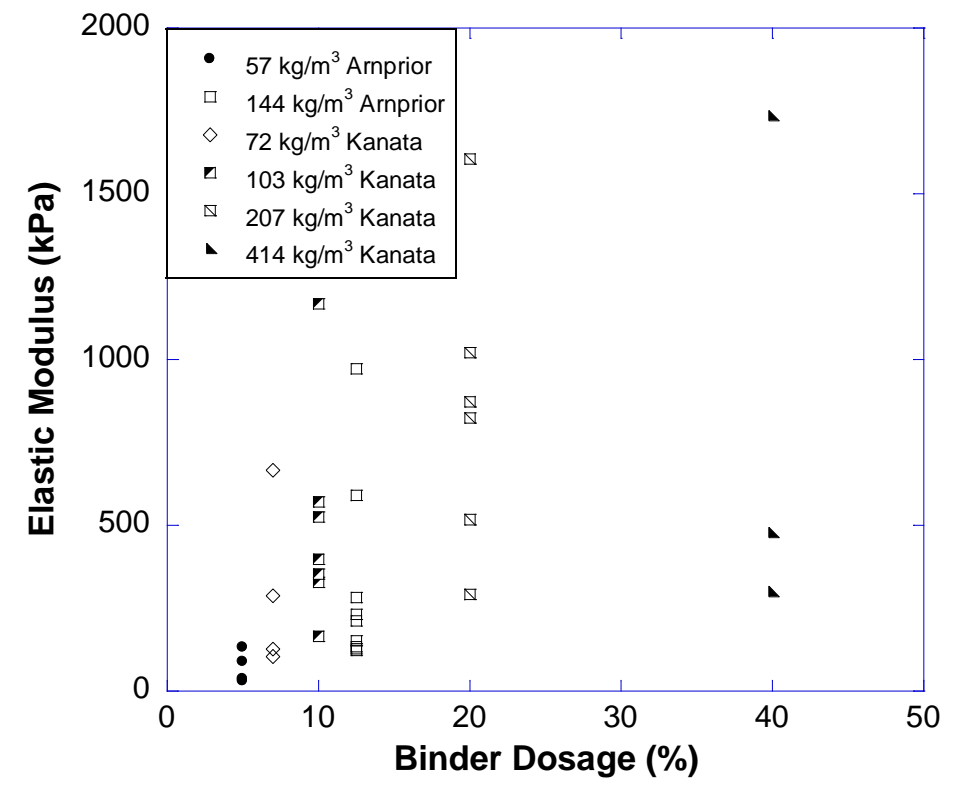

Figure 4-29 Elastic modulus vs. binder dosage for cement treated clay samples

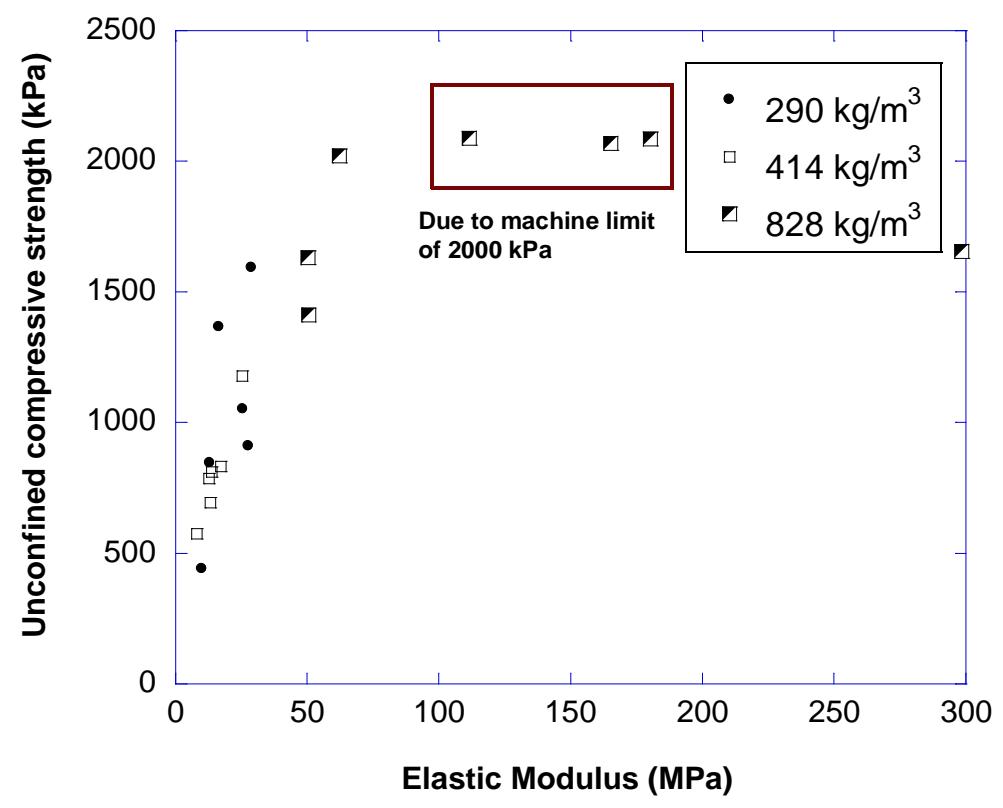

Figure 4-30 UCS vs. elastic modulus for slag/cement treated Kanata clay 


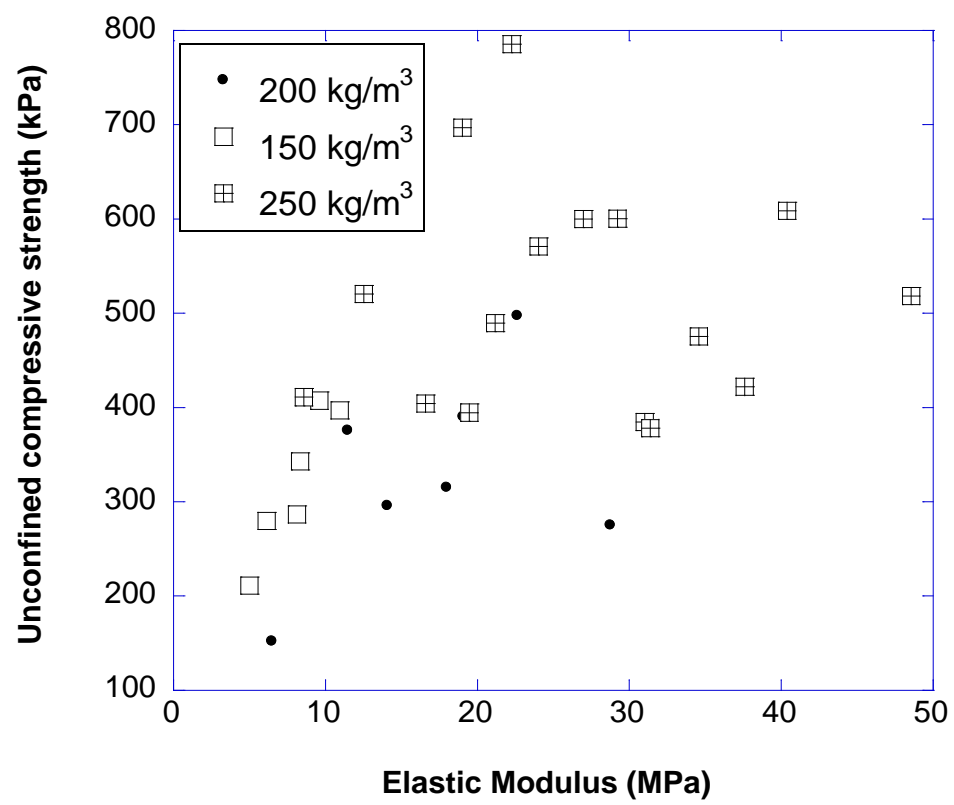

Figure 4-31 UCS vs. elastic modulus for cement treated organic silty clay

\subsubsection{Organic Silty Clay}

For cement treated organic silty clay, increasing UCS correlates to increasing elastic modulus (Figure 4-31). Elastic modulus in this instance is measured as secant modulus of half the UCS of the sample. For $150 \mathrm{~kg} / \mathrm{m}^{3}$ and $200 \mathrm{~kg} / \mathrm{m}^{3}$ cement treated samples, the positive trend was readily observable; however, for $250 \mathrm{~kg} / \mathrm{m}^{3}$ cement treated samples, increasing elastic modulus did not result in increase in UCS at the same scale. A possible explanation for this phenomenon could be attributed by the lack of cement hydration, discrepancies in curing environment, and inaccuracies in sample preparations.

\subsection{Strength Improvement Ratio}

\subsubsection{Champlain Sea Clay}

The strength improvement ratio, calculated by the UCS of samples after and before treatment, measures the efficiency of DMM in improving the strength of clay. An average untreated UCS of $132 \mathrm{kPa}$ was used to calculate the strength increase ratio for both Arnprior samples and Kanata samples. The strength increase ratios with different cement dosages, binders, and soil types are shown in Figure 4-32. It can be found that there is almost no increase with a cement dosage of 57 $\mathrm{kg} / \mathrm{m}^{3}$. Once the dosage increases to $144 \mathrm{~kg} / \mathrm{m}^{3}$, a significant strength increase was noticed even with poor compaction method in Arnprior clay samples. Consistent strength increase with 
increasing cement dosage was observed for Kanata clay samples after the compaction method was improved.

For cement treated Kanata clay, the ratio of improvement was very encouraging. 25 times strength improvement was recorded for $103 \mathrm{~kg} / \mathrm{m}^{3}$ cement treated Kanata clay. With an increasing cement dosage, the strength increase ratio also increased in a directly proportional relationship. For slag/cement treated Kanata clay, increasing slag/cement dosage results in increasing strength improvement ratio, shown in Figure 4-33.

In general, strength improvement ratio can easily reach 10 times the original strength or more . For a weaker Kanata clay, the strength increase ratio is much higher than a relatively stronger Arnprior clay. This concludes preliminarily the efficiency of DMM in treating Champlain Sea clay.

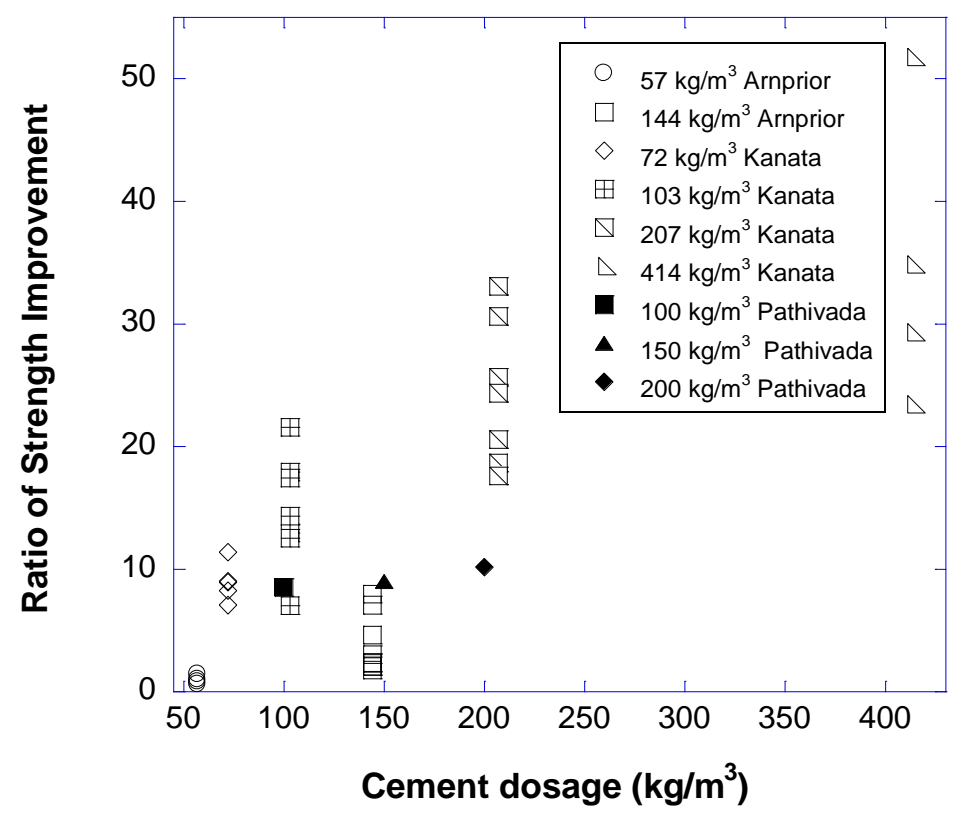

Figure 4-32 Strength increase ratio vs. binder dosage for cement treated clay samples 


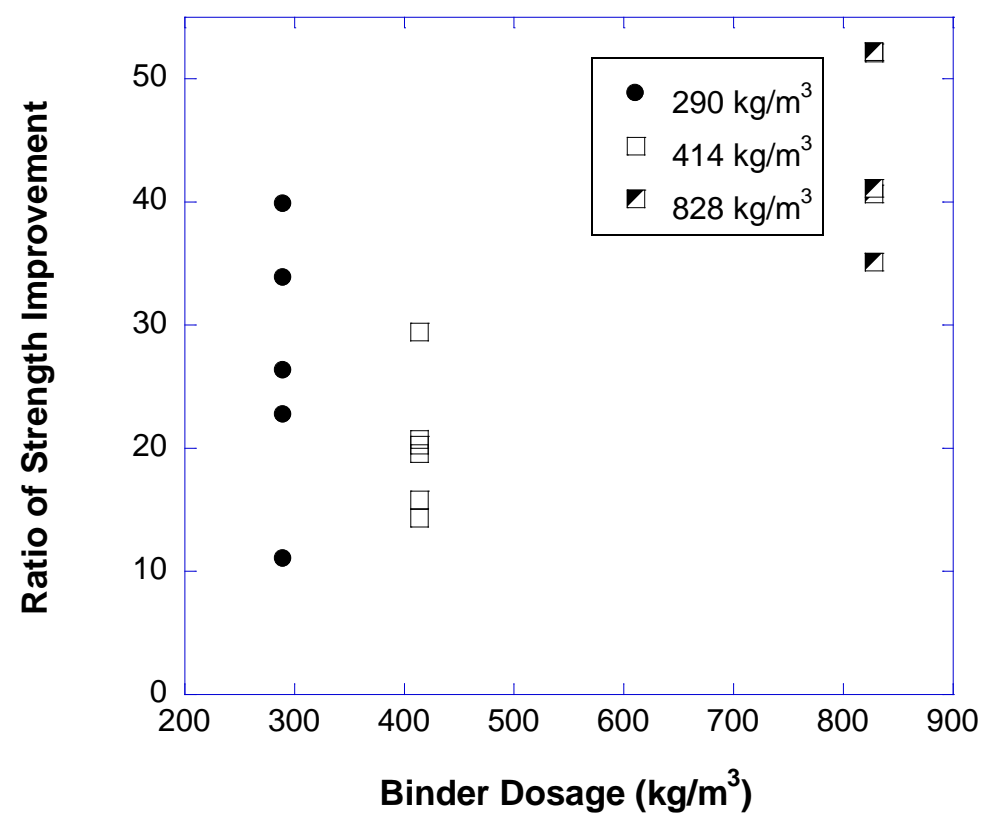

Figure 4-33 Strength increase ratio vs. binder dosage for slag/cement treated Kanata clay

Figure 4-34 and Figure 4-35 displays the relationship between ratio of improvement and curing duration for cement treated samples and slag/cement treated samples respectively. There is an initial increase in the strength increase ratio with time. After curing time reaches a certain time, there is no improvement noticed from the figure. In some cases, strength reduction occurred with increasing curing duration. A possible explanation for this phenomenon could be the decrease in soil salinity level with increasing water curing duration. A long-term investigation into the performance of DMM treated Champlain Sea clay is beneficial to fully understand the interaction between binders and soils. 


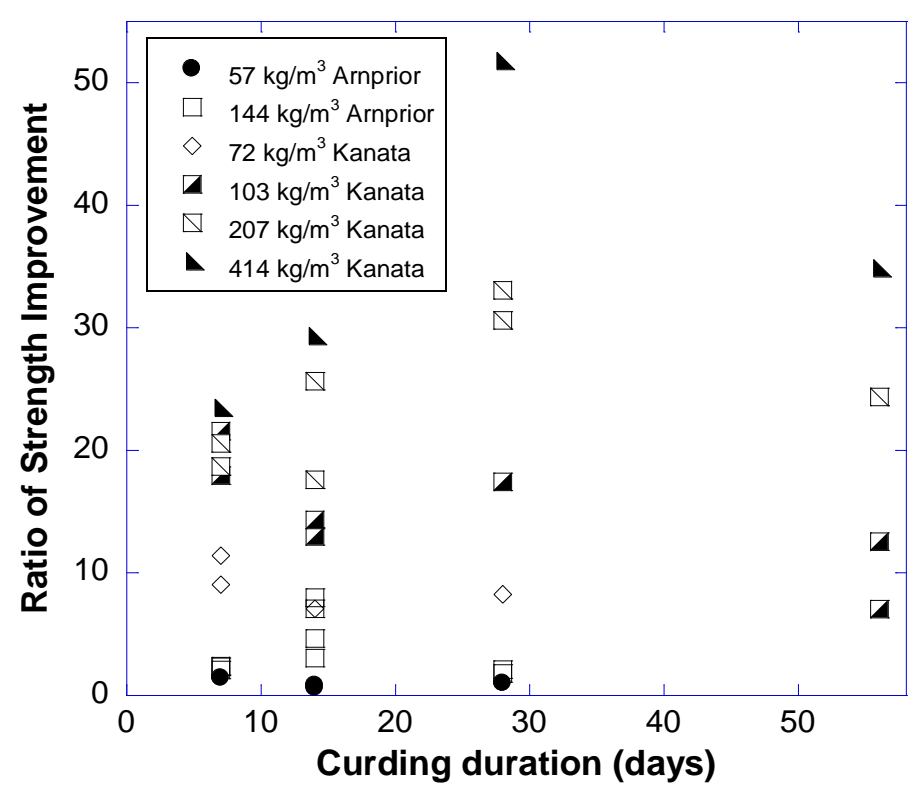

Figure 4-34 Strength increase with curing duration for cement treated clay samples

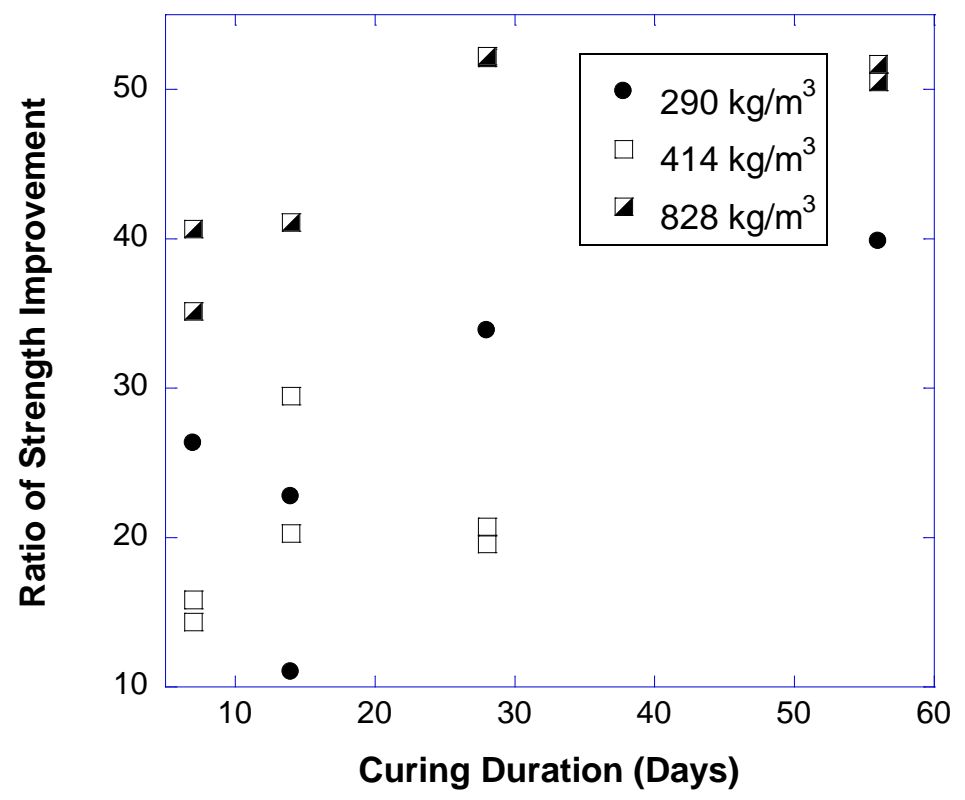

Figure 4-35 Strength increase with curing duration for slag/cement treated Kanata clay

\subsubsection{Organic Silty Clay}

The strength improvement ratio for organic silty clay was calculated by dividing the UCS of binder treated samples by $43 \mathrm{kPa}$, where $43 \mathrm{kPa}$ is the average UCS of the untreated organic silty clay. Based on Figure 4-36, increasing cement dosage increases the subsequent ratio of improvement. Cement dosages between $150 \mathrm{~kg} / \mathrm{m}^{3}$ and $200 \mathrm{~kg} / \mathrm{m}^{3}$ resulted in moderate increase of strength 
improvement ratio from 7.46 to 7.64 . Increasing the cement dosage to $250 \mathrm{~kg} / \mathrm{m}^{3}$ significantly increased the ratio of strength improvement to 12 , which also reflects the UCS of the samples. The results agree with past research which increasing cement binder result in increasing UCS.

Ratio of improvement's relationship to curing duration for cement treated silty clay is similar to UCS and binder dosage's relationship (Figure 4-37). Increasing the curing duration to 14 or 28 day will increase the ratio of improvement; however, further increase in curing duration reduces the strength improvement in $200 \mathrm{~kg} / \mathrm{m}^{3}$ and $250 \mathrm{~kg} / \mathrm{m}^{3}$ cement treated samples. Lack of cement binding and curing environment could have contributed to this effect.

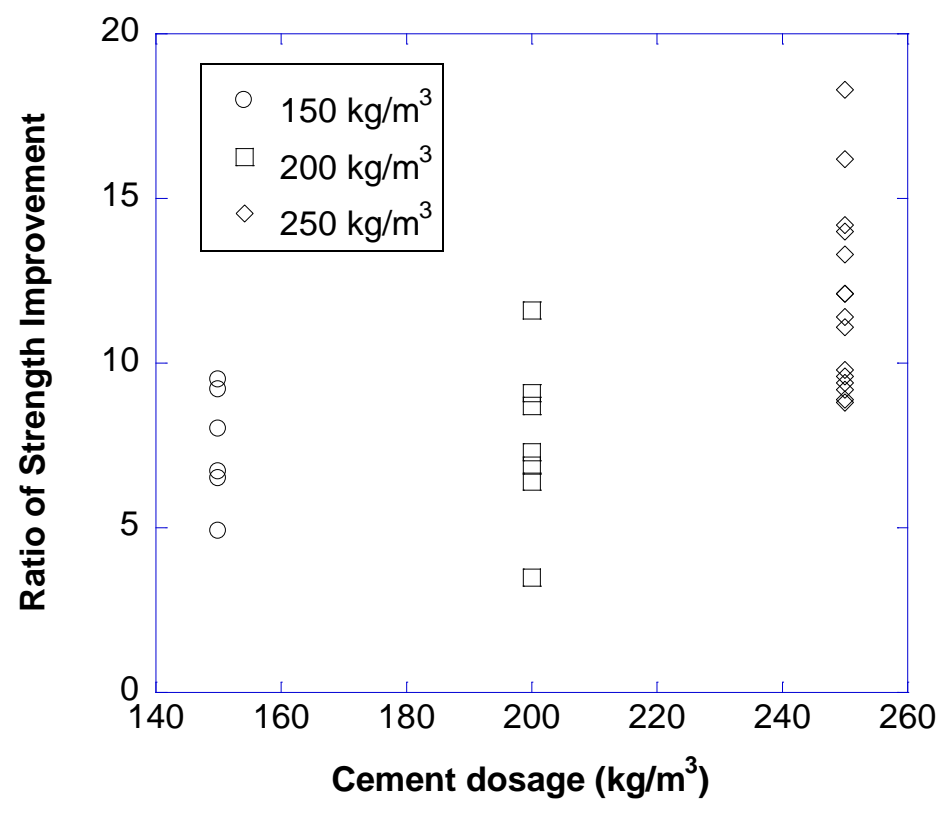

Figure 4-36 Ratio of strength improvement vs. cement dosage for cement treated organic silty clay 


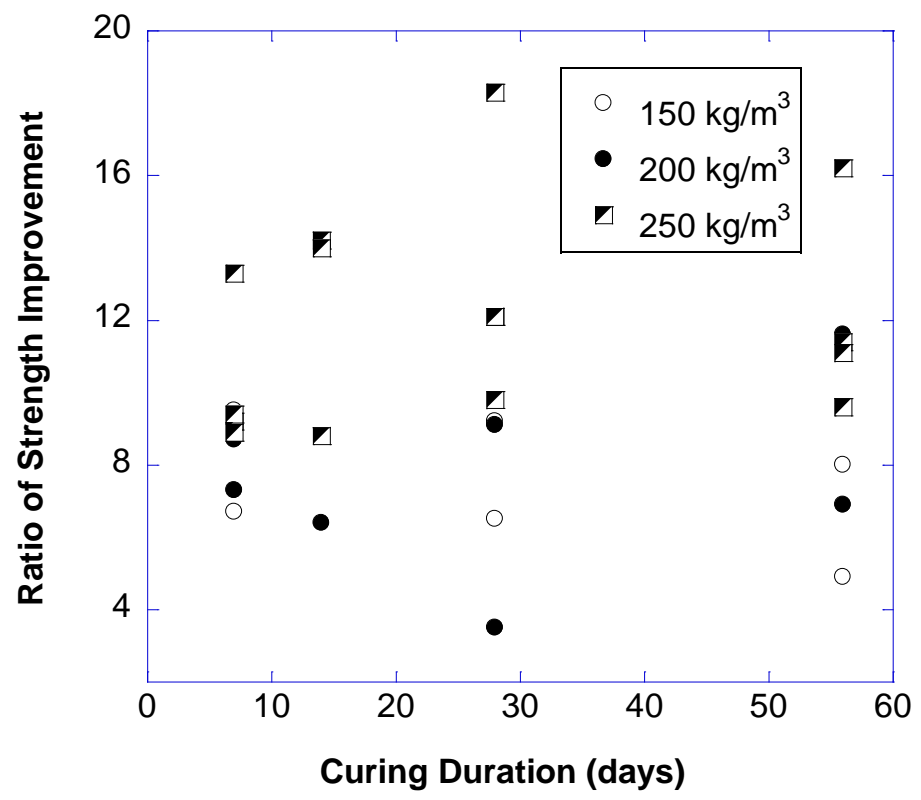

Figure 4-37 Ratio of improvement vs. curing duration for cement treated organic silty clay

\subsection{Compressibility Behaviour}

\subsubsection{Champlain Sea Clay}

CRS tests were performed on one untreated Kanata clay sample and one cement treated Kanata clay sample with a dosage of $150 \mathrm{~kg} / \mathrm{m}^{3}$ and 7 days of curing. Shear strain rates of $1 \%$ per hour for loading and $0.1 \%$ per hour for unloading was used for both samples. Equations 4-1 was used to calculate the compression index from the void ratio vs. effective stress curve. Figure 4-38 shows the e-log $\mathrm{p}$ curve of the clay samples before and after cement treatment. DMM can significantly reduce the compressibility of Champlain Sea clay. Yield strength, or preconsolidation pressure in undisturbed samples, obtained via Casagrande's method, increased from $160 \mathrm{kPa}$ to $650 \mathrm{kPa}$ for samples after $150 \mathrm{~kg} / \mathrm{m}^{3}$ of cement treatment. Change in void ratio decreased from 1.1 to 0.21 for samples after $150 \mathrm{~kg} / \mathrm{m} 3$ of cement treatment. Compression index $\left(\mathrm{C}_{\mathrm{c}}\right)$ also decreased from 0.67 to 0.11 for samples after $150 \mathrm{~kg} / \mathrm{m} 3$ of cement treatment. More tests are underway to understand the effects of cement dosage and curing time on the compressibility of Champlain Sea clay.

$C_{c}=\frac{e_{1}-e_{2}}{\log P_{2}-\log P_{1}}$

(Equation 4-1) 
Excess pore pressure of the sample was plotted against the effective stress of the sample (Figure 4-39). The fluctuation of excess pore pressure corresponds to stress changes effective stress. This trend agrees with past findings by Hwang (2006). With an increase in external load, pore water will not have enough time to dissipate from the Champlain Sea clay samples, which leads to a build up in excess pore pressure with increasing external load. The permeability of the sample decreases with increasing load (Figure 4-40). Adding cement to the sample reduces the permeability of the sample.

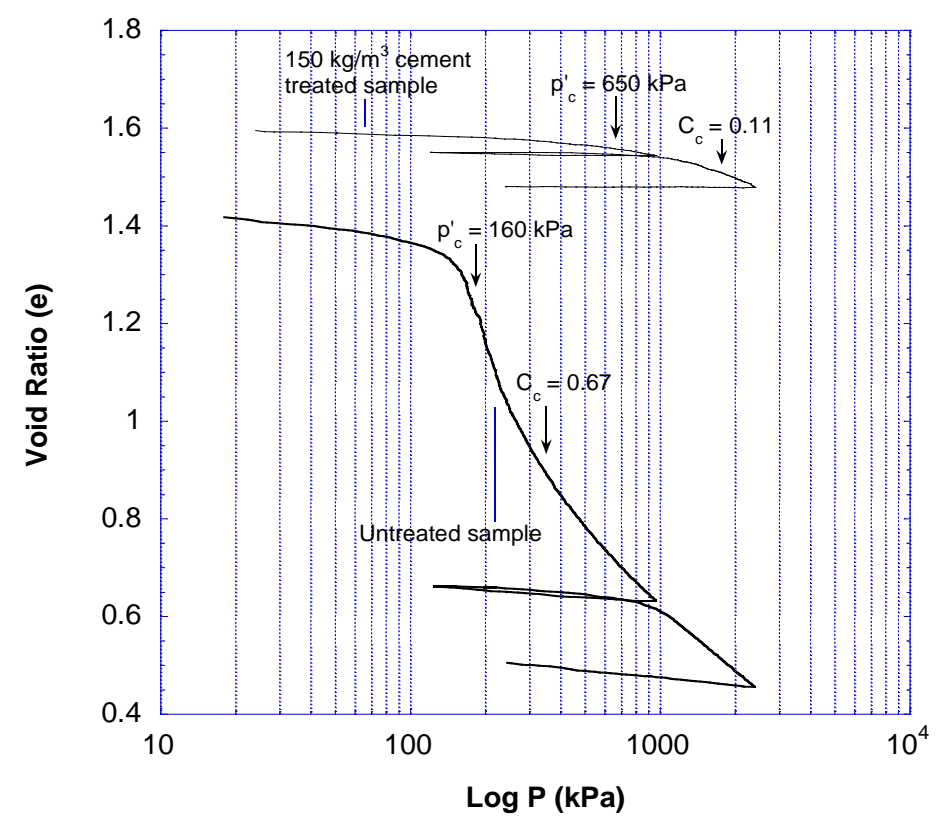

Figure 4-38 e-log $P$ curve for untreated and cement treated Kanta clay 


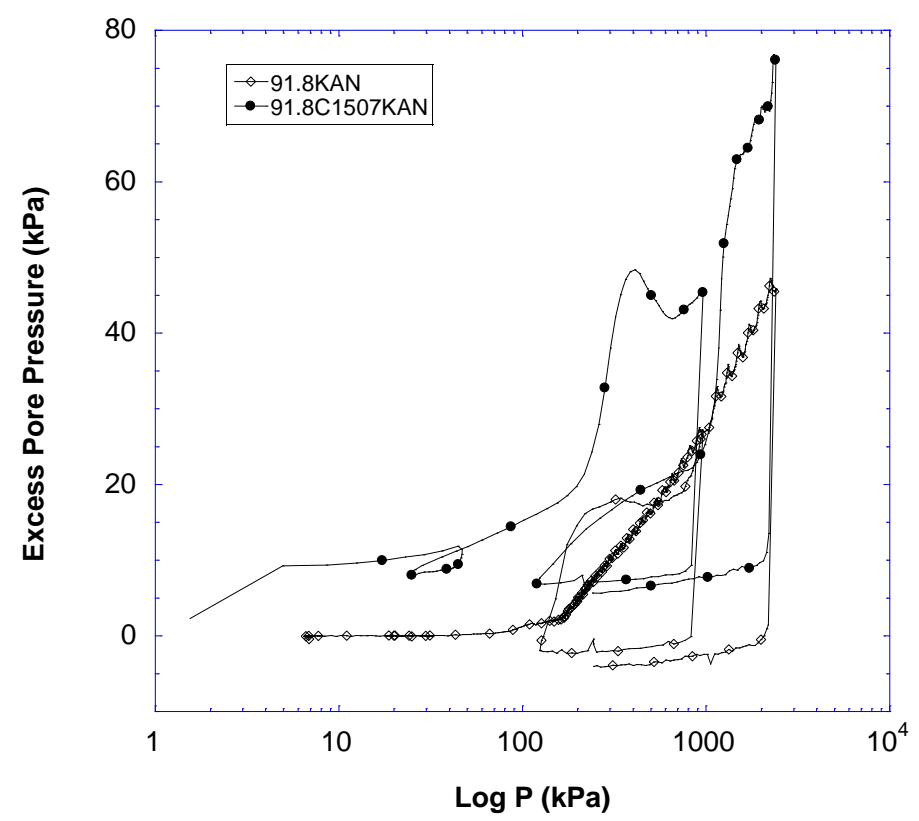

Figure 4-39 Excess pore pressure vs. effective stress for cement treated Champlain Sea clay

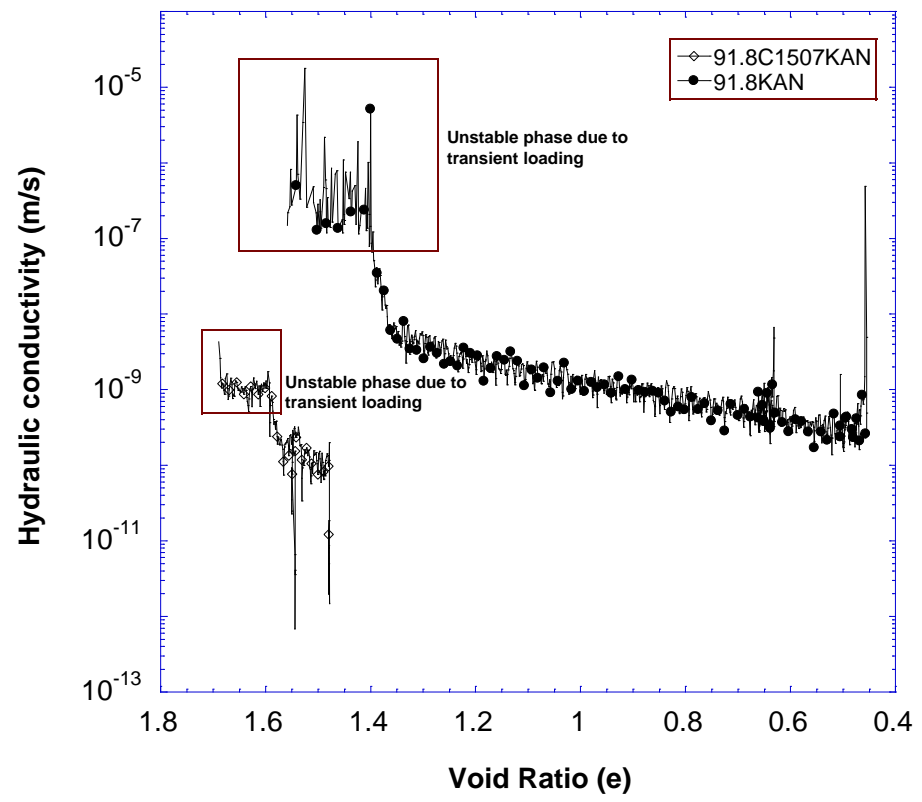

Figure 4-40 Hydraulic conductivity vs. void ratio for cement treated Champlain Sea clay 


\subsubsection{Organic Silty Clay}

A series of constant rate of strain (CRS) tests were conducted for cement treated samples at a dosage of $150 \mathrm{~kg} / \mathrm{m}^{3}, 200 \mathrm{~kg} / \mathrm{m}^{3}$, and $250 \mathrm{~kg} / \mathrm{m}^{3}$ and cured at 7 days. The CRS tests was also performed for a lime treated samples at a dosage of $100 \mathrm{~kg} / \mathrm{m}^{3}$ and cured at 7 days and untreated samples. The untreated clayey organic silt to silty clay sample was taken from Shelby tube while other samples were clayey silt with organics to organic silt from test pit. For GTPC150, GTPC200, and GTPC250, the CRS device's linear variable differential transformer (LVDT) sensor experienced a position error. The LVDT's physical slot may have been obstructed during the test. Thus, the data curves displayed a large compression in void ratio without any change in effective stress. Therefore, data curves were modified to represent the most accurate portions of the data. Figure 4-41 to Figure 4-46 show the e-log p curves for cement treated, lime treated, and untreated soil samples respectively. Compression index $\left(\mathrm{C}_{\mathrm{c}}\right)$, recompression index $\left(\mathrm{C}_{\mathrm{R}}\right)$, and effective compression index $\left(\mathrm{C}^{\prime}{ }_{\mathrm{c}}\right)$ were interpreted from the e $\log \mathrm{P}$ curves. Equations 3-1,3-2, and 3-3 were used to calculate $\mathrm{C}_{\mathrm{c}}, \mathrm{C}_{\mathrm{R}}$, and $\mathrm{C}^{\prime}{ }_{\mathrm{c}}$ respectively.

$C_{\mathrm{R}}=\frac{e_{1}-e_{2}}{\log P_{2}-\log P_{1}}$

(Equation 4-2)

$C^{\prime}{ }_{c}=\frac{C_{\mathrm{c}}}{1+e_{0}}$

(Equation 4-3)

Where $\mathrm{e}_{1}$ and $\mathrm{e}_{2}$ are the respective void ratios on the second loading stage of the e $\log \mathrm{P}$ curves, and $\mathrm{P}_{1} \& \mathrm{P}_{2}$ are the respective applied loads.

Cement dosages of $150 \mathrm{~kg} / \mathrm{m}^{3}$ and $200 \mathrm{~kg} / \mathrm{m}^{3}$ did not significantly decrease compression index for clayey silt with organics to organic silt. $\mathrm{C}_{\mathrm{c}}$ for both cement treated samples remained close to untreated clayey silty with organics to organic silt. With an increased cement dosage of $250 \mathrm{~kg} / \mathrm{m}^{3}$, compression index was reduced from 0.28 to 0.22 . Lime treated samples also had a reduced compression index of 0.23 from 0.28 . The increased dosage could represent a minimum threshold for clayey silt with organics to organic silts. $250 \mathrm{~kg} / \mathrm{m}^{3}$ cement treated clayey silt also had the highest UCS, which corresponds to the improved compressibility behaviour of the sample. 


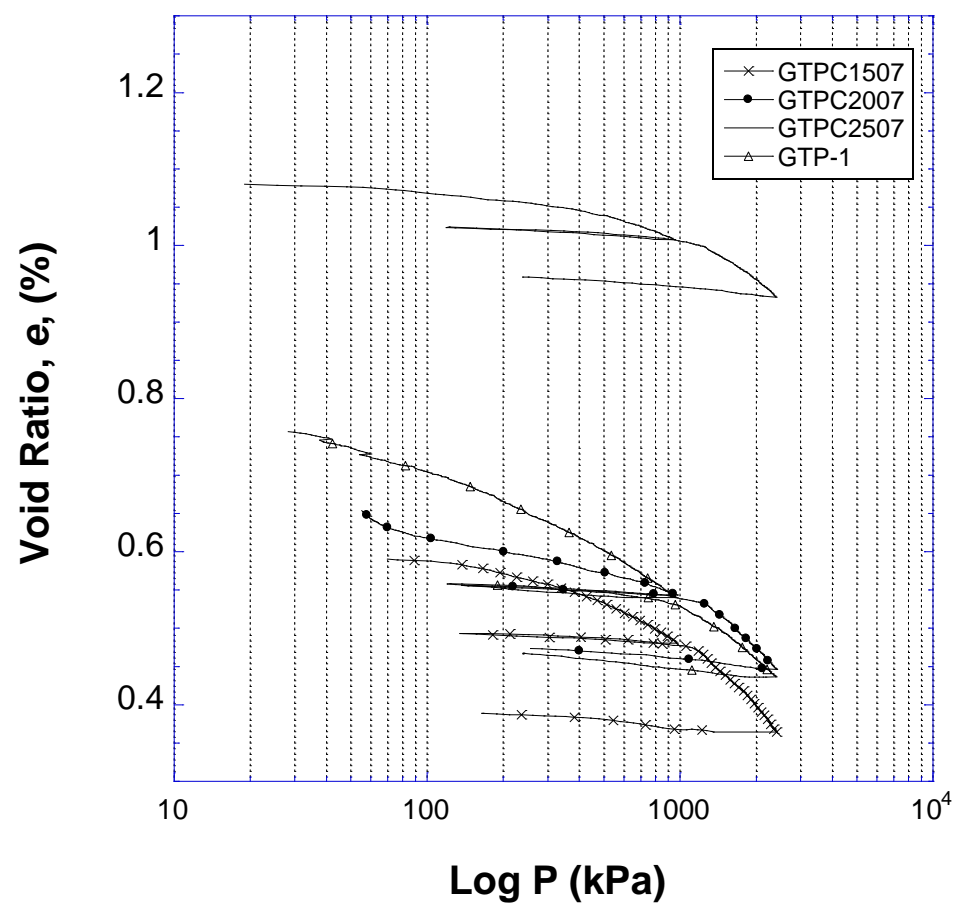

Figure 4-41 e vs. $\log p$ for cement treated clayey silt with organics to organic silt and untreated clayey silt with organics to organic silt

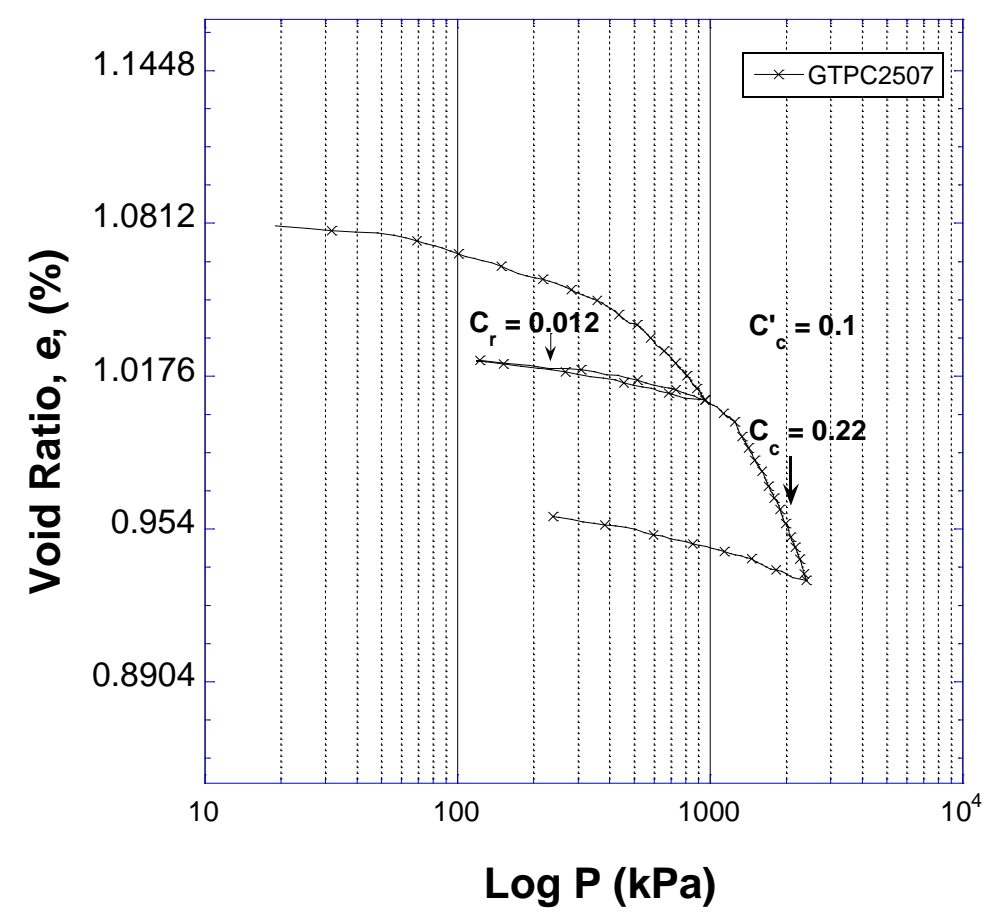

Figure 4-42 Compression index and recompression index for $250 \mathrm{~kg} / \mathrm{m}^{3}$ cement treated clayey silt with organics to organic silt 


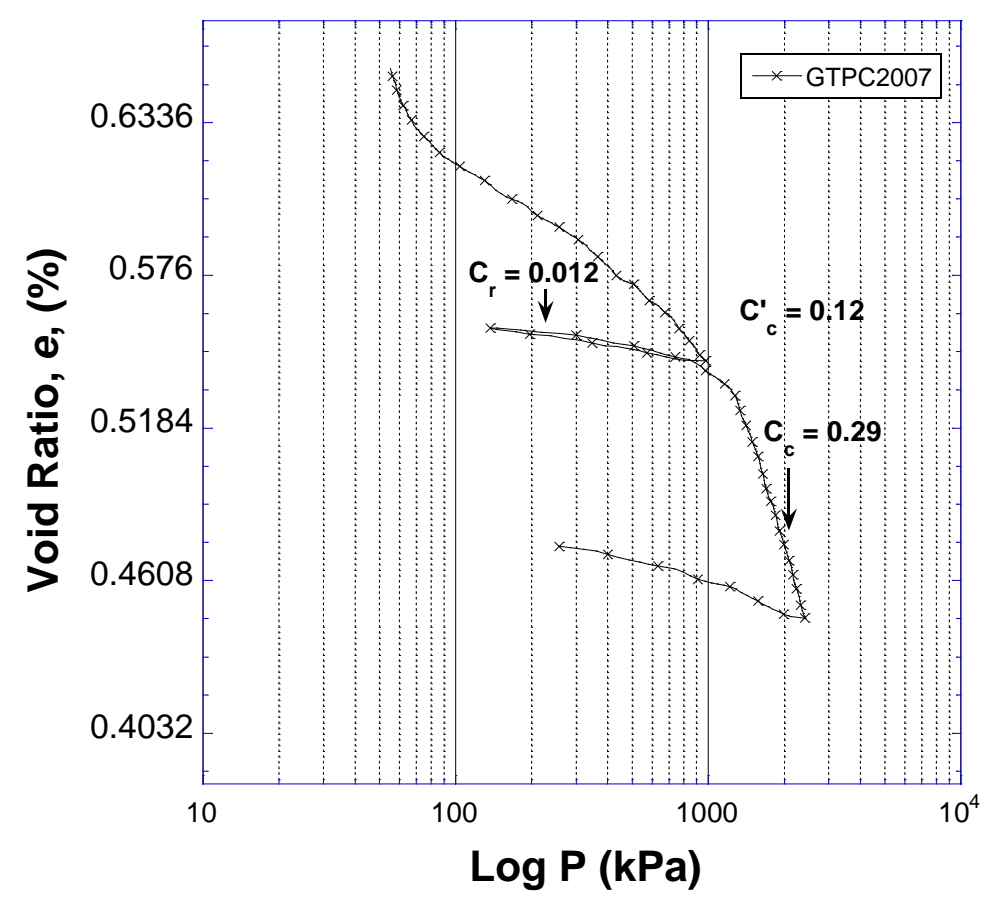

Figure 4-43 Compression index and recompression index for $200 \mathrm{~kg} / \mathrm{m}^{3}$ cement treated clayey silt with organics to organic silt

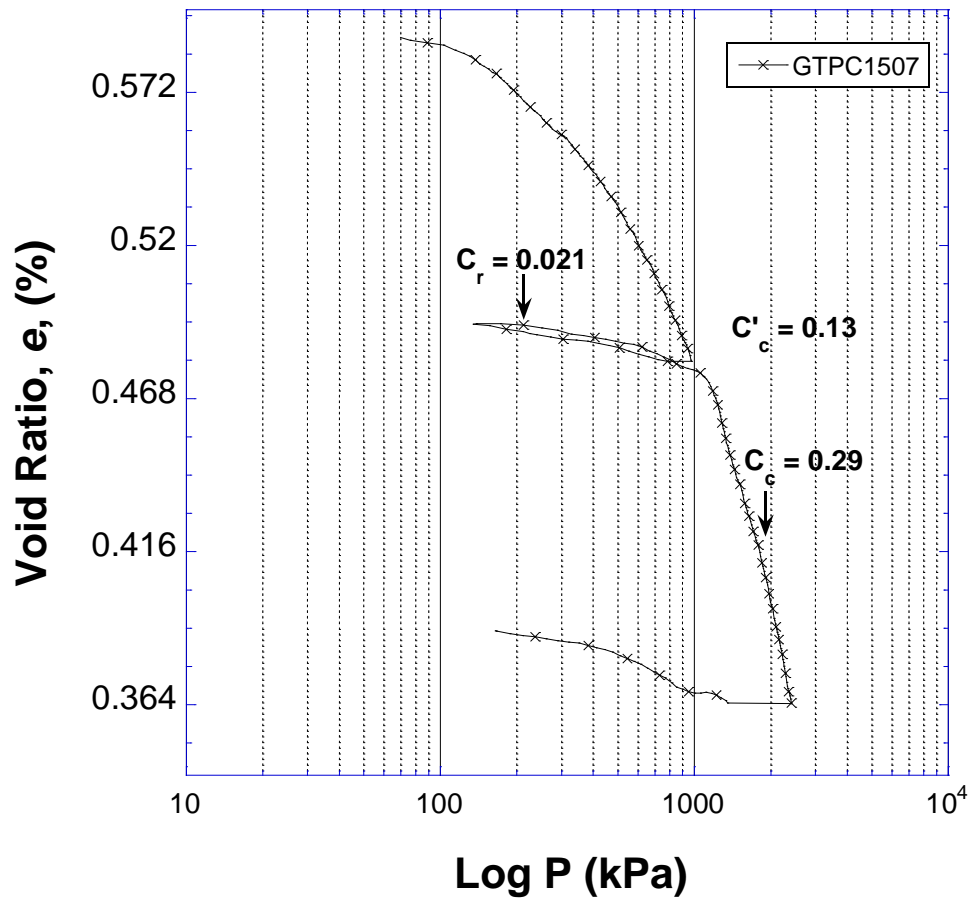

Figure 4-44 Compression index and recompression index for $150 \mathrm{~kg} / \mathrm{m}^{3}$ cement treated clayey silt with organics to organic silt 


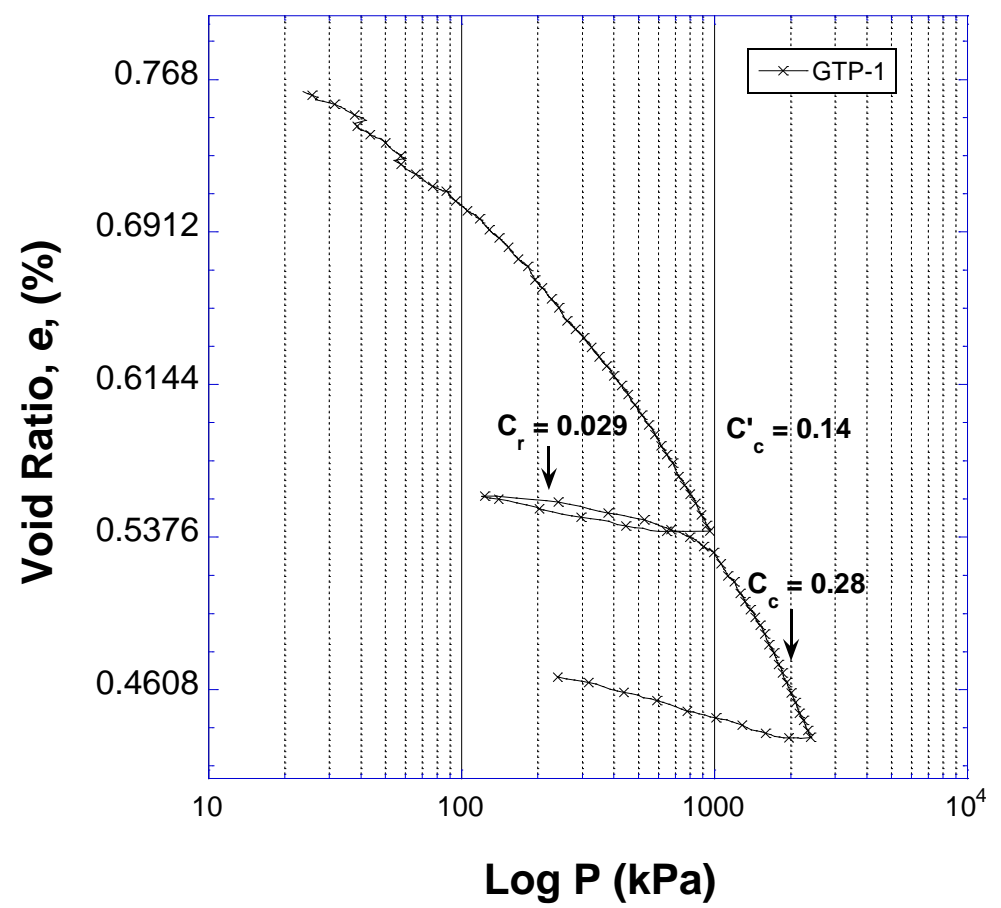

Figure 4-45 Compression index and recompression index for untreated clayey silt with organics to organic silt sample

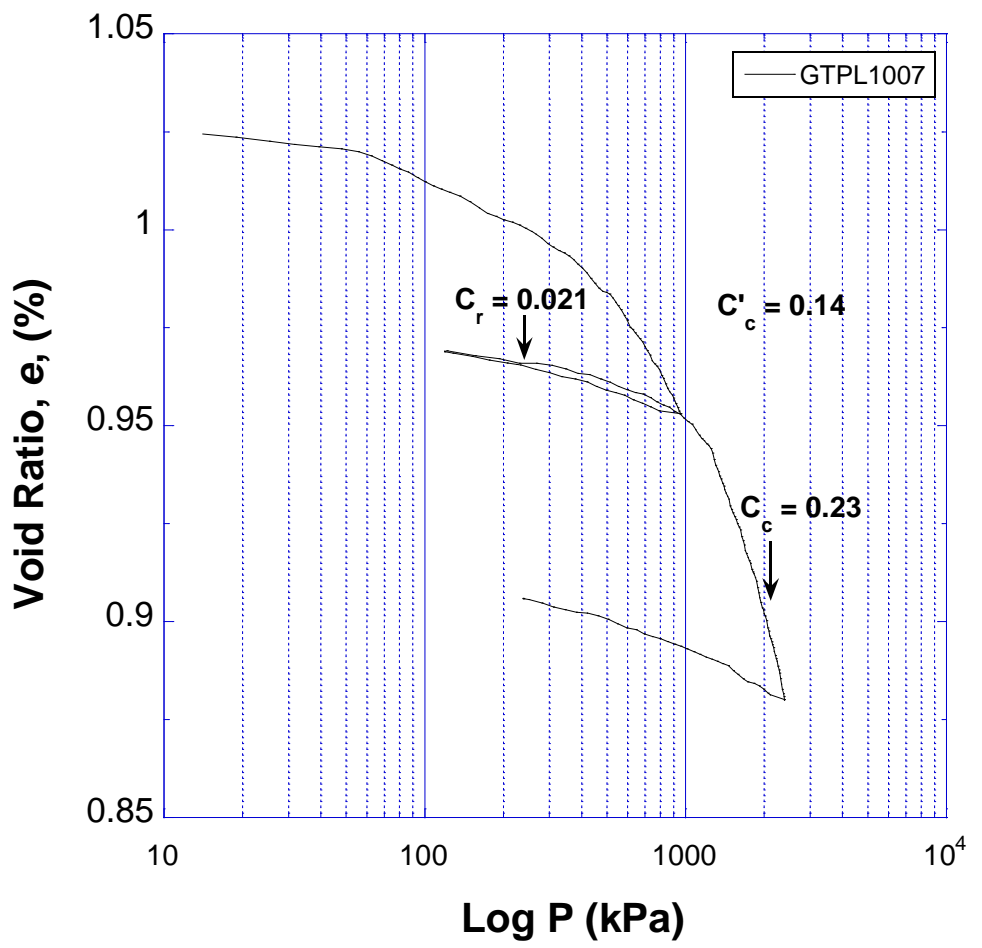

Figure 4-46 Compression index and recompression index for lime treated clayey silt with organics to organic silt 
The excess pore pressure vs. effective stress plot demonstrate the loading and unloading behaviour of the soil sample in respect to its pore water pressure. Increase in excess pore pressure corresponds to increase in effective stress (Figure 4-47) for cement treated and untreated clayey silt. The excess pore pressure curve highlights the loading profile of $150 \mathrm{~kg} / \mathrm{m}^{3}$ cement treated sample with a drastic decrease after the first loading is complete. Increase in excess pore pressure also represent consolidation taking place without enough time for water to dissipate. However, for $250 \mathrm{~kg} / \mathrm{m}^{3}$ cement treated clayey silt, the increase in excess pore pressure was very small throughout the loading and unloading stages. The small increase in excess pore pressure could be contributed by the low water to cement ratio of the sample, low compressibility, and improper seating mechanism.

The hydraulic conductivity of the cement treated clayey silt was plotted against its change in void ratio throughout the consolidation process. For $250 \mathrm{~kg} / \mathrm{m}^{3}$ cement treated clayey, an increase in void ratio corresponds to reduction in hydraulic conductivity, which agrees with Hwang (2006)'s findings on the compressibility behaviour of clay. The closure of voids with increasing load naturally leads to lower hydraulic conductivity. For $200 \mathrm{~kg} / \mathrm{m}^{3}$ cement treated clayey silt, a small reduction in hydraulic conductivity was observed with increasing void ratio. However, the magnitude of the change in hydraulic conductivity was much smaller. Untreated clayey silt also experienced a large reduction in hydraulic conductivity with a similar magnitude to $250 \mathrm{~kg} / \mathrm{m}^{3}$ cement treated sample. Figure 4-48 illustrates hydraulic conductivity in log scale vs. void ratio. The downward trend is obvious in the figure; however, there are streaks of data scatters, which can be contributed by the seating error of the experiment.

\subsection{Summary}

The present chapter discusses the findings from the experimental investigation. First, the stressstrain curves of UCS on untreated samples are presented as the main benchmark result. The influences from binder type, binder dosage, and soil type on UCS are discussed. In addition, other influencing factors are also discussed, including curing duration, sample density, mixing method, sample height to diameter ratio, water content. Furthermore, the relationships between elastic modulus and UCS and the strength increase ratio with binder dosage are also discussed in this chapter. In the next chapter, numerical modelling will be introduced and DMM's effect to reduce embankment settlement will be examined. 


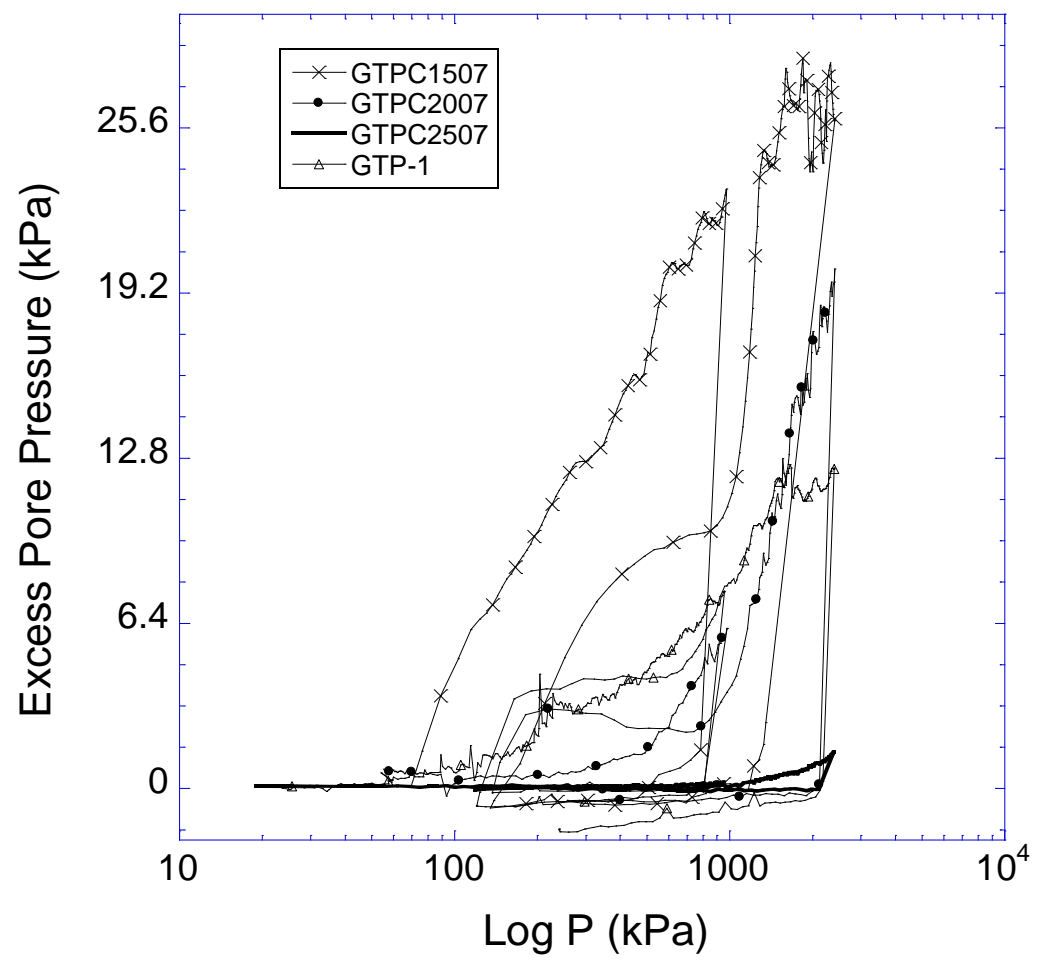

Figure 4-47 Excess pore pressure vs. effective stress for cement treated clayey silt

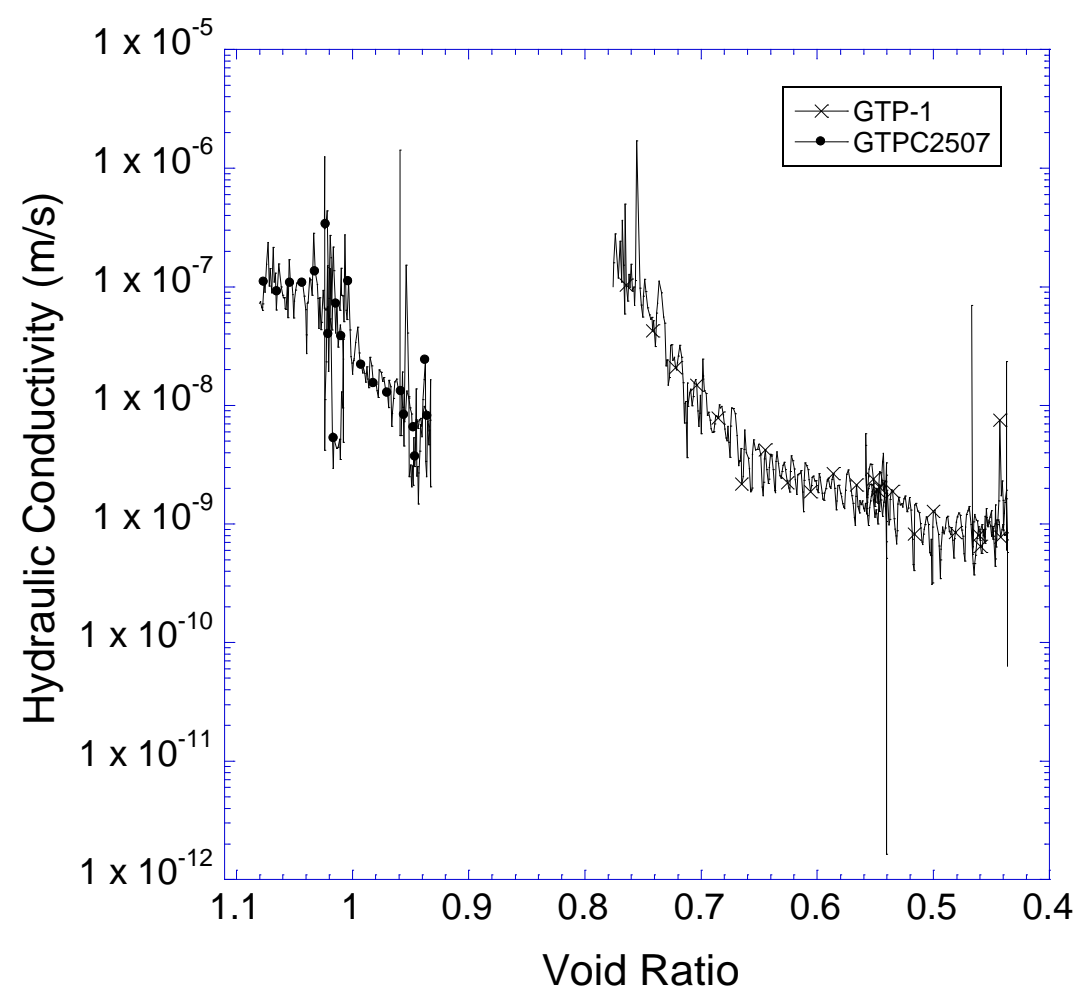

Figure 4-48 Log hydraulic conductivity vs. void ratio for cement treated clayey silt 


\section{NUMERICAL ANALYSIS OF DMM IN ONTARIO SOILS}

\subsection{Introductions}

This chapter will first introduce the concept of finite element method (FEM). The Modified CamClay model, which was used to simulate the behaviour of Champlain Sea clay undergoing a load, will be introduced. Next, a case study of using deep mixing method to improve soft clayey deposit in Japan is examined. A 2D model was also constructed in Plaxis 2D to verify the repeatability of result reported by the researchers. Using the verified model, a sensitive Champlain Sea clay ground profile is modelled and used to predict the reduction in settlement after applying DMM.

\subsection{Finite Element Method}

Finite element method (FEM) is a numerical method used to solve complex engineering and mathematics problem. It breaks down a complex structure, machine, or system into simple and solvable elements. These elements, which can be lines, bars, beams, triangles, and quadrilaterals, can be solved efficiently and assembled together as a global solution for the complex structure. The elements are known as nodes and are reconnected to comprise the solution.

The biggest difference between FEM and analytical solutions is the exactness of the answer. The nature of the FEM solution aims to approximate the final answer without sacrificing efficiency and overall scope; however, FEM cannot obtain the exact solutions of the structure or system. Analytical solutions can obtain exact solutions for loading problems; however, it is nearly impossible to solve complex mechanical loading problems without assumptions and approximations. For example, a commercial aircraft's wing experiences uplift, tension, compression, torsion, and many other complex forces. To calculate wing material's ability to withstand these forces, 3D FEM models can be assembled to simulate force reactions due to uplift.

FEM's origins can be traced back to the 1940s when Hrennikoff and McHenry proposed a lattice of line elements for the solutions of stresses in continuous solids. From then, other researchers started to develop the system of solutions. The flexibility method was proposed by Levy in 1947, who later proposed stiffness method to analyze complex but redundant aircraft wing (Logan, 2007). Boeing and Lockheed Martin greatly facilitated the early development of FEM due to FEM's power to greatly enhance aircraft design capabilities. FEM's initial application was largely 
confined to the aerospace industry. Computers were expensive devices back in the 1950s; therefore, only large corporations with deep pockets could afford to utilize this technology. Four scholars, J.H. Argyris, R.W.Clough, H.C. Martin, and O.C.Zienkiewicz were the spear heads in popularizing FEM and applying it to other fields of engineering and science (ColoradoU, 2016). A collaboration paper between Turner, Cloug, Martin, and Topp drafted in 1956 was widely recognized as the start of FEM. Clough and Martin, who were junior professors at their respective universities at the time, spent "faculty internship" at Boeing in 1952 to learn FEM from Turner. Clough later went on to form a dedicated research group at University of California Berkley to introduce FEM into civil engineering applications.

While FEM started as a classical mechanics solution, it can also be used to solve non-structural problems. Zienkiewicz and Cheung solved torsion of a shaft, fluid flow, and heat conduction in 1965 (Logan, 2007), which opened FEM's application for thermal loading and conduction. Geotechnical engineers use FEM to solve soil reaction and behaviours due to vertical load, lateral earth pressure, pore water pressure, and long term compression.

In 2D FEM modelling for geotechnical engineering, soil models are often idealized in either plane strain scenario or axi-symmetric scenario (Potts and Zdravkovic, 2001). Plane strain scenario takes a side cross section out of the soil structure and assumes an infinite extension in the $\mathrm{z}$ direction; deformation is only allowed in the $\mathrm{x}$ and $\mathrm{y}$ direction. Axi-symmetric scenario takes a slice out of the cylindrical soil structure and assumes the cross section can rotate on an invisible axis by $360^{\circ}$; the soil structure can deform in $\mathrm{x}$ and $\mathrm{y}$ direction. Constitutive models which are tailored specifically for the physical behaviour of different kinds of soil under external forces, have been created to address challenges encountered for each type of soil. This include the Mohr-Coulomb model, Cam-Clay model, Linear-Elastic model, Modified Cam-Clay model, Soft Soil model, and many more. Modified Cam-clay model was used to simulate the behaviour of the clay and the next section will discuss the model in detail.

\subsection{Modified Cam-Clay model}

Modified Cam-Clay model (MCC), developed by Roscoe and Burland in 1968, is an improve me nt upon the original Cam-Clay model developed by Roscoe and Schofield in 1963. MCC model relies on the critical state theory to predict key behaviours of the soil under compression, consolidation, 
and many other external stress states. The aspects of soil behaviour include strength of the soil, compressibility of the soil, and the critical state of the soil (Rocscience, 2017). MCC model is one of the most widely used soil model because of its ability to simulate drained behaviour and soil volume change accurately, especially for fine grained soil (Munda et al., 2014).

Under the criticial state soil mechanics, MCC describes the state of the soil is described by three parameters: the effective mean stress (p'), the deviatoric stress (q), and the specific volume (v). Each parameter can be calculated as described below:

$p^{\prime}=\frac{1}{3}\left(\sigma_{1}^{\prime}+\sigma_{2}^{\prime}+\sigma_{3}^{\prime}\right)$

(Equation 5-1)

Where $\sigma_{1}^{\prime}, \sigma_{2}^{\prime}$, and $\sigma_{3}^{\prime}$ are principal stresses.

$q=\frac{1}{\sqrt{2}} \sqrt{\left(\sigma_{1}^{\prime}-\sigma_{2}^{\prime}\right)^{2}+\left(\sigma_{2}^{\prime}-\sigma_{3}^{\prime}\right)^{2}+\left(\sigma_{3}^{\prime}-\sigma_{1}^{\prime}\right)^{2}}$

(Equation 5-2)

$v=1+e$

(Equation 5-3)

Where e is the void ratio of the soil.

When a soft fine grained soil undergoes consolidation in MCC under isotropic loading condition and perfectly drained condition, the resulting specific volume vs. stress relationship is a linear one (Rocscience, 2017). Figure 5-1 illustrates the loading and reloading behaviour of the soil. A straight virgin compression line can be seen from point $a$ to $b$ and the recompression curves can been from point $\mathrm{c}$ to $\mathrm{b}$. 


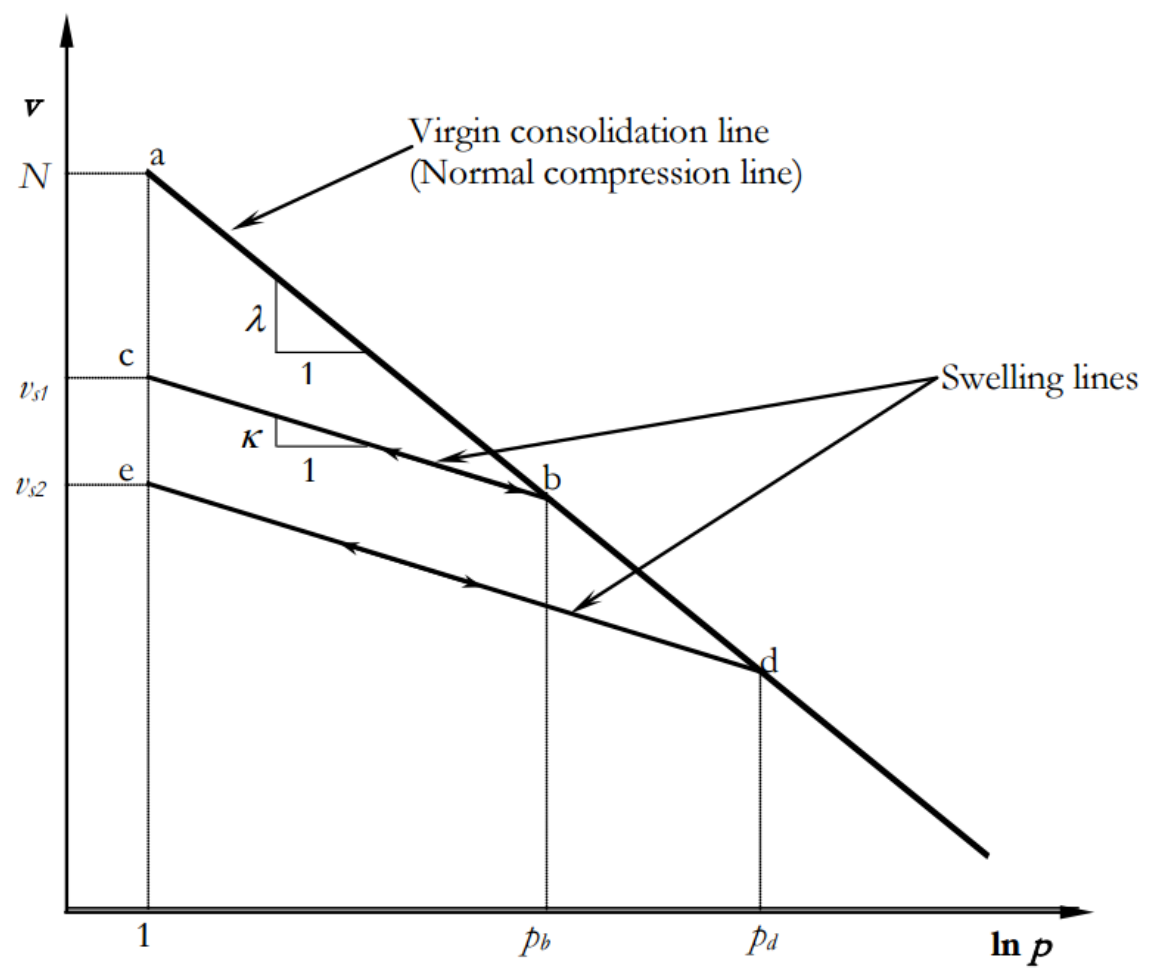

Figure 5-1 MCC model's consolidation profile for soft soil under is otropic conditions (Rocscience, 2017)

To implement the MCC model, material properties from the soil sample will be required as input parameters. The parameters include: $\lambda$, which is the slope of the virgin consolidation line; $\kappa$, which is the slope of the linear swelling lines; $\mathrm{M}$, which is the slope of the critical state line plotted in p'q plane; $\mathrm{N}$, which is the specific volume of the virgin consolidation line; and $\mu$, which is the Poisson's ratio of the soil (Munda et al., 2004).

The critical state of a soil is described as a state where the soil will continue to shear even without further change in stress or volume. Soils can reach this state of through sustained shearing. A critical state line can be plotted in the p'-q plane where the line intersects the origin and the top of the yield curve. The slope of this line is the material properties $M$, which is required as an input parameter. Figure 5-2 illustrates the biggest difference between Cam-Clay (CC) model and MCC model which is the yield surface. CC model's yield surface is described by a log arc relationship whereas MCC model's yield surface is an ellipse. 


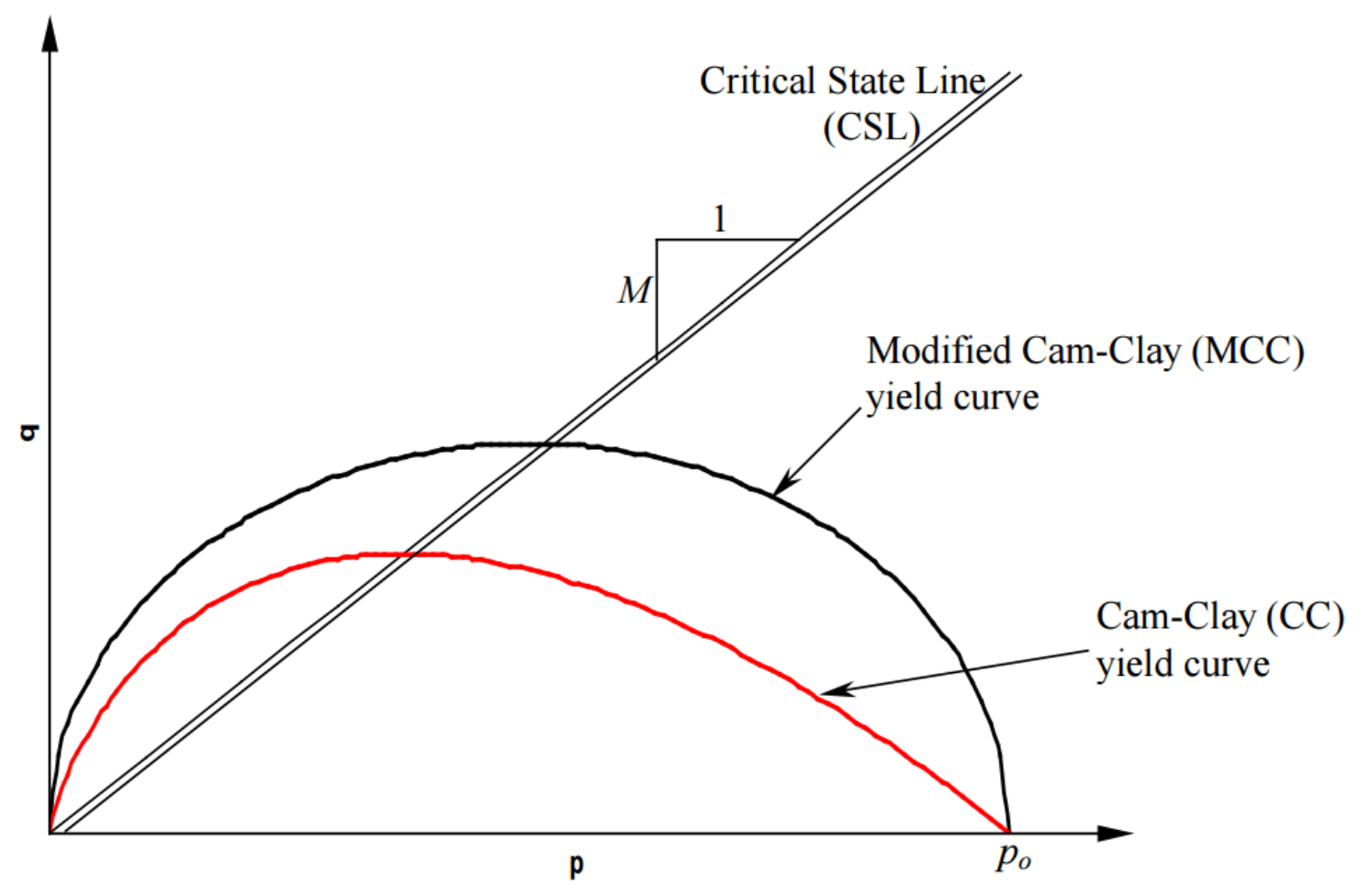

Figure 5-2 Yield curve of Cam-clay model and MCC model

MCC model could adequately predict the drained behaviour of soil under isotropic load. However, MCC model fails to predict the undrained behaviour of the soil.

\subsection{Plaxis 2D Model based on Chai}

A 2D FEM model was created based on Chai et al. (2015)'s work on simulating settlement reduction of an highway embankment in Japan using DMM. Chai's model was selected because the project is applied for the ground improvement of a highway embankment, which is the most common application for DMM. The geological condition of the site consists largely of Ariake clay which is a marine clay. The similarity in soil type would also help us to create an accurate model for Champlain Sea clay. Finally, Chai et al. (2015) compared field measured data with simulated settlement data, which allows a comprehensive evaluation of the model's viability.

\subsubsection{Model Geometry and Input Parameters}

The embankment is constructed as a plane strain case with only half of the embankment modeled due to symmetry. The embankment can only deform in $\mathrm{x}$ and y directions and no deformation in the $\mathrm{z}$ direction can occur. The embankment has a height of 6.5 meters, a top width of 6 meters, and 
a bottom width of 18.6 meters based on the construction of the dam. To avoid the boundary effect, the soil model was constructed with a depth of 35 meters and a width of 85 meters. The large width allows the model to run without being affected by the proximity of the closed boundary. Soil cement piles are drawn as separate soil layers with the properties wished in place. This technique allows the soil-cement to be better represented in the model. The interface between columns and soil layers was modeled as rigid layers with $R_{\text {inter }}$ of 1.0. The soil-cement columns have a length of 8.5 meters and a width (diameter) of 1.2 meters. The center to center column distance was set as 1.9 meters following the construction specification. A total of 9 columns were constructed in this model. Each soil layer was created by using the MCC model. Embankment fill's properties were created using the Mohr-Coulomb model and the soil-cement columns were created using the Linear-Elastic model. Figure 5-3 illustrates the geometry of the model input and Table 5-1 displays the input parameters for the soil layer, embankment fill, and the cement-soil column. Chai et al. (2015) estimated the modulus of the soil cement columns at 100 times the unconfined compressive strength (UCS). The tested UCS at the site was around $1000 \mathrm{kPa}$; therefore, Chai used a modulus of $100000 \mathrm{kPa}$. Hydraulic boundaries were applied to the left vertical side to prevent water flow under the embankment (Figure 5-4). Drainage is allowed on top, bottom, and side of the soil structure.

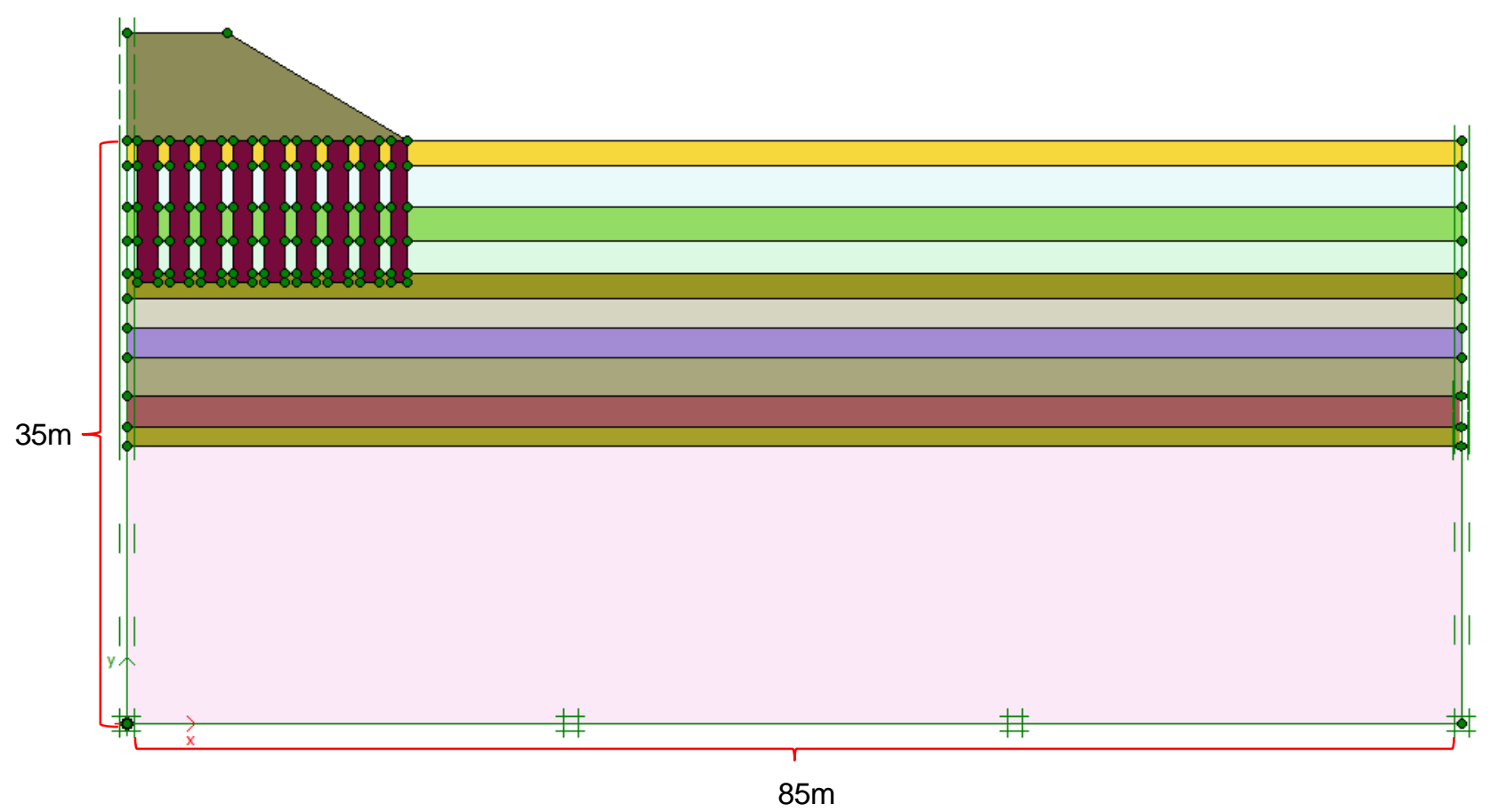

Figure 5-3 Geometric model of the plane strain model created on Plaxis 2D based on Chai et al. (2015) 


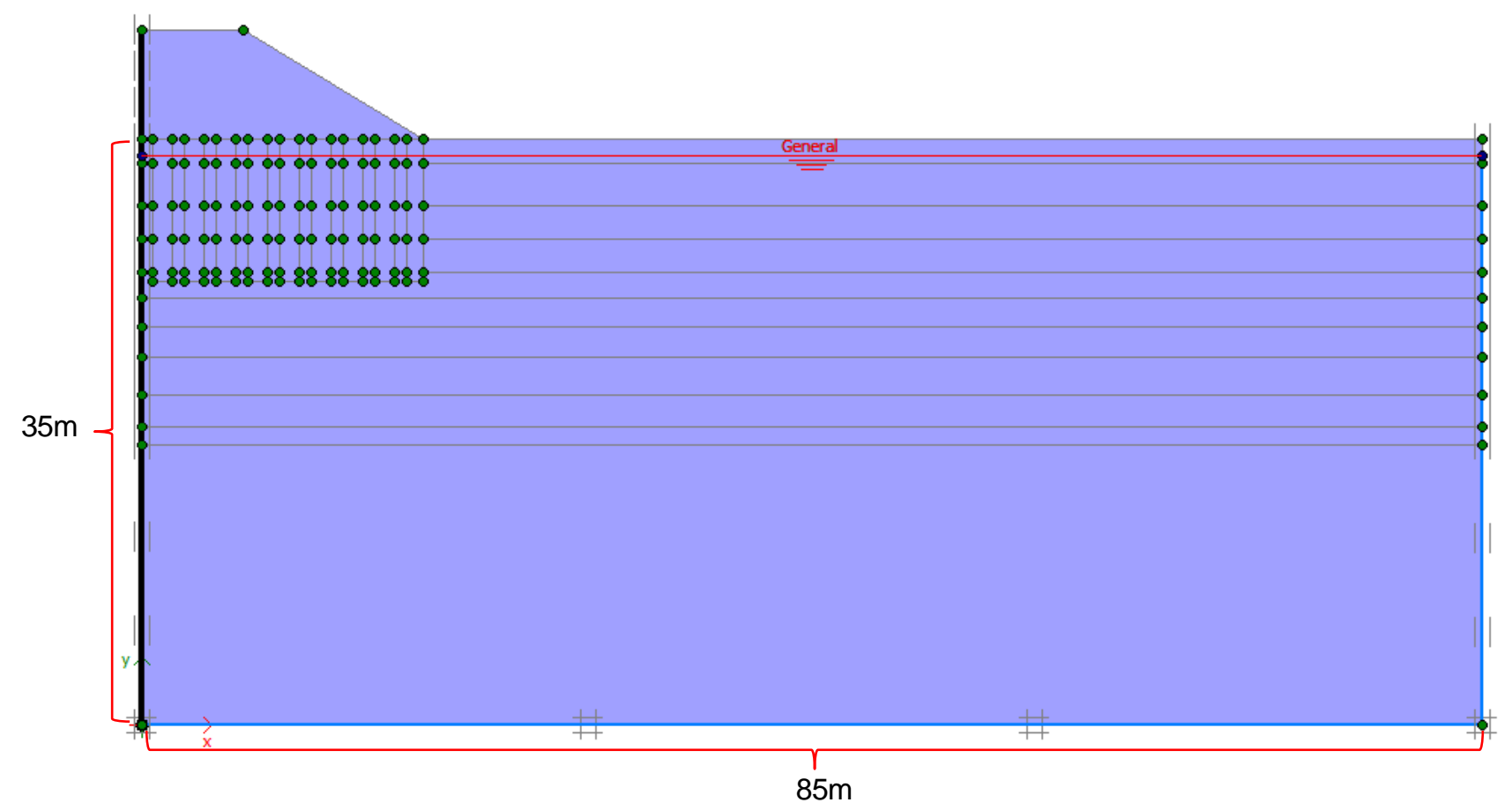

Figure 5-4 Hydraulic boundary conditions of the model

Table 5-1 MCC model input parameters for soil layers, embankment fill, and soil-cement column

\begin{tabular}{|c|c|c|c|c|c|c|c|c|c|c|c|c|c|}
\hline Depth & $\begin{array}{c}\mathbf{E} \\
(\mathbf{k P a})\end{array}$ & $\begin{array}{c}\gamma \\
(k N / m \\
3\end{array}$ & $\mathbf{e}_{\mathbf{o}}$ & $\begin{array}{c}\lambda(\mathbf{c} \\
\mathbf{k P a})\end{array}$ & $\kappa\left(\varphi^{0}\right)$ & $\mathbf{v}$ & $\mathbf{M}$ & $\begin{array}{c}K_{x}\left(10^{-4}\right. \\
\text { m/day })\end{array}$ & $\begin{array}{l}K_{y}\left(10^{-4}\right. \\
\text { m/day })\end{array}$ & $\mathbf{C}_{\mathbf{k}}$ & $\begin{array}{l}\text { interface } \\
\text { cohesion }\end{array}$ & $\mathbf{K}_{\mathbf{o}}$ & OCR \\
\hline $0-1.5$ & - & 16 & & & & & & & & & & 0.6 & \\
\hline $1.5-4$ & - & 13.4 & 3.1 & 0.87 & 0.087 & 0.15 & 1.2 & 6.6 & 4.4 & 1.6 & 0.001 & 0.6 & 2.5 \\
\hline $4-6$ & - & 14 & 2.81 & 0.87 & 0.087 & 0.15 & 1.2 & 5.3 & 7.9 & 1.4 & 0.001 & 0.5 & 1.5 \\
\hline $6-8$ & - & 14.1 & 2.58 & 0.58 & 0.058 & 0.15 & 1.2 & 5.6 & 8.4 & 1.3 & 0.001 & 0.5 & 1.1 \\
\hline $8-9.5$ & - & 14.3 & 2.49 & 0.43 & 0.043 & 0.15 & 1.2 & 4.6 & 6.9 & 1.2 & 0.001 & 0.5 & 1 \\
\hline $\begin{array}{l}9.5- \\
11.2\end{array}$ & - & 18 & 1.1 & 0.15 & 0.015 & 0.15 & 1.4 & 25 & 25 & 0.6 & 0.001 & 0.5 & 1 \\
\hline Sand & 25000 & 18 & 0.8 & 20 & 35 & 0.1 & - & 250 & 250 & 0.4 & 1.000 & 0.5 & 1 \\
\hline $\begin{array}{l}13- \\
15.3\end{array}$ & - & 18 & 0.8 & 0.12 & 0.012 & 0.15 & 1.4 & 25 & 25 & 0.4 & 0.001 & 0.5 & 1 \\
\hline $\begin{array}{c}15.3- \\
17.2\end{array}$ & 25000 & 19 & 0.8 & 20 & 35 & 0.1 & - & 250 & 250 & 0.4 & 1.000 & 0.5 & 1 \\
\hline
\end{tabular}




\begin{tabular}{|c|c|c|c|c|c|c|c|c|c|c|c|c|c|}
\hline $\begin{array}{c}17.2- \\
18.3\end{array}$ & - & 19 & 0.7 & 0.12 & 0.012 & 0.15 & 1.4 & 25 & 25 & 0.4 & 0.001 & 0.5 & 1 \\
\hline $\begin{array}{c}18.3- \\
35\end{array}$ & 20000 & 19 & 0.7 & 20 & 35 & 0.1 & - & 250 & 250 & 0.4 & 1.000 & 0.5 & 1 \\
\hline Emban & & & & & & & & & & & & & \\
\hline $\begin{array}{c}\text { kment } \\
\text { Fill }\end{array}$ & 1000 & 19 & - & 20 & 35 & 0.4 & - & 4.6 & 6.9 & 1.2 & 1.000 & 0.5 & - \\
\hline $\begin{array}{c}\text { Cement } \\
\text {-soil } \\
\text { column }\end{array}$ & $\begin{array}{c}10000 \\
0\end{array}$ & 19 & 2.745 & - & - & 0.15 & - & 5.5 & 6.9 & 1.4 & 1.000 & 0.5 & 1 \\
\hline
\end{tabular}

After creating the geometric model, the mesh of the model was generated via the "generate mesh" input in Plaxis 2D. The model uses a plane strain scenario with a 15 node triangular elements to construct the mesh. Figure 5-5 presents the generated mesh of the model. A refined coarseness was targeted towards the upper soil layer around the columns to better visualize the soil-cement interaction.

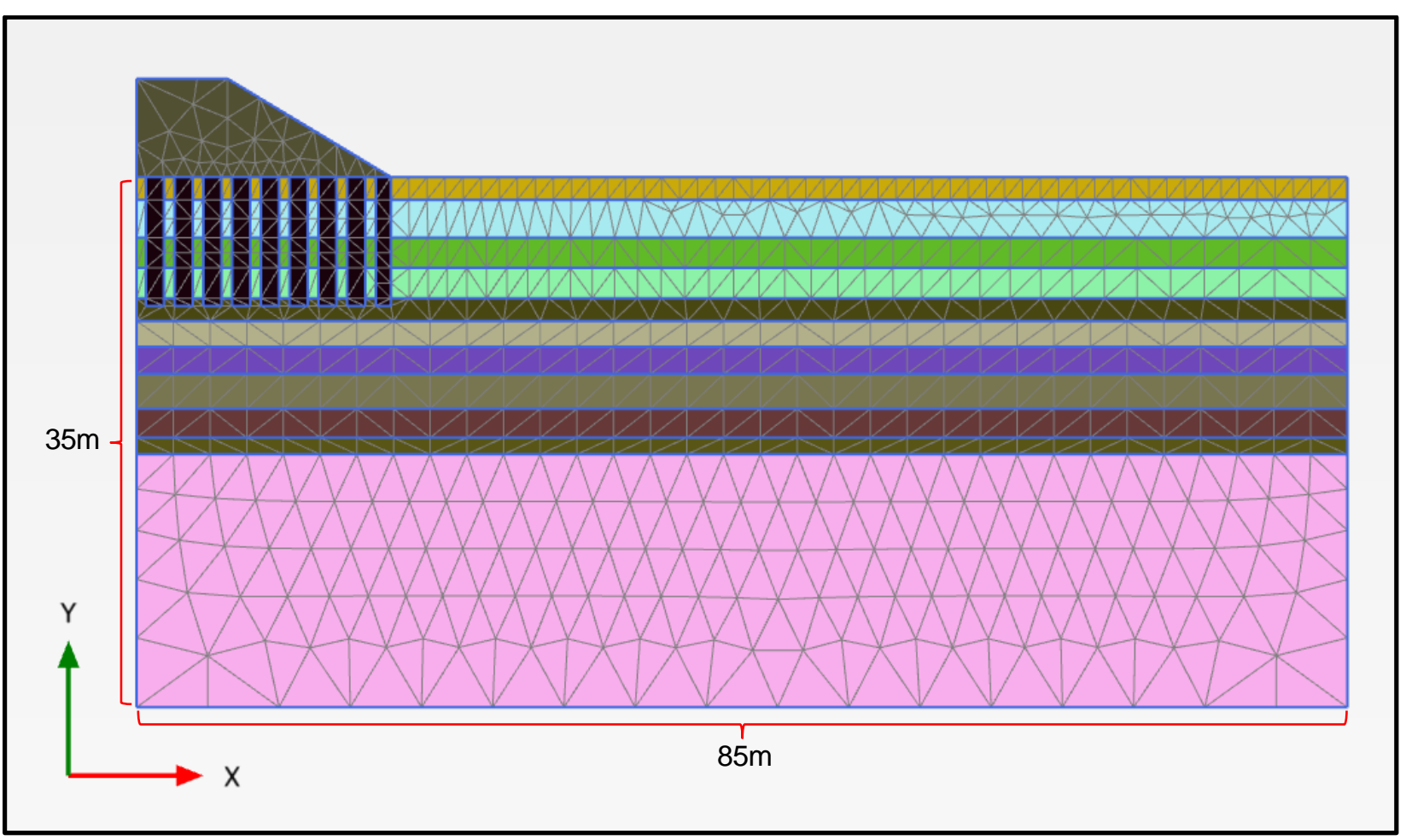

Figure 5-5 Generated mesh of the 2D model 


\subsubsection{Calculations and Results}

In the calculations step, three stages are implemented to allow primary consolidation settlement to take place. The first stage is the initial $\mathrm{K}_{0}$ procedure which generates the initial vertical effective stress and horizontal effective stress for the model (Plaxis, 2010). Pore water pressure is also generated based on the phreatic level. $\mathrm{K}_{0}$ procedure utilizes Jaky's empirical formula to obtain $\mathrm{K}_{0}$ value for normally consolidated clay (Plaxis, 2010):

$K_{0}=1-\sin \varphi$

Where $\varphi$ is the soil's friction angle. For over consolidated clay, overconsolidation ratio (OCR) and pre-overburden pressure (POP) need to implemented into the modified formula.

$K_{0}=(1-\sin \varphi) O C R^{\sin \varphi}$

During the initial stage, the soil layers and soil-cement columns are activated, but the not the embankment fill. Next, the consolidation stage (EPP) is implemented to simulate primary consolidation settlement after the construction of the embankment. Consolidation stage will allow the excess pore water pressure to be dissipated over a predetermined period. In this stage, the embankment structure is activated along with pore water pressure calculations. Staged construction is selected as the loading input with a time interval of 100 days. Pore pressure tension cut-off, additional steps, and max steps saved were all set at default values. Incremental multipliers and total multipliers were also set at default values.

Furthermore, another consolidation stage is implemented. However, the loading input was changed to minimum pore pressure instead. This stage aims to run the model until the internal pore pressure reaches a minimum value, acting as a stop condition for primary consolidation.

After the first consolidation stage, the soil model had a maximum deformation value of $0.65 \mathrm{~m}$. This value was increased to $0.79 \mathrm{~m}$ after the second stage of consolidation. The increase in deformation could be due to the prolonged consolidation (Figure 5-6).

The displacement vs. time profile for the top of column and bottom of the column agrees with Chai et al. (2015)'s results. Chai et al. (2015) also showed that simulated settlement comes close to measured settlement; however, condition of the embankment loading procedure was not specified by Chai. Therefore, minor differences between Chai's model and the model presented can lead to 
minor discrepancies. Hydraulic boundary was also sealed both vertical sides of the model while they may need to be open. The accuracy of the model can be improved by incorporating a more sophisticated stage construction approach. The embankment could be constructed in different layers and settlement could be allowed for longer periods of time. Figure 5-7 presents the displacement vs. time profile simulated by Plaxis 2D and measured data at the site by Chai et al. (2015).

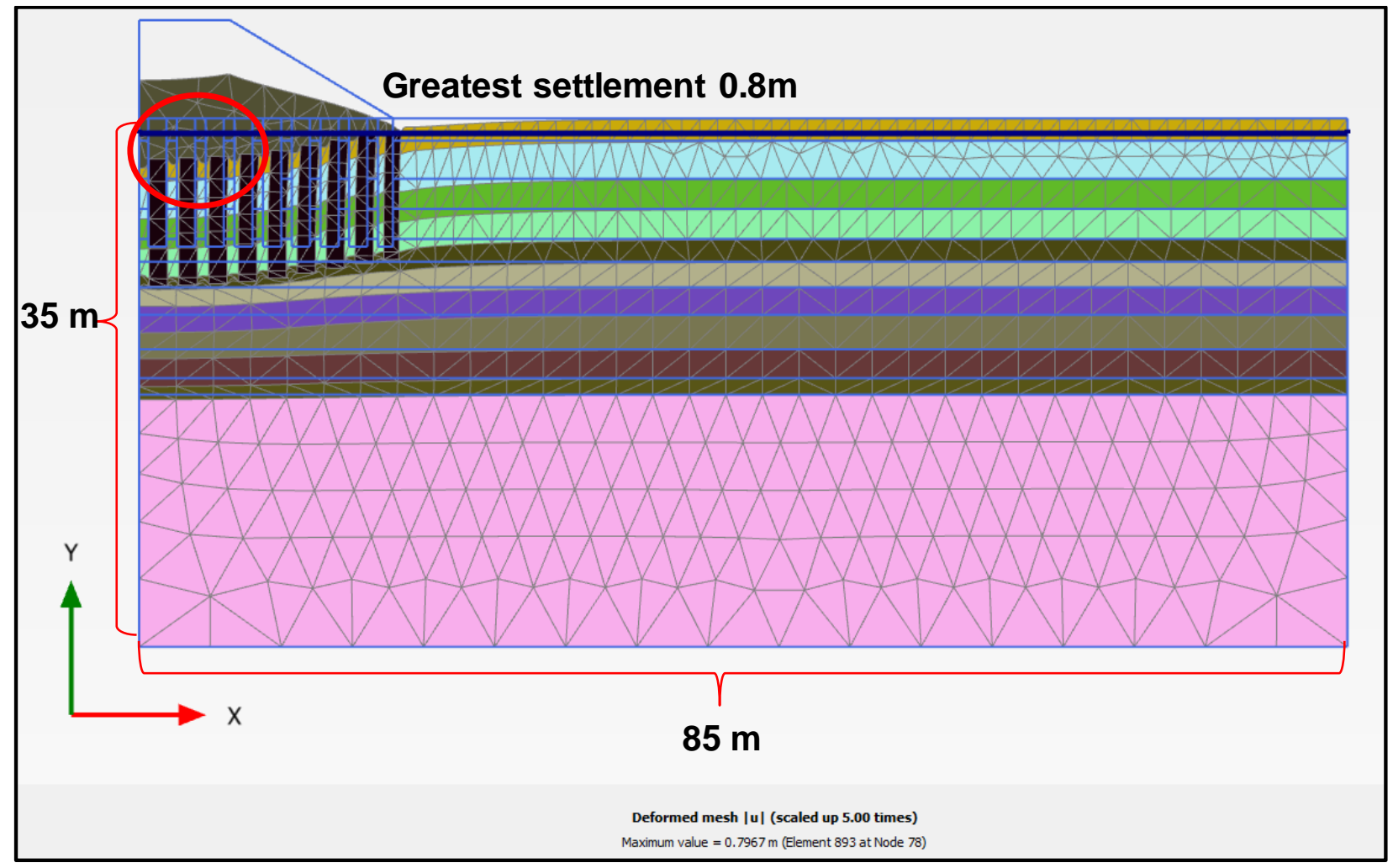

Figure 5-6 Deformed soil mesh after minimum pore water pressure stage 


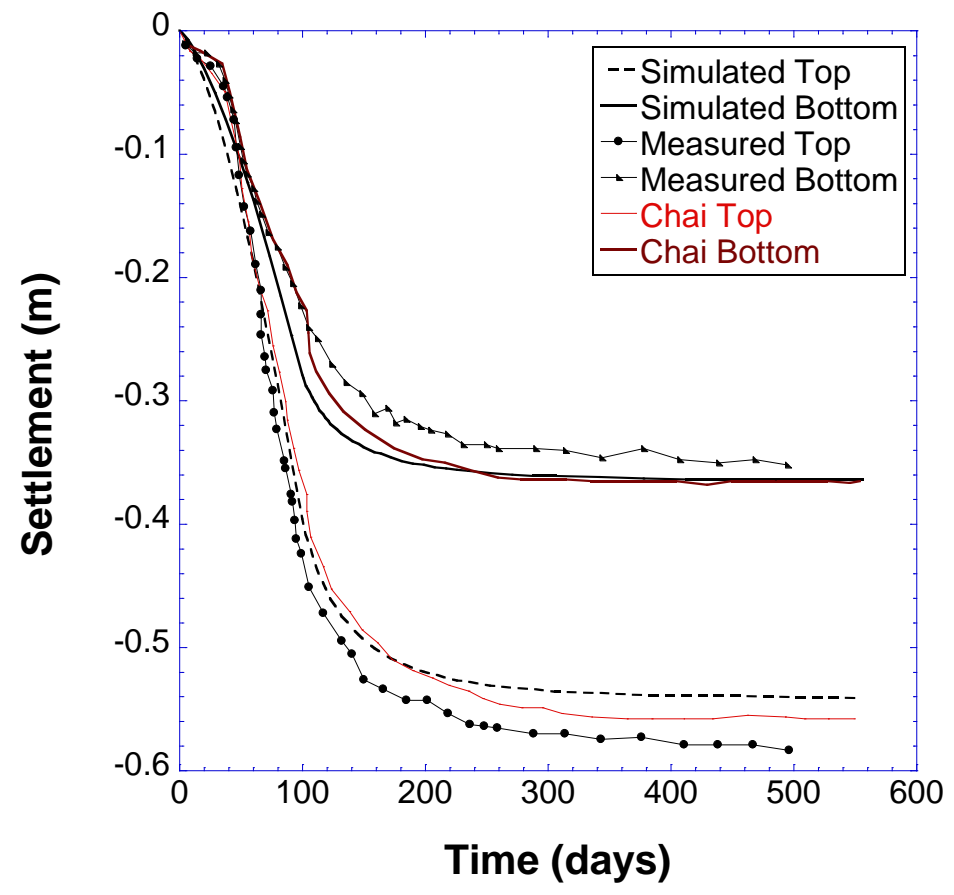

Figure 5-7 Displacement vs. time graph for Plaxis 2D simulated result and measured result

\subsection{Plaxis 2D Model based on Champlain Sea Clay from Arnprior}

After verifying the usability of the Plaxis $2 \mathrm{D}$ model, the model was used to simulate embankment settlement on a sensitive Champlain Sea clay profile with and without applying DMM. The comparative study will be able to illustrate the effectiveness of using DMM to decrease structure settlement and compressibility.

\subsubsection{Model Geometry and Input Parameters}

The soil profile was based on a local geotechnical investigation in Arnprior, Ontario (Shi, 2016). Sensitive Champlain Sea clay were modelled and divided into upper clay and lower clay. Upper clay is classified as soil found above 32 meters below ground and lower clay is classified as soil below 32 meters below ground. Upper clay often has higher inherent moisture content and lower undrained shear strength compared to lower clay. Both upper clay and lower clay have high sensitivity. Table 5-2 presents the input parameters for the soil profile, and Table 5-3 presents the input parameters for the soil-cement column. 
Table 5-2 Soil and cement column input parameters

\begin{tabular}{cccccccccc}
\hline Depth $(\mathbf{m})$ & $\gamma\left(\mathbf{k N} / \mathbf{m}^{3}\right)$ & $\mathbf{P}_{\mathbf{c}}(\mathbf{k P a})$ & $\boldsymbol{\lambda}$ & $\mathbf{\kappa}$ & $\mathbf{M}$ & $\mathbf{K}_{\mathbf{0}}$ & $\mathbf{v}$ & $\mathbf{k}(\mathbf{m} / \mathbf{d a y})$ & $\mathbf{e}_{\mathbf{0}}$ \\
\hline 0 to 2 & 16 & 210 & 0.28 & 0.008 & 1.17 & 1.4 & 0.4 & $5.18 \mathrm{E}-05$ & 2.15 \\
2 to 5 & 16 & 200 & 0.28 & 0.008 & 1.17 & 1.4 & 0.4 & $5.18 \mathrm{E}-05$ & $2.02-2.15$ \\
5 to 10 & 16 & 111 & 0.28 & 0.008 & 1.17 & 1.4 & 0.4 & $5.18 \mathrm{E}-05$ & $1.89-2.02$ \\
10 to 15 & 16 & 155 & 0.28 & 0.008 & 1.17 & 1.1 & 0.4 & $5.18 \mathrm{E}-05$ & $1.77-1.89$ \\
15 to 20 & 16 & 199 & 0.28 & 0.008 & 1.17 & 1.1 & 0.4 & $5.18 \mathrm{E}-05$ & $1.64-1.77$ \\
20 to 32 & 16 & 274 & 0.28 & 0.008 & 1.17 & 0.8 & 0.4 & $5.18 \mathrm{E}-05$ & $1.39-1.64$ \\
32 to 42 & 19 & 371 & 0.08 & 0.008 & 1.14 & 0.8 & 0.4 & $5.18 \mathrm{E}-05$ & $1.30-1.39$ \\
42 to 52 & 19 & 459 & 0.08 & 0.008 & 1.14 & 0.8 & 0.4 & $5.18 \mathrm{E}-05$ & $1.25-1.30$ \\
52 to 70 & 19 & 557 & 0.08 & 0.008 & 1.14 & 0.8 & 0.4 & $5.18 \mathrm{E}-05$ & $1.10-1.25$ \\
\hline
\end{tabular}

Table 5-3 Input parameters for soil-cement column

\begin{tabular}{cccccc}
\hline Depth $(\mathbf{m})$ & $\mathbf{E}(\mathbf{k P a})$ & $\gamma\left(\mathbf{k N} / \mathbf{m}^{\mathbf{3}}\right)$ & $\mathbf{K}_{\mathbf{0}}$ & $\mathbf{v}$ & $\mathbf{e}_{\mathbf{0}}$ \\
\hline $\mathrm{SC}$ column & 100000 & 19 & 0.5 & 0.15 & 1.4 \\
\hline
\end{tabular}

The height of the embankment will follow the dimensions as Chai et al.'s model with a height of 6.5 meters, a top width of 6 meters, and a bottom width of 16.8 meters. The soil layer has a depth of 70 meters and a width of 80 meters. The large model width mitigates possible boundary effect which may influence the results of the simulation. Figure 5-8 presents the embankment model with soil-cement columns. For the model with columns installed, a total of 9 columns are installed. The columns have a length of 8.5 meters, a width (diameter) of 1.2 meters, and a center to center distance of 1.9 meters for each column. The Young's modulus of soil-cement column was 100,000 kPa based on Chai's proposed relationship of 100 times the UCS of the sample. Standard fixities were applied to the soil model along the major nodes.

Next, mesh is generated via the "generate mesh" input. For the soil model without columns, the top clay layers were refined to simulate embankment settlement more accurately. For the model with columns, a similar approach is implemented where the column clusters and the surrounding soil layers were refined. This approach allows the model to simulate the soil-cement interaction with greater accuracy. Figure 5-9 presents the generated mesh of embankment with columns. 


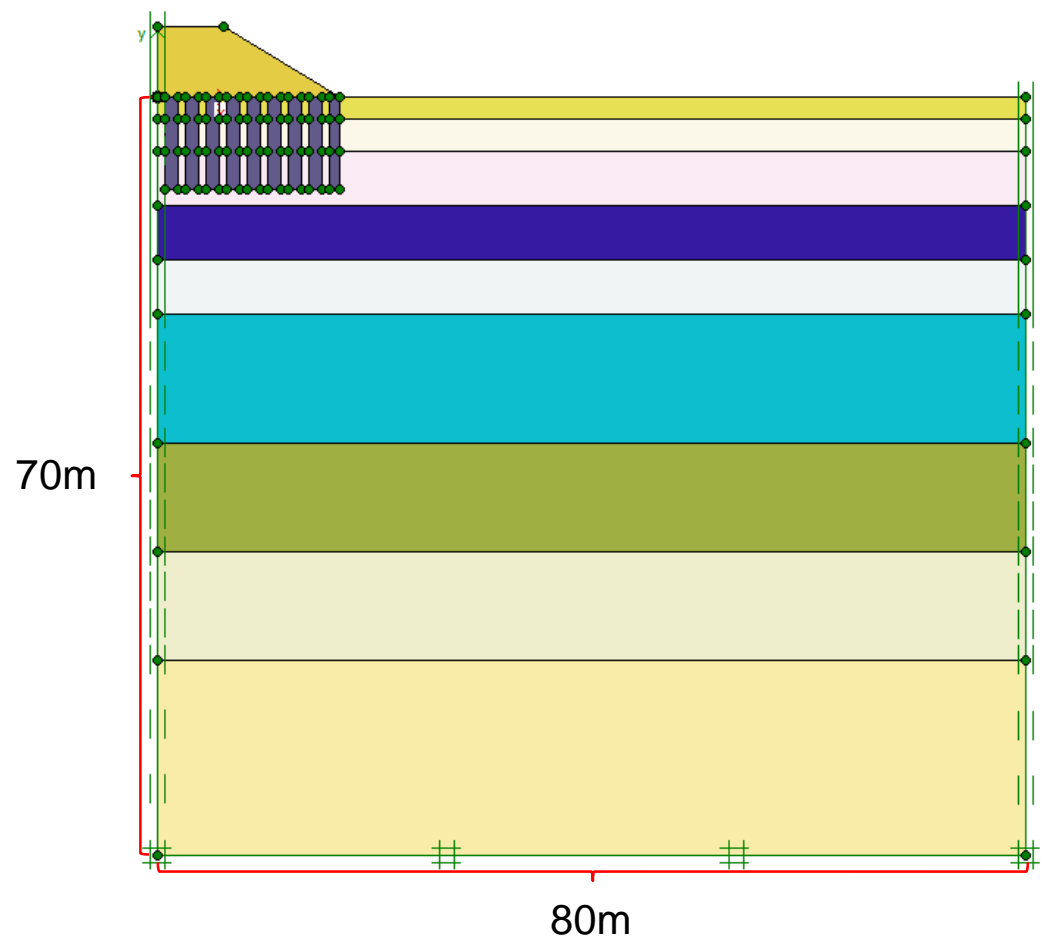

Figure 5-8 Model geometry of highway embankment with soil-cement columns

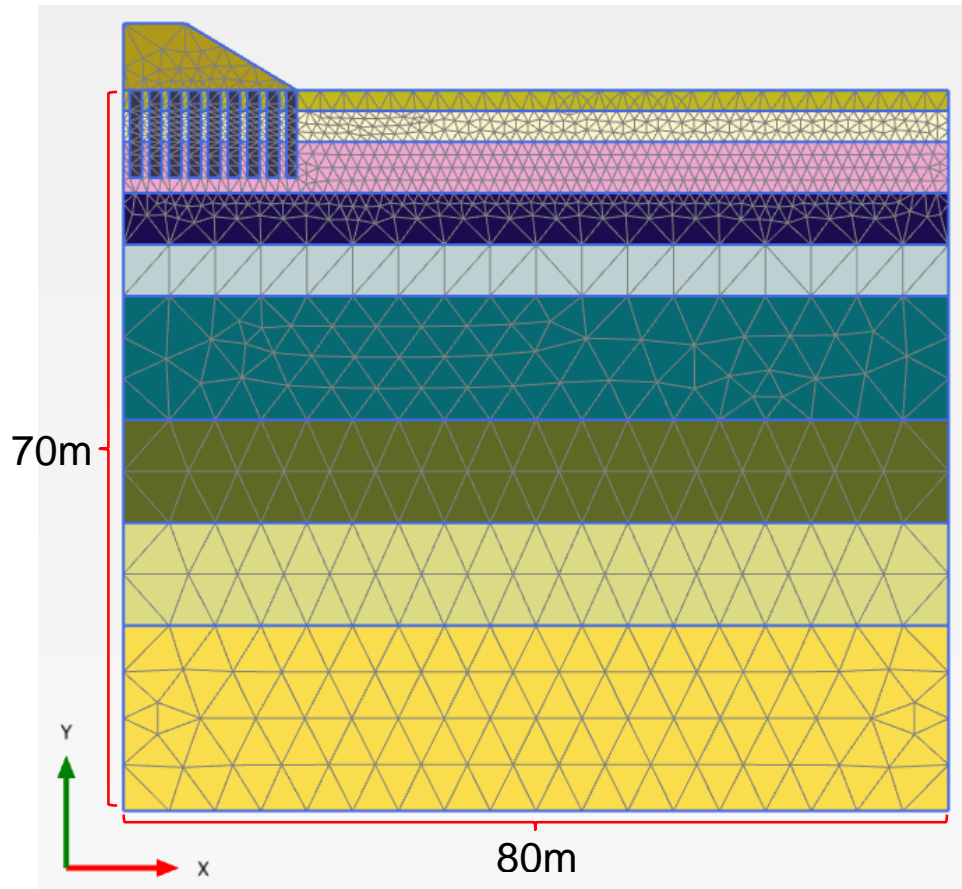

Figure 5-9 Generated mesh of the model with columns 


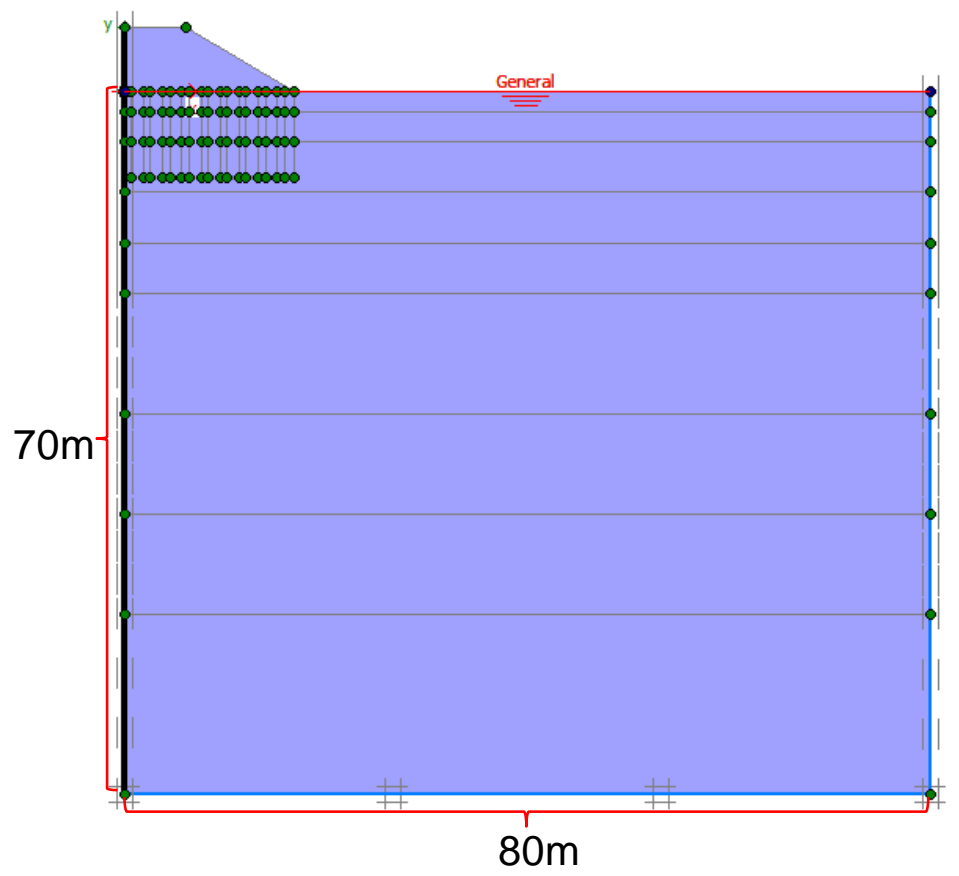

Figure 5-10 Hydraulic boundary condition for the model

\subsubsection{Calculations and Results}

In the calculations window, initial phase was first created to generate the effective vertical stress and horizontal stress. $\mathrm{K}_{0}$ procedure was used in this case. A phreatic level at ground level was assigned; therefore, all soil layers below the ground level was saturated. A flow boundary was implemented to prevent the flow of water on one side of the model (Figure 5-10). Since it is a plane strain model, water flow is not permitted to cross directly the embankment. Full drainage was allowed on the bottom and the exit side of the model. Next, a plastic drained phase was created to allow the embankment to complete its initial settlement. Plastic drained phase was chosen because it allows the model to ignore undrained behaviour within the soil layer (Plaxis, 2010). The plastic drained calculation can also predict the final settlement of the embankment over a long period while ignoring the loading history of the soil (Plaxis, 2010). This is beneficial because sensitive Champlain Sea clay have a large primary settlement phase and a prolonged secondary settlement phase. Modelling each phase of the settlement would yield inaccuracies. 
For embankment without soil-cement columns, a maximum settlement of 2.8 meters was observed with plastic drained calculations. After applying DMM columns, maximum settlement was reduced to 1.26 meters with plastic drained calculations (Figure 5-12). A consolidation (EPP) calculation was attempted for embankment with columns and the settlement value converged with the result of plastic drained calculation after 120 years. Figure 5-11 presents the settlement vs. time profile of the Champlain Sea clay with DMM piles.

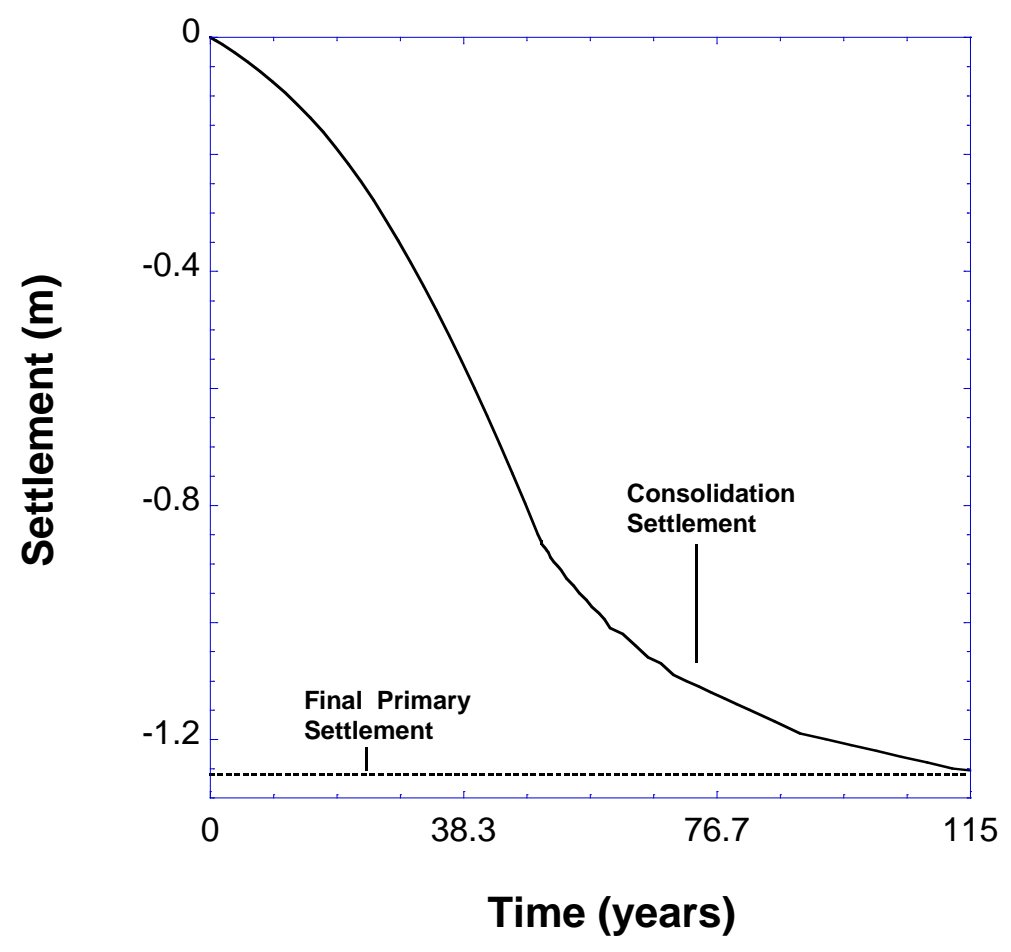

Figure 5-11 Settlement vs. time profile for simulated Champlain Sea clay with DMM piles 

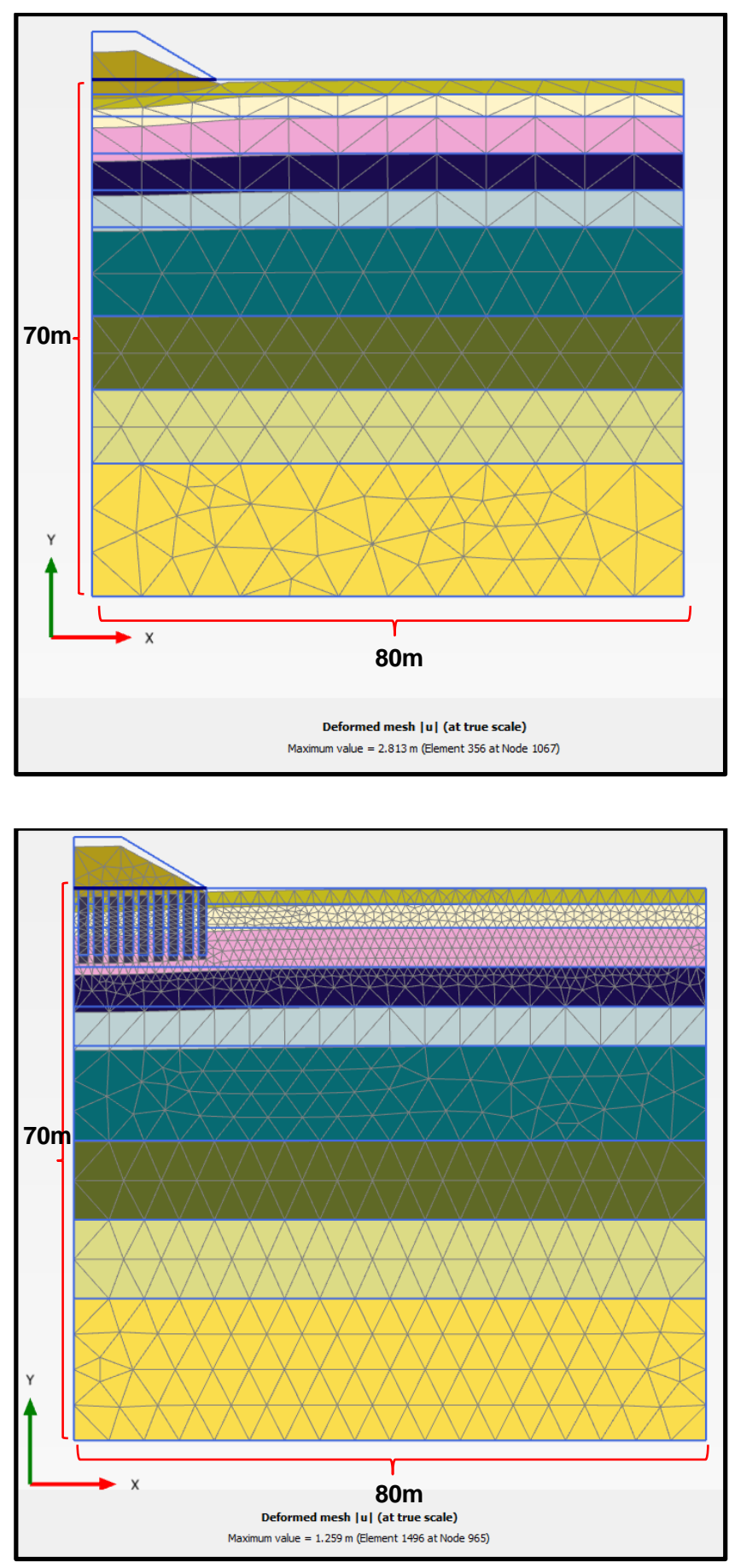

Figure 5-12 Settlement profile of the embankment without DMM piles (top) and with DMM piles (bottom) 


\section{SUMMARY AND CONCLUSIONS}

\subsection{Introductions}

In this study, an experimental investigation was conducted to use deep mixing method to improve two problematic soils in Ontario: Champlain Sea clay and organic silty clay. Champlain Sea clay samples were obtained from Arnprior and Kanata, and organic silty clay from King County. Cement, slag/cement, and lime were tested a potential binder. A series of geotechnical tests were conducted on the untreated and binder treated soil samples, including index property tests, minivane shear test, UCS test, and CRS consolidation test. A numerical model simulation was also completed in Plaxis 2D by using Modified Cam-clay model. Based on the test results, the following conclusions can be drawn.

\subsection{Main conclusions}

1. Cement is very effective in improving the strength properties of Champlain Sea clay. The improvement for UCS ranged from 2 times to more than 15 times over untreated samples. Cement dosages between $150 \mathrm{~kg} / \mathrm{m}^{3}$ to $200 \mathrm{~kg} / \mathrm{m}^{3}$ resulted in consistent UCS improvement.

2. Slag/cement is very effective in improving the strength properties of Champlain Sea clay from Kanata. The improvement ratio for UCS ranged from 20 times to more than 50 times. A slag/cement (3:1 mix ratio by weight) dosage of $290 \mathrm{~kg} / \mathrm{m}^{3}$ is the most cost effective dosage based on this study.

3. Cement is effective in improving the strength properties of organic silty clay. The UCS improvement ratio ranged from 3.5 times to more than 18 times with an average strength improvement ratio of 6.6 times. A cement dosage of $250 \mathrm{~kg} / \mathrm{m}^{3}$ achieved the highest and the most consistent UCS improvement for organic silty clay.

4. Lime is not as effective as cement in improving the strength properties of organic silty clay. Samples treated with lime received little to no strength improvement. This is similar to previous research results from others. The pore-fluid chemistry may be the reason for low improvement.

5. The UCS of cement treated Champlain Sea clay samples increases with an increasing curing time up to 14 days. After that there is no significant change observed in the samples. 
The high salinity level in pore fluid may have some influence on this behaviour. More study is to be conducted in this aspect.

6. The UCS of cement treated organic silty samples decreases with an increasing curing duration. This may be due to a lack of a chemical reaction between cement and organic silty clay. However, a $250 \mathrm{~kg} / \mathrm{m}^{3}$ cement dosage shows the improvement of UCS over time. This may imply that there is a threshold of cement dosage to achieve optimal results. More study is required to confirm this finding.

7. The elastic modulus increases with an increasing binder dosage and increasing UCS. The increase in elastic modulus also leads to increasing sample brittleness.

8. External variables, including soil type, binder type, binder dosage, curing duration, compaction method, and curing environment can significantly impact the result of the UCS. Binder dosage and binder type explicitly influence the UCS of the treated samples. Curing environment, compaction method, and soil type implicitly influence the UCS of the treated samples.

9. Cement mixing reduces the compressibility of both Champlain Sea clay and organic silty clay. With an increasing cement dosage, the compression index decreases along with a preconsolidation pressure increase.

10. The FEM simulation indicates that DMM can reduce significantly the settlement of a highway embankment. However, the time rate of settlement of and its long-term behaviour will need to be examined because Modified Cam-Clay cannot simulate creep behaviour of Champlain Sea clay. In addition, the detailed geometry design along with DMM parameters are required to be optimized to reach the best results.

\subsection{Future research}

This study achieved its scope by identifying the key parameters behind DMM's feasibility in treating problematic soils in Ontario. However, a more comprehensive study will be required to reinforce the results of the study

1. A comprehensive investigation into the properties of Champlain Sea clay and organic silty clay is required. Soil's mineralogy, chemical composition, and grain structure can be included to investigate its reaction with various binders. 
2. Variables such as water to cement ratio, inherent moisture content, and remolded moisture content can be incorporated into the experimental program as control parameters.

3. A more accurate curing environment can be incorporated in future studies. This will lower the inconsistency found between curing duration and UCS. A moisture controlled environment can further prevent the possibility of salt leaching in Champlain Sea clay. Passive osmosis of water can also be prevented.

4. The influence of salinity on the UCS for both untreated and binder treated samples can be incorporated for Champlain Sea clay testing. Salt leaching can also be investigated with water curing bath to determine the long term performance of binder treated Champlain Sea clay.

5. Compaction procedure can be further improved to incorporate standardized drop height and energy for each blow. A custom-made contraption will be required to compact the soil samples to ensure maximum repeatability.

6. Additional binders, such as lime/cement, can be incorporated into the testing program. The current study is only limited to cement, lime, and slag/cement. A more comprehensive investigation into the reaction mechanism of each binder with the minerals of the soil can be conducted. 


\section{REFERENCES}

Associates, G. (2015). Kitimat LNG Facility, Deep Soil Mixing Design Build - Bish Cove, British Columbia. Retrieved 05 30, 2016, from Canadian Consulting Engine er: http://www2.canadianconsultingengineer.com/awards/pdfs/2015/E1_GolderKitimatLNG DeeSoil.pdf

Bell, F. (1996). Lime stabilization of clay minerals and soils. Engineering Geology, 42, 223-237.

Blake, S., Hockman, B., \& Martin, M. (1987). Applications of Vacuum Dewatering Techniques to Hydrocarbon Remediation. Denver: Geraghty \& Miller Inc.

Cement, P. (2016). 94 lb. Portland Cement. Retrieved 06 02, 2016, from The Home Depot: http://www.homedepot.com/p/94-lb-Portland-Cement-112494/100570364

ColoradoU. (2016). The Origins of the Finite Element Method. Retrieved 06 16, 2016, from University

of Colorado Boulder: http://www.colorado.edu/engineering/CAS/courses.d/IFEM.d/IFEM.AppO.d/IFEM.App O.pdf

Cost, T., \& Ahlrich, R. (2003). Use of Slag Cement (GGBFS) in Soil Stabilization. Retrieved from Slag Cement Association http://www.slagcement.org/Publications/pdf/no25\%20Use \%20of\%20Slag\%20Cement\%2 0in\%20Soil\%20Cement.pdf

Deep Soil Mixing. (2016). Retrieved 05 03, 2016, from Keller Holding: http://www.kellerholding.com/deep-soil-mixing.html

Eades, J., \& Grim, R. (1960). Reaction of hydrated lime with pure clay mineral in soil stabilization. Highway Research Board Bulletin.

Eden, W., \& Mitchell, R. (1970). The Mechanics of Landslides in Leda Clay. Canadian Geotechnical Journal, 285 - 297.

Engineering, C. (2012). How are Soilcrete Column Constructed with Deep Soil Mixing? Retrieved 06 01, 2016, from Foundation, Concrete and Earthquake Engineering: http:/civil-enggworld.blogspot.ca/2012/11/How-Soilcrete-Column-Deep-Soil-Mixing.html

Gadd, N. (1963). Surficial Geogoly of Ottawa Map Area. Geological Survey Canada, 62. 
Golder Associates. (2016). Record of Borehole No. 16-B1. Missisauga: Golder Associates.

Gonzales, G., \& Moo-Young, H. (2004). Transportation Applications Of Recycled Concrete Aggregate. US Department of Transporation Federal Highway Administration.

Hobart. (2005, Aprii). A200 Mixer Technical Manual. Retrieved March 3rd, 2016, from Hobart Corp: https://my.hobartcorp.com/kroger/TechnicalServiceManuals/A200\%20Technical\%20Ma nual.pdf

Huang, P., Patel, M., Santagata, M., \& Bobet, A. (2009). CLASSIFICATION OF ORGANIC SOILS. West Lafayette: Purdue University .

Kemp, A., \& Lewis, C. (1968). A preliminary investigation of chlorophyll degradation in the sediments of Lakes Erie and Ontario. Ann Arbor: Great Lakes Research, University of Michigan.

Kitazume, M., \& Terashi, M. (2012). The Deep Mixing Method. Tokyo: CRC Press.

Law, K., \& Bozozuk, M. (1988). Engineering Problems in Leda Clay. ICEPRS 1988 (pp. 775-792). Beijing, China: National Research Council Canada.

Little, N., \& Nair, S. (2009). Recommended Practice for Stabilization of Subgrade Soils and Base Materials. College Station, TX: Texas Transporation Institute.

Locat, J., Berube, M., \& Choquette, M. (1990). Laboratory Investigation on the Lime Stabilization of Sensitive Clays: Shear Strength Development. Canadian Geotechnical Journal, 294 305.

Logan, L. (2007). A First Course in Finite Element Method. Madrid: Thomson.

Mesri, G., \& Godlewski, P. (1977). TIME- AND STRESS-COMPRESSIBILITY INTERRELATIONSHIP. Journal of Geotechnical and Geoenvironmental Engineering, 417-430.

Munda, J., Pradhan, A., \& Nayak, A. (2014). A Review on the performance of Modified Cam Clay Model for fine grained soil. Journal of Civil Engineering and Environmental Technology, $65-71$. 
NYSDOT. (2013). Geotechnical Design Manual - Ground Improvement Technology. Albany: New York State Department of Transportation.

Pathivada, S. (2005). EFFECTS OF WATER-CEMENT RATIO ON DEEP MIXING TREATED EXPANSIVE CLAY CHARACTERISTICS. The University of Texas at Arlington.

Penner, E. (1965). A Study of Sensitivity in Leda Clay. Canadian Journal of Earth Sciences, 425 -442 .

Penner, E., \& Burn, K. (1978). Review of engineering behaviour of marine clays in Eastern Canada. Canadian Geotechnical Journal, 269-285.

Plaxis. (2010). Plaxis 2D Reference Mnaula. Delft : Plaxis BV.

Potts, D., \& Zdravkovic, L. (2001). Finite element analysis in geotechnical engineering. Thomas Telford.

Prakashan, B. (2015, 11 20). Sustainable Construction;Can Geo-systems be helpful? Retrieved 06 01, 2016, from Linkedin: https://www.linkedin.com/pulse/sustainable-constructioncangeo-systems-helpful-prakashan-b-v

Quinn, P. (2012, 04 26). Landslide susceptibility in eastern Canada. Retrieved 06 01, 2016, from Pete's Thoughts: https $/ /$ petequinnramblings.wordpress.com/page/2/

Ramirez, J. (2009). CEMENT STABILIZATION OF ORGANIC SOILS FOR CONTROLLING SECONDARY COMPRESSION BEHAVIOR. Boca Raton, Florida: Florida Atlantic University.

Raymond, G., Gaskin, P., \& Addo-Abedi, F. (1979). Repeated Compressive Loading of Leda Clay. Canadian Geotechnical Journal, 1-10.

Rocscience. (2017, 03 13). Description of Cam-Clay and Modified-Cam-Clay Critical State Strength Models. Retrieved from Rocscience: https:/www.rocscience.com/help/phase2/webhelp/pdf_files/theory/CamClay.pdf

Shi, C. (2016). Research Progress Update Long-Term Settlement of Waba Dam. Toronto: Ryerson University.

Tang, J., Xi, P., Zhang, B., \& Hu, B. (2013). A finite element parametric modeling technique of aircraft wing structures. Chinese Journal of Aeronautics, 1202-1211. 
Thomas, R. (1968). A NOTE ON THE RELATIONSHIP OF GRAIN SIZE, CLAY CONTENT, QUARTZ AND ORGANIC CARBON IN SOME LAKE ERIE AND LAKE ONTARIO SEDIMENTS. Burlington: Department of Energy, Mines and Resources.

Tiwari, S., \& Kumawat, N. (2014). Recent Developments in Ground Improvement Techniques- A Reivew. International Journal of Recent Development in Engineering and Technology, 2(3), 67-78.

Tremblay, H., Duchesne, J., Locat, J., \& Leroueil, S. (2002). Influence of the nature of organic compounds on fine soil stabilization with cement. Canadian Geotechnical Journal, 535546.

Wang, L. (2002). Cementious Stabilization of Soils in the Presence of Sulfate. Wuhan: Wuhan University of Technology .

Wet Soil Mixing. (2015). Retrieved 05 03, 2016, from Hayward Baker Geotechnical Construction: http://www.haywardbaker.com/WhatWeDo/Techniques/GroundImprovement/WetSoilMi xing/default.aspx 